\author{
Universidade de São Paulo \\ Instituto de Física
}

\title{
Estudo de Efeitos da Polarização Eletrostática Periférica no Tokamak TCABR
}

\author{
Gustavo Guedes Grenfell
}

Orientador: Prof. Dr. Ivan Cunha Nascimento

Dissertação de mestrado apresentada ao Instituto de Física para a obtenção do título de Mestre em Ciências.

Banca Examinadora:

Prof. Dr. Ivan Cunha Nascimento- IFUSP

Prof. Dr. Munemasa Machida- UNICAMP

Prof. Dr. Edson Del Bosco - INPE 


\section{FICHA CATALOGRÁFICA \\ Preparada pelo Serviço de Biblioteca e Informação do Instituto de Física da Universidade de São Paulo}

\section{Grenfell, Gustavo Guedes}

Estudo de efeitos da polarização eletrostática periférica no Tokamak TCABR. São Paulo, 2016.

Dissertação (Mestrado) - Universidade de São Paulo. Instituto de Física. Deptoํ. Física Aplicada.

Orientador: Profo ${ }^{-}$Dro Ivan Cunha Nascimento

Área de Concentração: Astronomia/Física

Unitermos: 1.Tokamaks; 2. Física de plasmas; 3. Turbulência eletrostática. 


\title{
University of São Paulo \\ Institute of Physics
}

\section{Study of Edge Electrostatic Biasing on Tokamak TCABR}

\author{
Gustavo Guedes Grenfell
}

Advisor: Prof. Dr. Ivan Cunha Nascimento

Master's thesis submitted to the Institute of Physics to obtain the title of Master in Science.

Examining Committee:

Prof. Dr. Ivan Cunha Nascimento- IFUSP

Prof. Dr. Munemasa Machida- UNICAMP

Prof. Dr. Edson Del Bosco - INPE

São Paulo 


\section{Agradecimentos}

A execução deste projeto só foi possível graças à ajuda de muitas pessoas. Gostaria de agradecer especialmente ao meu orientador o professor Dr. Ivan Cunha Nascimento pelo projeto e pelo seu suporte, apoio e paciência, por sempre estar disponível para esclarecer dúvidas e oferecer sugestões. E ao Prof. Zwinglio de Oliveira Guimarães Filho que, apesar de não oficialmente, foi o meu co-orientador neste projeto, ajudando-me imensamente nos experimentos e nas análises de dados.

Aos meus pais pelo apoio e paciência durante essa fase.

Ao físico Juan Iraburu Elizondo pelo grande apoio no projeto. Ao Eng. Ablicio Pires Reis, que projetou as fontes senoidais de varredura e os circuitos de medidas, além de fornecer grande ajuda na melhoria dos sinais das sondas. Aos técnicos mecânicos da Oficina Central do IF-USP, Marcos Santos de Souza e Clineu Alonso Carreira pela ajuda na construção da sonda rake. Aos técnicos da Oficina Mecânica do Departamento de Física Aplicada do IFUSP, Raimundo Moreira Filho e Antonio Natalino Alves de Souza, pela ajuda na construção de peças para a sonda e movimentaor.

À todos do Laboratório de Física de Plasma (LFP), que sempre solícitos, prestaram grande ajuda no projeto . Ao técnico Nélio Roberto Nunes pela imensa ajuda na montagem e teste dos circuitos de medidas e pela ajuda na montagem da sonda rake. Ao Dr. Yuri Kuznetsov pelos conselhos e sugestões na construção da sonda e pela ajuda nas análises dos dados. Ao físico Wanderley Pires de Sá pelas sugestões e pela ajuda no sistema de aquisição de dados. Aos técnicos Rogerio Eduardo Capucci, Ivan Cardoso dos Santos e Leonid Rouchko por sempre estarem disponíveis à ajudar. Aos operadores do tokamak TCABR: inicialmente o físico Edson K. Sanada e no final do projeto o Eng. Alexandre Machado de Oliveira. À secretária do laboratório, Eleonora V. D. Lo Duca, pela ajuda e amizade. Aos professores: Ricardo Magnus Osório Galvão, José Helder Facundo Severo, Artour Elfimov e Iberê Luiz Caldas pelo apoio e sabedoria. E aos colegas do laboratório Gilson Ronchi, Tiago Fernandes, Andres Hernandez, Elion Hack e Paulo Puglia e aos colegas teóricos Vinicius Njaim Duarte e Diego Oliveira. Obrigado a todos, não só pela ajuda, mas também pela amizade.

Ao Conselho Nacional de Desenvolvimento Científico e Tecnológico ( $\mathrm{CNPq}$ ) pelo suporte financeiro. 


\section{Resumo}

Efeitos da polarização eletrostática de eletrodos na periferia de tokamaks têm sido investigados em pequenos tokamaks e mesmo em alguns tokamaks de grande porte. Em geral as experiências são realizadas em condições em que bifurcação do campo elétrico radial é obtida, processo este identificado como modo H de polarização. No Tokamak TCABR, as experiências indicam que o confinamento aumenta para tensões aplicadas até +300 volts, atingindo um máximo de duas vezes o tempo de confinamento do modo L, mas sem bifurcação. Indícios de bifurcação foram notados com $+400 \mathrm{~V}$ de polarização, mas a descarga termina devido à excitação da atividade MHD, ainda sob investigação. No presente trabalho, a pesquisa é aprofundada com a utilização de uma sonda de Langmuir com 18 pinos dispostos em duas fileiras sob a forma de um ancinho (rake probe) o que permite a medição da temperatura, densidade e flutuação de potencial ao longo do raio menor na periferia do Tokamak. A resolução temporal desse sistema é de cerca de $0,5 \mathrm{~ms}$, para a temperatura, e $5 \mu s$ para densidade e potencial flutuante do plasma. Outra sonda eletrostática com 5-pinos na mesma posição radial, mas em diferentes posições poloidal e toroidal foi usada para medições de turbulência e transporte de partículas. Os efeitos da polarização foram investigados e indicam que os níveis de turbulência e transporte começam a diminuir entre +150 e +200 $\mathrm{V}$ e para $+300 \mathrm{~V}$ chegam a atingir uma quase supressão. Nesse mesmo intervalo de tensão a densidade começa a aumentar e para $+300 \mathrm{~V}$ chega a ser um fator $\approx 2$. Quanto ao perfil de temperatura a variação é pouco significativa, mas as incertezas das medidas são maiores. Esses dados são compatíveis com a criação de uma barreira de transporte na região entre o eletrodo em $\mathrm{r}=17 \mathrm{~cm}$ e o limitador em a $=18 \mathrm{~cm}$. Além disso, o campo elétrico radial mostra forte cisalhamento nessa região. Tomando o início da subida do potencial flutuante como origem de uma escala de tempo, o atraso temporal do início da subida da densidade de elétrons e o atraso do início do decréscimo do transporte de partículas foram medidos. Os resultados são $\approx 50 \mu s$ para a densidade de elétrons e $\approx 60 \mu s$ para o transporte de partículas. A questão dos limiares de potência é discutida no texto. Os dados desta experiência indicam que o campo elétrico radial desempenha o papel principal para a melhoria do confinamento.

Palavras-chave: tokamak, física de plasmas, modo H, sonda de Langmuir. 


\section{Abstract}

Electrode biasing effects in the periphery of tokamaks have been investigated in small tokamaks and in a few large tokamaks. Usually the experiments are performed in conditions were bifurcation of the radial electric field is achieved, identified as biased $\mathrm{H}$ mode. In the tokamak TCABR, the biasing experiments indicate that the confinement increases for applied voltages up to +300 Volts, reaching a maximum of twice the confinement time of the $\mathrm{L}$ mode, but without bifurcation. Indications of bifurcation were detected with $+400 \mathrm{~V}$ biasing, but the discharge terminates due to excitation of MHD activity, still under investigation. In the present work, the research is improved with the use of a rake shaped 18-pins Langmuir probe, allowing the measurement of electron temperature, density and potential fluctuations along the minor radius near the edge of the tokamak with time resolution of about $0.5 \mathrm{~ms}$, for the temperature and $5 \mu \mathrm{s}$ for density and floating potential. Another electrostatic probe with 5-pins all in the same radial position, but in different poloidal and toroidal position was used for turbulence and particle transport measurements. The effects of biasing indicate that the levels of turbulence and transport begin to decrease between +150 and $+200 \mathrm{~V}$ and for $+300 \mathrm{~V}$ reaches an almost suppression. In that same voltage interval the density, begin to increase and for $300 \mathrm{~V}$ reach a factor of $\approx 2$. The temperature profile does not change significantly but the uncertainty of the measurements is larger. These data are compatible with the creation of a barrier between the position of the electrode at $\mathrm{r}=17 \mathrm{~cm}$ and the limiter of the tokamak at $\mathrm{a}=18 \mathrm{~cm}$. In addition, the radial electric field data show strong shear in this region. Taking the start of the increasing of the fluctuation potential as the origin of a time scale, the temporal delay of the start of the edge electron density increase and transport decrease were measured. The results are $\approx 50 \mu \mathrm{s}$ for the electron density and $\approx 60 \mu \mathrm{s}$ for the particle transport. The power threshold for the confinement improvement is discussed in the text. The data obtained in this experiment confirm that the shear of the electric field has the stronger role for the confinement improvement with biasing in TCABR tokamak.

Keywords: tokamak, plasma physics, H mode, Langmuir probe. 


\section{Sumário}

$\begin{array}{ll}\text { Lista de Tabelas } & 9\end{array}$

1 Introdução $\quad 11$

1.1 Critério de Lawson e dificuldades para obtenção da fusão . . . . . . . . . . . . 15

1.2 Objetivos . . . . . . . . . . . . . . . . . . 17

2 Tokamak 19

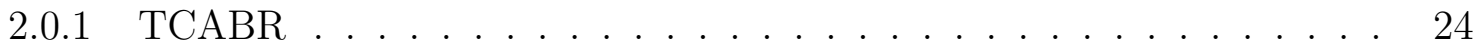

2.0.2 Principais diagnósticos do TCABR . . . . . . . . . . . . . . 25

3 Fundamentos de sondas eletrostáticas, modo $\mathbf{H}$, confinamento melhorado no tokamak TCABR e ferramentas de análise de dados experimentais $\quad 29$

3.1 Teoria de sondas eletrostáticas . . . . . . . . . . . . . . . . . . . . . 29

3.2 Modo H . . . . . . . . . . . . . . . . . . . . . . . . . . . . . . 34

3.2 .1 Confinamento melhorado no TCABR . . . . . . . . . . . . . 37

3.2.2 Pesquisas anteriores com eletrodo no TCABR . . . . . . . . . . . . 37

3.3 Ferramentas de análise . . . . . . . . . . . . . . . . . . . . . . . 38

3.3.1 Espectro de potência . . . . . . . . . . . . . . . . . . . 38

3.3.2 Transporte turbulento de partículas . . . . . . . . . . . . . . . 40

3.3.3 Transporte de energia . . . . . . . . . . . . . . . . . . . . . 42

3.3.4 Função $\mathrm{S}(\mathrm{k}, \mathrm{f}) \quad \ldots \ldots \ldots$. . . . . . . . . . . . . . . . . . . . . 42

3.3.5 Ajuste pelo método dos mínimos quadrados (MMQ) . . . . . . . . . 45

4 Sondas eletrostáticas $\quad 49$

4.1 Sonda rake. . . . . . . . . . . . . . . . . . . . . . . . . . 49

4.2 Sonda 5 -pinos . . . . . . . . . . . . . . . . . . . . . 53

4.3 Sistema de aquisição de dados . . . . . . . . . . . . . . . . . . . 55

$\begin{array}{lll}5 & \text { Medidas } & 57\end{array}$

5.1 Circuitos eletrônicos de medida . . . . . . . . . . . . . . . . . 57

5.2 Fontes de tensão . . . . . . . . . . . . . . . . . . . . . . 59

5.3 Obtenção dos parâmetros do plasma a partir do ajuste de curvas de Langmuir 59

5.4 Espectrograma da potência espectral de $V_{f}$ e $I_{s} \ldots \ldots \ldots \ldots$ 
5.5 Calculo do transporte de partículas . . . . . . . . . . . . . . . 65

5.6 Calculo da função $\mathrm{S}(\mathrm{k}, \mathrm{f})$ a partir de dois sinais de $V_{f} \ldots \ldots$. . . . . . . 70

6 Confinamento melhorado induzido por um eletrodo externo $\quad 73$

6.1 Efeitos globais nos parâmetros do plasma devido à polarização do eletrodo . 74

6.2 Perfis radiais médios antes e durante a polarização do eletrodo . . . . . . . . 76

6.2.1 Temperatura eletrônica $\left(T_{e}\right)$ e densidade eletrônica $\left(n_{e}\right) \quad \ldots \ldots$

6.2.2 Potencial de plasma $\left(V_{p}\right)$ e campo elétrico radial $\left(E_{r}\right) \quad \ldots \ldots . . . \quad 82$

6.3 Potência espectral e transporte de partículas . . . . . . . . . . . . . . 87

6.3.1 Redução do nível de flutuações induzida pela polarização no eletrodo $\quad 87$

6.3.2 Efeito do eletrodo no transporte de partículas . . . . . . . . . . 95

6.4 Função $\mathrm{S}(\mathrm{k}, \mathrm{f})$ e velocidade poloidal . . . . . . . . . . . . . . . . . . . . . . 99

7 Evolução temporal da transição para confinamento melhorado 103

7.1 Evolução temporal de $V_{p}$ e $E_{r} \ldots \ldots \ldots \ldots$

7.2 Evolução temporal de $n_{e} \ldots \ldots \ldots$. . . . . . . . . . . . . . 107

7.3 Escalas de tempo da transição para confinamento melhorado . . . . . . . . . 109

8 Discussões finais e conclusão $\quad 115$

Referências Bibliográficas $\quad 123$

$\begin{array}{lr}\text { Appendices } & 127\end{array}$

$\begin{array}{ll}\text { A Circuito eletrônico das fontes de tensão senoidal } & 129\end{array}$

$\begin{array}{ll}\text { B Circuito eletrônico esquemático do eletrodo } & 131\end{array}$

C Formula de Spitzer clássica: estimativa para temperatura eletrônica média $\begin{array}{ll}\text { do plasma } & 133\end{array}$ 


\section{Lista de Tabelas}

4.1 Configurações de medidas com a sonda rake . . . . . . . . . . . . . . 53

8.1 Comparação entre os limiares de potência das fórmulas do ASDEX e ITER com as potências aplicadas ao plasma com o eletrodo para diferentes polarizações . . . . . . . . . . . . . . . . . . . . . 117 


\section{Capítulo 1}

\section{Introdução}

É sabido que com o aumento da população mundial o consumo de energia deve crescer enormemente nos próximos anos, as projeções são de que o planeta atingirá a marca de 9,5 billhões de habitantes daqui aproximadamente 50 anos [1]. Paralelo a isso é esperado que haja um aumento da qualidade de vida, portanto, do consumo de energia elétrica (já que cada vez mais conforto está correlacionado ao consumo de energia elétrica) em regiões pobres e extremamente pobres do globo. No entanto, grande parte desse consumo de energia está também vinculado a emissão de $\mathrm{CO}_{2}$ na atmosfera, pois os combustíveis fósseis ainda terão um papel importante na composição da matriz energética mundial nos próximos anos, oferecendo um risco enorme ao planeta. Ciente de tal problema, países desenvolvidos tentam se comprometer por meio de acordos a reduzir o consumo de energia e tentam forçar a adoção de tais acordos por países em desenvolvimento, como o Brasil, a China e a Índia. No entanto, surge a questão ética de que países subdesenvolvidos e não industrializados também têm o direito de alcançar o "progresso"e o desenvolvimento, alcançados por países desenvolvidos. Porém, fica cada vez mais claro, que um futuro próspero para todo mundo só existirá se houver uma colaboração conjunta entre todos os países no presente. E isso significa tentar achar um equilíbrio entre o consumo de energia e a preservação do planeta; soluções energéticas inteligentes e energias alternativas limpas são desejáveis, possivelmente sendo a solução mais viável a esse problema.

Os combustíveis fósseis serão ainda por um longo período os principais componentes da matriz energética mundial. Historicamente, a lenha foi uma das primeiras formas de produção de energia, civilizações antigas usavam-na para uso doméstico, preparação de comida e aquecimento das casas, e para uso industrial, no derretimento de metais para construção de ferramentas e armas. O carvão posteriormente também passou a ser usado com essa finalidade. Com a revolução industrial, houve também uma revolução na produção de gases nocivos à atmosfera: a produção de $\mathrm{CO}_{2}$ aumentou substancialmente. As máquinas, cuja proliferação se deu de maneira exponencial, demandavam grandes quantidades de carvão e lenha (biomassa) para funcionarem. Posteriormente, o uso do petróleo ajudou a ampliar a produção do $\mathrm{CO}_{2}$ e de outros gases danosos à atmosfera, através do seu refinamento é 
possível obter gás combustível, GLP (Gás Liquefeito de Petróleo), gasolina, querosene e óleo diesel. Somado a tudo isso, aumentou-se o consumo de gás natural, óleos e xisto betuminoso, todos com alto grau de nocividade à atmosfera. A revolução industrial criou um padrão de vida que envolvia o consumo de uma quantidade de energia nunca antes vista.

Energias mais limpas, alternativas aos combustíveis fósseis, foram criadas e aperfeiçoadas com o passar dos anos. O etanol, por exemplo, é uma alternativa mais limpa à gasolina, embora ainda produza poluentes. Ele é considerado um combustível renovável, pois é produzido através de recursos naturais, a cana de açúcar e o milho. No entanto, sua produção demanda grandes áreas de terra, que poderiam ser usadas para a produção de alimentos, e o seu processo de produção não é totalmente ecológico. Outra alternativa são as hidrelétricas, elas usam a força das quedas de água de rios para girar turbinas e assim produzir energia elétrica. A desvantagem delas é a demanda de grandes reservatórios de água, sendo necessário muitas vezes alagar vastas regiões, frequentemente de alta biodiversidade nas encostas de rios. As energias renováveis limpas, como a solar, a eólica, as energias de marés e as geotérmicas, são soluções ecologicamente mais viáveis ao planeta. Porém, a capacidade energética delas é ainda limitada, contribuindo pouco para matriz energética mundial. No entanto, nos últimos anos houve uma intensificação do uso desse tipo de energia, principalmente a solar e a eólica, com grandes projetos em diversos países, como China, EUA, Alemanha e Japão. Possivelmente em um futuro próximo elas desempenharão um papel de destaque na matriz energética mundial.

No Brasil, a principal fonte de energia elétrica é a hidráulica. Dado o seu potencial energético, existem diversas hidrelétricas espalhadas pelo país, sendo a usina de Itaipu (empresa binacional: Brasil e Paraguai) a maior delas. Com o descobrimento do pré-sal o Brasil pode tornar-se um grande produtor de petróleo e, eventualmente, um grande exportador, dependendo do preço no mercado internacional, pois o custo de extração é alto. O país também é um grande produtor de etanol, nesta área leva grande vantagem devido ao alto rendimento da cana de açúcar. Outras fontes incluem: gás natural, solar, eólica e nuclear.

Outra fonte de energia que se tornou viável a partir do século XX é a nuclear, obtida através do processo de fissão de núcleos de Uranio. O isótopo físsel que é utilizado nos reatores é o urânio 235 encontrado na proporção de 0, 7 \% no uranio natural. Para melhor funcionamento dos reatores é necessário utilizar uranio enriquecido na proporção desde alguns pontos percentuais até $20 \%$. A fissão do uranio ocorre após um nêutron térmico ser absorvido pelo núcleo que então se fissiona em dois ou três núcleos mais leves. Contudo, esses núcleos são radioativos e têm meias vidas longas de até milhares de anos, chamados rejeitos radioativos com alta vida média. Este é apontado como o maior problema dos reatores de fissão, juntamente com o risco de acidentes. Ainda assim, ela é uma alternativa bastante necessária em termos de fonte de energia e muitos países no mundo, como França, EUA, Japão e Rússia, têm a energia nuclear a partir da fissão como uma das suas fontes principais de energia. Contudo, a alternativa nuclear mais limpa e com combustíveis abundantes é a fusão nuclear que atualmente ainda se encontra na fase de demonstração de viabilidade. 
A fusão nuclear é um dos processos mais energéticos conhecidos, é por ele que estrelas como o sol geram sua energia: núcleos de átomos leves, como hidrogênio e hélio são fundidos devido à enorme atração gravitacional nessa região. A fusão nuclear poderia ser uma possível alternativa energética não só à fissão, mas a outras fontes também, ela poderia compor de maneira significativa a matriz energética mundial [2]. Porém, as dificuldades de reproduzir o processo na Terra são enormes, sua obtenção de forma controlada e consequentemente a viabilização de reatores de fusão estão entre os grandes desafios da ciência e tecnologia atual. Muitos foram os esforços para o seu êxito, no entanto dificuldades técnicas e experimentais impossibilitaram o seu sucesso até agora $[3,4]$.

Não é exagero de quem pesquisa fusão nuclear afirmar que seu controle poderia significar a solução energética para o planeta a longo prazo. Isso porque haveria uma enorme quantidade de energia disponível e, possivelmente, barata. Os combustíveis da reação são praticamente inesgotáveis para o tempo de vida humano, os dois compostos comumente usados: deutério e trítio, são abundantes; o deutério tem nos oceanos uma fonte praticamente inesgotável e o trítio, que apesar de ser instável e não estar presente na natureza de forma natural, pode ser obtido através do lítio (abundante na natureza), pela captura radiativa de nêutrons térmicos de maneira relativamente simples. Além disso, a fusão não produz rejeitos radioativos diretamente da reação, apenas de maneira indireta, através dos nêutrons que são produzidos e que podem interagir com a parede do reator, tornando-a radioativa; no entanto tais rejeitos são ainda em menor escala que os da fissão e possuem meia vida menor, da ordem de centenas de anos. Contudo, as projeções para construção dos primeiros reatores a fusão não são nada favoráveis em relação a custo de projeto, os valores são da ordem de bilhões de dólares, sendo a parte estrutural e a planta de projeto os mais dispendiosos. No entanto tal custo é ainda muito incerto a médio e longo prazo, já que o preço de alguns componentes podem se tornar mais baratos com o passar dos anos, além do fato de que o desenvolvimento científico e tecnológico possivelmente poderá aperfeiçoar o projeto, reduzindo seu custo.

As reações de fusão mais simples de serem ativadas (alta seção de choque para baixas energias) são:

$$
\begin{gathered}
D+D=p+T+4,032 \mathrm{MeV} \\
D+D=n+{ }^{3} \mathrm{He}+3,27 \mathrm{MeV} \\
D+T={ }^{4} \mathrm{He}+n+17,6 \mathrm{MeV} \\
D+{ }^{3} \mathrm{He}={ }^{4} \mathrm{He}+p+18,4 M e V
\end{gathered}
$$

A última reação (entre o deutério e o hélio três) é considerada a reação ideal em termos práticos, pois além de não produzir nêutrons, o que implicaria a não produção de rejeitos 
radioativos, ela gera prótons como produto, estes por possuírem carga elétrica poderiam ser usados diretamente para produzir energia elétrica, evitando entrar em um ciclo termodinâmico, gerando, pois, energia com maior eficiência. Contudo, o hélio-3 é extremamente raro na terra, mas pode ser produzido através de reações nucleares, entretanto, para um reator seria necessário aquecer o plasma até temperaturas muito mais altas. Desta forma, não se visualiza sua utilização a não ser a muito longo prazo. Sabe-se que uma grande reserva de ${ }^{3}$ He existe na lua, proveniente de emissões solares. A reação mais fácil de ser obtida é entre os isótopos do hidrogênio: deutério e trítio devido às maiores seções de choque para baixas temperaturas, como é possível notar pela figura (1.1). Para que a reação ocorra, as partículas precisam ficar confinadas em um tempo suficientemente longo em um determinado volume, pois a seção de choque para espalhamento elástico é muito maior do que para fusão, logo é necessário muitas colisões elásticas até que uma reação de fusão possa ocorrer.

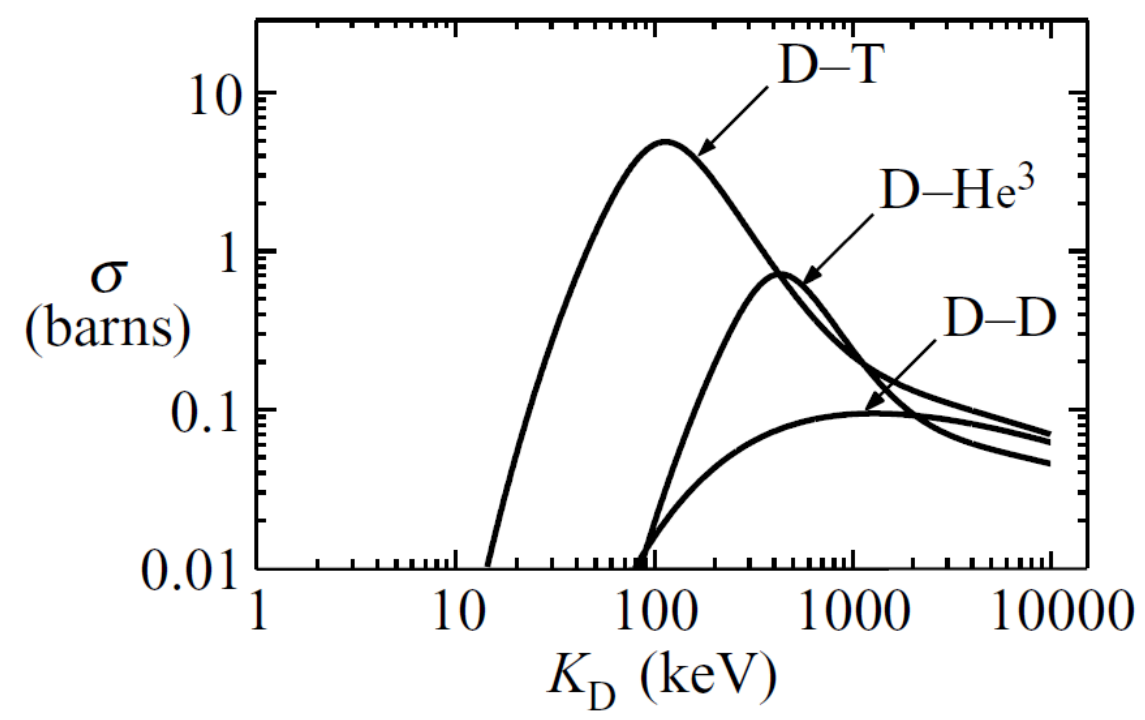

Figura 1.1: Seção de choque em função da energia para as três principais reações de fusão viáveis para um reator [5]. Nota-se que a reação entre o deutério e o trítio é a reação que apresenta a maior seção de choque para baixa energia.

Na figura 1.1, é mostrado um gráfico com as seções de choque (em unidade de $10^{-24} \mathrm{~cm}$, chamada de barn) em função da energia cinética (em keV) para as três reações de fusão que exigem as menores energias para serem atingidas: $D-T, D-H e^{3}$ e $D-D$. A reação $D-T$ é mais fácil de ser obtida, exige menor energia para ser ativada e mais alta probabilidade de ocorrer, seguida das reações $D-H e^{3}$ e $D-D$.

Para que a fusão possa ocorrer é necessário que os combustíveis fiquem confinados por um longo período em alta temperatura (alta energia), para alcançar as altas seções de choque da reação. É preciso confinar esses combustíveis, que são gases, em recipientes adequados por um período suficientemente longo e elevar a temperatura, obtendo-se plasmas, para que as reações de fusão nuclear se viabilizem. Este é um estado em que um gás está quase completamente ionizado e apresenta propriedades particulares, como comportamento coletivo. Logo, é necessário confinar plasmas (cujo comportamento é de difícil modelagem teórica) 
em altas temperaturas, com alta tendência à difusão.

Entre os dispositivos criados com a finalidade de se confinar plasmas superaquecidos com o intuito de viabilizar a fusão nuclear estão: espelhos magnéticos, $\theta$ - pinch, $z-$ pinch, dispositivos de confinamento inercial e stellarators; porém os que obtiveram melhores resultados até então são os chamados tokamaks. Projetado por Tamm e Sakharov [6] na União Soviética nos anos 50, o tokamak é um dispositivo que confina o plasma através de uma configuração de campos magnéticos em uma geometria toroidal. O controle desse processo exige um amplo conhecimento em física de plasmas. No entanto o entendimento completo da física do confinamento de plasma a partir de primeiros princípios ainda não é completo e está em constante evolução.

Um dos mais importantes avanços na melhoria do confinamento do plasma em tokamaks ocorreu em 1982 no tokamak ASDEX em um experimento realizado por F. Wagner e colaboradores [7] com a descoberta do modo de alto confinamento chamado modo H (High), em contraste com o modo L (Low) que até então era o modo usual de operação. Essa descoberta foi obtida em uma experiência de aquecimento auxiliar com a utilização de feixes de partículas neutras de alta energia, o confinamento do plasma aumentou em um fator 2 , comparado ao modo L. Nestes 34 anos desde essa descoberta houve um grande avanço no entendimento da física desse processo, mas mesmo assim um modelo completo ainda não existe. A descoberta do modo $\mathrm{H}$ provocou um grande entusiasmo entre os pesquisadores, impulsionando as pesquisas em fusão e incentivando a criação de grandes projetos de tokamaks. O mais importante é o projeto ITER (International Thermonuclear Experimental Reactor), que é um consórcio entre Estados Unidos, Japão, Rússia, China, Índia, Coréia do Sul e União Europeia para a construção de um grande tokamak em Cadarache na França, como possível protótipo dos futuros reatores de fusão, nele é esperado que se consiga pela primeira vez a ignição. O custo do projeto é estimado em 15 bilhões de euros.

\subsection{Critério de Lawson e dificuldades para obtenção da fusão}

É simples estimar a temperatura e a densidade necessária, juntamente com o tempo de confinamento de energia para que as reações de fusão ocorram de forma autossustentável. Considerando que a energia média de uma espécie (elétrons ou íons) é $3 n / 2 T$ (em eV), e que o número de íons é igual ao número de elétrons, a energia por unidade de volume (admitindo-se energias iguais para ions e elétrons) é: $3 n T$; logo, a energia total é [8]:

$$
W=3 \overline{n T} V
$$

Se $\tau_{E}$ é o tempo de confinamento de energia, a potência perdida é: 


$$
P_{p}=\frac{3 \overline{n T} V}{\tau_{E}}
$$

Essa é a potência necessária para manter um plasma com certa temperatura e densidade em um volume $V$. Quando ocorre fusão, as partículas alfa liberadas na reação contribuem para o aquecimento do plasma, fornecendo uma potência de:

$$
P_{\alpha}=\frac{1}{4} \overline{n^{2}<\sigma v>\varepsilon_{\alpha}} V
$$

$\operatorname{com} \varepsilon_{\alpha}$ a energia das partículas alfa e $\overline{n^{2}<\sigma v>}$ é um fator que está relacionado com a probabilidade de ocorrer as reações. Assim, pelo balanço de energia,

$$
P_{e}+P_{\alpha}=P_{p}
$$

em que $P_{e}$ é potência externa necessária para suprir as perdas, principalmente devido ao efeito bremsstrahlung,

$$
P_{e}+\frac{1}{4} \overline{n^{2}<\sigma v>\varepsilon_{\alpha}} V=\frac{3 \overline{n T} V}{\tau_{E}}
$$

$\mathrm{Na}$ condição de ignição, o aquecimento pelas partículas alfa deve superar as perdas e a potência externa torna-se desnecessária,

$$
P_{e}=\left(\frac{3 \overline{n T}}{\tau_{E}}-\frac{1}{4} \overline{n^{2}<\sigma v>\varepsilon_{\alpha}}\right) V
$$

assim,

$$
n \tau_{E}>\frac{12}{<\sigma v>} \frac{T}{\varepsilon_{\alpha}}
$$

Considerando a faixa de energia 10-20 keV (mais provável para a fusão), o termo $<\sigma v>$ é aproximadamente:

$$
<\sigma v>=1,1 \times 10^{-24} T^{2} m^{3} s^{-1}(T e m e V)
$$

além disso, considerando que a energia das partículas alfa é: $3,5 \mathrm{MeV}$; seque que:

$$
n T \tau_{E}>3 \times 10^{21} \mathrm{~m}^{-3} \mathrm{keV} \mathrm{s} .
$$

A expressão 1.6 é obtida considerando perfis planos (retangulares) de densidade e temperatura, tomando seu valor de pico, obtém-se o critério de Lawson [8] para ignição da fusão: 


$$
\hat{n} \hat{T} \tau_{E}>5 \times 10^{21} m^{-3} k e V s .
$$

O tempo de confinamento na prática é muito menor do que o estimado teoricamente, considerando teoria colisional clássica, isso porque o confinamento de energia é anômalo, pois a perda de energia é muito maior do que o previsto teoricamente. Para se ativar a ignição são necessárias altas temperaturas do plasma, que é obtida inicialmente através de aquecimento Ôhmico, por conta da corrente de plasma toroidal induzida; no entanto, à medida que a temperatura aumenta a resistividade elétrica do plasma diminui $\left(\propto T_{e}^{-3 / 2}\right)$, tornando o processo de aquecimento menos efetivo, sendo necessário utilizar aquecimento auxiliar. O aquecimento auxiliar pode ser obtido através da injeção de feixes de partículas neutras e pela injeção de ondas eletromagnéticas de radio frequência.

No modo $\mathrm{H}$ há um aumento de até um fator 2 no tempo de confinamento de energia, comparado aos disparos comuns no chamado modo L. Esta descoberta no tokamak ASDEX na Alemanha, impulsionou as pesquisas com tokamaks, viabilizando projetos grandes na área. No entanto, o entendimento da física do modo H não foi compreendido de imediato, foram necessários muitos experimentos para que se pudesse começar a entender quais eram os mecanismos por trás do processo. Muito se aprendeu desde então, mas há ainda muitas questões não esclarecidas, particularmente, não é possível descrever o fenômeno a partir de primeiros princípios, existem modelos que funcionam bem descrevendo certas características do fenômeno, mas que não são completos. Faz-se necessário ainda muitas informações experimentais, de tokamaks de todos os portes, para se conseguir alcançar um modelo que descreva completamente o fenômeno. Entender o processo pode ser fundamental para a obtenção de reatores de fusão otimizados, pois tal conhecimento pode vir a ajudar a controlar ou evitar regimes turbulentos, que levam à perda de partículas, possibilitando que se trabalhe no melhor regime possível para as limitações de cada máquina.

\subsection{Objetivos}

É consenso na comunidade internacional que a melhoria do confinamento de plasmas em dispositivos experimentais para a pesquisa da viabilidade da fusão termonuclear controlada como fonte inesgotável de energia tem sido e continua sendo uma das grandes metas a serem atingidas. Uma condição necessária para o sucesso desses trabalhos é o entendimento detalhado da física do confinamento e é nessa linha que se encaixam os trabalhos de pesquisa sobre confinamento melhorado no tokamak TCABR. Para o presente trabalho foram elencados os seguintes trabalhos experimentais:

- Medir extensivamente parâmetros do plasma na borda do TCABR e na região da camada de raspagem ("Scrape Off Layer- SOL) usando sondas eletrostáticas em disparos com um eletrodo polarizado na borda induzindo confinamento melhorado. Com um sistema com boa resolução temporal e espacial, especialmente projetado para essa finalidade, um dos ob- 
jetivos é tentar detectar o gatilho ("trigger") da transição para confinamento melhorado no TCABR, principalmente através de medidas da densidade de elétrons $\left(n_{e}\right)$, temperatura de elétrons $\left(T_{e}\right)$, potencial flutuante $\left(V_{f}\right)$, potencial de plasma $\left(V_{p}\right)$, campo elétrico radial $\left(E_{r}\right)$, flutuações da corrente de saturação de íons $\left(I_{s a t}\right)$ e $V_{f}$, turbulência e transporte de partículas;

- Estudar perfis médios de densidade eletrônica $\left(n_{e}\right)$, temperatura de elétrons $\left(T_{e}\right)$, potencial flutuante $\left(V_{f}\right)$, potencial de plasma $\left(V_{p}\right)$, campo elétrico radial $\left(E_{r}\right)$ na borda, antes e durante a polarização do eletrodo para diferentes tensões de polarização;

- Verificar em que condições se dá a melhora do confinamento de plasma no TCABR. Qual o efeito da tensão e posição do eletrodo no confinamento;

- Verificar se há criação de uma barreira de transporte e como ela está relacionada com outros parâmetros como campo elétrico radial e transporte de partículas;

- Tentar encontrar uma relação causal entre os eventos durante a transição para confinamento melhorado, estudando as escalas de tempo da transição;

- Estudar a função da temperatura no processo e como a sua correção em parâmetros do plasma, como campo elétrico radial e densidade de elétrons, assim como, o transporte de partículas, afeta os resultados.

Este trabalho está organizado da seguinte forma: o dispositivo experimental, isto é, o Tokamak TCABR e seus diagnósticos principais são explicados suscintamente no Capitulo 2. Os diagnósticos desenvolvidos para uso neste experimento, bem como as ferramentas de análise, são apresentados nos Capitulos 3 e 4, sob os títulos de Fundamentos de sondas eletrostáticas, modo H, confinamento melhorado no tokamak TCABR e ferramentas de análise de dados experimentais e Sondas Eletrostáticas, respectivamente. No Capitulo 5 são apresentadas as medidas efetuadas. Os resultados experimentais e discussões estão no Capitulo 6 e 7 e finalmente, no Capitulo 8 são apresentadas as discussões finais e a conclusão. 


\section{Capítulo 2}

\section{Tokamak}

Para se alcançar a fusão nuclear de forma controlada é necessário confinar plasmas superaquecidos por um tempo suficientemente longo para que as reações ocorram. Com essa finalidade existem duas linhas de pesquisa: confinamento inercial e confinamento magnético. No confinamento inercial são usados feixes de lasers de alta potência direcionados para um alvo comum, uma pequena pastilha de deutério e trítio, induzindo micro explosões. Já no confinamento magnético usa-se o fato das partículas do plasma serem carregadas eletricamente para confiná-las por meio de campos magnéticos, evitando assim que elas toquem superfícies materiais.

Na linha de confinamento magnético diversos tipos de dispositivos foram e continuam a ser testados, mas os que têm obtido os melhores resultados são os Tokamaks (acrônimo em russo das palavras: "toroidalnaya kamera magnitnaya katushka", cuja tradução livre é câmara toroidal magnética).

As primeiras máquinas criadas para confinar plasma com campos magnéticos foram do tipo linear, mas enfrentavam dificuldades devido principalmente a instabilidades que não puderam ser controladas e a fuga de partículas pelas extremidades do dispositivo. Sistemas magnéticos toroidais foram opções mais promissoras, com destaque para os stellarators nos Estados Unidos e os tokamaks na antiga União Soviética. Os stellarators enfrentaram a dificuldade de criar um campo magnético toroidal capaz de controlar a separação de cargas o que desde o início da pesquisa em fusão nos anos 1950/1951 na URSS já havia sido resolvido [6]. Posteriormente, os stellarators puderam ser construídos com campos magnéticos toroidais adequados e vêm apresentando resultados comparáveis aos dos tokamaks.

A princípio, pode parecer suficiente a existência de apenas um campo magnético na direção toroidal para confinar o plasma, as partículas viajariam livremente na direção do campo, mas girariam em torno dele, com um raio $r_{L}=\frac{m v_{\perp}}{|q| B}$ (raio de Larmor) e uma frequência típica, $\omega_{g}=\frac{|q| B}{m}$ (frequência de ciclotron), onde $m$ é a massa da partícula carregada, $q$ é a carga, $v_{\perp}$ é a velocidade perpendicular ao campo magnético e $B$ a intensidade do campo magnético. No entanto, na prática não é o que ocorre. Por conta da não uniformidade do campo magnético $\left(\propto \frac{1}{R}, R\right.$ raio maior do toroide) e pela sua curvatura (força centrifuga 
nas partículas) surgem duas derivas que tendem a separar cargas positivas de uma lado e negativas do outro. As duas derivas podem ser unificadas na seguinte expressão [9],

$$
\vec{v}_{R}+\vec{v}_{\nabla B}=\frac{m}{q} \frac{\vec{R}_{c} \times \vec{B}}{R_{c}^{2} B^{2}}\left(v_{\|}^{2}+\frac{1}{2} v_{\perp}^{2}\right)
$$

onde $m$ é massa da partícula, $R_{c}$ é o raio de curvatura do campo magnético, $B$ o campo magnético, $q$ a carga, $v_{\|}$é a velocidade paralela ao campo e $v_{\perp}$ é a velocidade perpendicular ao campo. Além disso, há também a deriva devido à força gravitacional na Terra que também tem o efeito de separar cargas positivas para um lado e negativas para o outro, porém o efeito é desprezível comparado com as duas derivas anteriores,

$$
\vec{v}_{g}=\frac{m}{q} \frac{\vec{g} \times \vec{B}}{B^{2}}
$$

O resultado dessa separação de cargas, dá origem a um campo elétrico no plasma, que provoca uma deriva do plasma como um todo para um mesmo sentido, podendo atingir a parede da câmara de confinamento,

$$
\vec{v}_{E}=\frac{\vec{E} \times \vec{B}}{B^{2}}
$$

A solução para esse problema é produzir, adicionalmente, um campo magnético na direção poloidal, a fim de se obter um campo resultante helicoidal, assim, as partículas estariam ora na parte mais interna do toroide, ora na parte mais externa, de forma que, em média, o efeito das derivas que tendem a separar as cargas seria nulo. Tanto os stellarators quanto os tokamaks usaram essa ideia, ou seja, ambos são dispositivos toroidais que confinam o plasma por meio de um campo helicoidal (soma vetorial entre $B_{\theta}$ e $B_{\phi}$ ). Porém, nos stellaratores esse campo é produzido por bobinas em torno da câmara, que são modeladas para que o campo resultante produzido por elas seja exatamente helicoidal. Enquanto que em tokamaks é produzido um campo toroidal, por bobinas enroladas no toroide, e um campo poloidal que é devido à uma corrente de plasma $I_{p}$ induzida na direção toroidal. A corrente de plasma é resultado da tensão induzida devido à variação de campo magnético em um transformador central, ou seja, por indução eletromagnética é criada uma tensão no toroide que é responsável pela criação de um campo elétrico também na direção toroidal, que gera $I_{p}$; o plasma seria o secundário do transformador central. Adicionalmente, há ainda a geração de campos horizontais e verticais para corrigir efeitos espúrios, permitindo um melhor controle do plasma.

Apesar de ambos os dispositivos serem promissores, os tokamaks atingiram estágios mais 
avançados de controle e equilíbrio até então. Eles, como já mencionado, são dispositivos na forma toroidal que confinam plasmas superaquecidos com a finalidade de se estudar a fusão nuclear. Para que as reações de fusão ocorram é necessário que os componentes da reação atinjam temperaturas da ordem de $10 \mathrm{keV}$ ou 100 milhões de Kelvins [8], vencendo a repulsão Coulombiana; nessa condição gases tornam-se plasma. Este plasma precisa ficar confinado por um tempo suficientemente grande para que a temperatura de ativação da reação de fusão seja atingida e para que as reações possam ocorrer. Contudo, o confinamento não é perfeito e as partículas "vazam"através das superfícies magnéticas de confinamento, com uma taxa de perda maior do que o esperado teoricamente pelas teorias clássicas e neoclássicas.

Em tokamaks há sempre uma bobina central, chamada de transformador de aquecimento ôhmico, como pode ser visto na Figura 2.1. Ao conectar uma fonte de tensão adequada ao transformador, a corrente na bobina aumenta e a variação temporal do fluxo magnético associado induz um campo elétrico que tem a direção toroidal. Se houver elétrons livres no interior da câmara de vácuo, estes serão acelerados pelo campo elétrico e ao colidir com as moléculas de $\mathrm{H}_{2}$ que preenchem a câmara provocarão a ruptura do gás (breakdown) e a formação do plasma de hidrogênio. Os elétrons livres que iniciam o processo podem ser emitidos por um filamento de tungstênio aquecido ou serem gerados aleatoriamente por raios cósmicos, traços de elementos radioativos presentes nos materiais da câmara, ionização por rádio frequência etc. Uma vez criado o plasma, o campo elétrico induzido produz uma corrente toroidal no próprio plasma, que tem dois efeitos principais: o aquecimento do plasma por efeito Joule e a criação de um campo magnético poloidal que é essencial para o confinamento magnético da coluna de plasma, juntamente com o campo toroidal produzido por bobinas externas. Esse aquecimento muitas vezes não é suficiente para que as reações de fusão se iniciem, sendo necessárias outras formas de aquecimento complementares, como a emissão de ondas de radio-frequência e a injeção de partículas neutras.

A soma vetorial dos campos toroidal e poloidal resulta em um campo total helicoidal, $\vec{B}_{\text {total }}=B_{\phi} \hat{\phi}+B_{\theta} \hat{\theta}$ (figura $2.2 \mathrm{a}$ ), que define superfícies magnéticas toroidais (figura 2.2 b).Parâmetros de plasma como temperatura, densidade e pressão tendem a ser constantes em uma mesma superfície magnética, podendo variar bruscamente em função do raio. O campo que passa apenas em um ponto no plano poloidal, depois de uma volta no toroide atinge outro ponto no mesmo plano, mantendo-se na mesma superfície de fluxo. Em uma dada superfície uma linha geralmente nunca fecha nela mesma, mapeando toda a superfície. Contudo, em alguns casos ela pode ser fechada, isso ocorre em uma situação de ressonância dada por,

$$
q \approx \frac{r B_{\phi}}{R B_{\theta}}
$$

onde $q$ é o fator de segurança (fórmula obtida considerando grande razão de aspecto: $R / a>1$, que é o caso do TCABR); $q$ também pode ser definido como $q=n / m$, onde 


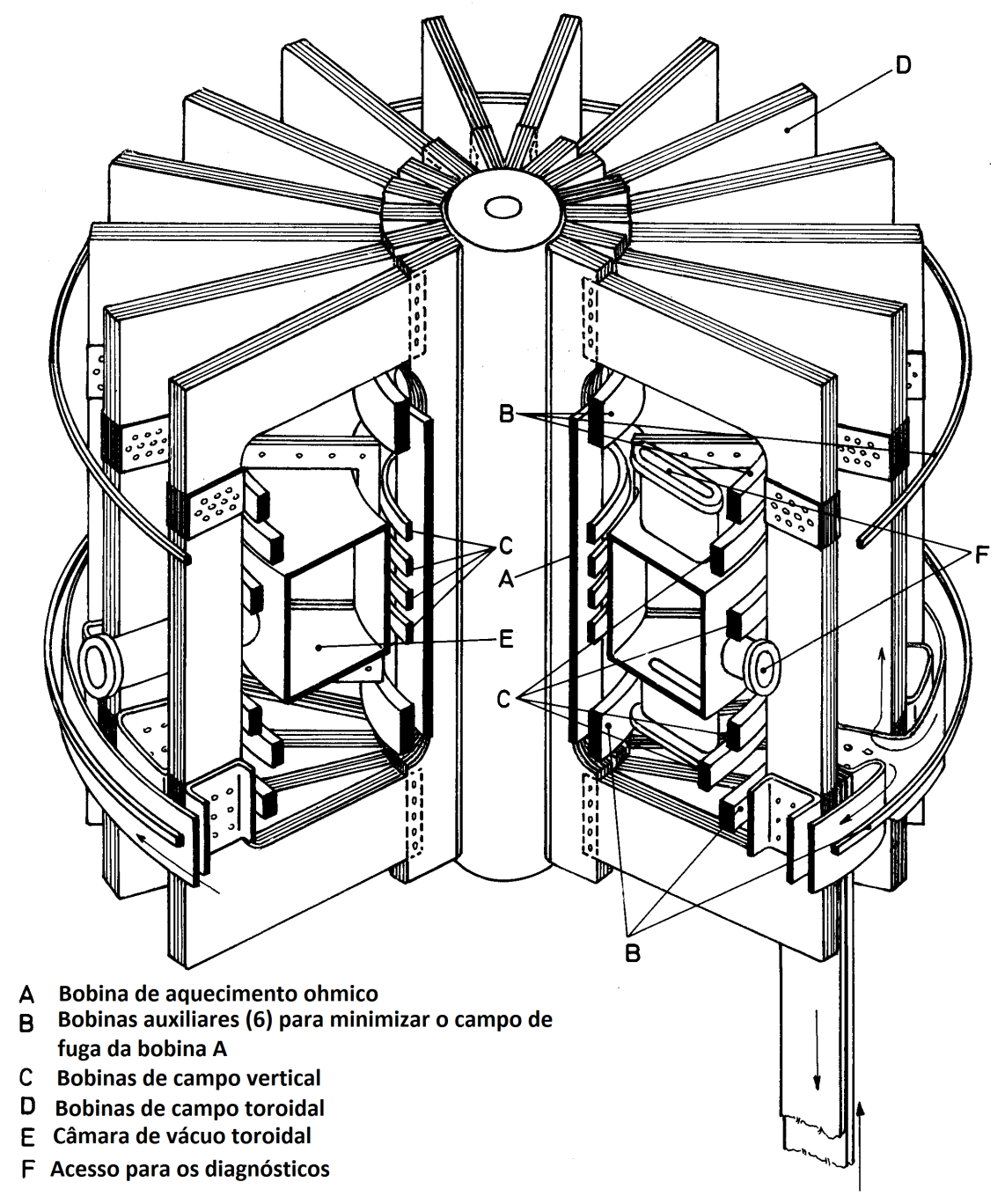

Figura 2.1: Figura esquemática do tokamak TCABR

$n$ é o número toroidal (número inteiro indicando o número de voltas na direção toroidal) e $m$ o número poloidal (número inteiro indicando o número de voltas na direção poloidal), estabelecendo superfícies racionais. Geralmente $\left|B_{\phi}\right| \gg\left|B_{\theta}\right|$, com exceção dos tokamaks esféricos (pequena razão de aspecto) como o MAST e o NSTX [8]. O fator de segurança também é importante para a estabilidade do plasma, para evitar algumas instabilidades, como a chamada instabilidade de "torção"(kink-instability)[8, 9], é necessário que o fator de segurança seja maior que dois na borda, $q(a)>2$. Tipicamente, tokamaks operam com $q(a) \approx 3$. 

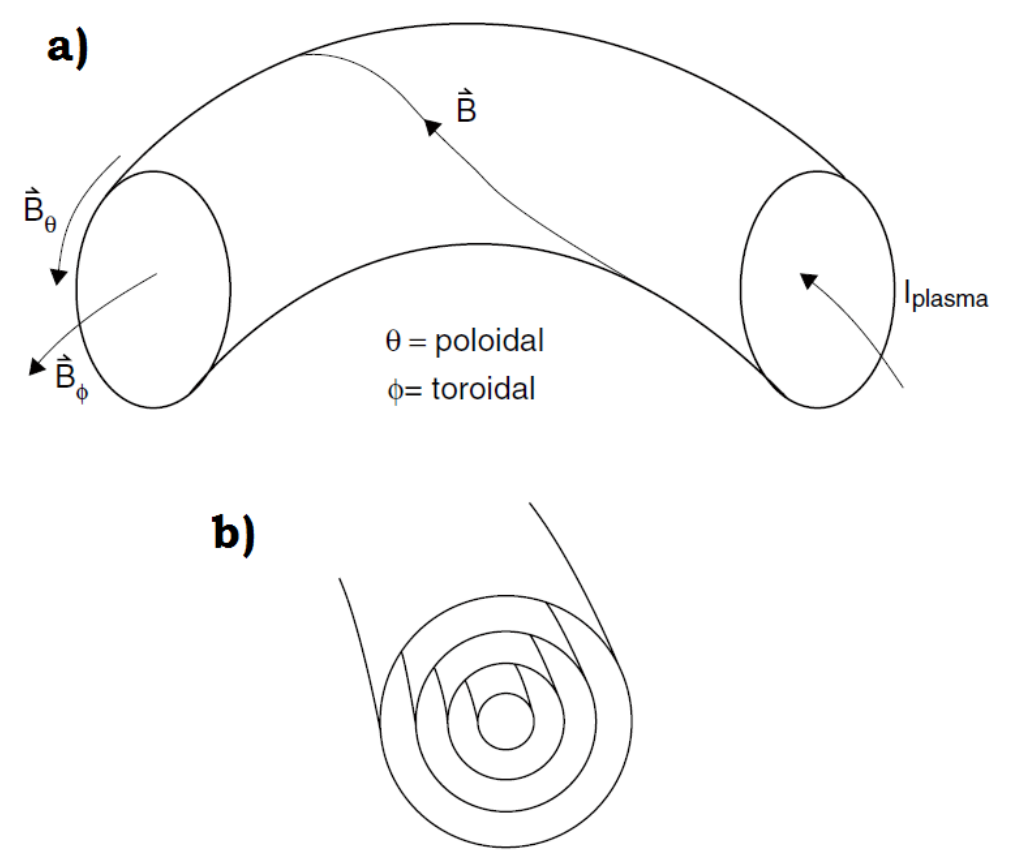

Figura 2.2: a) a soma vetorial dos campos nas direções toroidal (produzido por bobinas externas) e poloidal (criado pela corrente de plasma) gera um campo total na direção helicoidal. b) o campo produzido define superfícies de fluxo, como é possível ver em uma seção poloidal em um tokamak com plasma com seção circular (figura retirada de [10]).

O plasma confinado é limitado em uma região, até a última superfície magnética, última superfície fechada. Isso é feito de duas formas, através de um limitador, que é um material sólido em contato com a borda do plasma, geralmente grafite, que intercepta as linhas de campo. Ou através de um diversor, que é uma configuração de campos magnéticos que orienta as partículas na ultima superfície magnética para uma região coletora, a linha de campo que define a borda do plasma é chamada de "separatriz". Ambas as configurações estão relacionadas a uma necessidade inerente a dispositivos de fusão: a exaustão de partículas e energia do plasma de forma controlada. Na figura 2.3 é mostrado um exemplo simples entre as diferenças entre um limitador e de um diversor, através da seção poloidal de um tokamak.
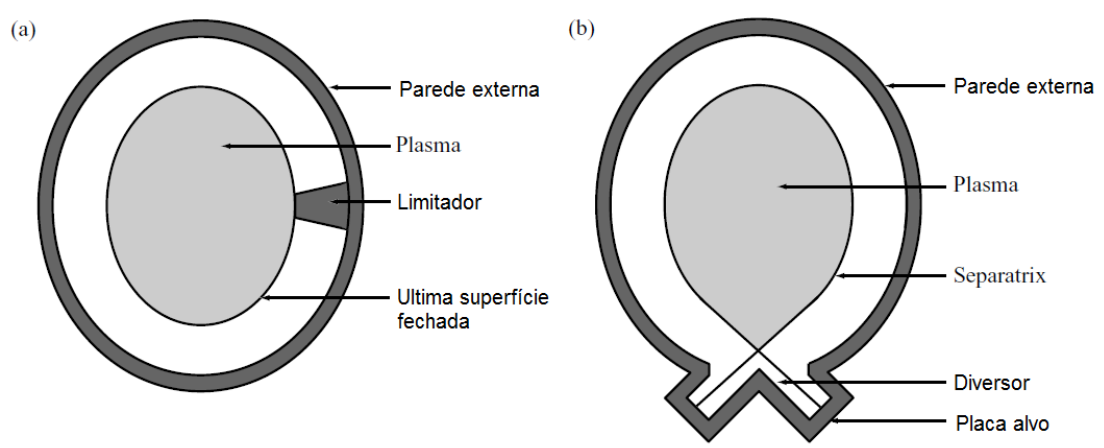

Figura 2.3: Formas de limitar o plasma confinado: a) Limitador; b) Diversor (figura retirada de [5]). 
Um sistema de coordenadas comum em física de plasmas e em especial no estudo de tokamaks é o chamado sistema de coordenadas pseudo toroidais (figura 2.4). É o sistema que será usado neste trabalho.

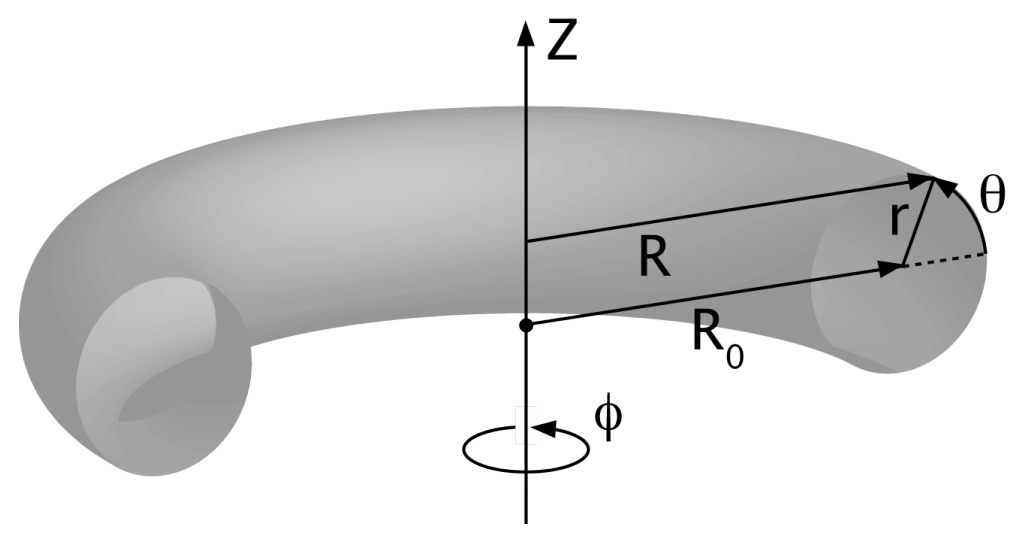

Figura 2.4: Sistema de coordenadas pseudo toroidais (http://fusionwiki.ciemat.es/).

\subsubsection{TCABR}

O Tokamak Chauffage Alfvén Brésilien (TCABR, figura 2.5) é um tokamak de porte médio localizado no Instituto de Física da Universidade de São Paulo (IF-USP). Seu raio maior é $R_{0}=0,615 m$ e seu raio menor é $a=0,18 m$ (razão de aspecto $\approx 3,4$ ). O campo magnético toroidal pode chegar a $\sim 1,07 T$, com densidade média (de linha) de elétrons entre $(0,9-3,0) \cdot 10^{19} m^{-3}$, corrente de plasma até $90 \mathrm{kA}$, com comprimento de pulso máximo de $\sim 100 \mathrm{~ms}$, temperatura de elétrons até $500 \mathrm{eV}$ e temperatura de íons até $200 \mathrm{eV}$ [11].

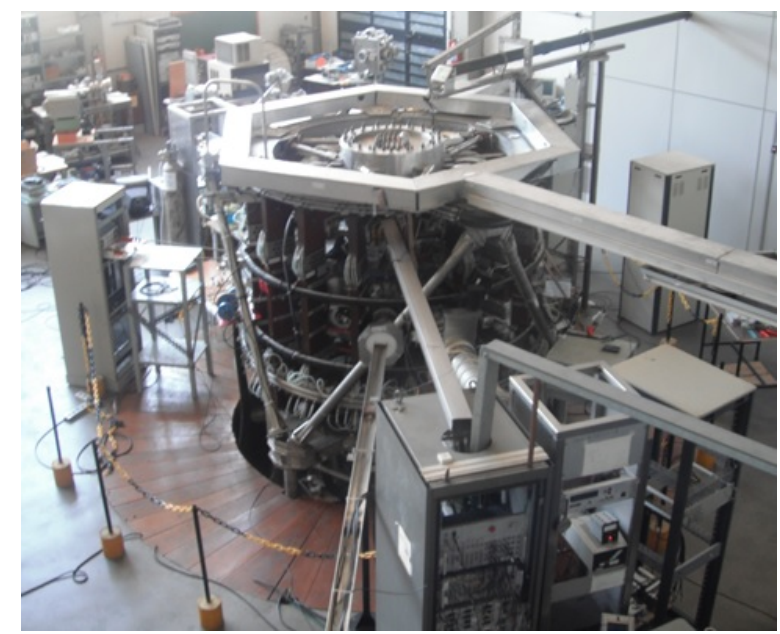

Figura 2.5: Foto do tokamak TCABR

As principais linhas de pesquisa no TCABR [12] são: o estudo da rotação do plasma, interação de ondas de Alfvén em plasmas, interação plasma-parede, instabilidades MHD, confinamento magnético, turbulência e transporte e física da borda do plasma, associada ao estudo de instabilidades e turbulência nessa região e de regimes de confinamento melhorado. O porte médio do TCABR possibilita pesquisas sobre a borda do plasma, já que é 
possível acessá-la utilizando sondas eletrostáticas e outros diagnósticos, diferentemente de máquinas grandes em que a temperatura do plasma é muito alta, podendo danificar qualquer dispositivo em seu interior se exposto por um longo tempo.

\subsubsection{Principais diagnósticos do TCABR}

\section{Corrente de Plasma}

A corrente de plasma em um tokamak é medida usando uma bobina de Rogowski (figura 2.6). Pela lei de Àmpere, uma corrente elétrica produz um campo magnético e a relação entre eles é dado por:

$$
I=\frac{1}{\mu_{0}} \oint \vec{B} \cdot \overrightarrow{d l}
$$

Considerando que a bobina tem $n$ voltas por unidade de comprimento e área exposta ao campo magnético (na direção poloidal), devido a corrente de plasma, igual a $A$, então a diferença de potencial na bobina é:

$$
\Phi=-\int_{t_{0}}^{t} V\left(t^{\prime}\right) d t^{\prime}=n A \oint \vec{B} \cdot \overrightarrow{d l} .
$$

Portanto, segue das duas equações que a corrente de plasma em função do tempo é:

$$
I(t)=-\frac{\int_{t_{0}}^{t} V\left(t^{\prime}\right) d t^{\prime}}{n A \mu_{0}}
$$

Na prática, a integração é feita usando um circuito elétrico integrador. 


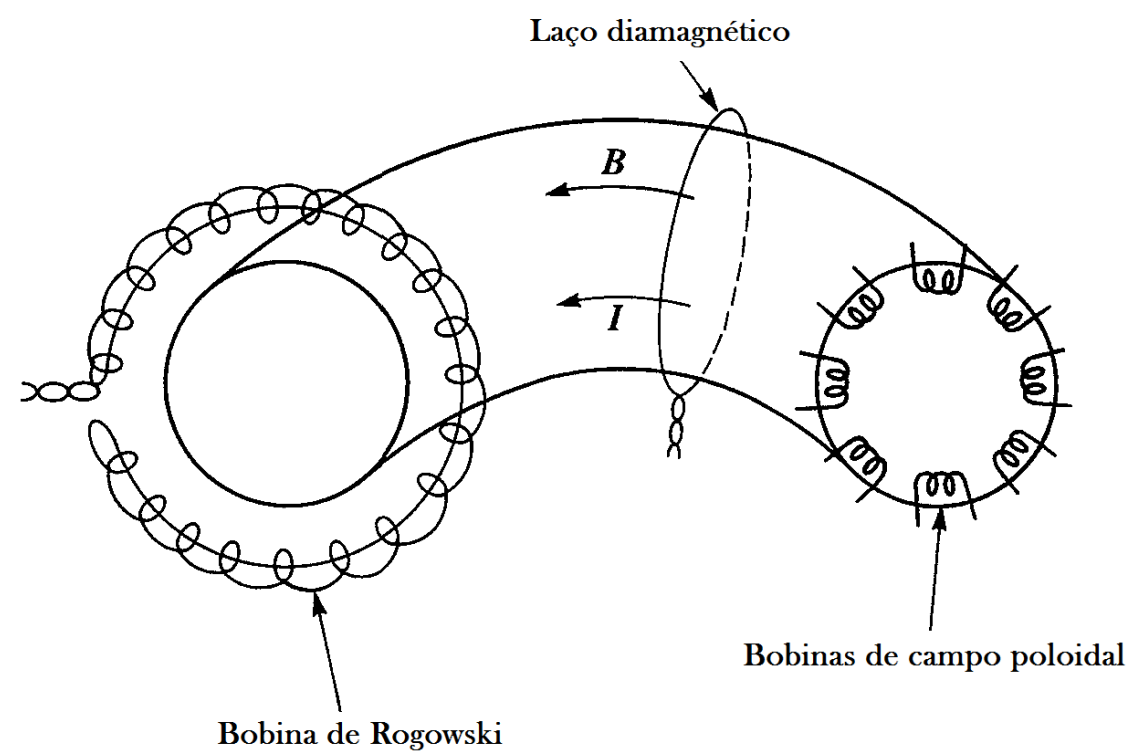

Figura 2.6: Bobina de Rogowski para medida de corrente de plasma em um tokamak. No TCABR a seção transversal do vaso é retangular, mas a coluna de plasma é circular. São apresentados, esquematicamente, o enlace da bobina diamagnética e bobinas magnéticas usadas para controle da posição radial da coluna de plasma (figura retirada de [8]).

\section{Tensão de enlace}

A tensão de enlace (ou Loop Voltage) é medida utilizando uma espira que envolve o vaso na direção toroidal. É a tensão induzida devido à variação de fluxo no transformador central. A corrente de plasma criada por essa tensão é medida pela bobina de Rogowski. Medindo-se a tensão de enlace e a corrente de plasma é possível estimar a temperatura média do plasma pela conhecida fórmula de Spitzer ${ }^{1}$. Uma aproximação para a fórmula de Spitzer (clássica) usando perfis médios dos parâmetros do plasma é dada no Apêndice C.

\section{Interferômetro}

O uso de interferômetria de microondas para medir a densidade eletrônica do plasma é um dos diagnósticos mais importantes em tokamaks, pois é essencial para o controle do plasma confinado. A técnica se baseia no fato de que uma onda eletromagnética se propagando em um plasma magnetizado e colisional em "modo ordinário"(vetor campo elétrico da onda paralelo ao campo magnético da máquina) e com frequência muito maior do que a frequência de plasma, tem sua fase alterada em relação a uma onda de referência idêntica, porém sem interagir com o plasma, da seguinte forma,

$$
\Delta \phi=\frac{\lambda e^{2}}{4 \pi \epsilon_{0} m_{e} c^{2}} \int n_{e} d l
$$

\footnotetext{
${ }^{1}$ NRL/PU/6790 04 477, NRL Plasma Formulary, Revised 2004, Naval Research Laboratory, WASHINGTON, dc 20375-5320
} 
onde $\lambda$ é o comprimento de onda do feixe. Assim, a integral de linha da densidade eletrônica é proporcional à diferença de fase entre um feixe que passa pelo plasma e outro que não. Realizando medidas com uma boa resolução temporal, obtém-se a evolução temporal da densidade eletrônica média [13],

$$
\bar{n}(t)=\frac{1}{\left(r_{2}-r_{1}\right)} \int_{r_{1}}^{r_{2}} n_{e}\left(r^{\prime}, t\right) d r^{\prime}=\frac{4 \pi \epsilon_{0} m_{e} c^{2}}{\lambda e^{2}\left(r_{2}-r_{1}\right)} \Delta \phi(t)
$$

\section{Linha de $H_{\alpha}$}

Durante um disparo, quando o plasma é formado no tokamak, as partículas neutras ou íons interagem muitas vezes com o limitador ou com a parede, retornando posteriormente ao plasma; tal processo é conhecido como reciclagem. Normalmente para um tokamak com limitador (como o TCABR) as moléculas que vem do limitador ou das paredes do vaso, no processo de reciclagem, estão neutras, no entanto, à medida que penetram no plasma elas logo se ionizam e são confinadas no campo magnético. Nesse processo, as partículas de hidrogênio emitem radiação na frequência do visível na linha de $H_{\alpha}$ (vermelho da linha de Balmer). Assim, o nível de emissão de $H_{\alpha}$ é um indicativo da taxa de reciclagem no sistema, uma eventual redução da intensidade dessa linha pode indicar uma redução da reciclagem, ou do fluxo de partículas para fora interagindo com a parede ou limitador.

A linha de $H_{\alpha}$ é medida no TCABR utilizando um fotodiodo e um filtro óptico que permite principalmente a passagem da linha $H_{\alpha}$ do hidrogênio.

Na figura 2.7 é apresentado um disparo típico do TCABR, com os diagnósticos apresentados: densidade média de plasma na linha central do interferômetro, corrente de plasma, tensão de enlace e sinal de $H_{\alpha}$.
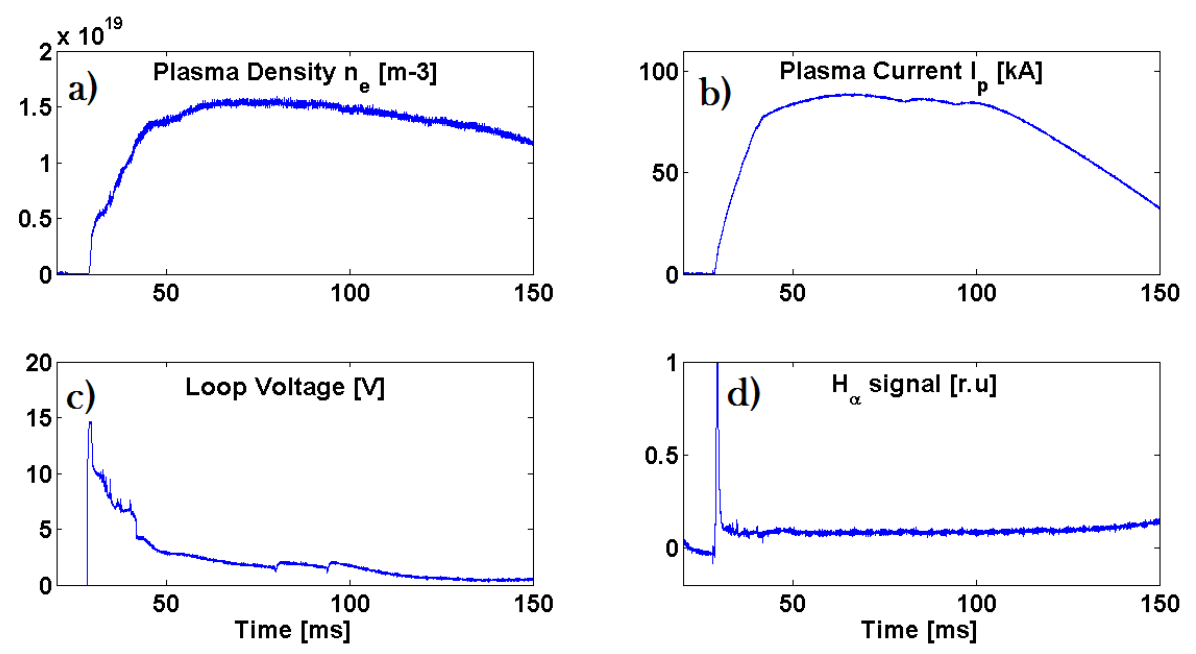

Figura 2.7: Típico disparo do TCABR. Evolução temporal a) densidade média de plasma na linha central do interferômetro; b) corrente de plasma; c) tensão de enlace e d) sinal da linha de $H_{\alpha}$. 
TOKAMAK 


\section{Capítulo 3}

\section{Fundamentos de sondas eletrostáticas, modo $\mathrm{H}$, confinamento melhorado no tokamak TCABR e ferramentas de análise de dados experimentais}

\subsection{Teoria de sondas eletrostáticas}

As sondas eletrostáticas foram inventadas pelo físico americano Irving Langmuir com a finalidade de medir as características físicas de descargas em gases [14]. Consistem basicamente de um eletrodo inserido no plasma que pode ou não estar polorizado em relação à superfície material que encerra o plasma. Através de medidas de corrente e tensão é possível estimar temperatura e densidade eletrônica e o potencial de plasma local. Por conta da sua característica invasiva, o diagnóstico de sonda geralmente é limitado à borda ou à região externa ao plasma em um tokamak, pois ela pode ser danificada em regiões mais internas devido a alta temperatura e maior densidade.

Ao aplicar uma tensão negativa na sonda com respeito ao limitador (ou parede) uma corrente essencialmente de íons é coletada (figura 3.1), para uma tensão ainda mais negativa a corrente passa ser aproximadamente constante, chamada de corrente de saturação de íons. Por outro lado, aumentando a tensão para valores positivos a corrente passa a ser predominantemente de elétrons. Ela satura para um dado valor de tensão, tal valor é igual ao potencial de plasma. Entre os dois extremos de saturação a curva cresce monotonicamente. O ponto de corrente nula na curva, em que a corrente de íons é igual à corrente de elétrons, é chamado de potencial flutuante $\left(V_{f}\right)$.

A teoria de sondas eletrostáticas é bem descrita pela teoria de bainha eletrostática [8, 10, 15]. Quando um material com uma superfície de absorção entra em contato com um plasma, este reorganiza-se de forma a equalizar o fluxo de partículas positivas e negativas perto da superfície do material. Os elétrons por terem mais mobilidade que os íons tendem 


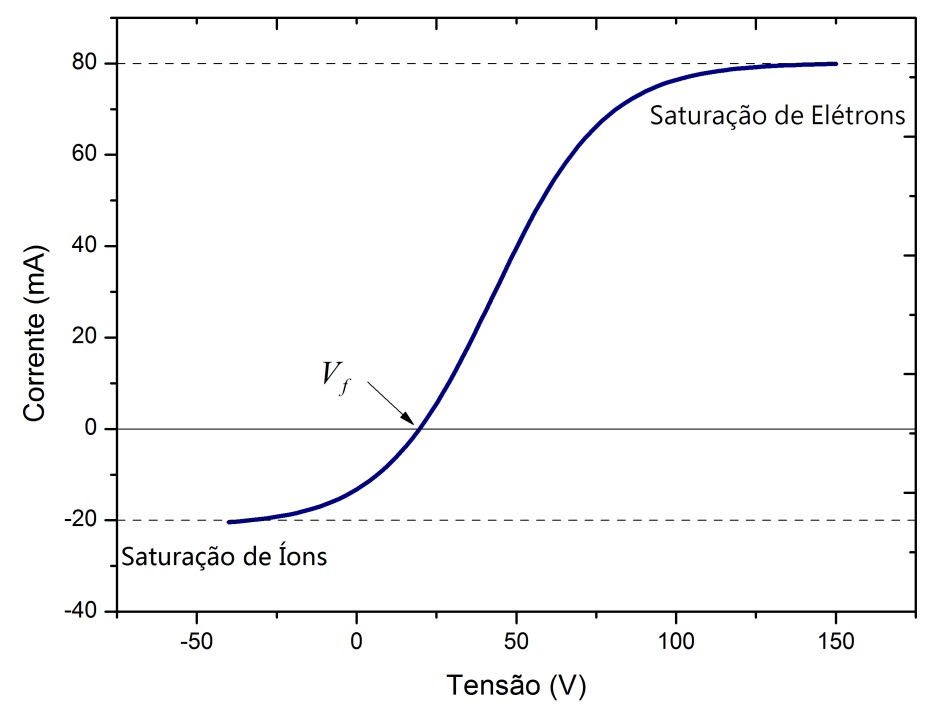

Figura 3.1: Curva característica de uma sonda eletrostática ou sonda de Langmuir

a interagir com o material externo mais rapidamente, porém a condição de neutralidade do plasma impõe uma redução dessa ruptura formada com a criação de um campo elétrico que acelera os íons e desacelera os elétrons. O fluxo passa a ser ambipolar. Como resultado desse efeito, o material passa a ter um potencial diferente do potencial de plasma local, porém apenas para uma distância muito pequena. Esse deslocamento coletivo do plasma blinda interferências elétricas externas.

A mudança do potencial na região vizinha ao material externo em contato com o plasma pode ser descrita pela equação de Poisson. Por simplicidade será considerado apenas o caso unidimensional, contudo o resultado é ainda bastante geral,

$$
\frac{d^{2} \phi}{d x^{2}}=\frac{e}{\varepsilon_{0}}\left(n_{e}-n_{i}\right)
$$

onde $n_{e}$ é a densidade eletrônica, $n_{i}$ é a densidade iônica e $e$ carga elétrica, considerando plasma de hidrogênio.

Devido a característica ambipolar do campo elétrico criado, a perda de elétrons é menor e a distribuição de velocidade é aproximadamente Maxwelliana, mesmo no interior da bainha, com o fator exponencial de Boltzmann. Pode-se demonstrar isso de maneira simplificada em uma dimensão considerando a equação de movimento dos elétrons e desconsiderando o campo magnético:

$$
n_{e} m_{e}\left(\frac{\partial v}{\partial t}+v \frac{\partial v}{\partial x}\right)=n_{e} e \frac{\partial \phi}{\partial x}
$$

em estado estacionário $\frac{\partial}{\partial t}=0$,

$$
n_{e} m_{e} v \frac{\partial v}{\partial x}=n_{e} e \frac{\partial \phi}{\partial x}
$$


considerando a equação da continuidade em estado estacionário,

$$
\begin{gathered}
\nabla \cdot\left(n_{e} v\right)=0 \\
n \frac{\partial v}{\partial x}+v \frac{\partial n}{\partial x}=0
\end{gathered}
$$

Segue então, substituindo na equação anterior,

$$
m_{e} v^{2} \frac{\partial n}{\partial x}=n_{e} e \frac{\partial \phi}{\partial x}
$$

Considerando ainda que $\frac{1}{2} m v^{2}=\frac{1}{2} k_{b} T$,

$$
\frac{d n}{n}=\frac{-e}{T_{e}} d \phi
$$

integrando,

$$
n_{e}=n_{0} e^{-\frac{e \phi}{T_{e}}}
$$

$\operatorname{com} T_{e} \equiv k_{b} T$.

Já a densidade iônica pode ser estimada pela conservação de energia,

$$
\frac{1}{2} m_{i} v_{i}^{2}=\frac{1}{2} m_{i} v_{0}^{2}-e \phi
$$

Em que $v_{0}$ é a velocidade dos íons na bainha. Considerando, na equação de continuidade que o fluxo de íons é constante,

$$
\begin{gathered}
n_{i} v_{i}=n_{0} v_{0} \\
n_{i}=n_{0}\left(\frac{\frac{1}{2} m_{i} v_{0}^{2}}{\frac{1}{2} m_{i} v_{0}^{2}-e \phi}\right)^{1 / 2}
\end{gathered}
$$

$\log \mathrm{O}$

$$
\frac{\mathrm{d}^{2} \phi}{\mathrm{d} x^{2}}=\frac{n_{0} e}{\epsilon_{0}}\left[\exp \frac{e \phi}{T_{e}}-\left(\frac{\frac{1}{2} m_{i} v_{0}^{2}}{\frac{1}{2} m_{i} v_{0}^{2}-e \phi}\right)^{1 / 2}\right]
$$

Considerando que o potencial devido a bainha é pequeno e varia pouco no seu comprimento,

$$
\exp \left\{\frac{e \phi}{T_{e}}\right\} \approx 1+\frac{e \phi}{T_{e}}
$$




$$
\left(\frac{\frac{1}{2} m_{i} v_{0}^{2}}{\frac{1}{2} m_{i} v_{0}^{2}-e \phi}\right)^{1 / 2}=1+\frac{e \phi}{m v_{0}^{2}}
$$

assim,

$$
\left[\exp \frac{e \phi}{T_{e}}-\left(\frac{\frac{1}{2} m_{i} v_{0}^{2}}{\frac{1}{2} m_{i} v_{0}^{2}-e \phi}\right)^{1 / 2}\right] \approx 1+\frac{e \phi}{T_{e}}-1-\frac{e \phi}{m v_{0}^{2}}
$$

e portanto,

$$
\begin{gathered}
\frac{\mathrm{d}^{2} \phi}{\mathrm{d} x^{2}}=\frac{n_{0} e^{2}}{\epsilon_{0} T_{e}}\left(1-\frac{T_{e}}{m_{i} v_{o}^{2}}\right) \phi \\
\frac{\mathrm{d}^{2} \phi}{\mathrm{d} x^{2}}=\left(1-\frac{T_{e}}{m_{i} v_{o}^{2}}\right) \frac{\phi}{\lambda_{D}^{2}}
\end{gathered}
$$

onde $\lambda_{D} \equiv \sqrt{\frac{\epsilon_{0} T_{e}}{n_{0} e^{2}}}$ é o comprimento de Debye. Considerando pequena variação do potencial no comprimento de Debye,

$$
v_{0} \simeq\left(T_{e} / m_{i}\right)^{1 / 2}
$$

A expressão anterior foi obtida desconsiderando a temperatura iônica, contudo seu efeito é levado em conta simplesmente considerando que,

$$
v_{0}=c_{s}=\sqrt{\frac{\left(T_{e}+T_{i}\right)}{m_{i}}}
$$

A densidade de corrente iônica é determinada a partir do critério de Bohm, o qual basicamente considera que o fluxo de íons na bainha é constante com velocidade igual a velocidade do som $\left(c_{s}\right)$. Assim, a densidade de corrente iônica é igual a:

$$
j_{i}=\alpha e n_{0} c_{s}
$$

com $\alpha \approx 0.5$ e $c_{s}=\sqrt{\left(Z T_{e}+\gamma_{i} T_{i}\right) / m_{i}}$, em que $\gamma_{i}=1$, coeficiente adiabático dos íons é considerado isotérmico.

Por outro lado, a densidade de corrente eletrônica na região da bainha é representada por uma distribuição maxwelliana, o fluxo de elétrons em direção a sonda é: $\frac{1}{4} n_{e} \bar{c}_{e}$, com $\bar{c}_{e}=\left(8 T_{e} / \pi m_{e}\right)^{1 / 2}$. Considerando a expressão da densidade eletrônica e levando em conta o efeito da emissão secundária de elétrons, obtém-se: 


$$
j_{e}=-\frac{1}{4} e n_{0}\left(\frac{8 T_{e}}{\pi m_{e}}\right)^{1 / 2}\left(1-\gamma_{e}\right) e^{\frac{e\left(V-V_{p}\right)}{T_{e}}}
$$

tomando agora o potencial de plasma como referência, onde $\gamma_{e}$ é o coeficiente de emissão secundária de elétrons.

Quando o potencial aplicado na sonda é igual ao potencial flutuante, a corrente coletada pela sonda é nula, assim:

$$
\begin{gathered}
j_{i} A=j_{e}\left(V_{f}\right) A \\
-\frac{e\left(V_{f}-V_{p}\right)}{T_{e}}=\frac{1}{2} \ln \left[\frac{m_{i}\left(1-\gamma_{e}\right)^{2}}{2 \pi m_{e} \alpha^{2}\left(1+T_{i} / T_{e}\right)}\right]
\end{gathered}
$$

segue que,

$$
V_{p}=V_{f}+\frac{T_{e}}{2 e} \ln \left[\frac{m_{i}\left(1-\gamma_{e}\right)^{2}}{2 \pi m_{e} \alpha^{2}\left(1+T_{i} / T_{e}\right)}\right]
$$

para um plasma de hidrogênio, $V_{p} \approx V_{f}+2,8 T_{e}$.

Além disso,

$$
j_{i} e^{-\frac{e\left(V_{f}-V_{p}\right)}{k_{b} T_{e}}}=\frac{1}{4} e n_{0} c_{e}\left(1-\gamma_{e}\right)
$$

Onde $A$ é a área de coleta da sonda. Logo, $j_{e}$ pode ser escrito como:

$$
j_{e}=-j_{i} e^{\frac{e\left(-V_{f}+V_{p}+V-V_{p}\right)}{k_{b} T_{e}}}=-j_{i} e^{\frac{e\left(V-V_{f}\right)}{T_{e}}}
$$

e, portanto, a corrente total é:

$$
\begin{aligned}
& I=I_{i}+I_{e}=\left(j_{i}+j_{e}\right) A \\
& I(V)=I_{i}\left[1-e^{\frac{e\left(V-V_{f}\right)}{T_{e}}}\right]
\end{aligned}
$$

A densidade eletrônica pode ser obtida da corrente de saturação de íons, considerando a expressão (3.7),

$$
n_{e}=\frac{I_{s i}}{\sqrt{T_{e}}} \sqrt{\frac{4 m_{i}}{A^{2} e^{2}}}
$$

Em todos os cálculos mostrados não foi considerado o efeito do campo magnético, no 
entanto, em um tokamak o campo magnético é importante, as partículas estão confinadas a ele, movendo-se, predominantemente, na direção das linhas de campo. Porém, na prática seu efeito é pouco perceptível, desde que as dimensões da sonda sejam menores que o comprimento característico do plasma; nesse caso, a corrente de saturação de elétrons diminuí, já que menos elétrons conseguem chegar ao eletrodo, porém, a curva característica da sonda pouco se altera, em particular, a inclinação entre a corrente de saturação de íons e a de elétrons é praticamente a mesma, ou seja, a temperatura é praticamente a mesma. Uma correção simples é considerar que a área coletora da sonda muda, ela passa a ser a projeção da área da sonda ao longo do campo magnético [15]. Para eletrodo cilíndrico,

$$
A_{p}=A\left(1+\frac{x_{s}}{a}\right)
$$

onde,

$$
\frac{x_{s}}{\lambda_{D}}=\frac{2}{3}\left[\frac{2}{\exp (-1)}\right]^{1 / 4}\left[\left(\frac{-e V_{0}}{T_{e}}\right)^{1 / 2}-\frac{1}{\sqrt{2}}\right]^{1 / 2}\left[\left(\frac{-e V_{0}}{T_{e}}\right)^{1 / 2}+\sqrt{2}\right]
$$

com $V_{0}$ o potencial na sonda.

Tal efeito é mensurável na prática, é o chamado "alargamento da bainha", a área de coleta pode variar com a tensão da sonda e como resultado a corrente de íons passa a ter um coeficiente angular não nulo. Na análise dos dados foi levado em conta este efeito ajustandose uma reta na corrente de íons, considerando que a corrente de saturação de íons era a extrapolação desse ajuste até a corrente para o potencial flutuante. A equação para a corrente de coleta da sonda passa a ser igual a:

$$
I(V)=j_{i} A_{e f f}(V)\left[1-e^{\frac{e\left(V-V_{f}\right)}{T_{e}}}\right]
$$

onde $A_{\text {eff }}(V)$ é uma área efetiva devido ao alargamento da bainha que depende da tensão aplicada na sonda.

\subsection{Modo $\mathrm{H}$}

A difusão do plasma descrita teoricamente para um tokamak, levando em conta efeitos geométricos toroidais (difusão neoclássica), prevê um coeficiente de difusão e de condutividade térmica bem maior do que a previsão clássica, considerando um tokamak como um cilindro comprido. No entanto, na prática seus valores são ainda bem maiores, experimentalmente eles são ordens de grandeza maiores do que o previsto pela teoria neoclássica [5]. A razão para esse comportamento é que o transporte (de partículas e energia) em um tokamak ocorre de maneira anômala, ou seja, por conta de efeitos turbulentos na região da borda do plasma, que a teoria neoclássica não considera. A origem do transporte anômalo resulta de microinstabilidades eletrostáticas, chamadas de ondas de deriva, que geram correlações 
turbulentas no plasma, deteriorando gradativamente seu confinamento.

Em 1982 no tokamak ASDEX em Garching na Alemanha foi descoberto um modo melhorado de confinamento do plasma que passou a ser chamado de modo H (High) [16], em contraste ao modo comum de operação Low (L). Foi obtido um aumento de até um fator 2 no tempo de confinamento de energia, através do aquecimento do plasma por partículas neutras energéticas. Posteriormente, foi ativado com ondas de radio-frequência em diferentes faixas: elétron-cyclotron, íon cyclotron, região híbrida e através do uso de um eletrodo polarizado eletricamente na região de borda, contudo exclusivamente em tokamaks de pequeno e médio porte $[17,18,19]$. A transição ocorre quando a energia externa aplicada supera um determinado limiar de energia que depende das características da máquina. Há expressões semi-empíricas, levando em conta dados de vários tokamaks (diferentes tamanhos e parâmetros de plasma), para a potência do limiar da transição espontânea (através de aquecimento auxiliar). Uma das primeiras foi obtida pelo grupo ASDEX [20],

$$
P_{L}^{A S D E X}=0,04\left(\bar{n}_{e} / 10^{20}\right) B S(M W)
$$

onde $\bar{n}_{e}$ é a densidade média de elétrons, $B$ o campo magnético total e $S$ é área do plasma. A expressão 3.14 é bastante útil na prática, no entanto uma versão teórica por princípios físicos é ainda procurada, conhecê-la poderia significar entender o processo de forma plena e, portanto, otimizá-lo. Outra expressão mais recente para a potência de limiar da transição é devido a equipe do ITER [20],

$$
P_{L}^{I T E R}=(0,45 \pm 0,10)\left(\bar{n}_{e} / 10^{20}\right)^{0,75} B R^{2}\left[0,6\left(\bar{n}_{e} / 10^{20}\right) R^{2}\right]^{\alpha}(M W)
$$

onde $R$ é o raio maior e $|\alpha| \leq 0,25$.

Em um primeiro período que se sucedeu o descobrimento do modo $\mathrm{H}$, muitos pesquisadores acreditavam que a sua obtenção estava relacionada com a presença de diversores. No entanto, logo também se conseguiu induzir modo H em tokamaks com limitadores [21] e até mesmo em stellarators [22]. Mas a presença de diversor facilita a transição, pois esse tipo de sistema libera menos impureza que os limitadores. Nestes, o plasma interage com uma superfície material (geralmente grafite) que o limita, porém esse contato libera grandes quantidades de impurezas que absorvem parte da energia "livre"no plasma, emitindo posteriormente em forma de radiação. Nos diversores, por outro lado, essa interação é menos invasiva, as partículas que escapam do confinamento são orientadas por uma configuração de campos magnéticos em direção à placas coletoras fora da região de confinamento, na "camada de raspagem"(scrape-off-layer) ampliada; no entanto mesmo essa configuração não é livre de impurezas, pois as partículas que provém do confinamento ao interagir com as placas podem "arrancar"partículas delas, por "sputtering"ou por outros mecanismos, sujando eventualmente o plasma. 
No modo H há uma grande redução no nível de turbulência na região da borda do plasma acompanhado da criação de uma barreira de transporte (ETB-Edge Transport Barrier) nessa região, devido às mudanças nos perfis radias de temperatura e densidade que se tornam mais íngremes, com um grande aumento dos seus gradientes. Por consequência, há uma grande diminuição no transporte de partículas e de energia na região externa a barreira e uma grande diminuição do nível de flutuações turbulentas. Nota-se, também um aumento da densidade central, aumento da energia armazenada no plasma e uma diminuição da emissão da linha $H_{\alpha}$, o que também indica uma redução do fluxo de partículas em direção à parede e ao limitador, logo uma menor taxa de reciclagem [23].

É bem aceito que o campo elétrico radial tem um papel importante para a existência do modo H. Na transição modo L-H há um aumento do seu gradiente na borda, o que força um cisalhamento no fluxo de plasma devido $E \times B$, destruindo as correlações turbulentas e aumentando a velocidade poloidal na periferia do plasma [23]. A supressão da turbulência segundo o critério Biglari-Diamond-Terry (BDT), [24] se dá quando,

$$
\left|\omega_{t}\right|<\left|k_{\theta} \Delta r V_{E}^{\prime}\right|
$$

onde $k_{\theta}$ é o número de onda poloidal característico da turbulência, $\Delta r$ é o comprimento da correlação radial, $V_{E}^{\prime}$ é a derivada radial da velocidade de equilíbrio $E \times B$ e $\omega_{t}=4 D(\Delta r)^{2}$, onde $D$ é a difusividade turbulenta. Contudo, o entendimento dos detalhes desse processo físico ainda não está suficientemente estabelecido. Não é totalmente claro ainda a ligação entre o aumento do gradiente do campo elétrico radial na borda com o aumento da velocidade poloidal nessa região, resultando na diminuição do nível de turbulência e do fluxo radial de partículas e energia, com a criação de uma barreira de transporte (existem modelos que tentam explicar essas mecanismos, como [25, 26, 27]. Além disso, não é claro pelas equações clássicas, em que instante a transição ocorre, experimentalmente ela acontece de maneira abrupta, nesse sentido é buscado uma bifurcação entre estados nas equações, representando os modos L e H. O gatilho que conduz a transição ainda não é evidente, qual é ou quais são os parâmetros responsáveis por ela. O campo elétrico na borda (ou seu gradiente) é um forte candidato; nesse sentido os experimentos em modo H são essenciais, pois fornecem evidências que auxiliam a modelagem do sistema. É procurada também uma expressão definitiva para o limiar de energia necessário para induzir o modo H, já que é uma questão prática para o funcionamento dos reatores de fusão.

A transição se manifesta experimentalmente através da bifurcação do campo elétrico, que conduz mudanças nos parâmetros de plasma, como densidade eletrônica e transporte. Outra característica do modo $\mathrm{H}$ são as instabilidades chamadas de ELMs (edge-localized mode)[28], embora haja casos de modo $\mathrm{H}$ em algumas máquinas sem a presença de ELMs [29]. Essas instabilidades são marcadas por "jatos"("bursts") de densidade de alta amplitude com frequências características (existem três tipos de ELM) que deterioram o confinamento, 
provocando periódicos relaxamentos na barreira de transporte, causando grande fuga de energia e partículas. Existem diversas pesquisas em ELMs visando encontrar uma forma de mitigá-los [30, 23], porém, existem linhas de pesquisa que entendem que a presença de ELM (principalmente o de tipo II [29]) pode ser uma ferramenta ao problema de exaustão de energia e partículas em grandes tokamaks (ou tokamaks esféricos), pois o período de relaxamento da barreira pode conduzir para fora um excedente indesejável de energia e partículas localizadas nas regiões centrais do plasma.

Em ordem mais baixa, a equação para o balanço de força na direção radial para uma única espécie é:

$$
E_{r}=-\frac{1}{n_{i} e_{i}} \frac{d p_{i}}{d r}-v_{\theta i} B_{\phi}+v_{\phi i} B_{\theta}
$$

onde $e_{i}$ é a carga da espécie $i, p_{i}$ a pressão, $n_{i}$ a densidade, $v_{\theta i}$ a velocidade poloidal e $v_{\phi i}$ a velocidade toroidal. Logo, as mudanças em $E_{r}$ podem estar relacionadas com mudanças em $\frac{d p_{i}}{d r}$ ou com mudanças nas velocidades $v_{\theta i}$ e $v_{\phi i}$. Dado a importância clara de $E_{r}$ na transição L-H, seu aumento passou a ser induzido em muitos tokamaks com a inserção de um eletrodo polarizado na borda do plasma $[17,18]$. No TCABR o confinamento melhorado é induzido dessa forma.

Apesar do modo H ter sido reportado como uma transição abrupta nos parâmetros de plasma, em algumas máquinas é possível induzir uma melhora no confinamento de plasma sem que, necessariamente, haja uma transição súbita, quando a potência fornecida ao plasma é abaixo do limiar de potência [31, 32, 33]. Contudo, os mesmos traços característicos do modo $\mathrm{H}$ são presentes, perfis íngremes na borda de $E_{r}$ e $n_{e}$, redução da turbulência, queda do transporte e aumento do tempo de confinamento de energia. São reportados, também, estados intermediários entre o modo L e o H [34, 35, 36], com a presença de Fluxos Zonais ("Zonal flows") e GAM (global acoustic modes).

\subsubsection{Confinamento melhorado no TCABR}

O modo H, ou confinamento melhorado, é obtido no TCABR utilizando um eletrodo de grafite com $8 \mathrm{~mm}$ de comprimento e $20 \mathrm{~mm}$ de diâmetro inserido na borda do plasma, no plano vertical da câmara toroidal (figura 4.8). A tensão aplicada no eletrodo pode chegar a +400 V, com uma corrente de até 200 A. Os sinais de corrente e tensão do eletrodo são adiquiridos no VME, com uma taxa de 250 kilosamples/s.

\subsubsection{Pesquisas anteriores com eletrodo no TCABR}

Nos primeiros experimentos realizados no TCABR com eletrodo já foi possível notar uma melhora no confinamento do plasma, com um decréscimo no nível de turbulência e transporte de partículas na borda, além do aumento da densidade média no centro da coluna e da redução da taxa de reciclagem, com a diminuição da linha do $H_{\alpha}$, no intervalo de tempo 
em que o eletrodo era aplicado [37].

Foi também estudada a influência da polarização do eletrodo na excitação ou supressão das instabilidades MHD [38]. Particularmente, foram estudadas situações em que as atividades MHD eram induzidas pela aplicação do eletrodo e situações em que o eletrodo suprimia instabilidades anteriores a sua aplicação. Foi visto também que as ilhas magnéticas do tipo $(3,1)$ desempenham uma influência negativa sobre o confinamento.

Foram estudadas também as correlações que se formam devido à polarização periférica e foram medidas altas correlações em sinais de potencial flutuante, mesmo entre sondas muito distante umas das outras, espaçadas em até aproximadamente 180 graus toroidalmente. Tal efeito foi identificado como sendo devido à existência de zonal flows (ZFs), que se formam em condições particulares em experimentos com o eletrodo [39].

\subsection{Ferramentas de análise}

A característica dos parâmetros de plasma medidos e a possível análise que se pode fazer deles permite dividi-los em duas categorias: parâmetros de equilíbrio e parâmetros flutuantes. As ferramentas de análise para os dois casos no geral são distintas, para as flutuações as análises espectrais são ferramentas poderosas, permitindo, por exemplo, estudar algumas características da turbulência, já para o caso de equilíbrio o interesse maior é em valores médios.

\subsubsection{Espectro de potência}

A transformada de Fourier continua de uma certa função $f(t)$ é definida como [40]:

$$
F(f)=\int_{-\infty}^{\infty} f(t) e^{-2 \pi i f t} d t
$$

com sua transformada inversa dada por:

$$
f(t)=\int_{-\infty}^{\infty} F(f) e^{2 \pi i f t} d t
$$

A correlação cruzada entre duas funções $x(t)$ e $y(t)$ é definida como:

$$
R_{x y}(t, \tau)=\int_{-\infty}^{\infty} y(t) x^{*}(t-\tau) d t
$$

$\mathrm{Ou}$

$$
R_{x y}(t, \tau)=<y(t) x^{*}(t-\tau)>
$$


segue que a auto correlação é,

$$
R_{x x}(\tau)=\int_{-\infty}^{\infty} x(t) x^{*}(t-\tau) d t
$$

$\mathrm{Ou}$

$$
R_{x x}(t, \tau)=<x(t) x^{*}(t-\tau)>
$$

Por outro lado, para um sinal $x(t)$, definido em um intervalo finito de tempo, $0 \leq t<T$, a tranformada de Fourier é:

$$
X(f)=\int_{0}^{T} x(t) e^{-2 \pi i f t} d t
$$

Na forma discretizada, a expressão 3.22 pode ser escrita como:

$$
X(l \Delta f)=\sum_{n=0}^{N-1} x\left(n t_{s}\right) e^{-2 \pi i l \Delta f n t_{s}} t_{s}, \quad \text { com }: \quad l=1,2, \ldots, N-1
$$

com $d t \approx t_{s}$, em que $t_{s}$ é o menor tempo para o qual os dados são adquiridos. Além disso, $f=l \Delta f, \operatorname{com} \Delta f=1 / T=1 / N t_{s}$; segue então que:

$$
X(l \Delta f)=\frac{1}{\Delta f}\left[\frac{1}{N} \sum_{n=0}^{N-1} x\left(n t_{s}\right) e^{-2 \pi i l n / N}\right]
$$

A transformada de Fourier na sua forma discreta pode ser obtida utilizando o algoritmo Fast Fourier Transform (FFT), que é disponível na biblioteca do MatLab. Com a finalidade de minimizar o fenômeno de "Leakage", comum quando se tenta obter a transformada de Fourier de um sinal com duração finita, foi aplicada uma janela do tipo Hanning ao sinal $[40]$,

$$
w_{\text {Hanning }}=\frac{1}{2}\left(1-\cos \frac{2 \pi t}{T}\right), \quad 0 \leq t<T
$$

A potência espectral de um sinal $x(t)$ para um tempo finito é definida como:

$$
S_{x x}(\omega)=\lim _{T \rightarrow \infty} \frac{1}{T}<|X(\omega)|^{2}>
$$

$\operatorname{com} \omega=2 \pi f . \mathrm{Ou}$, aproximadamente, igual a:

$$
S_{x x}(\omega) \approx \frac{1}{T}<|X(\omega)|^{2}>
$$

para $T$ muito grande.

De forma análoga, para dois sinais com duração finita: $x(t)$ e $y(t)$, definidos em $0 \leq t<T$, e 
com transformada de Fourier igual a $X(\omega)$ e $Y(\omega)$, respectivamente, o espectro de potência cruzada pode ser definido como:

$$
S_{x y}(\omega)=\lim _{T \rightarrow \infty} \frac{1}{T}<X(\omega) Y^{*}(\omega)>
$$

Ou aproximadamente,

$$
S_{x y}(\omega) \approx \frac{1}{T}<\left|X(\omega) Y^{*}(\omega)\right|>
$$

para $T$ muito grande.

Para processos estacionários, a correlação cruzada e a auto correlação tornam-se:

$$
\begin{aligned}
& R_{x y}(\tau)=<y(t) x^{*}(t-\tau)> \\
& R_{x x}(\tau)=<x(t) x^{*}(t-\tau)>
\end{aligned}
$$

com $R_{x y}$ e $R_{x x}$ independente de $t$. É possível demonstrar que se $X(f)$ e $Y(f)$ são não correlacionados, nesse sentido $x(t)$ e $y(t)$ são amplamente estacionários, então:

$$
R_{x y}(\tau)=\int_{-\infty}^{\infty} S_{x y}(f) e^{i 2 \pi f \tau} d f
$$

ou seja, a função de correlação cruzada é a transformada de Fourier da potência espectral cruzada.

\subsubsection{Transporte turbulento de partículas}

O fluxo médio de partículas devido à flutuações é definido como:

$$
\tilde{\Gamma}_{i}=<\tilde{n}(t) \tilde{v}_{i}(t)>
$$

onde $\tilde{n}$ e $\tilde{v}_{i}$ são as flutuações de densidade e velocidade, respectivamente.

Em um plasma turbulento podem surgir flutuações de densidade e campo elétrico que induzem transporte de partículas. Isso se dá com o surgimento de uma velocidade de deriva devido às flutuações do campo elétrico [41],

$$
\vec{v}_{E}=\frac{\vec{E} \times \vec{B}}{B^{2}}
$$

dessa forma, o fluxo médio de partículas torna-se,

$$
\tilde{\Gamma}_{k}=\frac{<\tilde{n}(t) \tilde{E}_{i}(t)>}{\tilde{B}_{j}(t)} .
$$


Considerando que o campo magnético está na direção toroidal e que é aproximadamente constante e as flutuações do campo elétrico ocorrem na direção poloidal, pela expressão anterior o fluxo de partículas na direção radial é:

$$
\tilde{\Gamma}_{r}=\frac{<\tilde{n}(t) \tilde{E}_{\theta}(t)>}{B_{\phi}},
$$

onde $\vec{E} \approx-\vec{\nabla} V_{p}$ na aproximação quase estática. Nota-se que a expressão anterior pode ser reescrita em termos da função de correlação cruzada [42], com $\tau=0$,

$$
\tilde{\Gamma}_{r}=\frac{1}{B_{\phi}} R_{n E_{\theta}}(\tau=0),
$$

mas no caso estacionário a função de correlação cruzada é a transformada de Fourier inversa da potência espectral cruzada,

$$
\tilde{\Gamma}_{r}=\frac{1}{B_{\phi}} \int_{-\infty}^{\infty} d f S_{n E_{\theta}}(f) e^{i 2 \pi f(\tau=0)}
$$

como $\operatorname{Re}\left\{S_{n E_{\theta}}\right\}$ é uma função par e $\operatorname{Im}\left\{S_{n E_{\theta}}\right\}$ é uma função ímpar, segue que

$$
\tilde{\Gamma}_{r}=\frac{1}{B_{\phi}} \int_{-\infty}^{\infty} d f S_{n E_{\theta}}(f)=\frac{2}{B_{\phi}} \int_{0}^{\infty} d f \operatorname{Re}\left\{S_{n E_{\theta}}(f)\right\}
$$

portanto, o fluxo médio de partículas na direção radial pode ser escrito como

$$
\tilde{\Gamma}_{r}=\int_{0}^{\infty} d f T(f)
$$

em que

$$
T(f)=\frac{2}{B_{\phi}} \operatorname{Re}\left\{S_{n E_{\theta}}(f)\right\}, f \geq 0,
$$

é a função densidade espectral de transporte.

Definindo o espectro de coerência da seguinte forma,

$$
\gamma_{n E}(f)=\frac{\left|S_{n E}(f)\right|}{\sqrt{S_{n}(f)} \sqrt{S_{E}(f)}},
$$

$T(f)$ pode ser escrito como,

$$
\begin{gathered}
T(f)=\frac{2}{B_{\phi}} \operatorname{Re}\left\{S_{n E_{\theta}}(f)\right\}=\frac{2}{B_{\phi}}\left|S_{n E_{\theta}}(f)\right| \cos \alpha_{n E}(f) \\
T(f)=\frac{2}{B_{\phi}} \gamma_{n E_{\theta}}(f) \sqrt{S_{n}(f)} \sqrt{S_{E_{\theta}}(f)} \cos \alpha_{n E_{\theta}}(f)
\end{gathered}
$$


onde $\alpha_{n E_{\theta}}$ é a diferença de fase entre a densidade e o campo elétrico poloidal.

\subsubsection{Transporte de energia}

O transporte de energia através do campo magnético, ou o fluxo de energia na direção radial, pode ser escrito da seguinte forma [43]:

$$
Q_{t o t}=\bar{q}_{c}+\frac{3}{2} \bar{T} \bar{\Gamma}_{r c}+\frac{3}{2} \bar{n} \frac{<\tilde{T} \tilde{E}_{\theta}>}{B_{\phi}}+\frac{3}{2} \tilde{\Gamma}_{r} \bar{T}
$$

onde o índice (c) indica termo clássico, enquanto que ( $)$ indica termo turbulento. $\bar{n}$ e $\bar{T}$ são, respectivamente, densidade e temperatura média e $\Gamma_{r}$ é o fluxo radial de partículas. Os dois últimos termos da expressão anterior são as contribuições anômalas, ou turbulentas, no fluxo de energia, sendo o primeiro deles o termo condutivo e o segundo o termo convectivo,

$$
\begin{gathered}
\tilde{Q}_{\text {cond }}=\frac{3}{2} \bar{n} \frac{<\tilde{T} \tilde{E}_{\theta}>}{B_{\phi}} \\
\tilde{Q}_{\text {conv }}=\frac{3}{2} \tilde{\Gamma}_{r} \bar{T}
\end{gathered}
$$

O termo condutivo pode ser escrito de forma análoga à expressão do fluxo turbulento de partículas na direção radial (como visto na seção anterior), com a flutuação da temperatura no lugar da flutuação da densidade.

$$
\tilde{Q}_{\text {cond }}=\frac{3 \bar{n}}{B_{\phi}} \int_{0}^{\infty} d f \operatorname{Re}\left\{S_{T E_{\theta}}(f)\right\}
$$

\subsubsection{Função $\mathrm{S}(\mathrm{k}, \mathrm{f})$}

O espectro de número de onda-frequência (wavenumber-frequency espectrum), representado geralmente pela função $S(k, f)$, é uma técnica que permite estudar flutuações no espaço e no tempo em um determinado meio. Para alguns meios a relação de dispersão é determinística, ou seja, para uma dada frequência há um número de onda correspondente, $k=k(\omega)$. Porém, existem meios em que as ondas se relacionam de maneira não linear, resultando em uma relação de dispersão ampla, com diferentes possíveis $k$ para um dado $\omega$; tipicamente tais meios são chamados de turbulentos. Rigorosamente, $S(k, f)$ é a transformada de Fourier, espacial e temporal, da função de correlação cruzada $R(\chi, \tau)$ na condição estacionária e homogênea. No entanto, na prática as flutuações no espaço são muito difíceis de serem medidas, exigiria um número grande de sondas em várias posições diferentes, o que geralmente não é viável de ser feito, principalmente, porque poderia perturbar o meio de medida. Porém, há uma abordagem que possibilita estimar $S(k, f)$ através apenas de dois sinais espaçados, com a estimativa de um $k$ local [44]. 
Considerando dois sinais espaçados: $g\left(x_{1}, t_{1}\right)$ e $g\left(x_{2}, t_{2}\right)$; a função de correlação cruzada é,

$$
R\left(x_{1}, x_{2}, t_{1}, t_{2}\right)=R\left(x_{1}-x_{2}, t_{1}-t_{2}\right)
$$

$\operatorname{com} R\left(x_{1}, x_{2}, t_{1}, t_{2}\right)=<g\left(x_{1}, t_{1}\right) g^{*}\left(x_{2}, t_{2}\right)>$. Segue então que,

$$
\begin{gathered}
S\left(k_{1}, \omega_{1},-k_{2},-\omega_{2}\right)=\int_{-\infty}^{\infty} \int_{-\infty}^{\infty} \int_{-\infty}^{\infty} \int_{-\infty}^{\infty} d x_{1} d t_{1} d x_{2} d t_{2} R\left(x_{1}, t_{1}, x_{2}, t_{2}\right) \\
\quad \times e^{-i\left(\omega_{1} t_{1}-\omega_{2} t_{2}-k_{1} x_{1}+k_{2} x_{2}\right)} \\
S\left(k_{1}, \omega_{1},-k_{2},-\omega_{2}\right)=\int_{-\infty}^{\infty} \int_{-\infty}^{\infty} \int_{-\infty}^{\infty} \int_{-\infty}^{\infty} d x_{1} d t_{1} d x_{2} d t_{2}<g\left(x_{1}, t_{1}\right) g^{*}\left(x_{2}, t_{2}\right)> \\
\quad \times e^{-i\left(\omega_{1} t_{1}-\omega_{2} t_{2}-k_{1} x_{1}+k_{2} x_{2}\right)} \\
S\left(k_{1}, \omega_{1},-k_{2},-\omega_{2}\right)=<G\left(k_{1}, \omega_{1}\right) G^{*}\left(k_{2}, \omega_{2}\right)>
\end{gathered}
$$

Na condição estacionária e para um meio homogêneo, $\chi=x_{1}-x_{2}$ e $\tau=t_{1}-t_{2}$,

$$
\begin{gathered}
S\left(k_{1}, \omega_{1},-k_{2},-\omega_{2}\right)=\int_{-\infty}^{\infty} \int_{-\infty}^{\infty} d \chi d \tau R(\chi, \tau) e^{-i\left(\omega_{1} \tau-k_{1} \chi\right)} \\
\times \int_{-\infty}^{\infty} d t_{2} e^{-i\left(\omega_{1}-\omega_{2}\right) t_{2}} \int_{-\infty}^{\infty} d x_{2} e^{i\left(k_{1}-k_{2}\right) x_{2}}
\end{gathered}
$$

como: $\delta(x-\alpha)=\frac{1}{2 \pi} \int_{\infty}^{-\infty} e^{i p(x-\alpha)} d p$, portanto

$$
<G\left(k_{1}, \omega_{1}\right) G^{*}\left(k_{2}, \omega_{2}\right)>=(2 \pi)^{2} S\left(k_{1}, \omega_{1}\right) \delta\left(k_{1}-k_{2}\right) \delta\left(\omega_{1}-\omega_{2}\right)
$$

segue dos resultados anteriores para o caso estacionário e homogênio que,

$$
S(k, \omega)=\int_{-\infty}^{\infty} \int_{-\infty}^{\infty} d \chi d \tau R(\chi, \tau) e^{-i(\omega \tau-k \chi)}
$$

Para o caso finito é possível demonstrar [44] que,

$$
S(k, \omega)=\lim _{T, L \rightarrow \infty} \frac{1}{L T}<G_{1}(k, \omega) G_{2}^{*}(k, \omega)>
$$

onde $T$ e $L$ são tempo e comprimento característico, respectivamente.

Para dois sinais a uma distância $d$, pode-se estimar o número de onda local $k$ considerando o espectro cruzado entre os sinais, já que ele fornece a diferença de fase para cada instante 
de tempo. Dessa forma, sendo:

$$
S_{x y}(t, \omega)=<X(t, \omega) Y^{*}(t, \omega)>=\left|S_{x y}(t, \omega)\right| e^{i \alpha_{x y}}
$$

então

$$
k(t, \omega)=\frac{\alpha_{x y}(t, \omega)}{d}
$$

Assim, $S(k, f)$ pode ser estimado da seguinte forma, limita-se o intervalo de valores de $k \in[-\pi / d \pi / d]$, a fim de evitar ambiguidade, então é calculado $S_{x y}(t, \omega)$ e $k(t, \omega)$. Assim, para cada frequência, obtém-se todos os possíveis valores de $k$ para a janela de tempo escolhida, $S(k, f)$ é a contribuição em potência para os diferentes $k$ no intervalo fixado em uma dada frequência; ou seja, é feito um histograma em $k$ das potências para cada $f$ fixado.

$$
S\left(k_{1}, f_{1}\right)=\sum_{l} S_{x y}\left(t_{l}, f_{1}\right) I\left[\frac{\alpha_{x y}\left(t_{l}\right)}{d}=k_{1}\right]
$$

com

$$
I\left[\frac{\alpha_{x y}\left(t_{l}\right)}{d}=k_{1}\right]=\left\{\begin{array}{lll}
1, & \text { se } & \frac{\alpha_{x y}(t)}{d}=k_{1} \\
0, & \text { se } & \frac{\alpha_{x y}(t)}{d} \neq k_{1}
\end{array}\right.
$$

generalizando,

$$
S(k, f)=\sum_{j}^{N} \sum_{i}^{M}\left\{\sum_{l}^{P} S_{x y}\left(t_{l}, f_{j}\right) I\left[\frac{\alpha_{x y}\left(t_{l}, f_{j}\right)}{d}=k_{i}\right]\right\}
$$

com

$$
I\left[\frac{\alpha_{x y}\left(t_{l}, f_{j}\right)}{d}=k_{i}\right]=\left\{\begin{array}{lll}
1, & \text { se } & \frac{\alpha_{x y}\left(t_{l}, f_{j}\right)}{d}=k_{i} \\
0, & \text { se } & \frac{\alpha_{x y}\left(t_{l}, f_{j}\right)}{d} \neq k_{i}
\end{array}\right.
$$

em que $j=(1,2, \ldots, N), N$ é o comprimento da janela de frequência, $i=(1,2, \ldots, M), M$ é o comprimento do vetor $k$, para $[-\pi / d, \pi / d]$, e $l=(1,2, \ldots, Q), Q$ é o comprimento da janela de tempo.

Com $S(k, f)$ calculado ou $S(k, \omega)$, substituindo $f$ por $\omega=2 \pi f$, os espectros de potência $S(\omega)$ e $S(k)$ são:

$$
\begin{aligned}
& S(\omega)=\int_{-\infty}^{\infty} S(k, \omega) \frac{d k}{2 \pi} \\
& S(k)=\int_{-\infty}^{\infty} S(k, \omega) \frac{d \omega}{2 \pi}
\end{aligned}
$$

É possível também estimar a velocidade de fase média local a partir da função $\mathrm{S}(\mathrm{k}, \mathrm{f})$. Tal informação é particularmente útil neste trabalho, pois pode fornecer uma idéia quantitativa do efeito do cisalhamento local do fluxo de plasma quando se aplica um eletrodo polarizado na sua borda. De maneira simples, pode-se estimar a velocidade de fase média pela seguinte expressão: 


$$
\bar{v}_{\theta}=\frac{\int_{-\infty}^{\infty} \int_{-\infty}^{\infty} v_{\theta} S(k, f) d f d k}{\int_{-\infty}^{\infty} \int_{-\infty}^{\infty} S(k, f) d f d k}
$$

$\operatorname{com} v_{\theta}=\frac{\omega}{k}$, para $k \neq 0$

\subsubsection{Ajuste pelo método dos mínimos quadrados (MMQ)}

O Método dos Mínimos Quadrados (MMQ) é uma técnica bastante poderosa de ajuste de dados utilizando uma determinada função. Ele se baseia no fato de que o melhor ajuste é aquele no qual a soma dos resíduos (diferença relativa entre um dado experimental e a função de ajuste) elevado ao quadrado e dividido pelas correspondentes variâncias (quadrado do desvio padrão) é o menor possível.

Seja $f(x, \mathbf{a})$ uma função de ajuste, em que $\mathbf{a}=\left(a_{1}, a_{2}, \ldots, a_{N}\right)$ é o numero de parâmetros e supondo que tal função seja usada para ajustar um conjunto de dados $\left(x_{i}, y_{i}\right)$, com $i=$ $(1,2,3, \ldots M)$, em que $M \geq N$ e considerando que os parâmetros variem linearmente em relação aos dados, o resíduo é definido como,

$$
R_{i}=y_{i}-f\left(x_{i}, \mathbf{a}\right)
$$

e a média de um conjunto de dados é igual a:

$$
\bar{y}=\frac{1}{L} \sum_{k=1}^{L} y_{k}
$$

Uma estimativa para a variância, se os dados forem estatisticamente independentes (covariância nula entre eles), é:

$$
\sigma^{2}=\frac{1}{L-1} \sum_{k=1}^{L}\left(y_{k}-\bar{y}\right)^{2}
$$

onde $L$ é o número de pontos.

A soma do quadrado dos resíduos dividido pelas variâncias é então:

$$
Q(\mathbf{a})=\sum_{i=1}^{M} \frac{R_{i}^{2}}{\sigma_{i}^{2}}=\sum_{i=1}^{M} \frac{\left[y_{i}-f\left(x_{i}, \mathbf{a}\right)\right]^{2}}{\sigma_{i}^{2}}
$$

O mínimo de $Q$ é obtido quando o gradiente em relação aos parâmetros é nulo, ou seja:

$$
\frac{\partial Q}{\partial a_{j}}=\frac{\partial}{\partial a_{j}}\left\{\sum_{i}^{M} \frac{\left[y_{i}-f\left(x_{i}, a_{j}\right)\right]^{2}}{\sigma_{i}^{2}}\right\}=2 \sum_{i}^{M} \frac{R_{i}}{\sigma_{i}^{2}} \frac{\partial R_{i}}{\partial a_{j}}=0
$$


$\operatorname{com} j=(1,2, \ldots N)$.

Dessa forma, obtém-se um sistema com $N$ equações e $N$ incógnitas. A solução das equações fornece os parâmetros que melhor ajusta os dados. Os detalhes dos cálculos a partir do sistema obtido acima, com simplificações que levam ao cálculo da matriz de covariância dos parâmetros, fornecendo um erro aproximado para eles, além de uma maneira prática de representar o método em forma matricial, pode ser visto na referência [45].

Muitas vezes é necessário fazer um ajuste com uma função cujos parâmetros não dependem linearmente dos dados (por exemplo para uma ajuste exponencial, $\propto e^{a x}$ ). Uma aproximação para esses casos é expandir em serie de Taylor a função do ajuste até primeira ordem (linear) em torno de uma condição inicial de ajuste. Evidentemente, tal condição inicial é muito importante, pois garante a linearidade da função na região e, portanto, a convergência do ajuste.

Assim, é necessário escolher valores iniciais para os parâmetros, que são fornecidos iterativamente, até se obter uma melhor estimativa. Em cada iteração um novo conjunto de a são obtidos, considerando que $a_{j} \approx a_{j}^{k+1}=a_{j}^{k}+\Delta a_{j}$ (onde $k$ indica a iteração) e considerando a linearização da função do ajuste por uma expansão em série de Taylor em torno dos parâmetros a informados até a primeira ordem,

$$
f\left(x_{i}, a^{k+1}\right) \approx f\left(x_{i}, a^{k}\right)+\sum_{j} \frac{\partial f\left(x_{i}, a^{k}\right)}{\partial a_{j}}\left(a^{k+1}-a^{k}\right)
$$

O procedimento é então o usual, substitui-se a função aproximada na expressão para $Q(\mathbf{a})$ e minimiza-se tomando as derivadas igual a zero, porém agora as soluções estarão em termos de: $\delta a_{j}=a_{j}^{k+1}-a_{j}^{\prime}{ }^{k+1}$.

O MMQ apesar de ser um método muito poderoso para o ajuste de dados experimentais usando uma dada função, ele não garante que a função escolhida é a melhor para aquele ajuste, ou seja ele apenas fornece os parâmetros que melhor ajusta os dados para a função escolhida, os que minimizam os resíduos ao quadrado dividido pelas variâncias. A princípio, pode-se ajustar um conjunto de dados que claramente tem um comportamento exponencial com uma reta, o MMQ fornecerá os parâmetros que melhor ajusta os dados, mesmo que o ajuste não seja o adequado. Uma forma bastante útil para saber se de fato a função ajustada é a melhor para aquele conjunto de dados é o chamado teste do $\chi^{2}$.

Diferente do MMQ, para o teste do $\chi^{2}$ é necessário que os dados obedeçam a distribuição gaussiana. $\mathrm{O} \chi^{2}$ é definido como:

$$
\chi^{2}=\sum_{i=1}^{M} \frac{\left[y_{i}-f\left(x_{i}, \tilde{\mathbf{a}}\right)\right]^{2}}{\sigma_{i}^{2}},
$$

onde ã indica parâmetros finais do ajuste, depois de todas as iterações, diferente da expres- 
são similar para $Q(\mathbf{a})$ que é para uma dada iteração. A função $\chi^{2}$ segue uma distribuição conhecida $\operatorname{com} \nu=M-N$, número de graus de liberdade, com $M$ o número de pontos e $N$ o número de parâmetros. É possível demonstrar que seu valor esperado é igual ao número de graus de liberdade: $\nu$; com desvio padrão igual a: $\sqrt{2 \nu}$. Portanto, se o valor de $\chi^{2}$ obtido do ajuste estiver dentro desse intervalo o ajuste é aceitável. 
48 FUNDAMENTOS DE SONDAS ELETROSTÁTICAS, MODO H, CONFINAMENTO MELHORADO NO TOKAMAK TCABR E FERRAMENTAS DE ANÁLISE DE DADOS EXPERIMENTAIS 


\section{Capítulo 4}

\section{Sondas eletrostáticas}

Neste trabalho foram usadas duas sondas eletrostáticas: sonda rake de 18 pinos e sonda de 5-pinos. Com a sonda rake o objetivo foi medir, na borda do plasma, perfis radiais, da temperatura eletrônica $\left(T_{e}\right)$, da densidade eletrônica $\left(n_{e}\right)$, do potencial flutuante $\left(V_{f}\right)$, do potencial de plasma $\left(V_{p}\right)$ e do campo elétrico radial $\left(E_{r}\right)$, além das flutuações desses parâmetros em diferentes posições. Com a sonda de 5-pinos o objetivo foi medir transporte turbulento de partículas e o estudo da turbulência ou redução dela, usando a função $S(k, f)$.

\subsection{Sonda rake}

A sonda rake possuí 18 pinos dispostos em duas fileiras espaçadas em 4,3 $\mathrm{mm}$, de forma a estarem na mesma posição poloidal em relação à câmara do tokamak, porém em diferentes posições radiais e toroidais. Ela foi projetada de forma a possuir as menores dimensões possíveis para seu porte, porém garantindo uma boa resistência mecânica, já que seria necessário manuseá-la na montagem. Suas dimensões são: 8,0 $\mathrm{mm}$ de altura, 10,0 $\mathrm{mm}$ de largura e 52, $0 \mathrm{~mm}$ de comprimento. Os eletrodos são de tungstênio em forma cilíndrica com comprimento exposto de $3,0 \mathrm{~mm}$ e diâmetro de $0,8 \mathrm{~mm}$. O corpo da sonda é feito de nitreto de boro (BN). A distância entre dois eletrodos próximos é igual a 5,0 $\mathrm{mm}$, comprimento escolhido com a intenção de se conseguir uma boa resolução espacial, mas sem correr o risco de um eletrodo interferir com um outro, pois são uma ordem de grandeza menor do que o comprimento de Debye (Figura 4.1). 


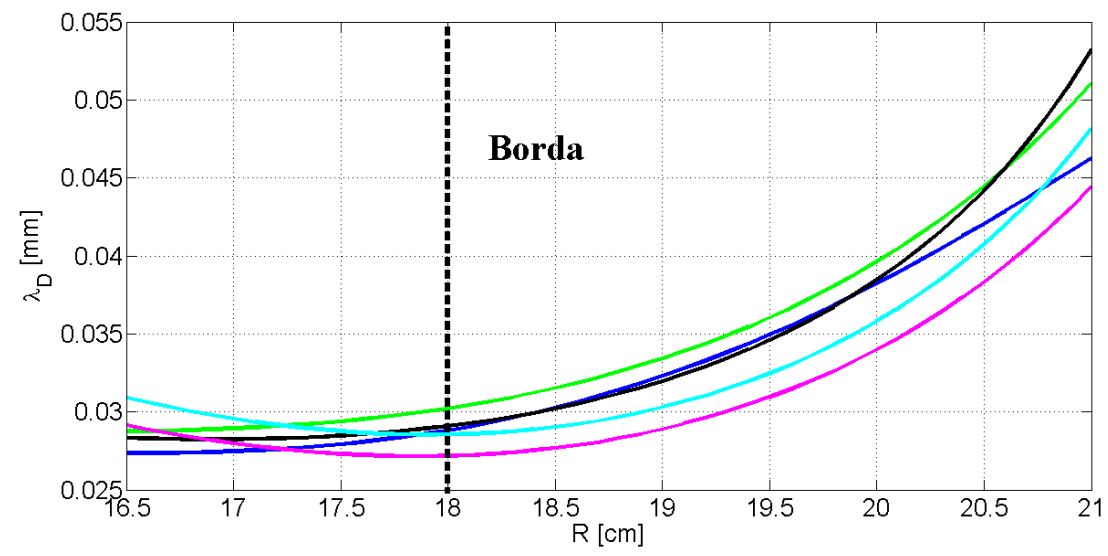

Figura 4.1: Perfis médios do comprimento de Debye na borda para diferentes disparos no intervalo do platô (corrente de plasma aproximadamente constante).

O gráfico da figura (4.1) foi obtido considerando os perfis médios da densidade e da temperatura eletrônica na borda obtidos das medidas com a sonda rake em vários disparos sem eletrodo na região do platô da corrente de plasma. Os valores de $\lambda_{D}$ na borda foram estimados a partir de medidas antigas de sondas no TCABR. A construção da sonda rake foi feita na Oficina Central do IF-USP.

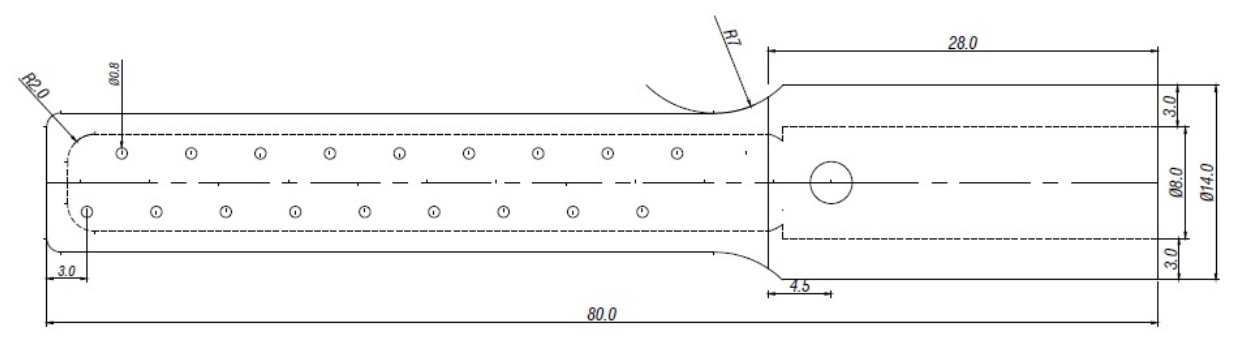

Figura 4.2: Desenho da sonda rake de 18 pinos. 


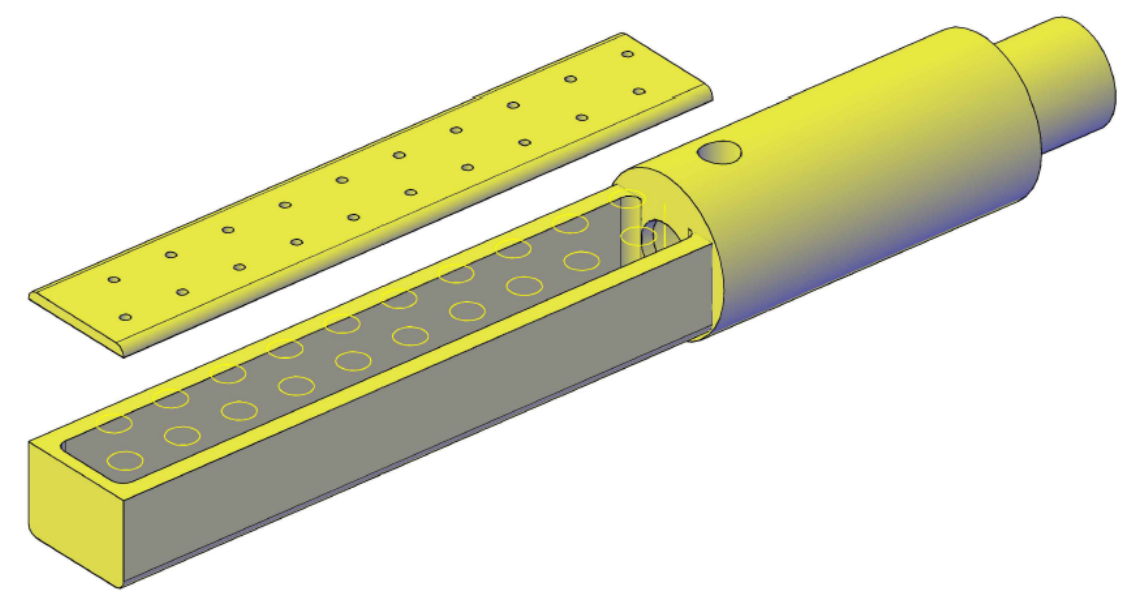

Figura 4.3: Visão tridimensional da sonda rake

A sonda rake (figura 4.4) permite uma boa resolução espacial e temporal dos parâmetros do plasma na borda. O objetivo da sua construção foi utilizá-la para medir perfis radiais nessa região em apenas um disparo, evitando fazê-lo em descargas separadas, pois nem sempre é possível manter uma boa reprodutibilidade dos parâmetros do plasma no tokamak TCABR. Dessa forma, ela permite acompanhar a evolução temporal de parâmetros do plasma na borda, tal como: temperatura eletrônica $\left(T_{e}\right)$, densidade eletrônica $\left(n_{e}\right)$ e campo elétrico radial $\left(E_{r}\right)$. Particularmente, ela é importante no estudo do confinamento melhorado do plasma, obtido com o uso do eletrodo, pois viabiliza o registro da evolução temporal e espacial dos parâmetros do plasma para cada descarga.

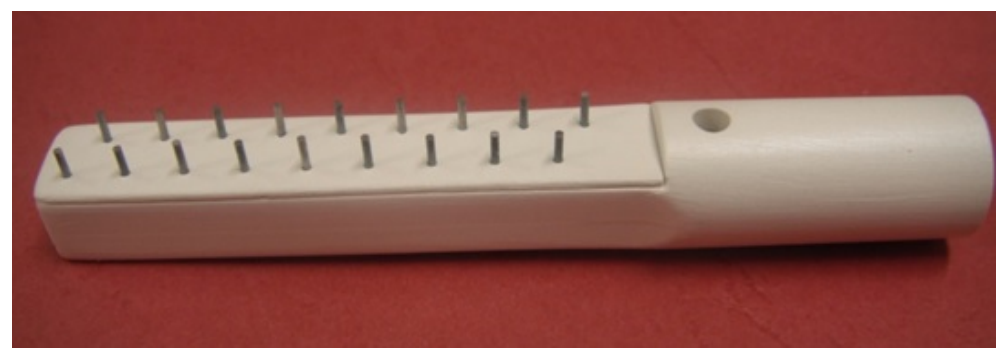

Figura 4.4: Imagem da sonda rake de 18 pinos

Pelas características da sonda, compacta e com muitos pinos, e considerando que os sinais medidos são de alta frequência e, que seriam medidas correntes com variação temporal rápidas em diversos pinos, havia a preocupação de evitar interação cruzada ("crosstalk") entre os sinais $[46,47]$. Com intuito de eliminar, ou ao menos tornar esse efeito tão pequeno que não fosse necessário corrigi-lo a posteriori, foi idealizada uma configuração de par-traçado individual para cada pino da sonda (figura 4.5), com terra no vaso do TCABR. O objetivo foi diminuir a área efetiva de interação entre fios vizinhos, isso porque cada fio de ligação da sonda (na configuração "par-trançado") possui um fio de terra enrolado, como uma malha de blindagem, diminuindo interferências magnéticas e eletrostáticas. Tal configuração é diferente da usual para sondas no TCABR, que possui fios individuais para cada pino, com terra na estrutura metálica do movimentador. Dessa forma, a área efetiva de interferência é maior, 
aproximadamente um retângulo formado entre o comprimento do fio e o raio do tubo do movimentador. No entanto, na prática o efeito da interferência é pequeno para sondas que possuem poucos pinos.

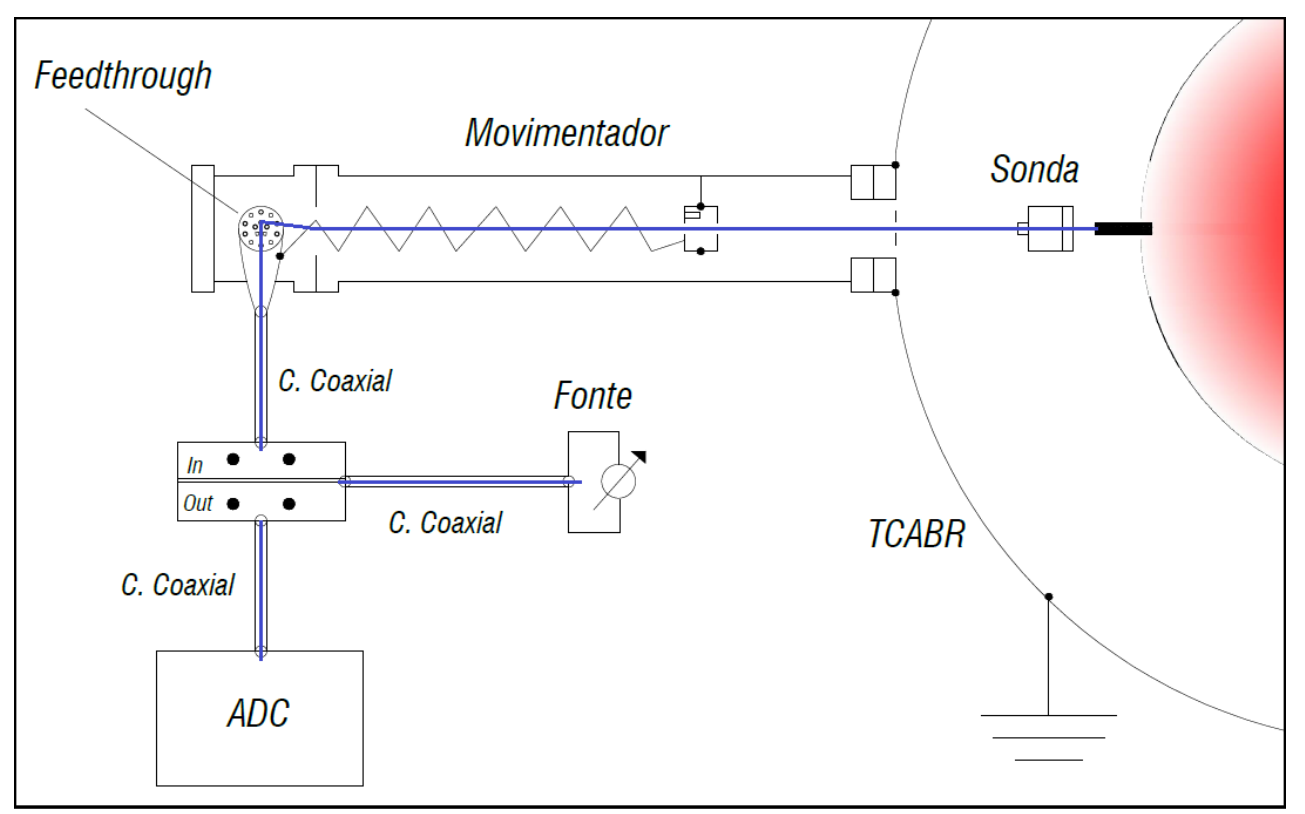

Figura 4.5: Esquema de ligações elétricas entre sonda rake e o ADC (Analog-to-Digital-Converter) de aquisição dos sinais de corrente e tensão da sonda.

A sonda rake foi amplamente utilizada neste trabalho e as medidas com ela foram feitas em três configurações diferentes: todos os pinos polarizados com tensão senoidal, todos os pinos com sinal de tensão constante e negativa e todos os pinos com sinal flutuante. Cada uma das três configurações possibilitou medidas de diferentes parâmetros, com diferentes resoluções temporais. Um resumo das três configurações e os parâmetros possíveis de serem obtidos em cada uma delas é apresentado na tabela 4.1. 
Tabela 4.1: Configurações de medidas com a sonda rake

\begin{tabular}{l|ccc}
\hline $\begin{array}{l}\text { 1: Tensão } \\
\text { senoidal }\end{array}$ & Curva característica & $T_{e}, n_{e}$ e $V_{f}$ & $\begin{array}{c}\text { Resolução temporal } \\
\text { limitada pelo período da senoide }\end{array}$ \\
\hline $\begin{array}{l}\text { 2: Tensão } \\
\text { constante }\end{array}$ & $\begin{array}{c}\text { Corrente de } \\
\text { saturação de íons }\end{array}$ & $n_{e}$ & $\begin{array}{c}\text { Alta resolução temporal, } \\
\text { frequência de aquisição do ADC }\end{array}$ \\
\hline $\begin{array}{l}\text { 3: Tensão } \\
\text { flutuante }\end{array}$ & Potencial flutuante & $V_{f}$ & $\begin{array}{c}\text { Alta resolução temporal, } \\
\text { frequência de aquisição do ADC }\end{array}$
\end{tabular}

\subsection{Sonda 5-pinos}

A sonda de 5-pinos (figura 4.6) é um tipo de sonda de Langmuir projetadade forma que seus pinos ficassem todos na mesma posição radial (aproximadamente mesma superfície magnética), porém em diferentes posições poloidais e toroidais. A sonda possuí 5 pinos de tungstênio cilíndricos com $0,8 \mathrm{~mm}$ de diâmetro e 2,5 $\mathrm{mm}$ de comprimento exposto, em um corpo de nitreto de boro (BN). A distância entre os pinos é de 5,0 $\mathrm{mm}$. Ela foi construída no Institute of Plasmas and Nuclear Fusion em Lisboa, Portugal.

Diferente da sonda rake, que permite obter $n_{e}, T_{e}, V_{f}$ e $V_{p}$ em diferentes posições radiais, a sonda 5-pinos permite obter os mesmos parâmetros, porém em uma mesma posição radial a cada disparo, viabilizando o cálculo do transporte de partículas e energia, bem como o estudo da turbulência, graças ao espaçamento poloidal e toroidal entre os pinos.

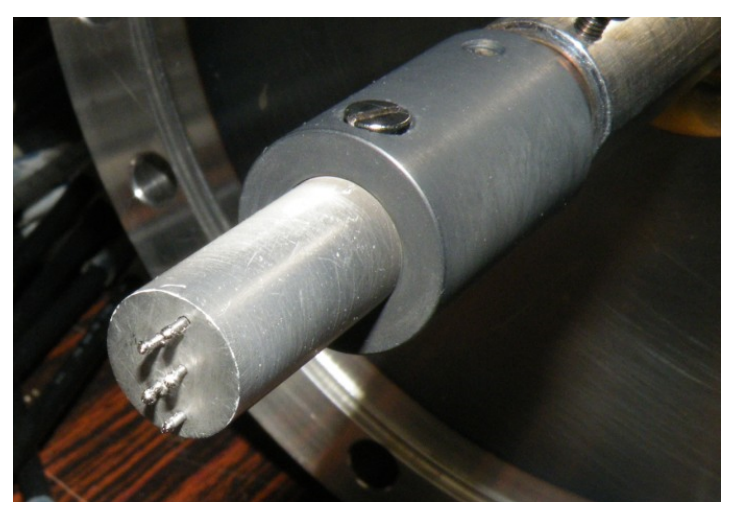

Figura 4.6: Foto da sonda 5 pinos

A sonda de 5-pinos foi usada essencialmente nas medições de transporte de partículas e estudo de flutuações com a função $S(k, f)$, na posição radial fixada em $18 \mathrm{~cm}$.

A configuração elétrica da sonda de 5-pinos é diferente da sonda rake, ela possui fios individuais para cada pino, com a ligação de terra do vaso transferida da estrutura metálica do movimentador e do vaso para as fontes e para o ADC via cabos coaxiais com conectores do tipo BNC (figura 4.7). No entanto, a desvantagem dessa configuração é a maior área efetiva de interferência, aproximadamente, um retângulo formado entre o comprimento do fio e o raio do tubo do limitador, contudo, o efeito é pequeno para sondas que possuem poucos pinos. 


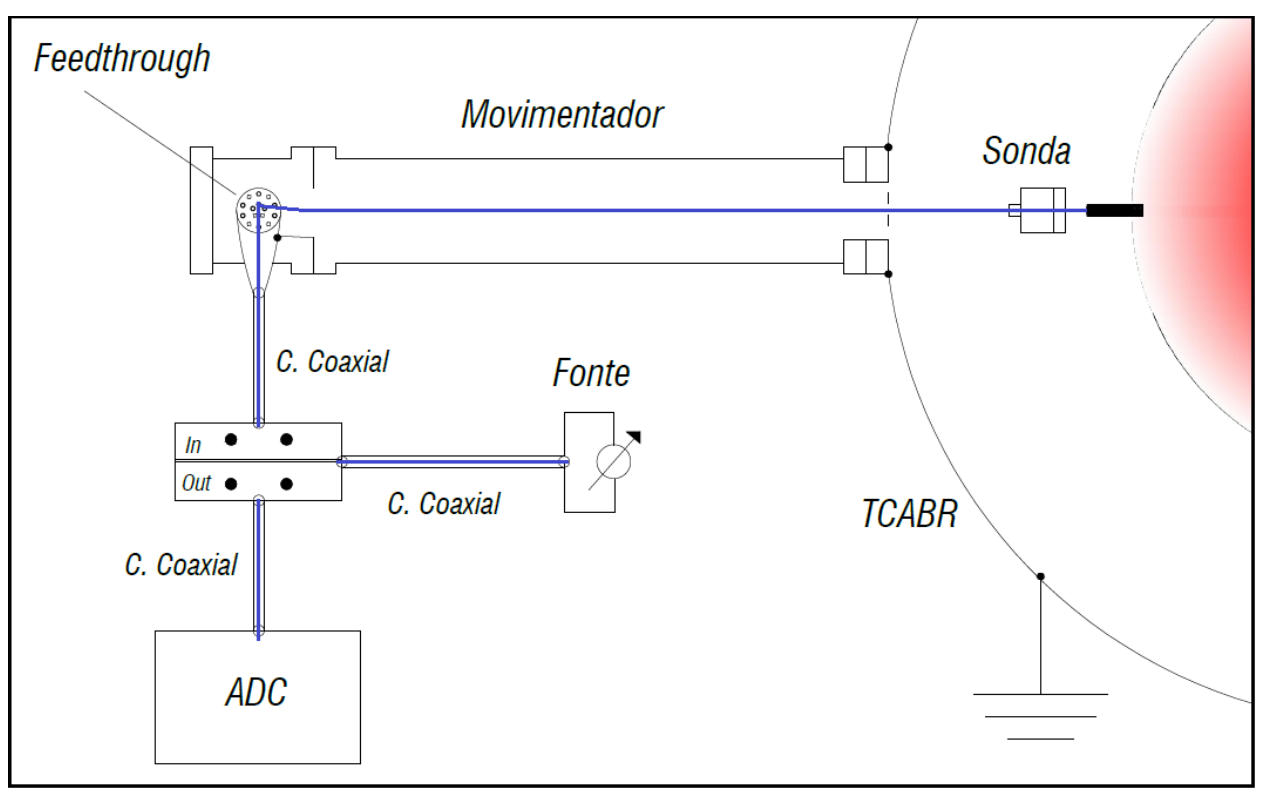

Figura 4.7: : Esquema de ligações elétricas entre a sonda 5-pinos e o ADC de aquisição dos sinais de corrente e tensão.

Ambas as sondas foram instaladas no plano equatorial do TCABR, enquanto que o eletrodo está instalado no plano vertical (figura 4.8). 

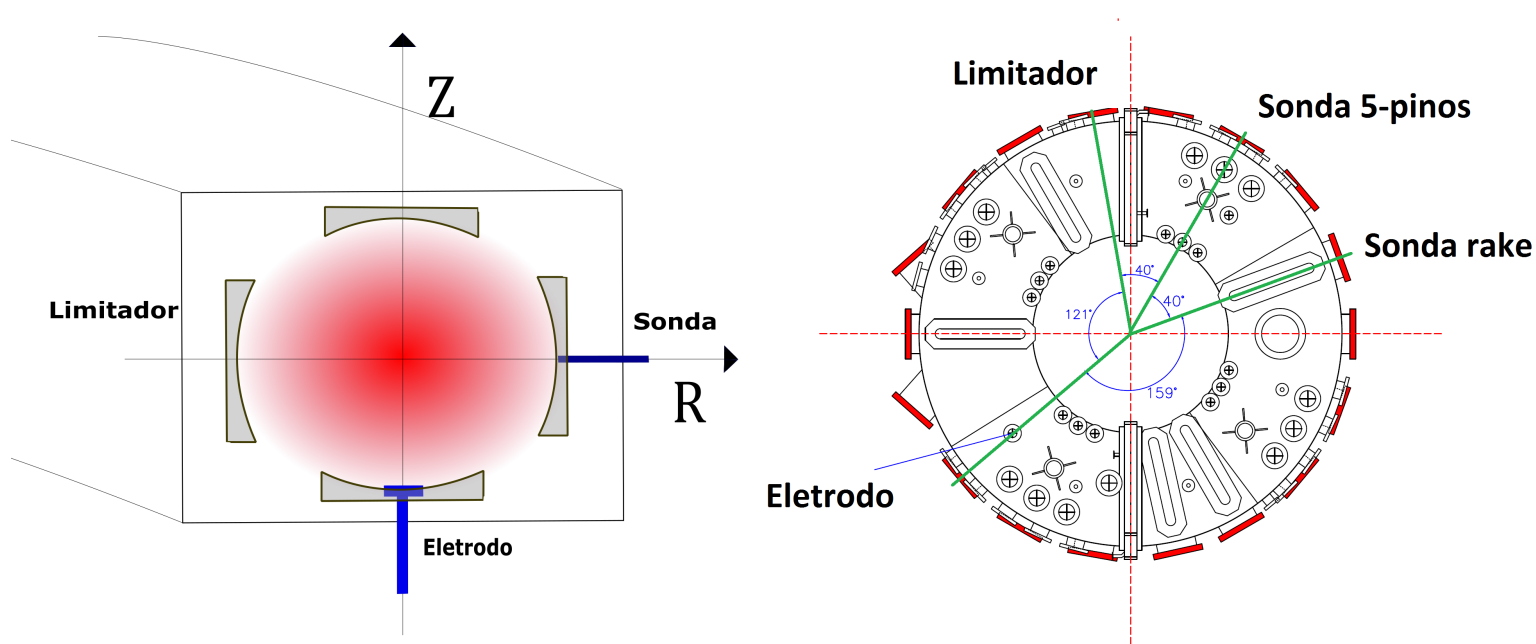

Figura 4.8: Posição poloidal e toroidal: da sonda de 5 pinos no tokamak TCABR

\subsection{Sistema de aquisição de dados}

O sistema de aquisição de dados converte sinais analógicos em sinais digitais. Ele é composto de um sistema VME com canais de 10 bits, com módulos para sinais de $+2,5 \mathrm{~V}$ a -2,5 V, correspondendo a 1024 níveis de $5 \mathrm{mV} /$ nível e até 1 Megasamples $/ \mathrm{s}$ de taxa de amostragem e um sistema NI com canais de 16 bits, com módulos para sinais de $+10,0 \mathrm{~V}$ a - 10,0 V; correspondendo a 65536 níveis de 0,3 mV/nível e até 2 Megasamples/s. Os dados das sondas foram adquiridos no NI e os demais sinais: interferômetro, corrente de plasma, corrente no eletrodo etc no VME.

Os dados dos disparos são publicados em um banco de dados online disponível para o grupo de plasma do IF-USP. Utilizando o programa MDSplus é possível acessá-los. 


\section{Capítulo 5}

\section{Medidas}

\subsection{Circuitos eletrônicos de medida}

Circuitos ativos com casador de impedância e filtros passa baixas para os canais de corrente e tensão foram projetados e construídos no Laboratório de Física de Plasmas do IF-USP (figuras 5.1 e 5.2). A frequência de corte para todos os canais foi ajustada em torno de $700 \mathrm{kHz}$, abaixo da frequência de Nyquist ( $1 \mathrm{MHz}$ ), de forma a evitar "Aliasing", porém, grande o suficiente para permitir o estudo da turbulência até $300 \mathrm{kHz}$. Além disso, tentou-se garantir que a perda de fase com a frequência para todos os canais (que ocorre nas proximidades da frequência de corte) pudesse ser desconsiderada, evitando assim erros que envolvessem o cálculo da diferença de fase entre sinais.

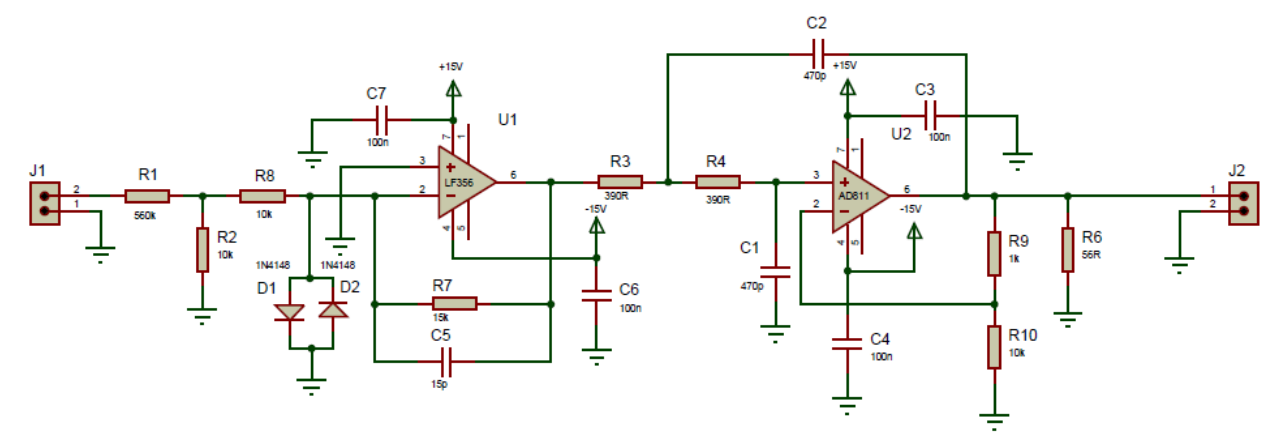

Figura 5.1: Circuito elétrico para medida de potencial flutuante. 


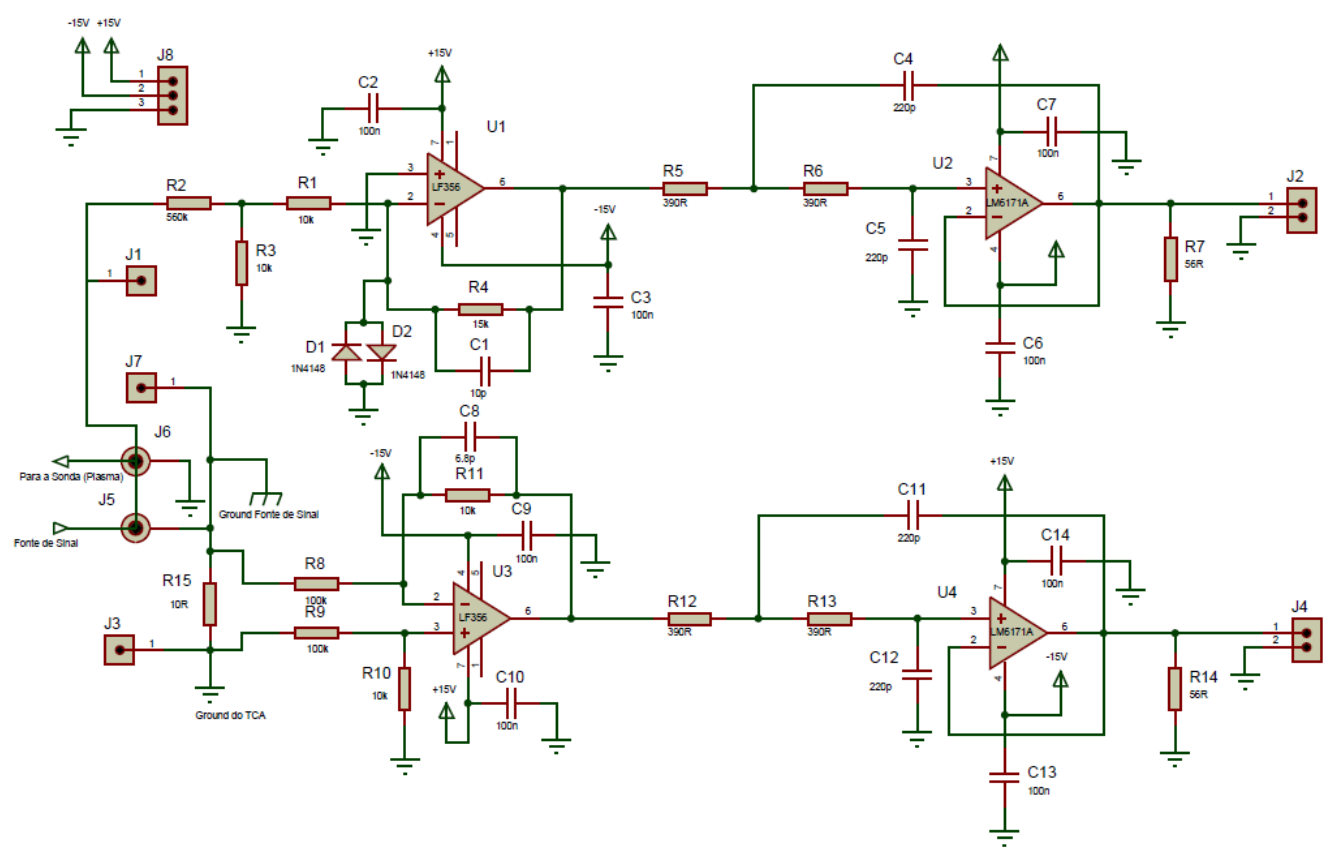

Figura 5.2: Circuito elétrico para medida de tensão e corrente das sondas. O circuito de tensão é semelhante ao circuito de medida de potencial flutuante.

A resposta dos circuitos com a frequência foi obtida fazendo uma varredura com um gerador de funções, adquirindo os dados em um osciloscópio. O resultado é mostrado na figura 5.3 para dois canais, um de corrente e outro de tensão:

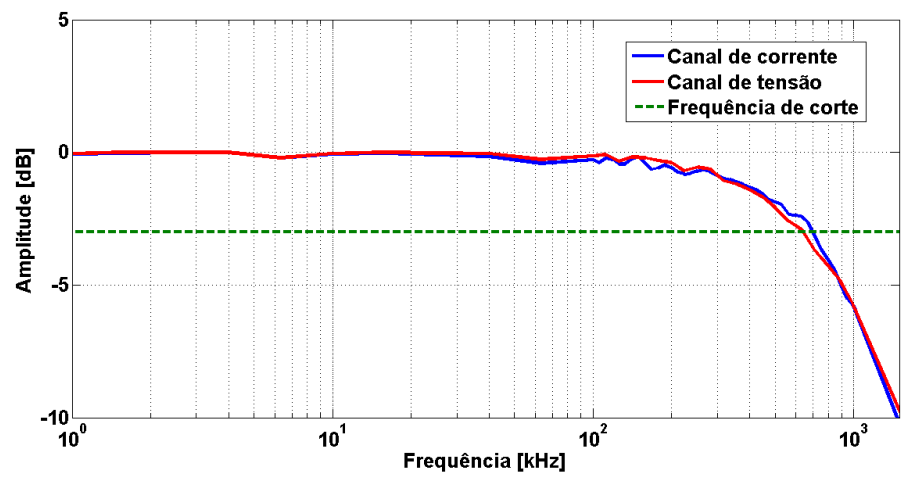

Figura 5.3: Resposta em amplitude para dois canais: um de corrente e outro de tensão. 


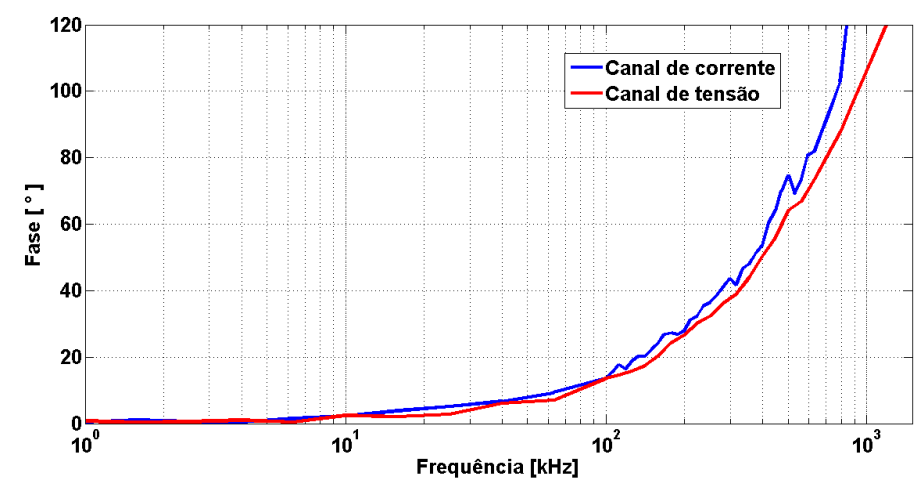

Figura 5.4: Variação da fase para dois canais, um de corrente e outro de tensão.

Nota-se pela resposta em amplitude que a frequência de corte de ambos os canais está, em torno de $700 \mathrm{kHz}$ e, acima desse valor a amplitude cai de maneira abrupta. Além disso, a resposta de fase dos canais (corrente e tensão) em relação a um sinal de entrada (referência) é pequena (figura 5.4) e, para baixas frequências, até por volta de $300 \mathrm{kHz}$ pode ser desconsiderada. Acima desse valor, quando a frequência se aproxima da frequência de corte, a diferença de fase passa a ser importante, o que comprometeria análises espectrais de potências cruzadas.

\section{$5.2 \quad$ Fontes de tensão}

Foram usadas duas fontes de tensão neste trabalho, uma fonte que gerava sinais de tensão senoidais e uma fonte de tensão constante. A fonte de sinal senoidal permitia o ajuste da frequência, amplitude e patamar (offset) de voltagem. A fonte de tensão constante, que na verdade é um banco de capacitores, de micro-Faradays cada um, carregados por uma fonte DC externa, ajustada para gerar um sinal constante negativo de aproximadamente $-100 \mathrm{~V}$, quando o plasma no TCABR é formado. A variação de voltagem dos capacitores quando ligados é suficientemente pequena e pode ser desconsiderada durante a descarga tokamak. O circuito se fecha com o limitador que é ligado ao ponto de terra do tokamak.

A fonte de tensão senoidal foi projetada com intuito de ser usada em experimentos de medida de curvas características de sondas de Langmuir e possuí 20 canais, podendo fornecer tensões com forma senoidal, dente de serra ou quadrada com ajuste manual da frequência, amplitude e patamar (offset) de voltagem. O circuito das fontes de tensão senoidal pode ser visto no Apêndice A.

\subsection{Obtenção dos parâmetros do plasma a partir do ajuste de curvas de Langmuir}

Utilizando a sonda rake foi possível medir perfis médios de parâmetros do plasma na região de borda, tal como densidade eletrônica, temperatura de elétrons e potencial flutuante 
usando a teoria de sondas de Langmuir (Capítulo 3). Ao aplicar uma tensão em um eletrodo inserido no plasma em relação ao terra (parede do vaso e limitador) uma corrente elétrica é coletada. Se a tensão no eletrodo for muito negativa em relação ao potencial de plasma local, tal corrente será predominantemente de íons. Aumentando a tensão (tornando-a menos negativa) a corrente iônica diminui ao passo que a corrente eletrônica aumenta, chegando ao ponto de tensão em que a corrente coletada pela sonda é nula (potencial flutuante). Para tensões ainda maiores a corrente passa a ser predominantemente de elétrons e seu aumento se dá de forma exponencial, já que a densidade de corrente eletrônica tem um comportamento Maxwelliano. Para um plasma magnetizado, como é o caso de um tokamak, o perfil da curva característica das sondas de Langmuir pouco se altera, mas há, no entanto, uma mudança na área de coleta da corrente, que nesse caso não é a área superficial do eletrodo, mas sim uma projeção dessa área no campo magnético; ela passa a ter uma dependência com a tensão no eletrodo. Particularmente, esse efeito pode ser notado experimentalmente na corrente iônica (para tensões bem negativas em relação ao potencial de plasma local), ela não satura, mas sim apresenta um pequeno ângulo de inclinação. Diagnósticos de plasma utilizando sondas eletrostáticas são descritos em [48, 49].

A corrente total coletada pela sonda pode ser descrita pela expressão (3.10), no entanto, para valores negativos da voltagem existe o efeito da inclinação da corrente iônica devido à expansão da pré-bainha [15], que é levado em conta neste trabalho considerando um termo adicional na expressão da corrente total de coleta, termo que varia linearmente com a tensão na região da corrente iônica (até aproximadamente $V_{f}$ ). A expressão utilizada foi:

$$
I(V)=I_{s a t}\left[1-e^{\frac{e\left(V-V_{f}\right)}{k_{b} T_{e}}}-|\alpha|\left(V-V_{f}\right)\right],
$$

onde $I_{\text {sat }}$ á a corrente de saturação de íons, $V_{f}$ o potencial flutuante, $T_{e}$ a temperatura eletrônica e $\alpha$ é a inclinação da reta que está associada com a expansão da pré-bainha.

Com a finalidade de se obter a evolução temporal dos parâmetros, os eletrodos da sonda foram polarizados utilizando uma fonte de tensão que gerava um sinal sinusoidal com frequência fixa $(\sim 1 k H z)$ e tensão ajustável. Na figura (5.5) é mostrado um exemplo da polarização senoidal em um dos pinos da sonda rake com a correspondente corrente coletada. Em cada meio período da onda $(\sim 0,5 \mathrm{~ms})$, obtém-se uma curva característica média, ou seja, a princípio tem-se uma resolução temporal dessa ordem. No entanto, na prática os ajustes são feitos levando em conta a média de mais de uma curva característica, tipicamente mais de quatro curvas, ou quatro meio períodos da senoide, isso porque os sinais de corrente apresentam alta flutuação, típico de um sinal turbulento.

Assim, para cada período escolhido, geralmente mais de quatro rampas, foram feitos ajustes pelo método dos mínimos quadrados da curva característica média correspondente e replicado para o tempo total escolhido para o ajuste, tipicamente mais do que $10 \mathrm{~ms}$. Além disso, foram feitas superposições de rampas nos ajustes (geralmente duas rampas $\sim 1 k H z$ ), 

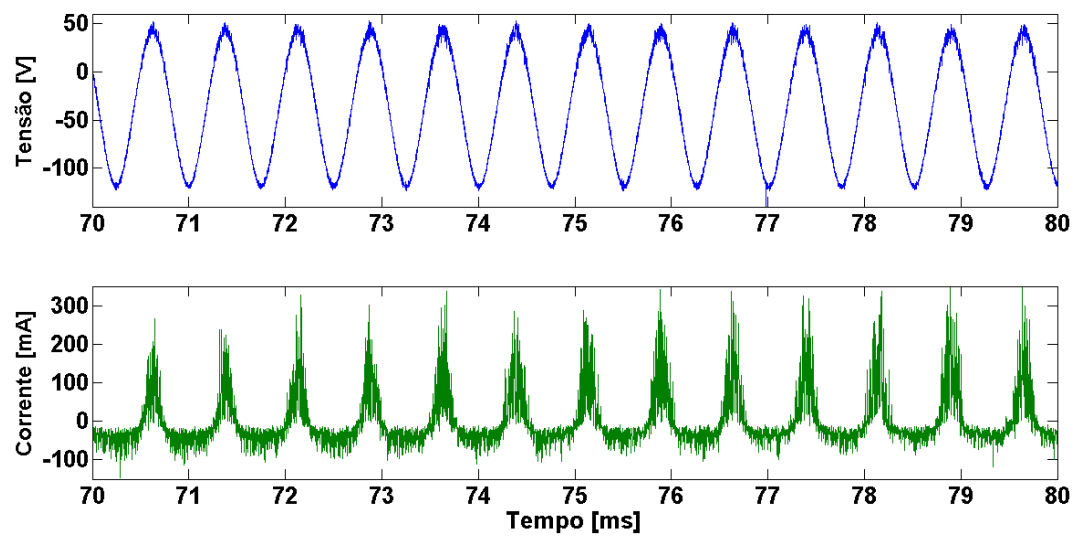

Figura 5.5: Tensão senoidal de polarização da sonda (em cima, azul) e corrente coletada correspondente (em baixo, verde). O período da senoide é $\sim 1 \mathrm{kHz}$.

permitindo uma melhor resolução temporal. Os ajustes foram feitos utilizando uma função no MatLab ${ }^{1}$. O programa solicita o intervalo temporal total em que o ajuste é realizado, o número de rampas em que cada ajuste é feito e o numero de rampas de superposição. Os intervalos de tensão na sonda que serão considerados no ajuste podem ou ser informados previamente ou selecionados no gráfico da curva média utilizando um cursor (figura (5.6)).

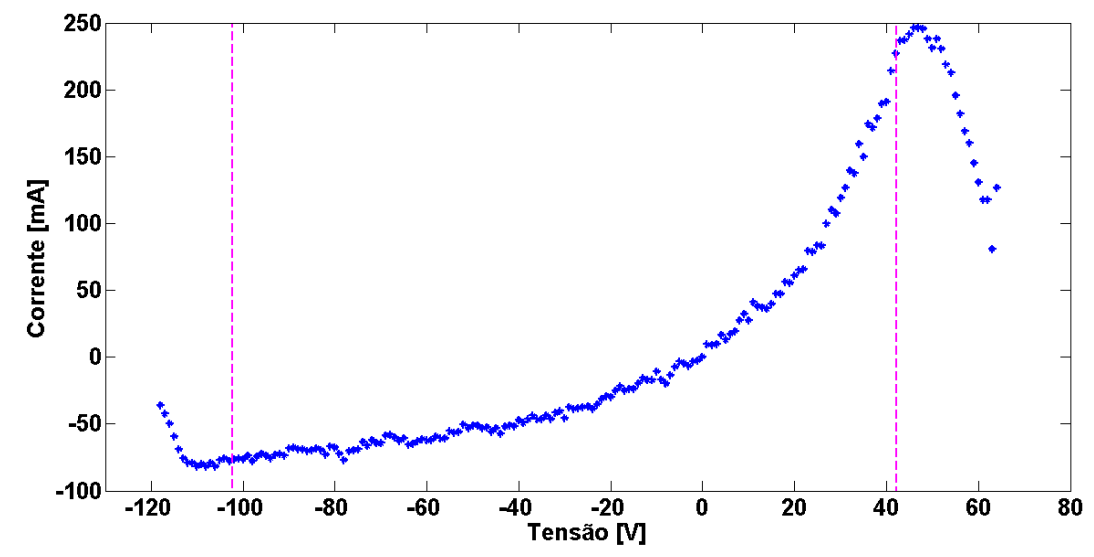

Figura 5.6: Típica curva característica média em um ajuste. As linhas tracejadas verticais correspondem aos intervalos de tensão selecionados com o cursor pelo usuário onde os ajustes devem ser realizados.

O ajuste então é feito utilizando a função (5.1), obtendo-se, assim, a evolução temporal dos parâmetros (figura 5.7). O parâmetro $\alpha$, que está relacionado com a expansão da pré bainha, pouco se altera experimentalmente entre diferentes disparos, mesmo mudando a posição da sonda ou o tempo em que o ajuste é realizado. Dessa forma, considerou-se uma média desse parâmetro, juntamente com um erro aproximado, a fim de se fornecer uma condição inicial para o parâmetro, limitando as margens em que ele poderia variar. $\mathrm{O}$ valor inicial escolhido para o parâmetro foi: $\alpha=(4,0 \pm 0,2) \cdot 10^{-3}$

\footnotetext{
${ }^{1}$ Esse código foi escrito em colaboração com o Prof. Zwinglio de Oliveira Guimarães Filho e seu aluno de doutorado Wilson Andres Hernandez Baquero
} 


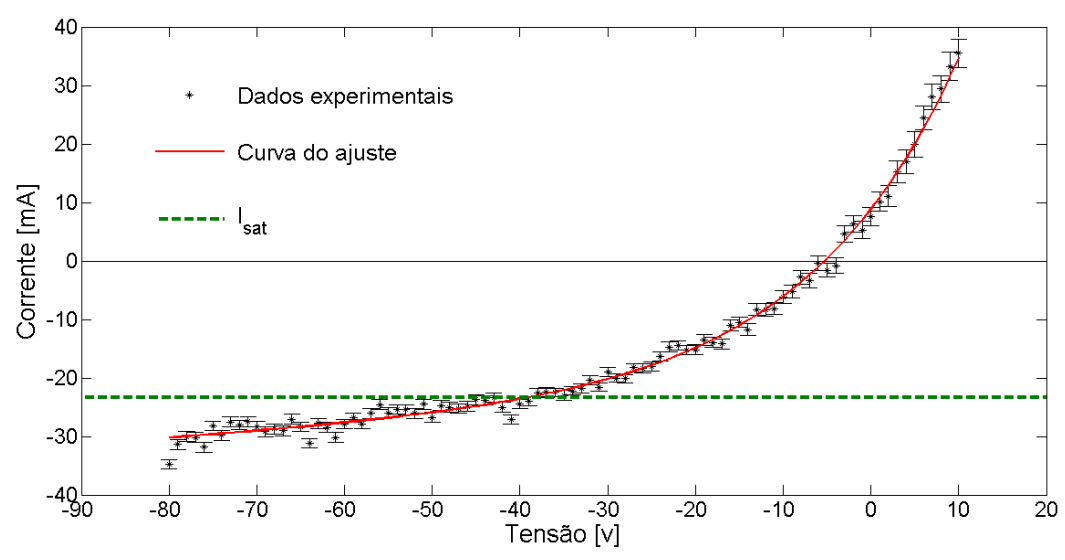

Figura 5.7: Ajuste de uma curva característica média usando a expressão (5.1), levando em conta o efeito da expansão da pré bainha. A linha tracejada em verde corresponde a corrente de saturação de ions, obtida pelo ajuste.

O parâmetro $I_{\text {sat }}$ fornece diretamente a corrente de saturação de íons, levando em conta o efeito da expansão da pré bainha, através do termo linear na corrente de íons. O termo $V_{f}$ fornece uma aproximação para o potencial flutuante local e o termo $T_{e}$ para a temperatura eletrônica local. Pode-se notar pela evolução temporal desses parâmetros (figura 5.8) que eles variam bastante em torno de um valor médio, mesmo considerando o ajuste na região do platô da corrente de plasma, intervalo temporal em que os parâmetros do plasma são mais estáveis, isto é, a corrente de plasma e a densidade pouco se alteram.
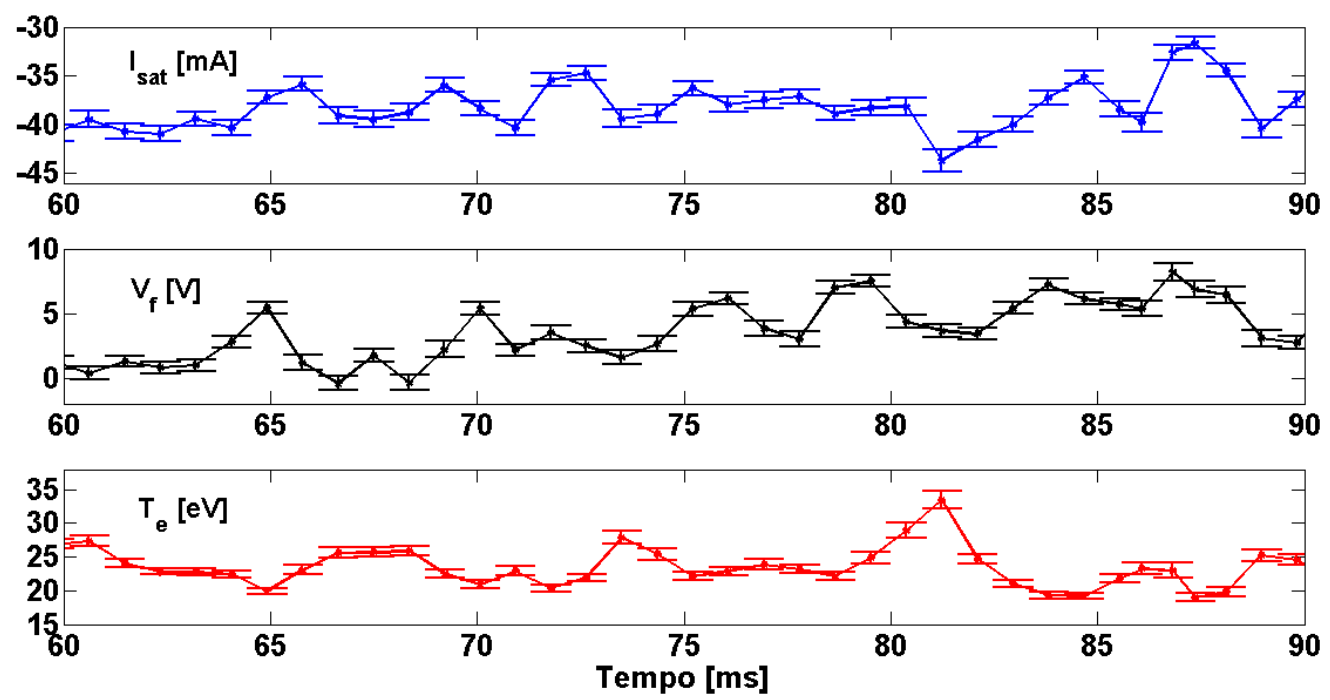

Figura 5.8: Evolução dos parâmetros do ajuste utilizando a função 5.1, no intervalo entre 60-90 ms. 


\subsection{Espectrograma da potência espectral de $V_{f}$ e $I_{s}$}

A análise por potência espectral é bastante útil no contexto de pesquisas de física de plasmas e fusão nuclear. Existem diversas oscilações no plasma que estão relacionas com instabilidades características, como as instabilidades MHD (magnetohydrodynamics), os GAMs (geodesic acoustic mode) e os ELMs (edge-localized mode); todas elas geralmente apresentam oscilações características em frequências bem definidas. Além disso, os níveis de flutuação de um determinado parâmetro de plasma em diferentes posições podem fornecer informações úteis a respeito das características turbulentas da região.

Para construir um espectro de potência de um dado sinal é necessário que ele seja realizado em uma janela temporal relativamente grande, para que se tenha um bom intervalo de frequências possíveis. Além disso, uma alta frequência de aquisição no ADC permite a visualização de frequências mais altas e garante um bom espaçamento entre elas. O espectro de potências, então, mostrará quais são as frequências dominantes que compõem um dado sinal.

No entanto, é interessante às vezes saber como uma certa oscilação evolui no tempo, a fim de saber em quais circunstâncias ela foi criada (o que aconteceu em outros parâmetros do plasma no instante em que ela ocorreu), como ela evolui e como ela desaparece (se acontecer). Além disso, possíveis reduções nos níveis de flutuação devido à influência de agentes externos podem ser notadas na potência espectral de um dado sinal, mas para conhecer o instante exato de ocorrência é necessário ter controle de como o espectro do sinal evolui no tempo. A melhor maneira de se conseguir visualizar esse efeito é através de um espectrograma.

Espectrogramas são representados geralmente em gráficos de cores, sendo a abscissa o tempo e a ordenada a frequência. As cores representam a potência espectral. Para construí-lo é necessário que se divida uma janela grande de tempo em janelas de tempo menores. Em cada pequena janela é calculada a potência espectral, obtendo-se, assim, para cada tempo um conjunto de frequências em que cada qual tem associada a ela uma potência espectral. Completando todas as janelas de tempo obtêm-se algo parecido com o gráfico da figura (5.9), em que é mostrado um epectrograma com um sinal de potencial flutuante medido utilizando a sonda de 5-pinos. O gráfico foi construído usando a função "Imagesc"do MatLab. 

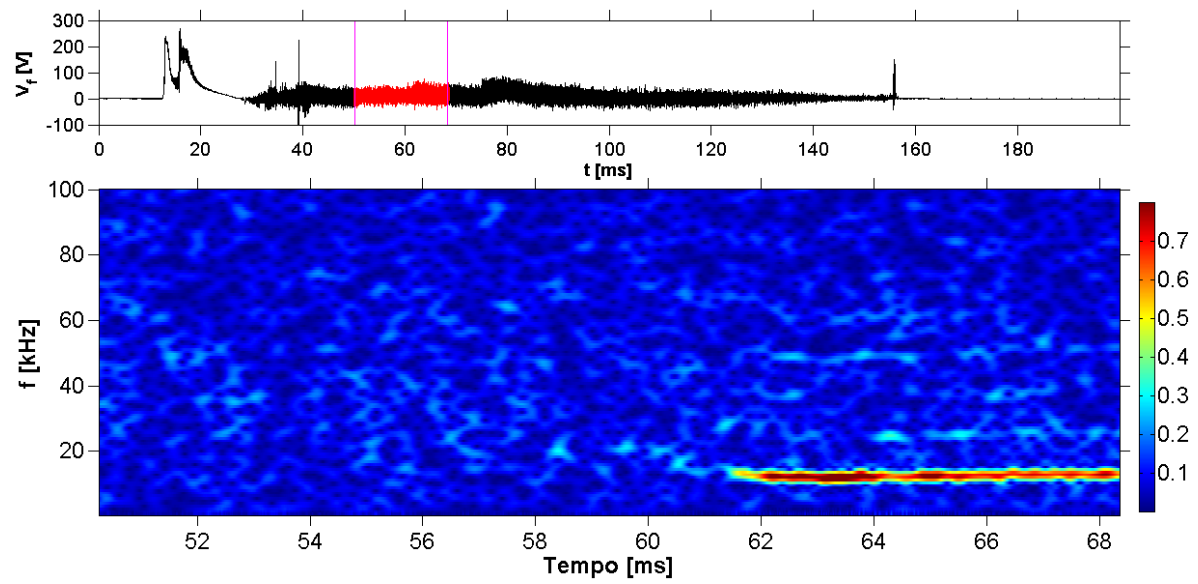

Figura 5.9: Exemplo do espectrograma de um sinal de $V_{f}$ da sonda 5-pinos. A instabilidade MHD (frequência em torno de $13 \mathrm{kHz}$ ) aparece entre 62 e $68 \mathrm{~ms}$

Particularmente, os espectrogramas são bastante úteis neste trabalho, pois é esperado que a aplicação de um eletrodo externo na borda do TCABR cause algum efeito no nível de flutuações dos sinais de $V_{f}$ e $I_{\text {sat }}$. Sem polarização o espectrograma de $V_{f}$ e $I_{\text {sat }}$ em diferentes pinos da rake é representado nas figuras 5.11 e 5.12 com o mais avançado em $17,0 \mathrm{~cm}$ (1,0 cm dentro do plasma) e o mais recuado em 20,5 cm (2,5 cm fora do plasma, na região da camada-de-raspagem - "scrape off layer"). Para estabelecer uma marcação nos pinos a fim de separar os de uma fileira com os da outra e os mais avançados dos mais recuados, foram colocados identificações em cada um deles, separando as fileiras por letras: $\mathrm{A}$ e $\mathrm{B}$; e os pinos por números de: 1 à 9 (figura 5.10).

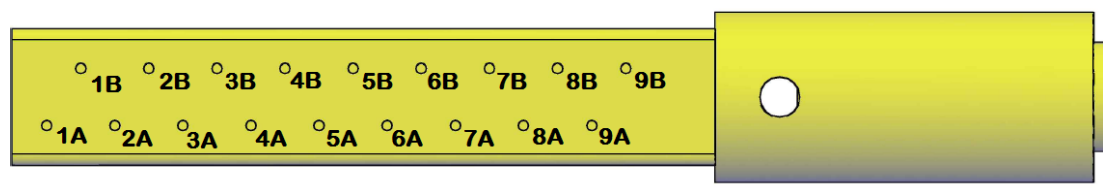

Figura 5.10: Identificação dos pinos da sonda rake

Nota-se nos dois gráficos 5.11 e 5.12 que a intensidade das flutuações e a potência espectral caem para raios maiores, no sentido da região da camada-de-raspagem (scrape- off -layer), embora em 5.12 haja um aumento da potência espectral para os pinos nas posições 18,0 e 18,5 cm, característica das flutuações eletrostáticas periféricas no TCABR. 

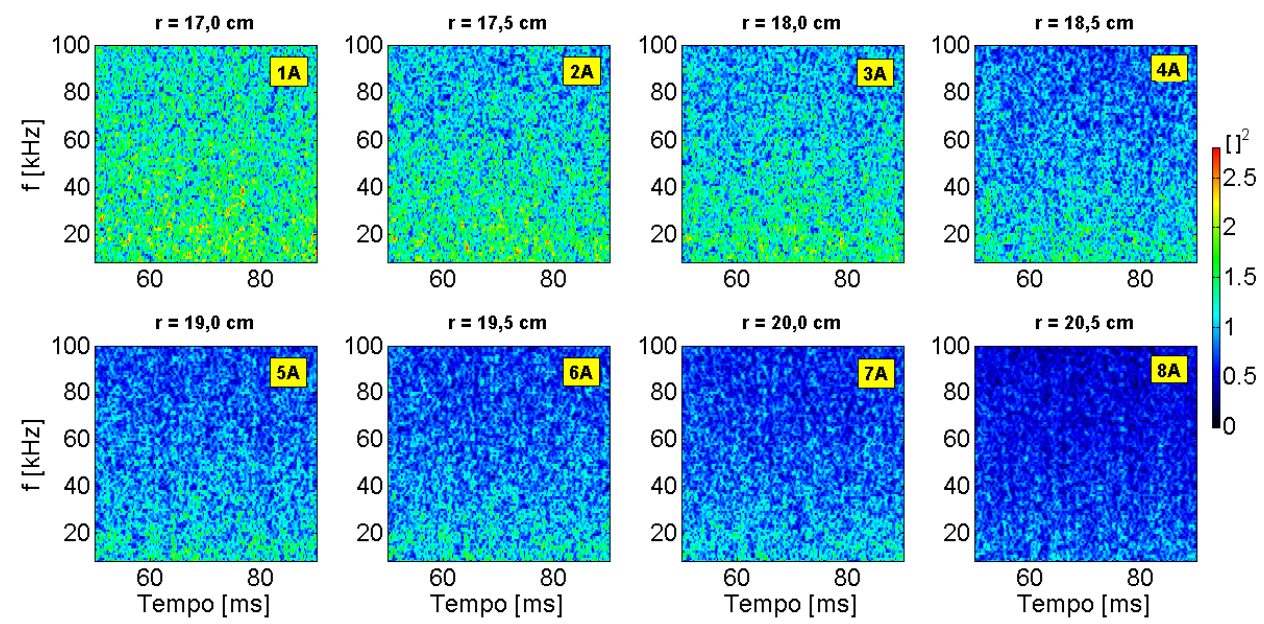

Figura 5.11: Espectrograma de $I_{\text {sat }}$ de oito sinais da rake espaçados radialmente, em um disparo sem polarização no eletrodo. Os retângulos em amarelo são referentes às identificações dos pinos da sonda rake.
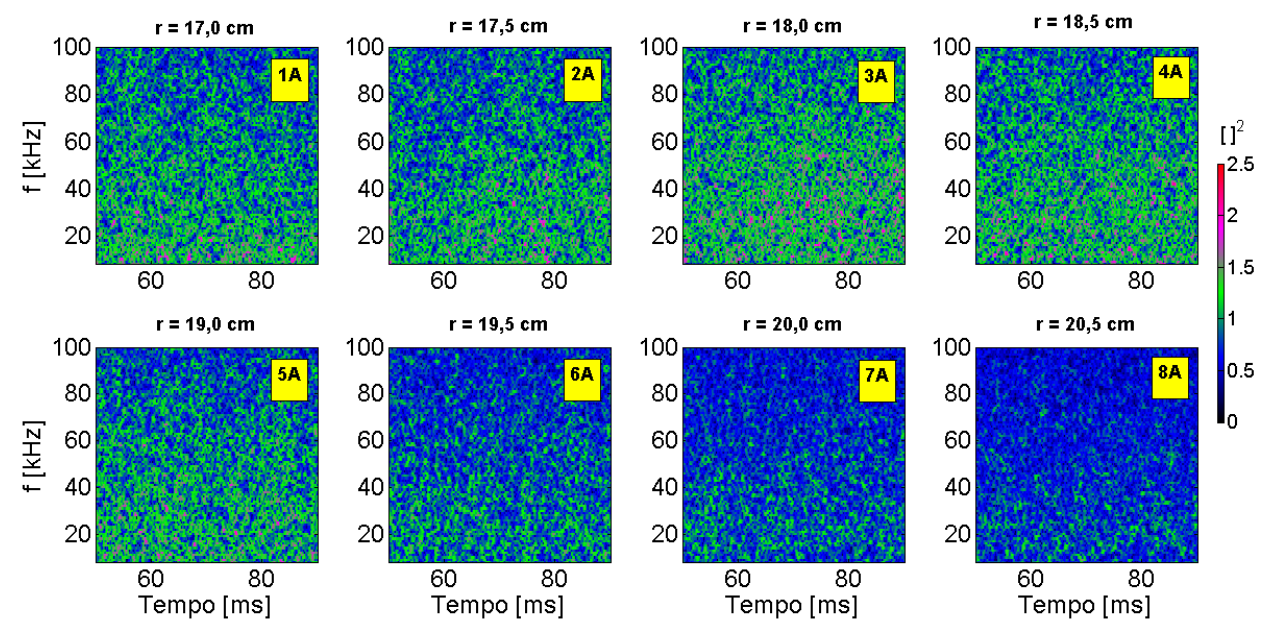

Figura 5.12: Espectrograma de $V_{f}$ de oito sinais da rake espaçados radialmente, em um disparo sem polarização no eletrodo.

\subsection{Calculo do transporte de partículas}

Na situação prática o cálculo do transporte de partículas é feito da seguinte forma: são necessários três pinos próximos na mesma posição radial em uma sonda de Langmuir, com um deles medindo corrente de saturação de íons e os outros dois separados poloidalmente medindo o potencial flutuante (para se obter o campo elétrico poloidal local). Obtém-se a transformada de Fourier das séries temporais da densidade eletrônica (obtida da série da corrente de saturação de íons) e do campo elétrico (das duas séries de potencial flutuante com distância poloidal conhecida) utilizando FFT. O espectro cruzado será,

$$
S_{n E}=<N(f) E^{*}(f)>
$$


ou seja, a transformada de Fourier da densidade multiplicada pelo conjugado da transformada de Fourier do campo elétrico poloidal. Como,

$$
S_{n E}=\left|S_{n E}\right| e^{i \alpha_{n E}}
$$

e a potência espectral de $n_{e}$ e $E_{\theta}$ separadamente é,

$$
S_{n}=|N(f)|^{2} ; \quad S_{E}=|E(f)|^{2}
$$

a densidade espectral de transporte de partículas é então:

$$
T(f)=\frac{2}{B_{\phi}} \gamma_{n E_{\theta}}(f) \sqrt{S_{n}(f)} \sqrt{S_{E_{\theta}(f)}} \cos \alpha_{n E_{\theta}}(f)
$$

com,

$$
\gamma_{n E}(f)=\frac{\left|S_{n E}(f)\right|}{\sqrt{S_{n}(f)} \sqrt{S_{E}(f)}}
$$

O transporte total é, portanto, obtido integrando $T(f)$ em todas as frequências,

$$
\Gamma=\int_{0}^{\infty} T(f) d f
$$

Na figura (5.13) é apresentado um exemplo do cálculo de transporte para um disparo sem o eletrodo. A densidade espectral de transporte é apresentada em um espectrograma, com o eixo x identificando o tempo e o y a frequência. As cores são identificadas com a intensidade do transporte e o seu sentido. Azul é o transporte para fora e vermelho é o transporte para dentro, enquanto que o branco identifica a ausência de transporte de partículas turbulento. Na parte de baixo da figura 5.13 é mostrado o transporte de partículas turbulento total na direção radial em função do tempo, obtido integrando em cada pequena janela de tempo $T(f)$ em todas as frequências. Nota-se que o transporte total é no sentido para fora, ou seja, em um disparo comum há uma perda constante de partículas.

É mostrado na figura 5.15 como é a configuração usual para as medidas de transporte turbulento de partículas utilizando a sonda de 5-pinos no TCABR. Todos os pinos estão na mesma posição radial (mesma superfície magnética); em três pinos são ligados $V_{f}(1,2$ e 3), espaçados poloidalmente, e nos outros dois $I_{\text {sat }}$ (4 e 5). Dessa forma, são possíveis duas configurações de transporte equivalentes: 1-2-4 e 2-3-5. A princípio, é possível medir em outras configurações como 1-2-5 ou 2-3-4, mas nesses casos as aproximações são menos realistas (figura 5.14). 


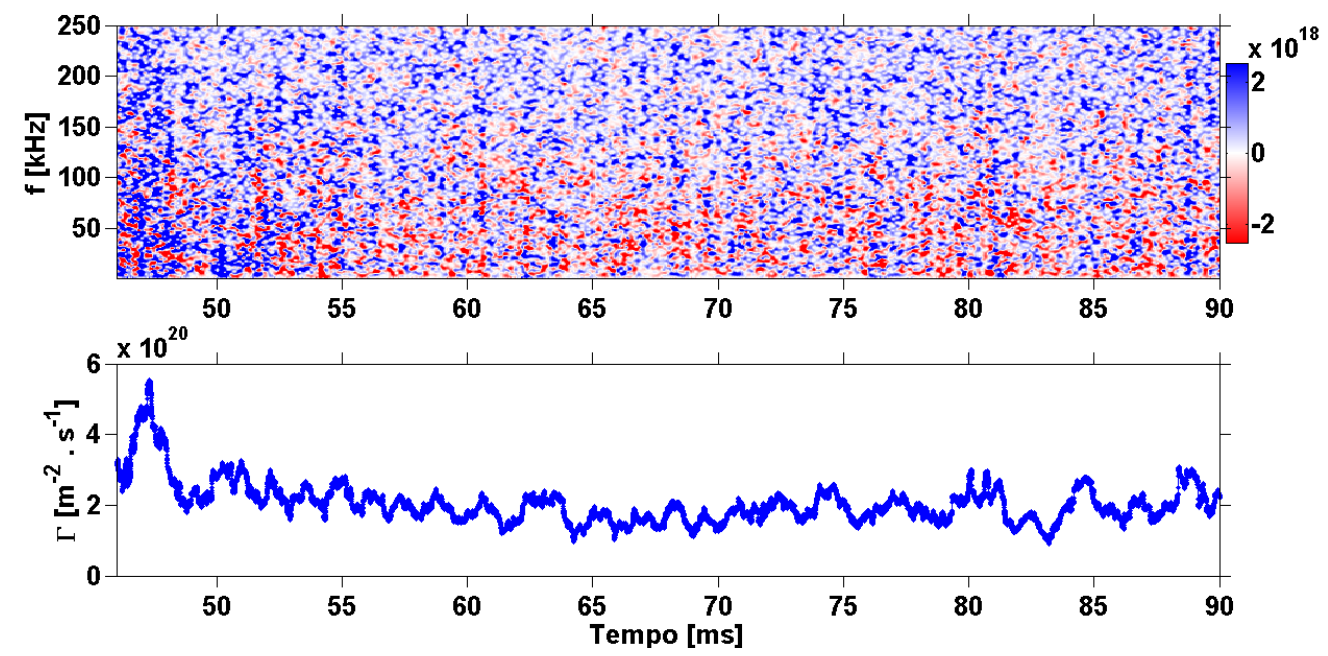

Figura 5.13: Gráfico do transporte radial turbulento de partículas obtido de medidas com a sonda de 5-pinos localizada em 17,5 $\mathrm{cm}$ em um disparo típico do TCABR (disparo: \#33770), sem o eletrodo polarizado. Na parte de cima é apresentado o espectrograma da densidadde espectral de transporte em um gráfico de cores, em que azul é para fora e vermelho para dentro, enquanto que o branco é a ausência de transporte. Na parte de baixo é apresentado o transporte turbulento total na direção radial, obtido realizando a integral de $T(f)$ em todas as frequências.

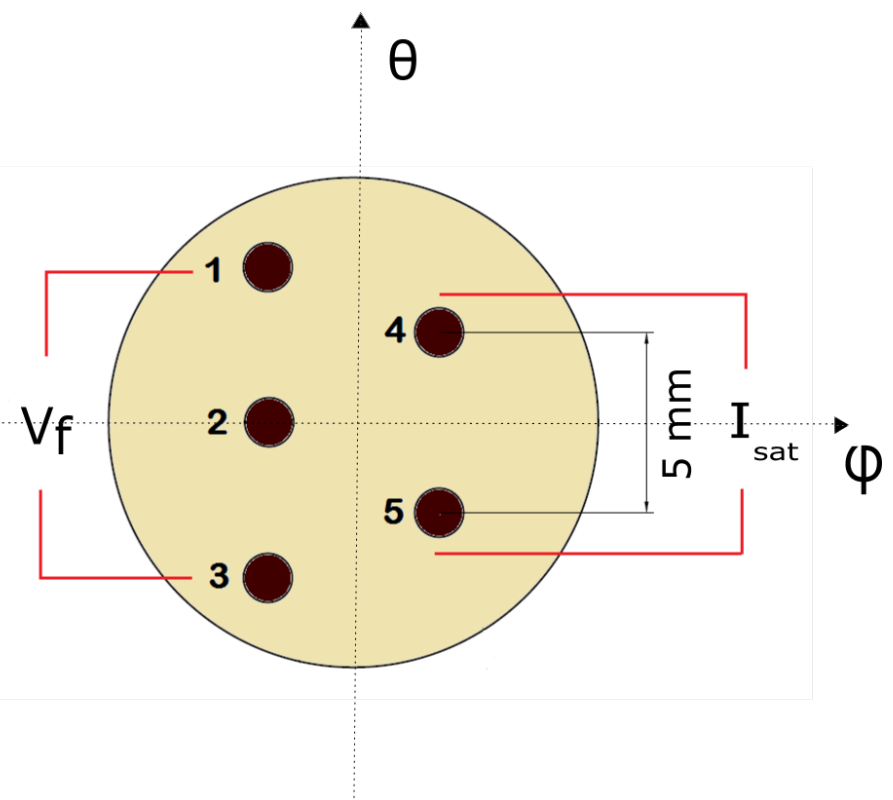

Figura 5.14: Configuração de pinos usual para medida de transporte de partículas na sonda de 5-pinos

O transporte total, como visto, pode ser obtido integrando a função $T(f)$ em todas as frequências. Porém, ele também pode ser obtido diretamente das séries temporais de $n_{e}$ e $E_{\theta}$, já que

$$
\tilde{\Gamma}_{r}=\frac{<\tilde{n}(t) \tilde{E}_{\theta}(t)>}{B_{\phi}}
$$

porém os métodos são equivalentes, com pequenas diferenças (figura5.16). 


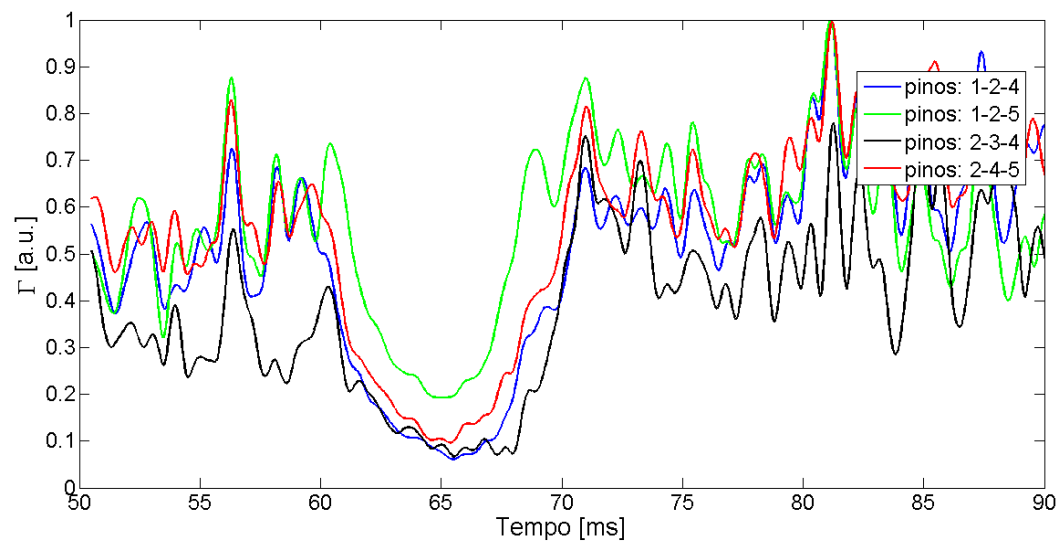

Figura 5.15: Diferença entre o transporte total calculado em diferentes configurações de pinos de acordo com a figura 5.14, em um disparo com eletrodo polarizado em +250 V.
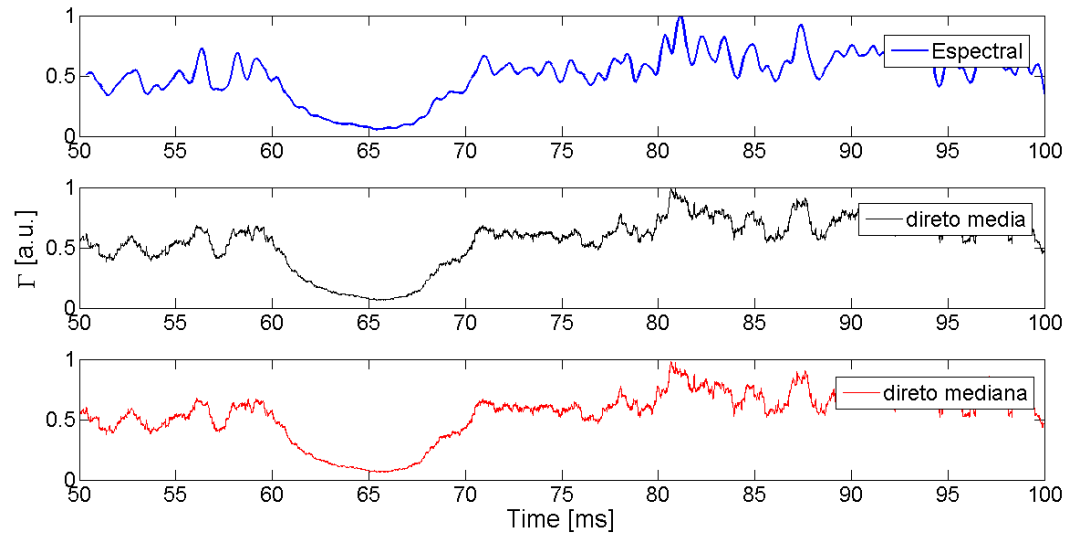

Figura 5.16: Comparação entre o transporte total turbulento de partículas calculado pela a densidade espectral de transporte e pelo método direto, tirando a média do sinal ou a mediana, em um disparo com eletrodo polarizado em $+250 \mathrm{~V}$.

Neste trabalho havia o interesse de medir o transporte de partículas antes, durante e depois da aplicação do eletrodo (bias), com a finalidade de se constatar uma eventual diminuição do transporte de partícula nas posições analisadas, o que poderia indicar uma melhora no confinamento do plasma. Contudo, nessa situação algumas precauções precisam ser levadas em conta ao realizar os cálculos. O eletrodo induz uma variação de potencial muito grande na vizinhança da região em que ele foi aplicado no plasma, isso é notado no potencial flutuante medido pelas sondas como uma variação abrupta de potencial que dura tipicamente o tempo em que o eletrodo foi aplicado (geralmente $20 \mathrm{~ms}$ ). Mas o cálculo de transporte é feito em janelas bem menores que o tempo do eletrodo, o resultado é que a variação lenta do eletrodo contribui de maneira irregular para o espectro dos sinais, tipicamente em baixas frequências. Esse tipo de fenômeno é conhecido na literatura como "Trend"[40]. Uma possível solução é ajustar os dados por um polinômio de grau elevado e então subtraí-lo do sinal original, eliminando assim as flutuações que são mais lentas do que a janela temporal escolhida para análise. Como exemplo, é possível ver a aplicação desse método em um sinal de potencial flutuante na figura 5.17, o resultado no espectro de potência pode ser visto na 
figura 5.18.

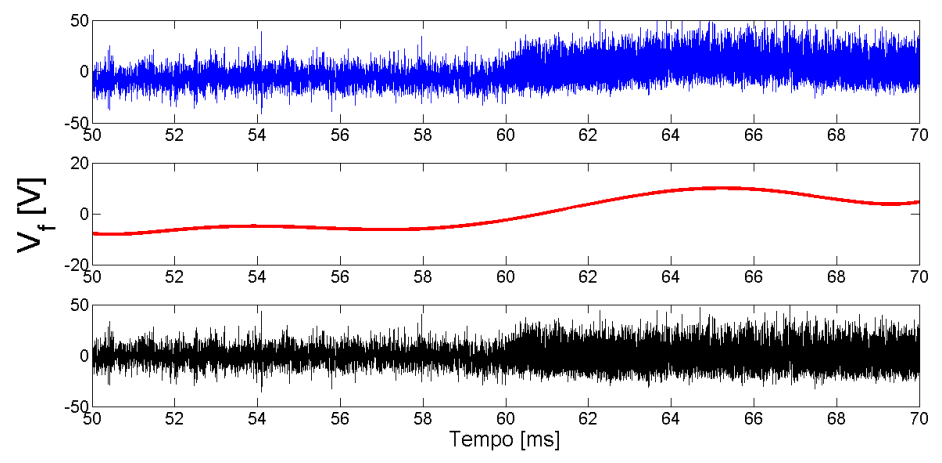

Figura 5.17: Eliminação da tendência ("Trend") no sinal de potencial flutuante em um disparo com o eletrodo

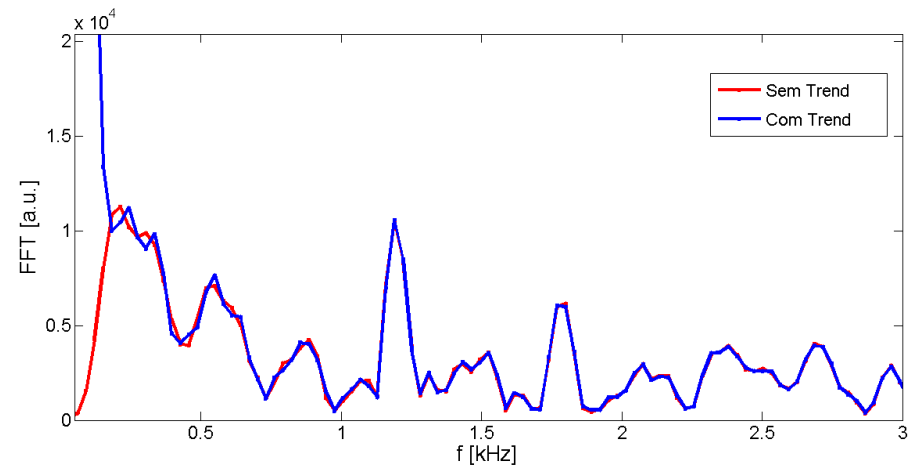

Figura 5.18: Efeito da eliminação do "Trend"no espectro 


\subsection{Calculo da função $\mathrm{S}(\mathrm{k}, \mathrm{f})$ a partir de dois sinais de $V_{f}$}

O cálculo da função $\mathrm{S}(\mathrm{k}, \mathrm{f})$ neste trabalho limitou-se a sinais de potencial flutuante medidos pela sonda de 5-pinos. Os sinais considerados tem um espaçamento poloidal conhecido, de forma que é possível estimar o número de onda local através da diferença de fase e da distância entre os pinos. Portanto, as informações relativas à propagações no intervalo entre os pinos se limita à direção poloidal na simetria toroidal do TCABR. A função $\mathrm{S}(\mathrm{k}, \mathrm{f})$ pode ser determinada a partir da expressão (3.44). Para o seu cálculo é necessário a potência espectral cruzada entre dois sinais espaçados. A diferença de fase entre eles obtida permite o cálculo de $k$.

A seguir é mostrado um exemplo da função $\mathrm{S}(\mathrm{k}, \mathrm{f})$ obtida de medidas de $V_{f}$ da sonda de 5-pinos na região da borda do plasma $(r=18,0 \mathrm{~cm})$. A função é representada em um gráfico de cores (figura 5.19), em que o eixo das abscissas identifica os valores de $k$ e o eixo das ordenadas os valores de $f$; as cores representam a intensidade de $\mathrm{S}(\mathrm{k}, \mathrm{f})$.

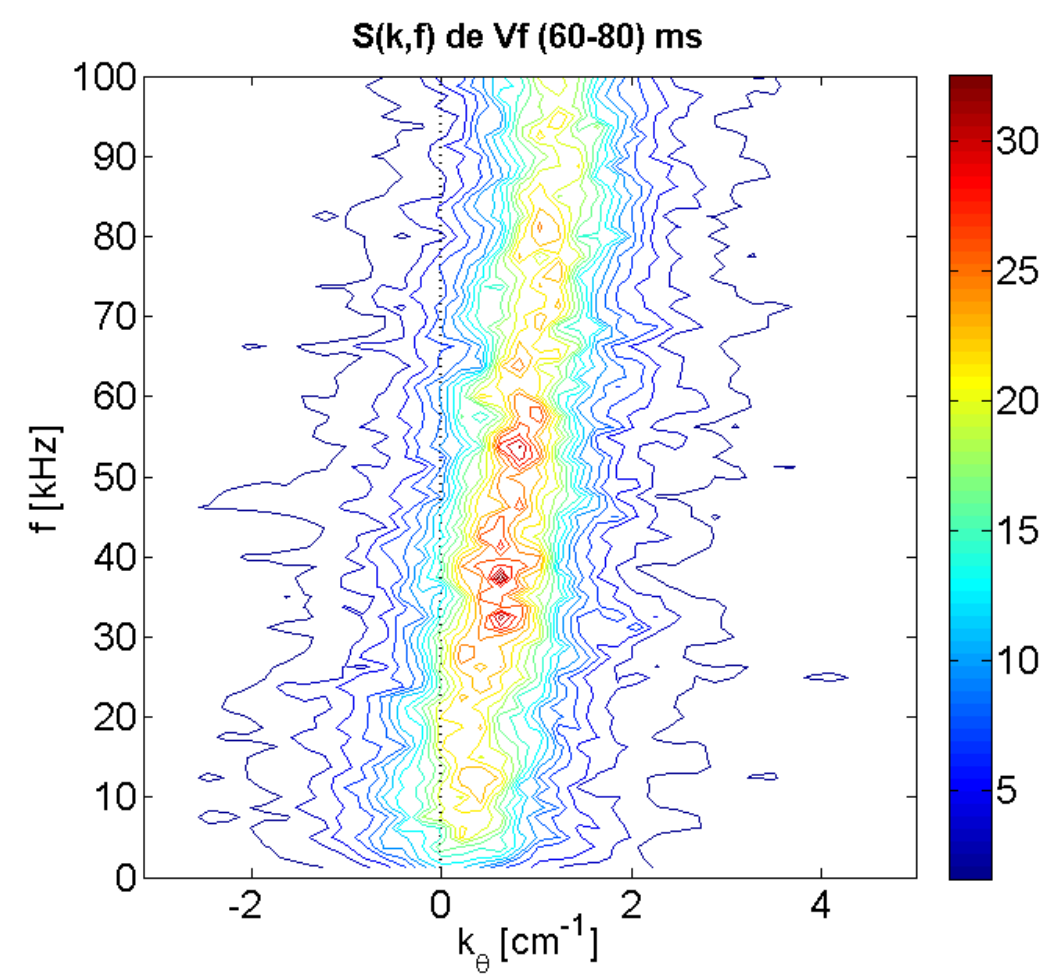

Figura 5.19: $S(k, f)$ de dois sinais de potêncial flutuante, distantes $5 \mathrm{~mm}$ na região da borda do plasma (raio 18,0 cm), entre 70-80 ms.

Através da função $\mathrm{S}(\mathrm{k}, \mathrm{f})$ é possível obter os valores dos espectros em função apenas da frequência $\mathrm{S}(\mathrm{f})$ (potência espectral cruzada) ou apenas em função do número de ondas $\mathrm{S}(\mathrm{k})$; utilizando as expressões (3.46). O resultado é apresentado nos gráficos das figuras 5.19 e 5.20: 

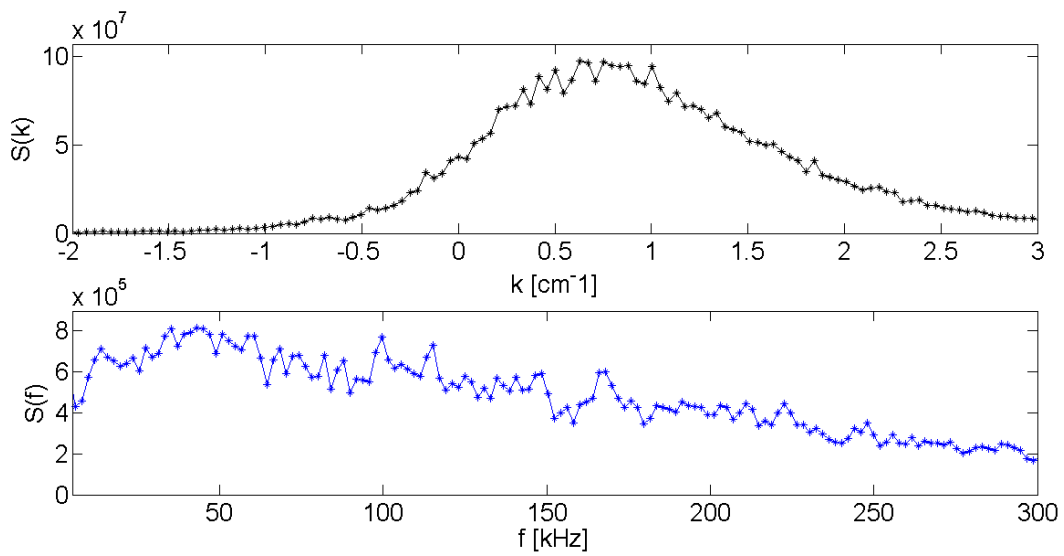

Figura 5.20: Espectros de $S(k)$, parte de cima, e $S(f)$, parte de baixo, obtidos da função $S(k, f)$ do gráfico da figura 5.19.

Nota-se pelo gráfico de $\mathrm{S}(\mathrm{k})$ (figura 5.20), que os números de ondas estão mais concentrados na parte positiva, como é mostrado no gráfico de $\mathrm{S}(\mathrm{k}, \mathrm{f})$ na figura 5.19.

Outra informação relevante que pode ser obtida da função $S(k, f)$ é a velocidade de fase média na direção poloidal $\left(\bar{v}_{\theta}\right)$. Seu valor será importante quando for discutido a influência da polarização do eletrodo na função $\mathrm{S}(\mathrm{k}, \mathrm{f})$, capitulo 6 , pois poderá fornecer informações a respeito do cisalhamento do fluxo de plasma na direção poloidal. Rigorosamente, $\bar{v}_{\theta}$ pode ser obtido da expressão (3.47). Na situação prática ele é dado por:

$$
\bar{v}_{\theta}=\frac{\sum_{k=k_{\min }}^{k_{\max }} \sum_{f=f_{\min }}^{f_{\max }} \frac{2 \pi f}{k} S(k, f) \Delta f \Delta k}{S_{k f}}
$$

definido para $k \neq 0$. Considerando que,

$$
S_{k f} \equiv \sum_{k=k_{\min }}^{k_{\max }} \sum_{f=f_{\min }}^{f_{\max }} S(k, f) \Delta f \Delta k
$$

Na figura 5.21 é mostrada a velocidade de fase poloidal obtida a partir da função $\mathrm{S}(\mathrm{k}, \mathrm{f})$ da figura 5.19. Desconsiderou-se uma faixa de $-0,05 \mathrm{~cm}^{-1} \leq k_{\theta} \leq 0,05 \mathrm{~cm}^{-1}$, a fim de evitar a singularidade $\left(k_{\theta}=0\right)$. 


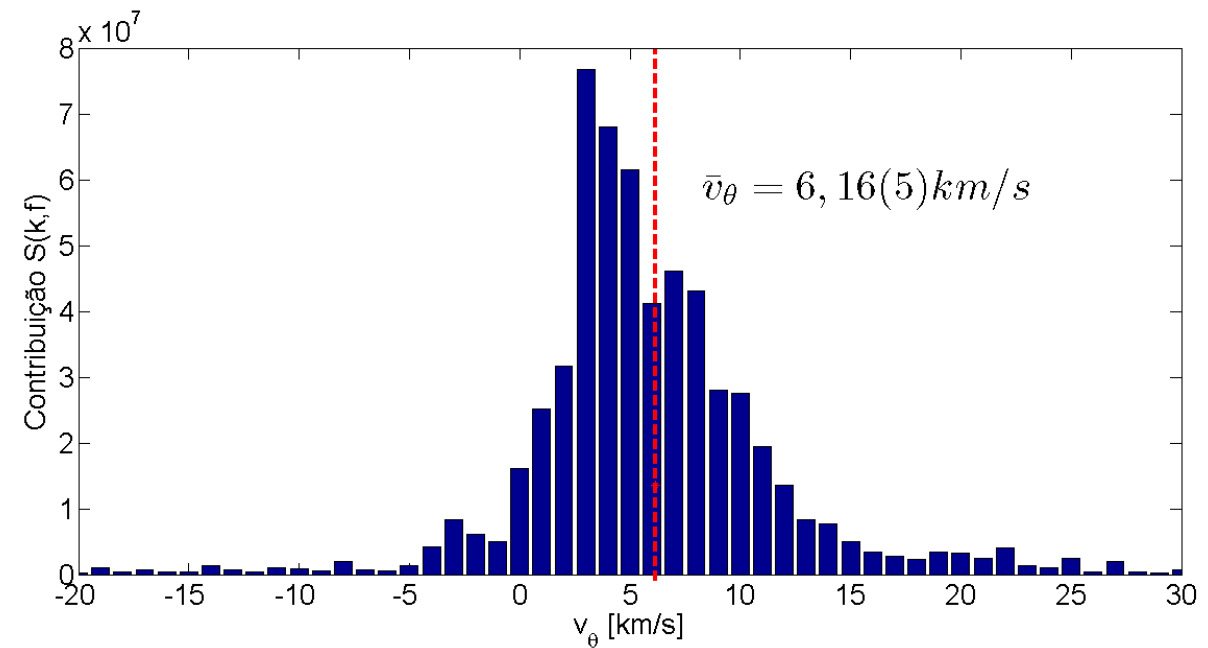

Figura 5.21: Distribuição da velocidade de fase poloidal, obtida da função $S(k, f)$. A média é indicada pela linha vertical tracejada em vermelho. Foi desconsiderada uma faixa de $-0,05 \mathrm{~cm}^{-1} \leq$ $k_{\theta} \leq 0,05 \mathrm{~cm}^{-1}$, a fim de evitar a singularidade $\left(k_{\theta}=0\right)$. 


\section{Capítulo 6}

\section{Confinamento melhorado induzido por um eletrodo externo}

A indução de confinamento melhorado é feita no TCABR através da aplicação de um eletrodo polarizado na borda do plasma. A tensão e a posição do eletrodo são evidentemente fatores importantes para a transição. O modo $\mathrm{H}$ de confinamento é alcançado quando a potência de aquecimento auxiliar fornecida ao plasma supera um dado limiar de potência, que para vários tokamaks obedece as expressões semi-empíricas (3.14) e (3.15). Quando tal valor é atingido há uma mudança nos parâmetros do plasma, com o surgimento de uma barreira de transporte na borda, diminuição da turbulência e do transporte e o aumento da energia no confinamento. Na transição para o modo H é comum o aparecimento de instabilidades na borda do plasma chamadas de ELM (Edge-Localized Mode), que deterioram o confinamento, com quase periódicos "jatos"("bursts") de alta intensidade que provocam relaxamento na barreira de transporte [29]. Além disso, a transição também é marcada pela bifurcação no campo elétrico radial [31]. Porém, foi verificado no TCABR que com polarização eletrostática periférica e em alguns tokamaks do mesmo porte [33] pode haver uma significativa melhora no confinamento mesmo quando a potência fornecida é menor do que o limiar necessário para a transição.

No TCABR ainda não se detectou claramente bifurcação no campo elétrico radial ou ELMs, mas uma melhora no confinamento do plasma com a polarização periférica tem apresentado um aumento do confinamento de partículas de até um fator 2 , valor este equivalente ao modo H com bifurcação para confinamento de energia em tokamaks de grande porte. Entretanto, no TCABR valores altos de confinamento só foram obtidos em condições de alta pureza do plasma, como é de se esperar, e com altas tensões de polarização, de até +450 V. Em condições de $Z_{\text {efetivo }}$ alto, altas oscilações MHD são excitadas, deteriorando o confinamento, podendo causar disrupção em alguns casos.

Outro fator importante para a indução de confinamento melhorado no TCABR é a posição do eletrodo. É amplamente aceito que o cisalhamento no fluxo de plasma na borda devido ao aumento do campo elétrico radial desempenha um papel decisivo para a transição. 
No TCABR esse efeito é gerado por um eletrodo externo inserido na borda, que drena uma corrente elétrica radial entre o eletrodo e o limitador, criando um campo elétrico nessa direção. Portanto, é esperado que a barreira de transporte seja criada nesse intervalo radial. Por outro lado, o eletrodo perturba o plasma e pode ser danificado por ele, logo o seu avanço em relação a borda é restrito. O maior avanço com o eletrodo é de $1,5 \mathrm{~cm}(r=16,5 \mathrm{~cm})$, maiores inserções aumentam a chance de disrupção da coluna de plasma. Tipicamente, em experimentos com eletrodo no TCABR, sua posição é ajustada para $r=16,5 \mathrm{~cm}$ ou $r=$ 17, $0 \mathrm{~cm}$, sem grandes diferenças de efeito. Sendo assim, foi escolhida uma posição fixa para os experimentos com eletrodo neste trabalho: $r=17,0 \mathrm{~cm}$. O motivo é a possibilidade de explorar melhor a região da barreira de transporte sem grandes riscos de danificar as sondas (em $r=16,5 \mathrm{~cm}$ o risco seria maior). Posições mais recuadas a princípio também seriam possíveis, no entanto o intervalo espacial para a criação da barreira seria menor, o que provavelmente dificultaria sua criação.

Neste capítulo o objetivo é estudar as mudanças nos parâmetros de plasma na borda para diferentes tensões no eletrodo. Para cada tensão de polarização no eletrodo eram feitos três disparos, um em cada configuração de medida na sonda rake: pinos polarizados com tensão senoidal, tensão constante e em potencial flutuante (Ver tabela 4.1), enquanto que a sonda de 5-pinos estava na configuração para medida de transporte de partículas na região entre 17,5-18,0 cm. Em todos os resultados a seguir o eletrodo e a sonda rake (pino mais avançado) estavam fixos na posição $r=17,0 \mathrm{~cm}$. A sonda de 5-pinos foi colocada em duas posições diferentes: $\mathrm{r}=17,5 \mathrm{~cm}$ e $\mathrm{r}=18,0 \mathrm{~cm}$. A polarização do eletrodo foi sempre no intervalo: $60-80 \mathrm{~ms}$.

\subsection{Efeitos globais nos parâmetros do plasma devido à polarização do eletrodo}

No primeiro trabalho publicado no TCABR com eletrodo polarizado na borda do plasma [37] já foi possível notar uma melhora no seu confinamento, com uma redução das flutuações e do transporte turbulento de partículas. Outro traço característico do confinamento melhorado apresentado nesse trabalho é a queda do sinal da linha de $H_{\alpha}$, indicando redução da taxa de reciglagem, ou do fluxo de partículas que escapam do confinamento. Além disso, há um substancial aumento da densidade eletrônica na linha média central do interferômetro. A combinação: queda de $H_{\alpha}$ e aumento da densidade central são características globais da melhora do confinamento, pois se fosse por outro efeito que não da melhora do confinamento, a linha de $H_{\alpha}$ não reduziria da forma que reduz, possivelmente haveria um aumento. A figura 6.1 apresenta um disparo com o eletrodo polarizado em $+300 \mathrm{~V}$ (na posição 17,0 cm), com esses dois parâmetros: $H_{\alpha}$ e densidade de plasma média na linha central do interferômetro, além da tensão no eletrodo e da corrente de plasma (esta fornece informação sobre a estabilidade do disparo). 

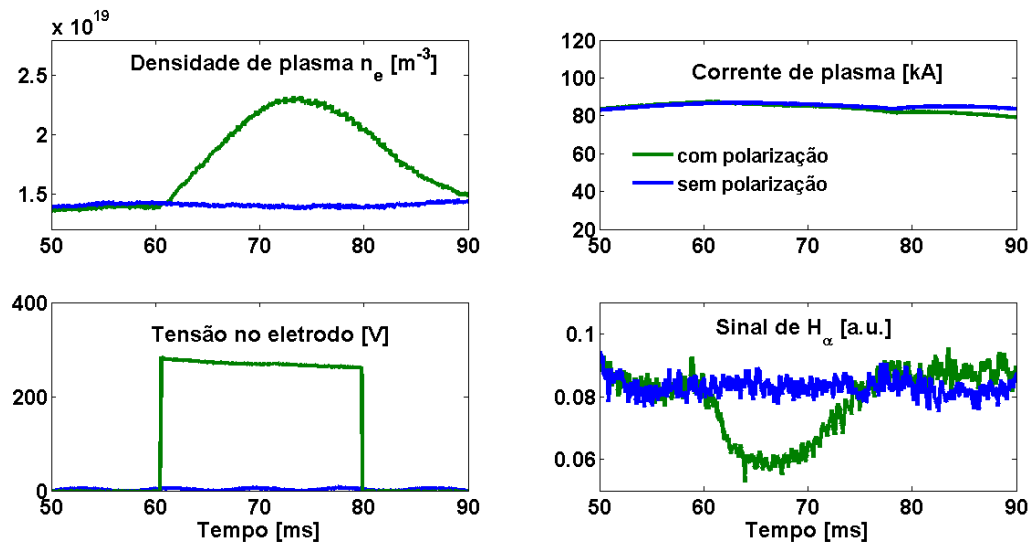

Figura 6.1: Dois disparos no TCABR com (\#32556, verde) e sem (\#32554, azul) polarização de +300 V no eletrodo. O primeiro gráfico, em cima à esquerda, é a densidade média na linha central do interferômetro $\left(n_{e}\right)$, o segundo, em cima à direita, é a corrente de plasma $\left(I_{p}\right)$, o terceiro, em baixo e à esquerda, é a tensão de polarização no eletrodo e o quarto, em baixo e à direita, é a linha espectral de $H_{\alpha}$.

Na figura (6.1) é possível notar que quando o eletrodo é polarizado há um aumento grande na densidade de plasma no centro da coluna e uma diminuição significativa da emissão de $H_{\alpha}$, indicando uma menor reciclagem nas paredes e no limitador, enquanto que a corrente de plasma mantém-se quase constante. Esses são indícios globais de uma melhora no confinamento do plasma.

Na figura 6.2 é apresentado um disparo com o eletrodo polarizado em $+250 \mathrm{~V}$ (na posição 17,0 cm), novamente com: $H_{\alpha}$, densidade de plasma média na linha central do interferômetro, tensão no eletrodo e corrente de plasma.
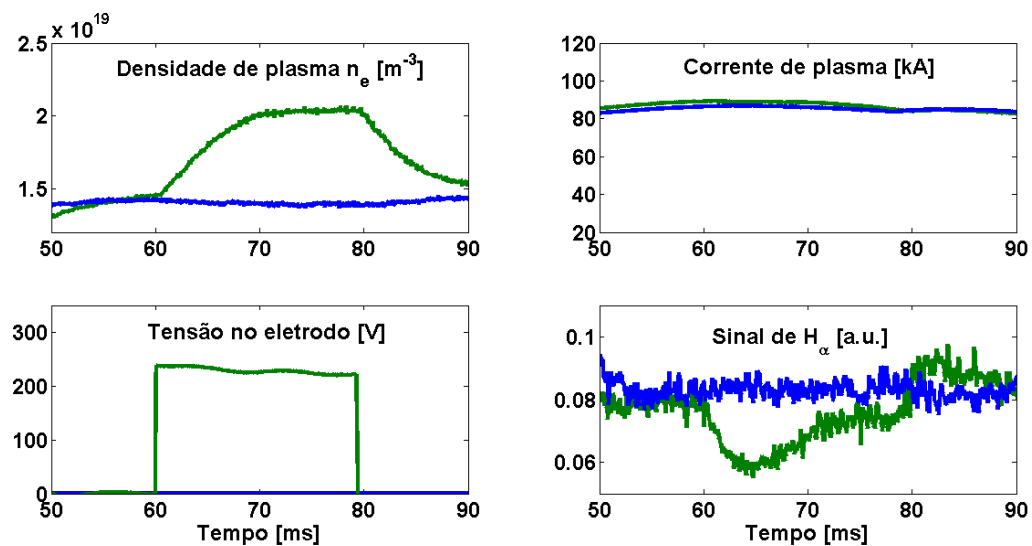

Figura 6.2: Dois disparos no TCABR com (\#32922, verde) e sem (\#32554, azul) polarização de +250 V no eletrodo. O primeiro gráfico, em cima à esquerda, é a densidade média na linha central do interferômetro $\left(n_{e}\right)$, o segundo, em cima à direita, é a corrente de plasma $\left(I_{p}\right)$, o terceiro, em baixo e à esquerda, é a tensão de polarização no eletrodo e o quarto, em baixo e à direita, é a linha espectral de $H_{\alpha}$.

O aumento da densidade nesse caso é menor em relação ao disparo com $+300 \mathrm{~V}$, com queda de $H_{\alpha}$ semelhante. 


\subsection{Perfis radiais médios antes e durante a polarização do eletrodo}

Os perfis radiais médios foram medidos utilizando a sonda rake nas três configurações de medidas (tabela 1.1). A obtenção dos parâmetros a partir do ajuste das curvas características já fornece valores médios, isso porque cada curva é realizada em um intervalo de tempo de aproximadamente $0,5 \mathrm{~ms}$ (semi-período do sinal de tensão senoidal), que é um tempo relativamente longo se comparado com o tempo das flutuações características do plasma. Mas, o ajuste na prática foi feito considerando a média de no mínimo quatro curvas, com a finalidade de melhorar a sua qualidade; o tempo de cada ajuste é então superior a 2,0 ms. Porém, ainda foram feitas superposições das curvas, ou seja, o ajuste era realizado em uma janela de aproximadamente 2,0 ms, sendo que o próximo ajuste ainda considerava parte das curvas do ajuste anterior; a superposição considerada neste trabalho foi de duas curvas. Através do ajuste das curvas características da sonda na configuração de tensão senoidal foi possível obter a temperatura (diretamente do ajuste), densidade eletrônica (com correção da temperatura), potencial de plasma (com correção da temperatura) e campo elétrico radial (através da derivada da função de ajuste do potencial de plasma).

Nas medidas diretas de potencial flutuante e de corrente de saturação de íons, isto é, sem ajuste de curvas, a resolução temporal foi alta $\sim 0,5 \mu s$, pois a limitação é o período de aquisição do ADC (NI, 2 Megasamples/s). Isso permitiu o estudo com mais detalhe da transição devida ao eletrodo e da evolução temporal dos parâmetros durante a polarização (próximo capítulo). Além disso, possibilitou a obtenção dos perfis médios da densidade eletrônica, do potencial de plasma e do campo elétrico (com as correções de temperatura, utilizando os perfis médios obtidos do ajuste das curvas características em disparos diferentes) em janelas temporais de curta duração.

\subsubsection{Temperatura eletrônica $\left(T_{e}\right)$ e densidade eletrônica $\left(n_{e}\right)$}

A temperatura eletrônica é obtida neste trabalho somente através do ajuste das curvas características na configuração de tensão senoidal, logo sua resolução temporal está limitada ao período das senóides, na prática de aproximadamente $1 \mathrm{~ms}$, considerando quatro curvas, com superposição de duas. Portanto, não foi possível estudar flutuações rápidas de temperatura e suas consequências na turbulência, bem como no transporte de energia (termo condutivo turbulento). Contudo, foi possível estudar os perfis radiais médios de temperatura na borda do plasma utilizando a sonda rake, em janelas temporais de até $10 \mathrm{~ms}$. Dessa forma, foi possível analisar a mudança do perfil médio de temperatura eletrônica antes, durante e depois da aplicação do eletrodo para diferentes tensões de polarização e, com os perfis obtidos, corrigir a densidade eletrônica e o potencial de plasma.

A densidade eletrônica foi obtida de duas formas: através da corrente de saturação de íons obtida no ajuste das curvas características na configuração de tensão senoidal, juntamente 
com a temperatura eletrônica (que também é obtida no ajuste), que é utilizada para obter a densidade utilizando a expressão (3.11), e pela série temporal da corrente de saturação de íons, obtida na configuração de tensão constante negativa na sonda, com correções no seu valor, levando em conta o efeito da expansão da pré bainha, e com a correção de temperatura para obter a densidade, sendo nesse caso necessário utilizar perfis médios obtidos de outros disparos.

O objetivo foi estudar os dois perfis radias na borda: de $T_{e}$ e de $n_{e}$, antes, durante e depois da polarização no eletrodo, sobretudo com o interesse de averiguar o possível aparecimento de uma barreira de transporte, ligado a uma melhora de confinamento do plasma, que para esses parâmetros significaria uma mudança nos seus perfis, particularmente, com um aumento do gradiente de densidade nas proximidades da posição do eletrodo $(17,0 \mathrm{~cm})$ e uma diminuição dos valores na camada-de-raspagem. Essa combinação pode indicar a formação de uma barreira de transporte, pois se a densidade aumentar devido ao aumento de impurezas ou pela injeção de gás, isto se daria de maneira uniforme e não haveria, sobretudo, redução da densidade na região da camada de raspagem (scrape-off-layer) ou aumento do seu gradiente na região da borda. Além disso, o objetivo também era examinar as condições para a formação dessa barreira.

O estudo dos perfis de temperatura e densidade será dividido em duas partes. Na primeira parte serão estudados os perfis que são obtidos das médias dos parâmetros do ajuste das curvas características, na configuração senoidal. Já na segunda parte serão apresentados os perfis de densidade obtidos da série temporal da corrente de saturação de íons.

\section{$T_{e}$ e $n_{e}$ na borda a partir do ajuste das curvas características}

Os dados aqui apresentados provém de um dia de medida. Na configuração de tensão senoidal, a sonda rake foi posicionada em $17 \mathrm{~cm}$, assim como o eletrodo. Foram feitos, então, sucessivos disparos, variando-se a tensão de polarização do eletrodo em cada um deles. A intenção foi manter a maior reprodutibilidade possível entre eles, isso porque as condições do plasma podem mudar durante uma sessão de medidas em um dia de disparos, os realizados na parte da manhã podem ser diferentes comparados com disparos realizados na parte da tarde, apesar do esforço do operador em manter os parâmetros de controle dos disparos com as mesmas características.

Os perfis médios antes e durante a polarização do eletrodo foram ajustados utilizando-se o método dos mínimos quadrados, usando a seguinte a função:

$$
F(r)=A_{1}+A_{2} e^{-r A_{3}}
$$

em que $F(r)$ é uma função genérica, neste caso $T_{e}(r)$ e $n_{e}(r)$, e $\mathbf{A}_{s}$ são os parâmetros do ajuste. Pelo número de pontos ajustáveis e pelo número de parâmetros do ajuste, o valor da função $\chi^{2}$ estava dentro do intervalo aceitável do número de graus de liberdade. 
Na figura 6.3 são apresentados os perfis de $T_{e}$ e $n_{e}$ antes e durante a polarização de +150 V no eletrodo. Nota-se que não há grandes mudanças nos perfis, indicando que para essa tensão não há indução de uma barreira de transporte. É possível perceber também que as barras de erro da temperatura são proporcionalmente bem maiores do que as de densidade. Isso se deve à característica do sinal de temperatura, que apresenta níveis de flutuações maiores do que o sinal de densidade, sendo tais oscilações maiores para os pinos mais internos.
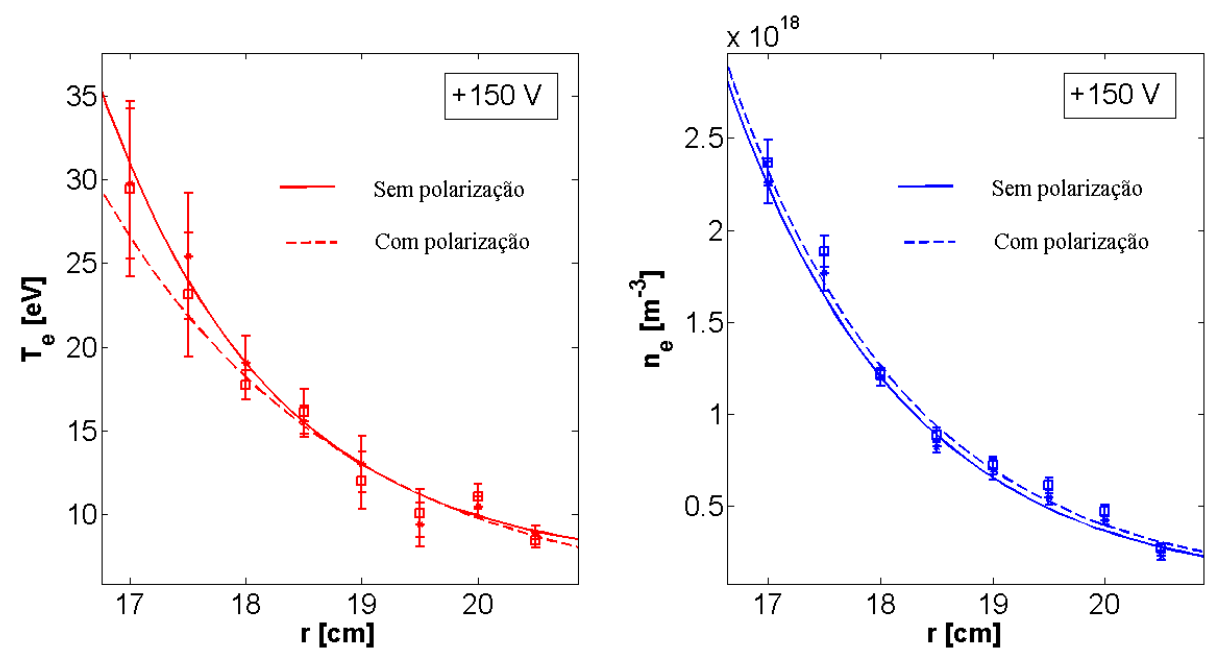

Figura 6.3: Perfis de temperatura eletrônica $\left(T_{e}\right)$ e densidade eletrônica $\left(n_{e}\right)$, antes (linha cheia) e depois (linha tracejada) da aplicação de +150 V no eletrodo (disparo \#34098) 
Para tensão de $+200 \mathrm{~V}$ (figura 6.4), já é possível notar uma mudança no perfil de densidade eletrônica, com um aumento do seu gradiente entre $17-18 \mathrm{~cm}$ e uma redução na camada-de-raspagem. Tal resultado é compatível com a criação de uma barreira de transporte. A temperatura eletrônica, no entanto, pouco se altera.
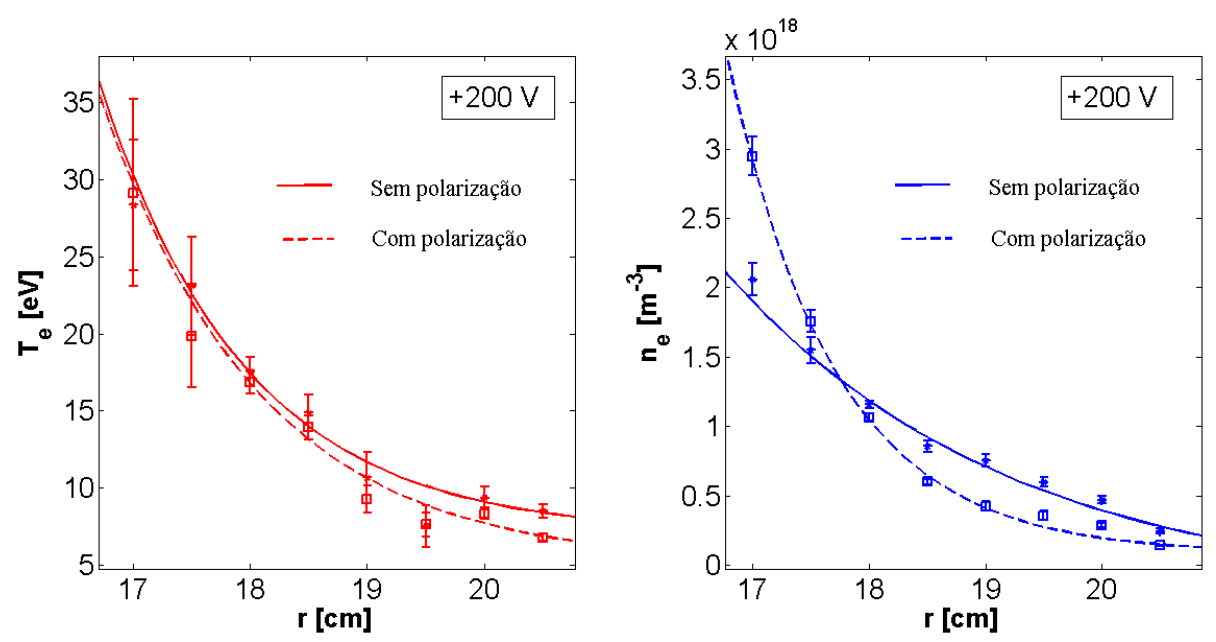

Figura 6.4: Perfis de temperatura eletrônica $\left(T_{e}\right)$ e densidade eletrônica $\left(n_{e}\right)$, antes (linha cheia) e depois (linha tracejada) a aplicação de +200 V no eletrodo (disparo \#34100)

Aumentando ainda mais a tensão no eletrodo (figura 6.5), para o valor de $+250 \mathrm{~V}$, a formação da barreira é ainda mais clara. Como pode ser visto pelo perfil de densidade, nota-se que há duas regiões bem definidas: para $r$ maior do que aproximadamente $17,7 \mathrm{~cm}$ a densidade é, em valor absoluto, menor do que era antes do eletrodo ser polarizado. Por outro lado, para $r$ menor do que aproximadamente $17,7 \mathrm{~cm}$, a densidade é maior em valor absoluto. Entre os dois extremos, o gradiente aumenta durante a polarização. A barreira de transporte é esperada estar na posição aproximadamente em torno de 17,7 cm. Uma estimativa para o comprimento da barreira será dada na próxima seção, quando serão discutidos os perfis de campo elétrico radial. Novamente, o perfil de temperatura eletrônica parece pouco se alterar sob influência do eletrodo. 

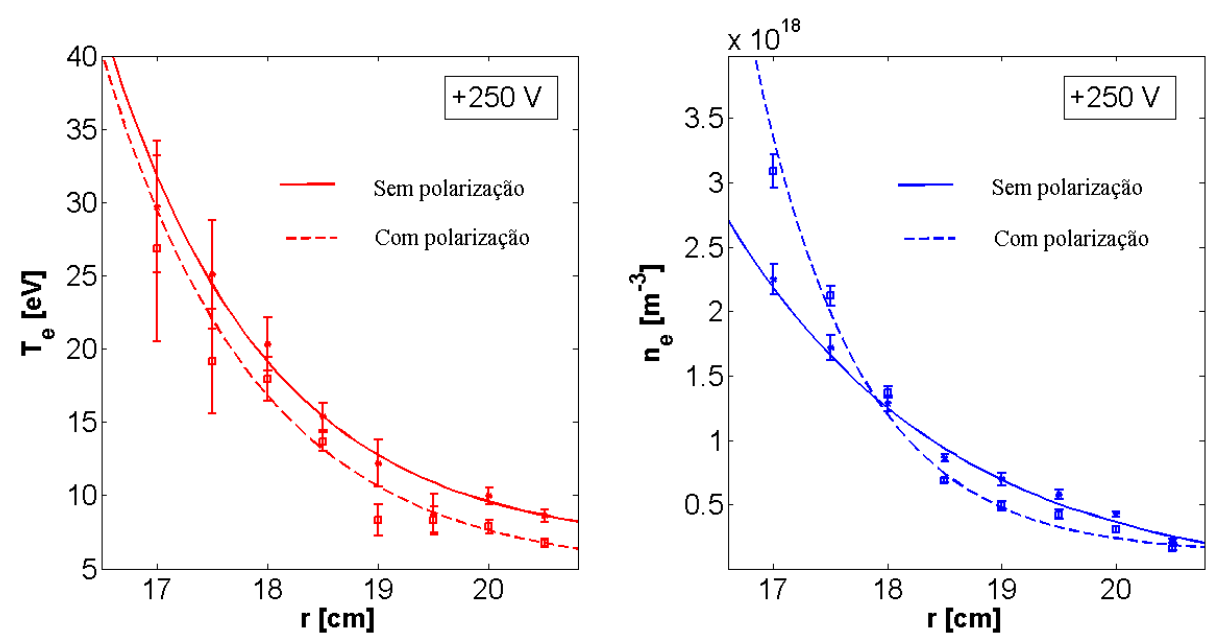

Figura 6.5: Perfis de temperatura eletrônica $\left(T_{e}\right)$ e densidade eletrônica $\left(n_{e}\right)$, antes (linha cheia) e depois (linha tracejada) da aplicação de +250 V no eletrodo (disparo \#34099)

Para $+300 V$ o efeito é ainda maior e a barreira se forma com clareza, como é possível ver no perfil de densidade (figura 6.6). Novamente, o perfil de temperatura pouco se altera, embora, nesse caso, as barras de incertezas sejam bem maiores, principalmente, para os pinos mais internos, o que causa maior indefinição se houve ou não uma mudança no perfil devido a influência do eletrodo.
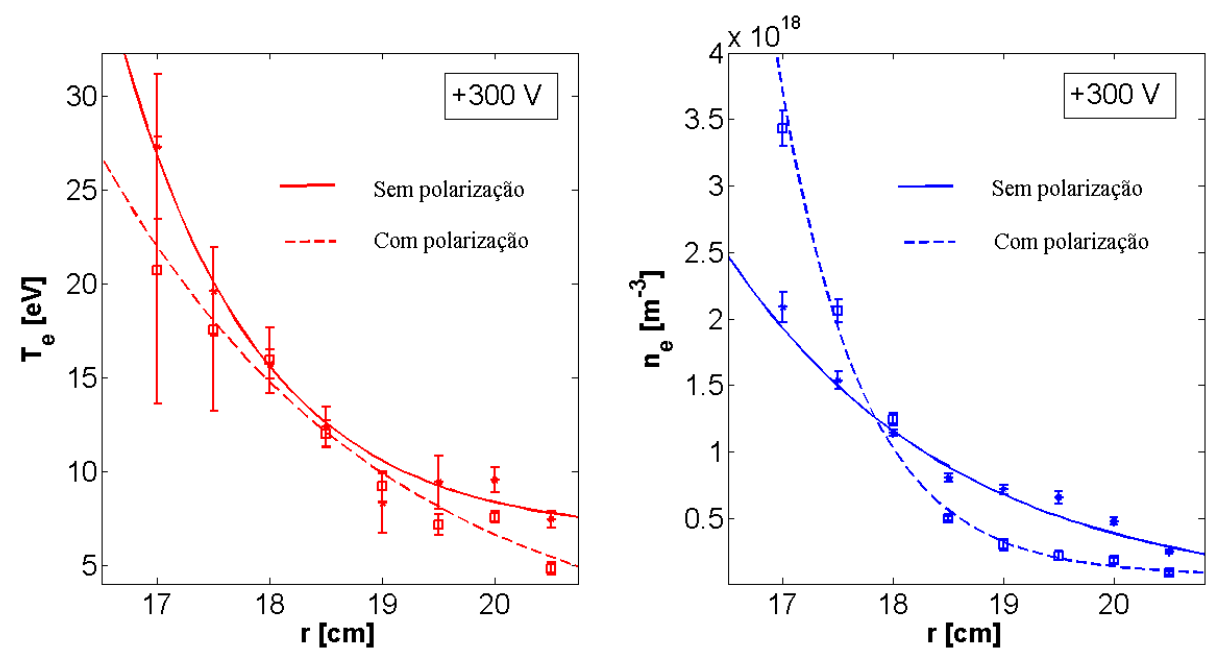

Figura 6.6: Perfis de temperatura eletrônica $\left(T_{e}\right)$ e densidade eletrônica $\left(n_{e}\right)$, antes (linha cheia) e depois (linha tracejada) da aplicação de +300 V no eletrodo (disparo \#34101) 


\section{Densidade $n_{e}$ na borda: medidas na configuração de tensão constante}

A densidade eletrônica na teoria de sondas eletrostáticas é obtida através da corrente de saturação de íons no critério de Bohm. Logo, uma forma simples de se obter a densidade (ou algo proporcional a ela) é através da medida da corrente coletada pela sonda quando a tensão de polarização é constante e negativa. Na prática o que se obtém é algo semelhante à corrente de saturação de íons, mas que, no entanto, não é igual a ela, já que como foi visto é necessário levar em conta o efeito da expansão da pré bainha para um plasma magnetizado. Fazendo as correções necessárias e considerando a temperatura eletrônica, obtém-se uma série temporal da densidade eletrônica, que é uma ferramenta bastante poderosa no estudo das turbulências na borda e transporte de partículas, como será visto.

Nesta configuração embora a resolução temporal seja melhor do que na configuração das curvas características, com tensão senoidal, a forma de se estimar a densidade é menos precisa. O ajuste das curvas características fornece no tempo em que a curva é formada os valores de $I_{\text {sat }}$ (já corrigido) e de $T_{e}$, que juntos podem ser usados diretamente para obtenção de $n_{e}$, ou seja, as correções são feitas em cada janela de tempo em que o ajuste é considerado. Na configuração de tensão constante o único parâmetro obtido da medida é a corrente saturação de íons não corrigida. Para se obter a densidade nesse caso foram considerados perfis médios de $V_{f}$ e $T_{e}$ na borda, obtidos de outros disparos.

A correção em $I_{\text {sat }}$ a partir da corrente medida para tensão constante negativa, considerando a expressão de ajuste (5.1), é igual a:

$$
I_{\text {sat }}=\frac{I_{\text {medido }}}{\left[1-e^{\frac{e\left(V_{\text {fonte }}-V_{f}\right)}{T_{e}}}-|\alpha|\left(V_{\text {fonte }}-V_{f}\right)\right]}
$$

onde $V_{\text {fonte }}$ é a tensão de polarização constante e negativa na sonda e $\alpha$ é o parâmetro empírico relacionado com a expansão da pré-bainha.

As medidas foram feitas com a rake e o eletrodo na posição $17,0 \mathrm{~cm}$. O eletrodo foi polarizado em diferentes tensões: $+150 \mathrm{~V},+200 \mathrm{~V},+250 \mathrm{~V}$ e $+300 \mathrm{~V}$. Os resultados são apresentados na figura 6.7, com todos os gráficos na mesma escala.

Nota-se novamente a formação da barreira de transporte para as tensões: $+200 \mathrm{~V},+250 \mathrm{~V}$ e $+300 \mathrm{~V}$. Para a tensão de $+150 \mathrm{~V}$ o perfil praticamente não se altera, indicando que essa polarização não é suficiente para induzir a barreira. Para a tensão de $+200 V$ percebe-se uma pequena mudança no perfil, que já sinaliza a formação da barreira. Para as tensões de $+250 \mathrm{~V}$ e +300 $\mathrm{V}$ a mudança no perfil é bastante clara, a barreira é formada de maneira perceptível em torno da posição $\sim 17,7 \mathrm{~cm}$. 

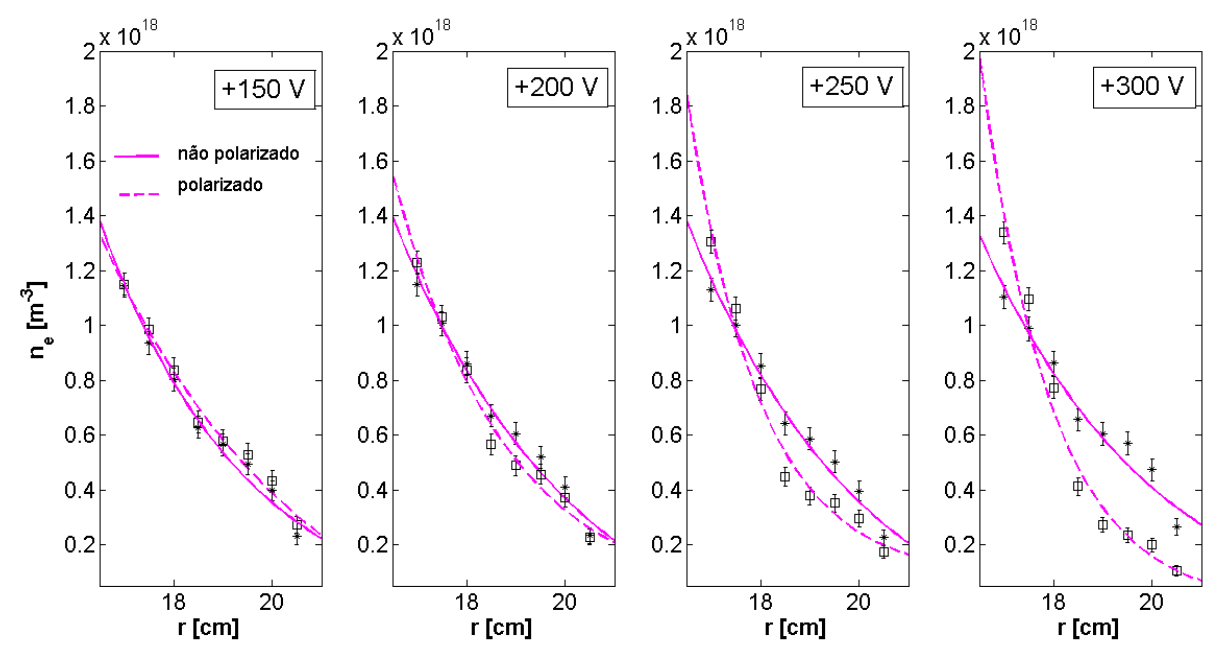

Figura 6.7: Perfis médios da densidade eletrônica $\left(n_{e}\right)$ em diferentes tensões no eletrodo: $+150 \mathrm{~V}$ (disparo \# 34105), +200V (\# 34107), +250V (\# 34106) e +300 V (\# 34108), obtidos a partir das séries temporais de $I_{\text {sat }}$ (corrigido com $V_{f}$ ) e da temperatura eletrônica média $\left(T_{e}\right)$. A curva cheia indica o perfil médio antes da polarização $(55-60 \mathrm{~ms})$ e a curva tracejada o perfil durante a polarização no eletrodo (65 - $70 \mathrm{~ms}$ ). Todos os gráficos estão na mesma escala.

\subsubsection{Potencial de plasma $\left(V_{p}\right)$ e campo elétrico radial $\left(E_{r}\right)$}

O potencial de plasma local pode ser obtido através das medidas de potencial flutuante e temperatura eletrônica locais, por meio da expressão (3.9), considerando que $V_{p} \approx V_{f}+\frac{2,8}{e} T_{e}$. O campo elétrico na direção radial é aproximadamente $E_{r}=-\frac{d V_{p}}{d r}$. Uma maneira de se obter o potencial de plasma é através de $V_{f}$ e $T_{e}$ obtidos dos ajustes nas medidas das curvas características na configuração de tensão senoidal. Obtém-se os parâmetros em intervalos de cerca de $1 \mathrm{~ms}$, em torno de quatro rampas com duas de superposição. A estimativa da temperatura é, nesse caso, boa, já que ela depende da inclinação da curva característica média, que geralmente é bem definida, a obtenção do potencial flutuante é, no entanto, mais crítica, pois ela é definida em um ponto: valor de tensão no qual a corrente total coletada pela sonda é nula. Ou seja, um ponto apenas define $V_{f}$, o que faz com que sua medição seja bastante complicada, visto que os sinais medidos oscilam bastante, característica inerente ao plasma turbulento na região de borda. Uma estimativa melhor para $V_{f}$ é dada através da medida da sua série temporal, na configuração de potencial flutuante. Obtém-se seu valor com alta resolução temporal, possibilitando fazer médias em janelas relativamente grandes (usualmente $\sim 5 \mathrm{~ms}$ ), com uma grande quantidade de pontos. A desvantagem é que nessa configuração não se obtém a temperatura eletrônica diretamente, no entanto, como foi visto na seção anterior, a temperatura pouco se altera sob influência do eletrodo, de forma que usar a sua curva na determinação de $V_{p}$ é uma boa aproximação.

\section{$V_{p}$ e $E_{r}$ : através dos parâmetros de ajuste das curvas características}

Apesar das dificuldades na determinação de $V_{f}$ por meio do ajuste das curvas características, mesmo considerando a média de mais de uma curva no ajuste, os resultados ainda 
assim são interessantes. A comparação é feita entre os perfis de $V_{p}$ e $E_{r}$ antes e durante a polarização do eletrodo, considerando a média de vários desses ajustes, entre um intervalo de aproximadamente $10 \mathrm{~ms}$ logo antes e $10 \mathrm{~ms} \log$ depois.

As medidas foram feitas com a sonda rake. Para cada pino, ou posição radial, foi feita uma média de $V_{p}$ (com a correção de temperatura em $V_{f}$ diretamente do ajuste), com as devidas incertezas, levando em conta as flutuação nos sinais e o erro dos parâmetros nos ajustes; obtendo-se, assim, um perfil médio radial na borda para $V_{p}$. Os pontos obtidos são então ajustados com uma função polinomial em torno da borda $(18 \mathrm{~cm})$. O ajuste mais adequado em termos de qualidade, com $\chi^{2}$ dentro do intervalo aceitável, foi de um polinômio de grau cinco. O campo elétrico era então obtido das derivadas em relação a posição radial das funções de ajuste de $V_{p}$.

Em todas as tensões de polarização no eletrodo consideradas foi possível notar uma mudança nos perfis de $V_{p}$ e $E_{r}$. Inicialmente para a tensão de $+150 V$ (figura 6.8) é possível notar um aumento no potencial de plasma para os pinos nas posições mais avançadas (menor que $\approx 18 \mathrm{~cm}$ ), enquanto que o potencial nos pinos mais recuados praticamente não se altera. Isso se reflete em um aumento do campo elétrico radial na região em torno de $17-18 \mathrm{~cm}$, o que possivelmente provoca um cisalhamento no fluxo de plasma (termo $\vec{E} \times \vec{B}$ ), que, como será visto, pode reduzir o nível de flutuações nos sinais de $V_{f}$ e $I_{s a t}$, diminuindo a turbulência. Porém $+150 \mathrm{~V}$, como foi visto, não é suficiente para induzir uma barreira de transporte e também não é suficiente para induzir uma redução significativa em $V_{f}$ e $I_{\text {sat }}$ (como será visto), portanto não provoca uma redução relevante no transporte turbulento de partículas.
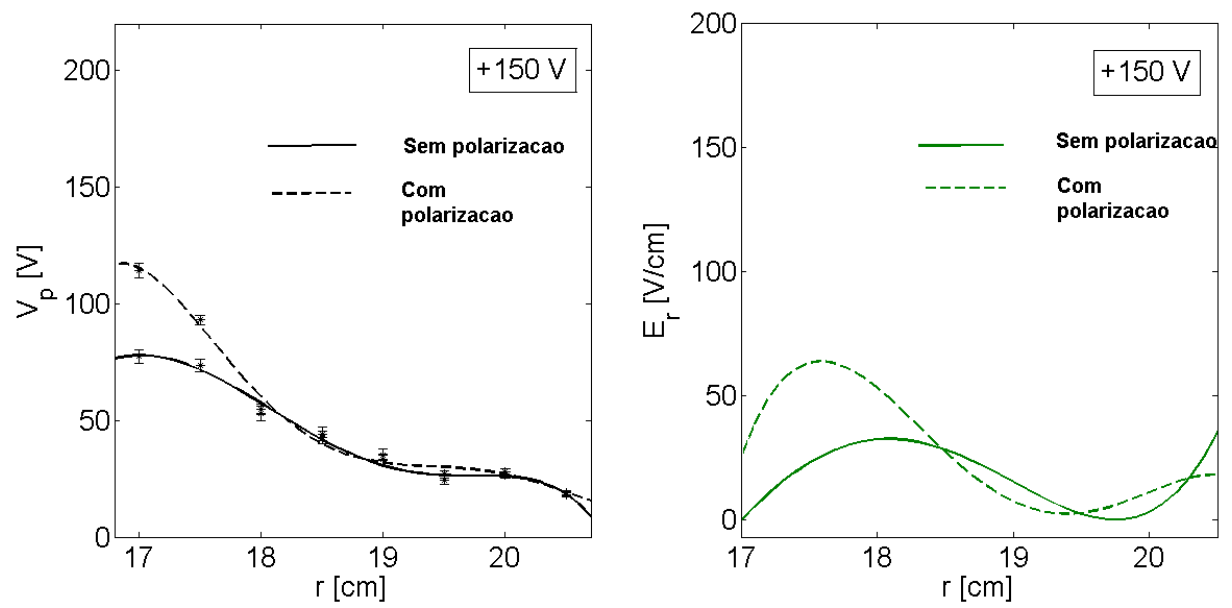

Figura 6.8: Perfis médios na borda de $V_{p}$ e $E_{r}$ antes (linha cheia) e durante (linha tracejada) a aplicação de uma polarização $+150 V$ no eletrodo (disparo \#34098).

Para tensão de $+200 \mathrm{~V}$ o aumento no potencial de plasma e no campo elétrico radial é ainda maior (figura 6.9). O que possivelmente provoca um maior cisalhamento no fluxo de plasma, que nesse caso é suficiente para a criação de uma barreira de transporte (como visto na seção anterior), provavelmente obedecendo o critério de BDT (3.16), quebrando as correlações turbulentas, favorecendo a criação da barreira. Os perfis são um tanto que 
diferentes dos obtidos para $+150 \mathrm{~V}$, refletindo as imprecisões do método que, no entanto, não é levado em conta nas barras de incertezas, dado as dificuldade de se estimar.
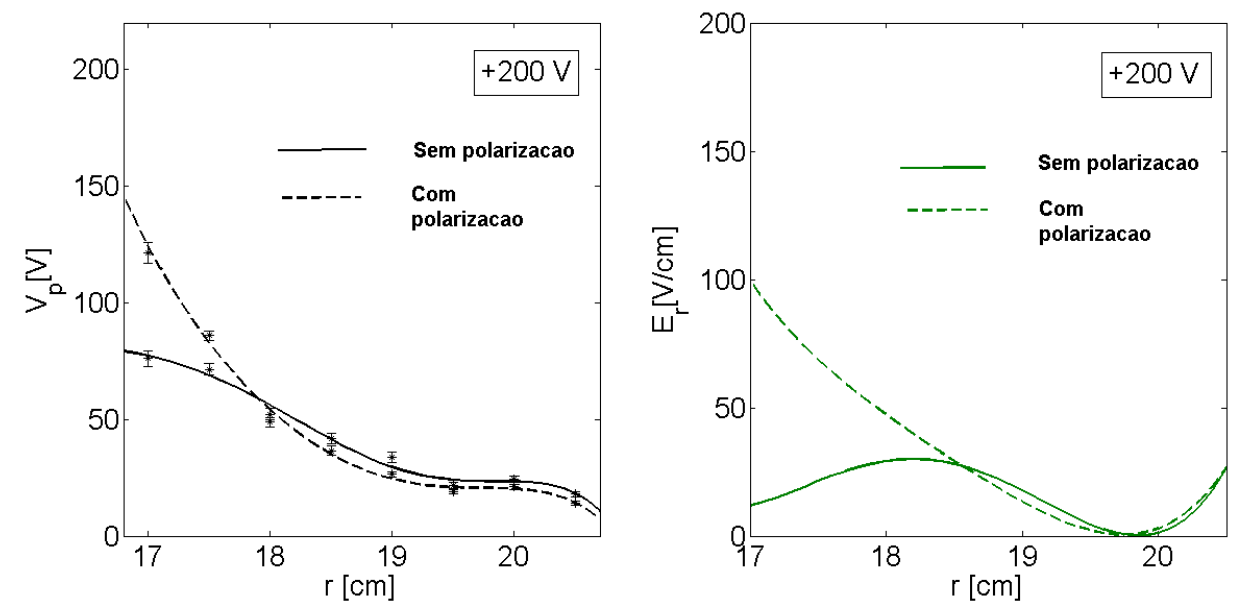

Figura 6.9: Perfis médios na borda de $V_{p}$ e $E_{r}$ antes (linha cheia) e durante (linha tracejada) a aplicação de uma polarização $+200 \mathrm{~V}$ no eletrodo (disparo \#34100).

Com tensões ainda maiores: $+250 \mathrm{~V}$ e $+300 \mathrm{~V}$, as variações em $V_{p}$ e $E_{r}$ podem ser vistas nas figuras 6.10 e 6.11 , respectivamente. O efeito em $E_{r}$ para $+250 \mathrm{~V}$ é parecido com o efeito em $+200 \mathrm{~V}$ e é mais acentuado em $+300 \mathrm{~V}$, como pode ser visto nos gráficos. Em ambos os gráficos há um grande aumento no gradiente do campo elétrico radial entre as proximidades de $17,5-18,5 \mathrm{~cm}$ para $+250 \mathrm{~V}$ e 17,0 - 18,5 cm para $+300 \mathrm{~V}$. Com maior cisalhamento no fluxo de plasma a chance da barreira de transporte ser formada é maior, pois a redução nos níveis de flutuação é esperada ser mais intensa (de fato ocorre, como será visto nas próximas seções) e, consequentemente, a redução no transporte turbulento é maior. Uma estimativa do tempo característico das transições será dada no próximo capítulo, com a finalidade de tentar achar uma relação causal para transição no TCABR. Existem trabalhos como [32], que também induzem confinamento melhorado por um eletrodo externo, que analisaram a evolução da transição, encontrando uma relação causal entre os efeitos, na ordem: aplicação da polarização no eletrodo, aumento do gradiente do campo elétrico na borda, cisalhamento no fluxo de plasma com aumento da velocidade poloidal, redução dos níveis de flutuações e transporte e criação de uma barreira de transporte. 

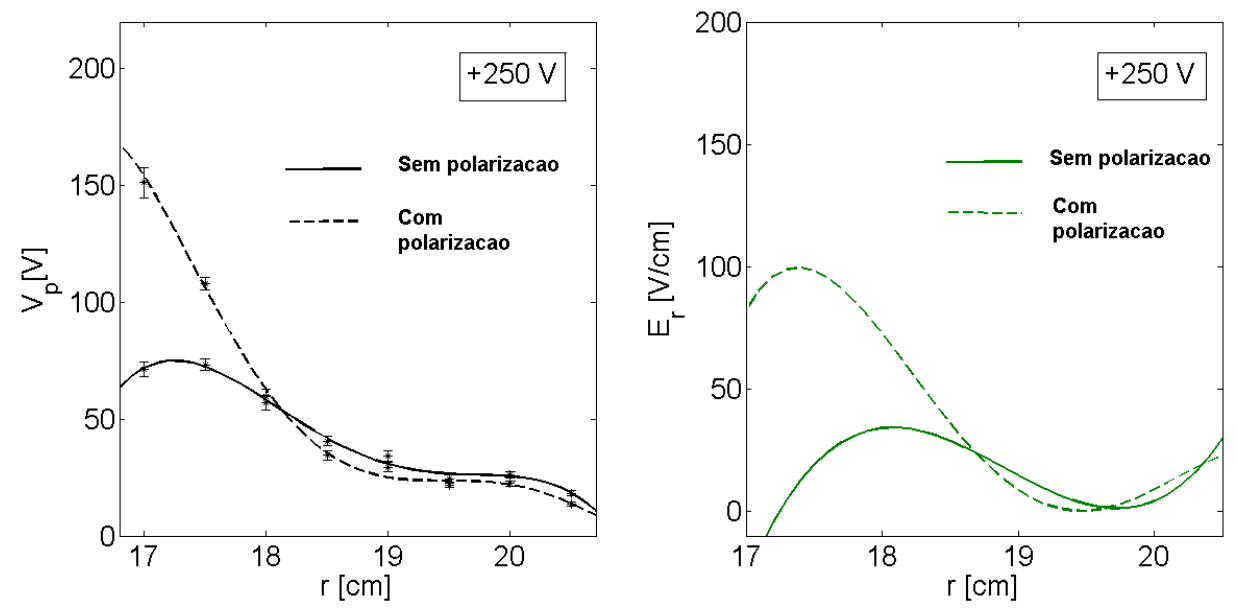

Figura 6.10: Perfis médios na borda de $V_{p}$ e $E_{r}$ antes (linha cheia) e durante (linha tracejada) a aplicação de uma polarização $+250 \mathrm{~V}$ no eletrodo (disparo \# 34099).
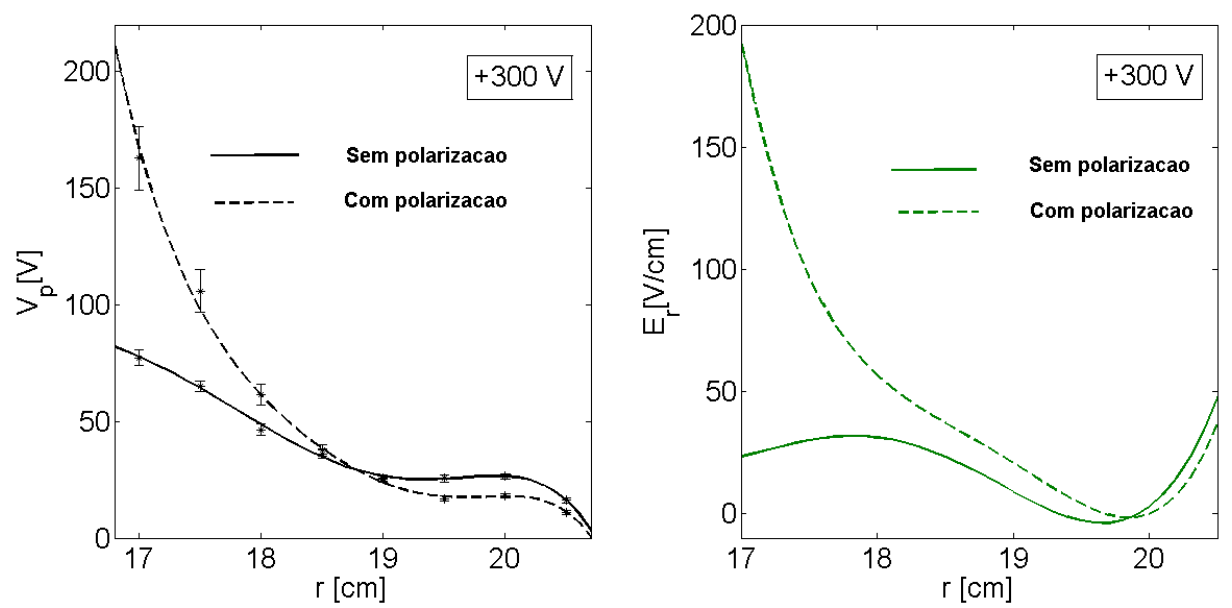

Figura 6.11: Perfis médios na borda de $V_{p}$ e $E_{r}$ antes (linha cheia) e durante (linha tracejada) a aplicação de uma polarização $+300 \mathrm{~V}$ no eletrodo (disparo \# 34101).

\section{$V_{p}$ e $E_{r}:$ série temporal de $V_{f}$}

Na configuração de tensão flutuante nos pinos é possível obter séries temporais de $V_{f}$. Não há fontes externas de corrente nesse caso, simplesmente os pinos são inseridos no plasma, flutuantes em relação ao terra do limitador. Por conta das interações com o plasma e sua característica de blindar campos externos, o fluxo de partículas na sonda torna-se aproximadamente nulo, ou seja a corrente coletada por ela é nula. A sonda fica então em potencial flutuante, que é medido em relação ao terra do vaso do TCABR por meio de um circuito externo. Essa configuração é claramente melhor do que a anterior, pois nesse caso é imposto que o pino fique em potencial flutuante, dessa forma obtém-se uma evolução de $V_{f}$ com alta resolução temporal.

Como foi visto na seção anterior, o perfil de temperatura eletrônica pouco se altera sob influência do eletrodo. Por esse motivo foi usado um perfil de $T_{e}$ obtido em um outro disparo (com parâmetros semelhantes aos disparos estudados nesta sessão) em que a sonda estava 
na configuração de tensão senoidal, com intuito de se obter a correção para o potencial de plasma local, a partir dos perfis médios de $V_{f}$ obtidos. Os perfis de temperatura usados foram obtidos de disparos que ocorreram no mesmo dia em que foi medido $V_{f}$. A mudança no perfil de $V_{p}$ por conta da influência do eletrodo deve-se apenas à mudança no perfil do potencial flutuante, já que a temperatura praticamente não se altera. No entanto a contribuição de $T_{e}$ em valor absoluto para $V_{p}$ é enorme, como pode ser visto na figura (6.12).

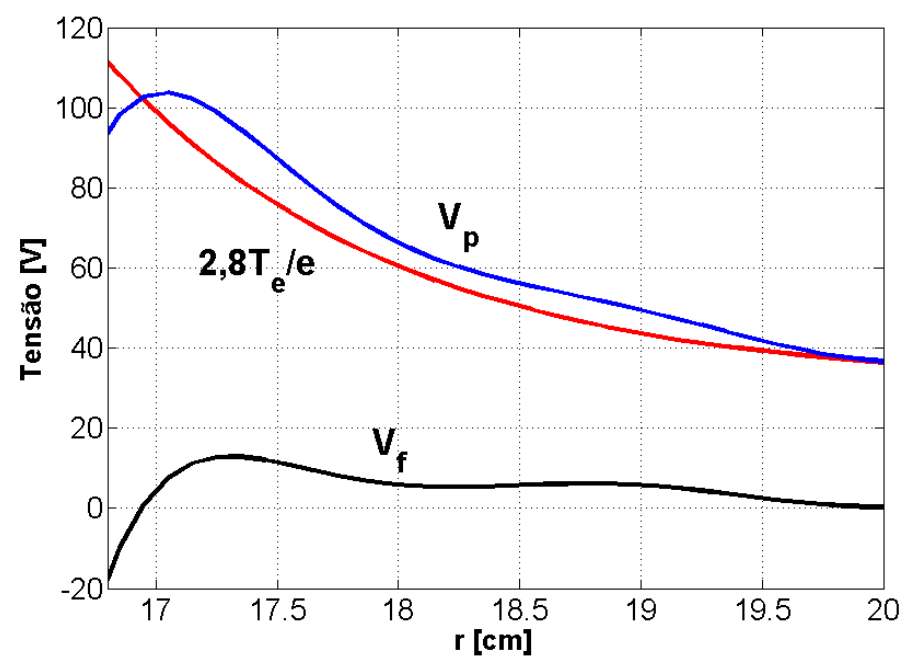

Figura 6.12: Perfis médios de $V_{f}$ e 2, $8 T_{e} /$ e e o correspondente perfil $V_{p}$ obtido dos outros dois $\left(V_{p} \approx V_{f}+2,8 / e T_{e}\right)$ em um disparo sem polarização no eletrodo.

O eletrodo novamente foi inserido na posição $17,0 \mathrm{~cm}$ (1 cm no interior do plasma), assim como a sonda rake. Foram feitos então disparos em cuja polarização do eletrodo foi: $+150 \mathrm{~V},+200 \mathrm{~V},+250 \mathrm{~V}$ e $+300 \mathrm{~V}$, ligado no intervalo de tempo entre $60-80 \mathrm{~ms}$. Os resultados são apresentados na figura (6.13).
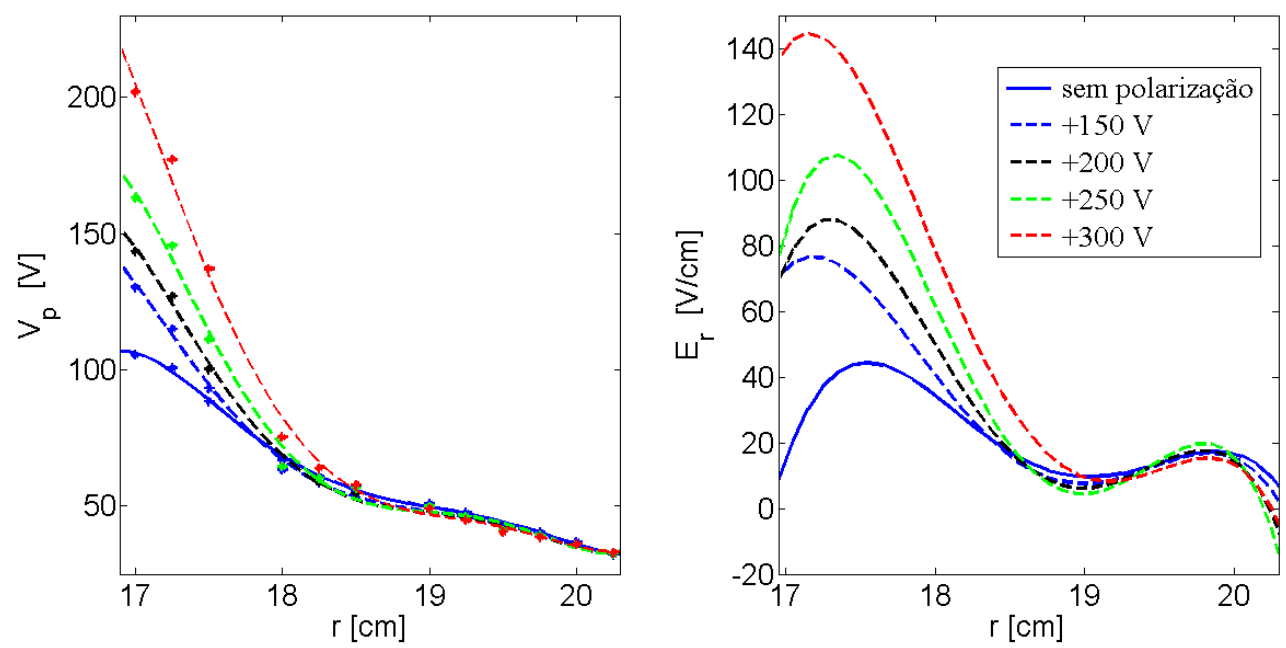

Figura 6.13: Perfis médios de $V_{p}$ e $E_{r}$ em diferentes polarizações no eletrodo: $+150 \mathrm{~V}$ (disparo \# 34110), +200 V (\#34112), +250V (\#34111) e +300 V (\#34113) e sem polarizá-lo. Nota-se que há um grande aumento do gradiente de $E_{r}$ quando o eletrodo é polarizado e esse aumento é tanto maior quanto maior é a tensão no eletrodo. 
O gráfico da figura 6.13 sintetiza o efeito do eletrodo no potencial de plasma e campo elétrico radial na região da borda do plasma no TCABR, nas quatro tensões de polarização no eletrodo consideradas: $+150 \mathrm{~V},+200 \mathrm{~V},+250 \mathrm{~V}$ e $+300 \mathrm{~V}$. O perfil de $V_{p}$ é mais íngreme quanto maior é a tensão de polarização no eletrodo, com um aumento do seu valor nos pontos mais internos (aproximadamente até $18,0 \mathrm{~cm}$ ) e, praticamente, ele não se altera para os pontos mais externos (aproximadamente posições maiores que 18,0 cm). Tal resultado era esperado, já que é formada uma corrente elétrica radial entre o eletrodo e o limitador (parâmetro também medido), entre $\sim 17-18 \mathrm{~cm}$. Como consequência surge um campo elétrico radial que é mais intenso quanto maior a tensão no eletrodo. O alto gradiente desse campo, que se forma nas regiões aproximadamente ente 17,5-18,0 cm, possivelmente, gera um cisalhamento no fluxo de plasma, quebrando as correlações turbulentas e provocando o aparecimento de uma barreira de transporte (como visto na seção anterior), reduzindo o transporte e aumentando a energia de confinamento.

\subsection{Potência espectral e transporte de partículas}

Outro efeito da polarização do eletrodo é a redução do nível de flutuações nos sinais de $V_{f}$ e $I_{\text {sat }}$ e a consequente redução do transporte. Segundo o critério de BDT [24], o cisalhamento do campo elétrico radial no fluxo de plasma é responsável pela redução da turbulência e pela diminuição do transporte radial, pois são quebradas as correlações turbulentas que são formadas na borda do plasma. Assim, é esperado que quanto maior esse cisalhamento, maior será tal redução, favorecendo a criação de uma barreira de transporte.

\subsubsection{Redução do nível de flutuações induzida pela polarização no eletrodo}

Para o estudo do nível de flutuações são usadas as séries temporais de $V_{f}$ e $I_{\text {sat }}$, que permitem o estudo de oscilações em altas frequência (até por volta de $300 \mathrm{kHz}$, dada as limitações dos circuitos de medida, como discutido no capitulo 4). As flutuações em $V_{f}$ estão relacionadas à turbulência na borda e à perda não ambipolar de partículas, com células convectivas e micro instabilidades [20]. Já em $I_{\text {sat }}$, parâmetro que está relacionado com a densidade eletrônica a menos de correções, notam-se diversas oscilações, como as chamadas instabilidades MHD, que são oscilações com frequência definida em torno de $13 \mathrm{kHz}$, que podem também ser notadas em $V_{f}$. Particularmente, a série temporal de $I_{\text {sat }}$ detecta oscilações não regulares de alta amplitude, que nesse contexto são chamadas de "jatos"("bursts"). Eles, que se formam no plasma turbulento, são espécie de bolhas de alta densidade que viajam no plasma, contribuindo significamente para a perda de partículas. Quando o eletrodo é aplicado há uma diminuição das oscilações em $V_{f}$ e $I_{\text {sat }}$, indicando uma diminuição do grau de turbulência, como pode ser visto nas figuras 6.14 e 6.15. Nos gráficos são apresentadas as potências espectrais em forma de espectrograma de $V_{f}$ e $I_{\text {sat }}$ em medidas com a sonda rake, 
onde foi tomada apenas a parte flutuante dos sinais.
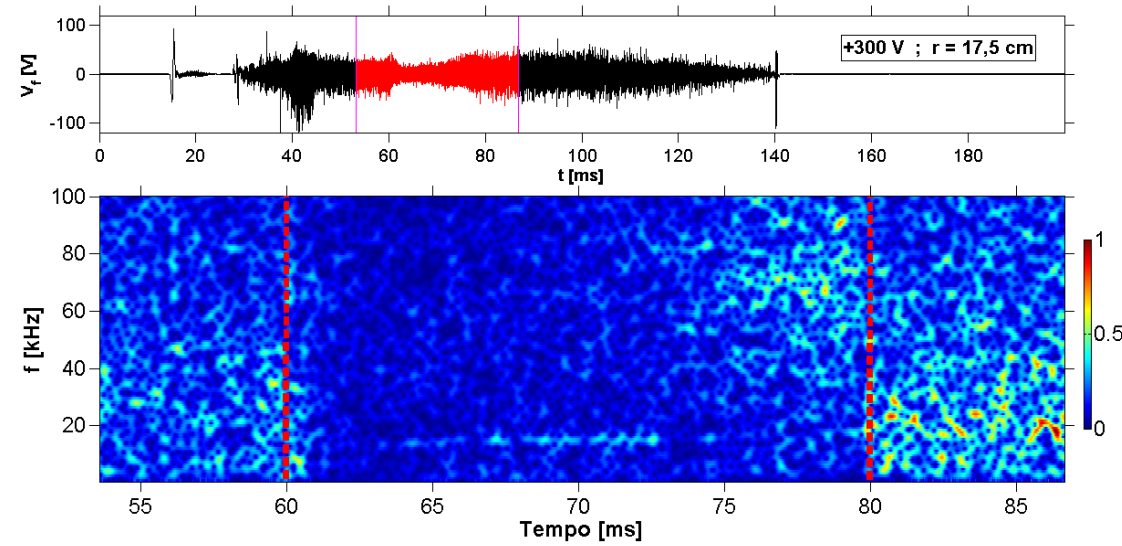

Figura 6.14: Parte oscilatória de um sinal de potencial flutuante medido pela sonda rake na posição $r=18,0 \mathrm{~cm}$ (parte de cima) e correspondente espectrograma do sinal (parte de baixo) realizado em uma janela de aproximadamente $35 \mathrm{~ms}$ ( parte vermelha do sinal, na figura de cima). (disparo \#34113)
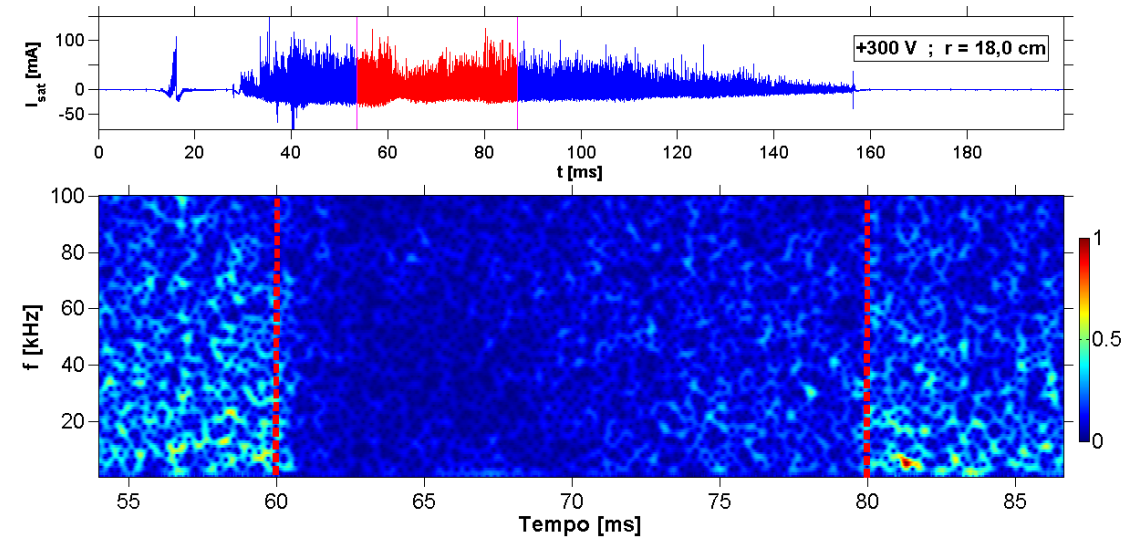

Figura 6.15: Parte oscilatória de um sinal de corrente de saturação de ions medido pela sonda rake na posição $r=18,0 \mathrm{~cm}$ (parte de cima) e correspondente espectrograma do sinal (parte de baixo) realizado em uma janela de aproximadamente $35 \mathrm{~ms}$ ( parte vermelha do sinal, na figura de cima). (disparo \#34108) 


\section{Sonda rake: corrente de saturação de íons $\left(I_{\text {sat }}\right)$}

A alta polarização no eletrodo gera um alto gradiente de campo elétrico radial na borda, provocando um aumento da rotação poloidal, possivelmente quebrando as correlações turbulentas nessa região. Isso faz com que haja uma redução na quantidade e intensidade dos "jatos"(bursts) de densidade na borda e as oscilações de alta amplitude em frequências mais baixas. A seguir é apresentado o espectrograma da potência espectral da parte flutuante de sinais de corrente de saturação de íons em oito pinos diferentes, com espaçamento entre eles de $5 \mathrm{~mm}$, entre 17,0 - 20,5 cm, para diferentes tensões no eletrodo. Ambos: sonda rake (pino mais avançado) e eletrodo foram posicionados em 17,0 cm.
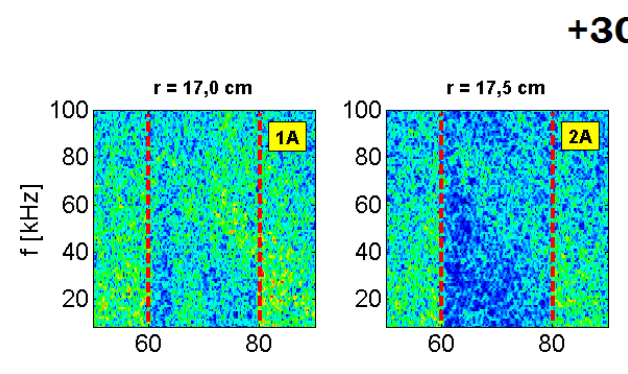

$300 \mathrm{~V}$
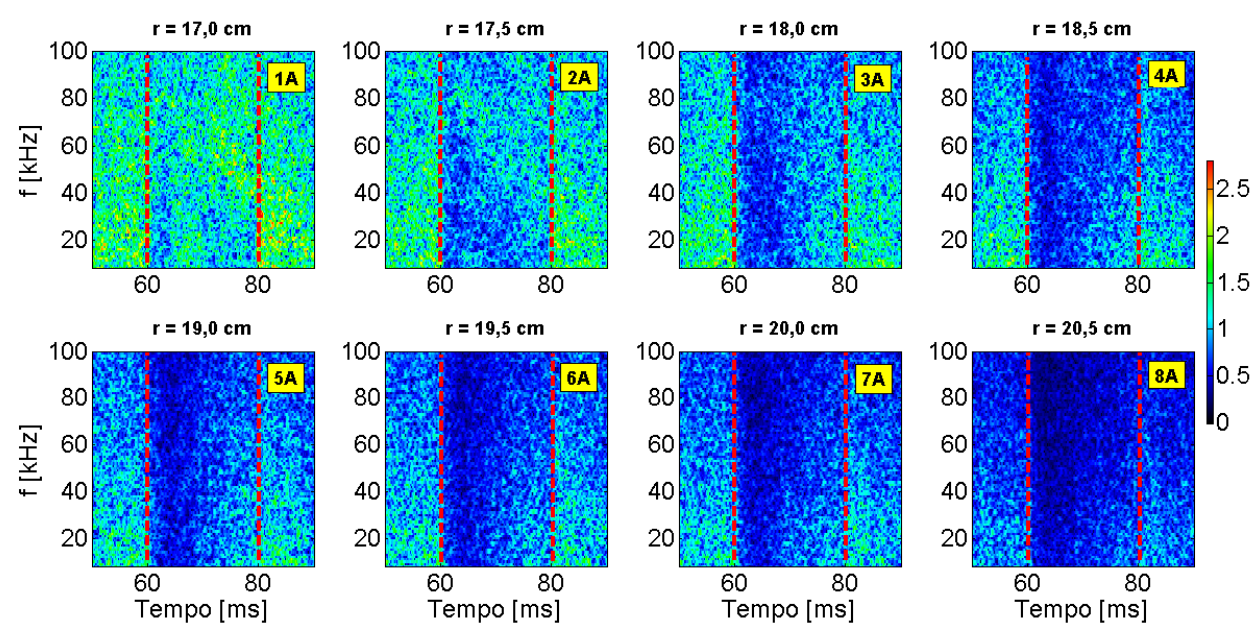

Figura 6.16: Espectrograma dos sinais de corrente de saturação de ions $\left(I_{\text {sat }}\right)$ dos oito pinos da fileira $A$ da sonda rake, entre 17,0-20,5 cm, com espaçamento de $5 \mathrm{~mm}$, em um disparo com polarização no eletrodo de $+300 \mathrm{~V}$ (disparo \#34108), entre 60-80 ms (linhas verticais tracejadas em vermelho).

Nota-se que durante a polarização no eletrodo nas tensões $+300 \mathrm{~V}$ e $+250 \mathrm{~V}$, entre 6080 ms (figuras 6.16 e 6.17, respectivamente), a redução do nível de flutuações é bastante acentuada para os pinos considerados. No entanto, é possível ver também que o efeito no pino mais avançado $(17,0 \mathrm{~cm})$ é menos pronunciado, se comparado com os três pinos mais recuados. Tal resultado é coerente com a idéia de que o cisalhamento no fluxo de plasma é o fator responsável pela diminuição da turbulência, pois o pino mais avançado está em uma posição em que o cisalhamento (gradiente do campo elétrico) é pouco intenso, enquanto que os outros três pinos mais recuados estão em uma região de alto cisalhamento. Os quatro pinos mais recuados, já na região da camada-de-raspagem, também sentem uma redução do nível de flutuações, isso porque o perfil de densidade eletrônica muda quando o eletrodo é aplicado, como visto na sessão 6.2.1, tornando-se mais íngreme na região de borda e mais rarefeito na camada de raspagem (scrape off layer), comparado ao perfil antes da polarização. Dessa forma menos partículas se encontram na região externa a barreira. 


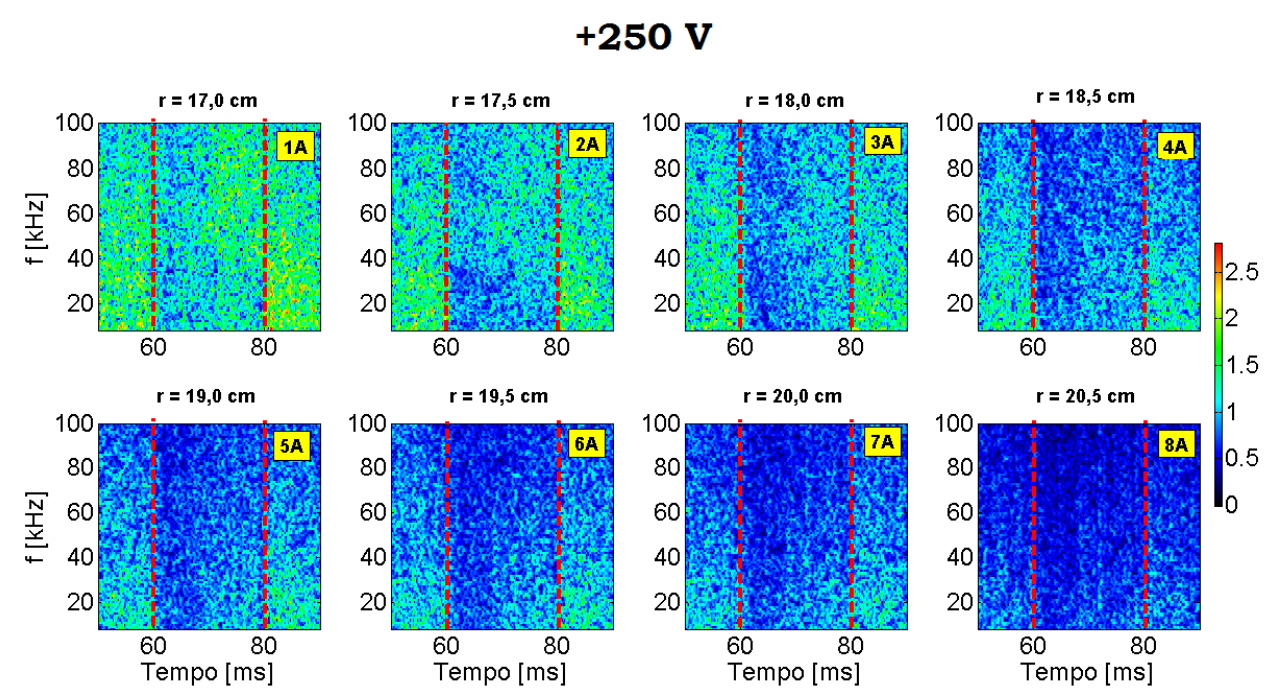

Figura 6.17: Espectrograma dos sinais de corrente de saturação de ions $\left(I_{\text {sat }}\right)$ dos oito pinos da fileira $A$ da sonda rake, entre 17,0-20,5 cm, com espaçamento de $5 \mathrm{~mm}$, em um disparo com polarização no eletrodo de $+250 \mathrm{~V}$ (disparo \#34106), entre 60-80 ms (linhas verticais tracejadas em vermelho).

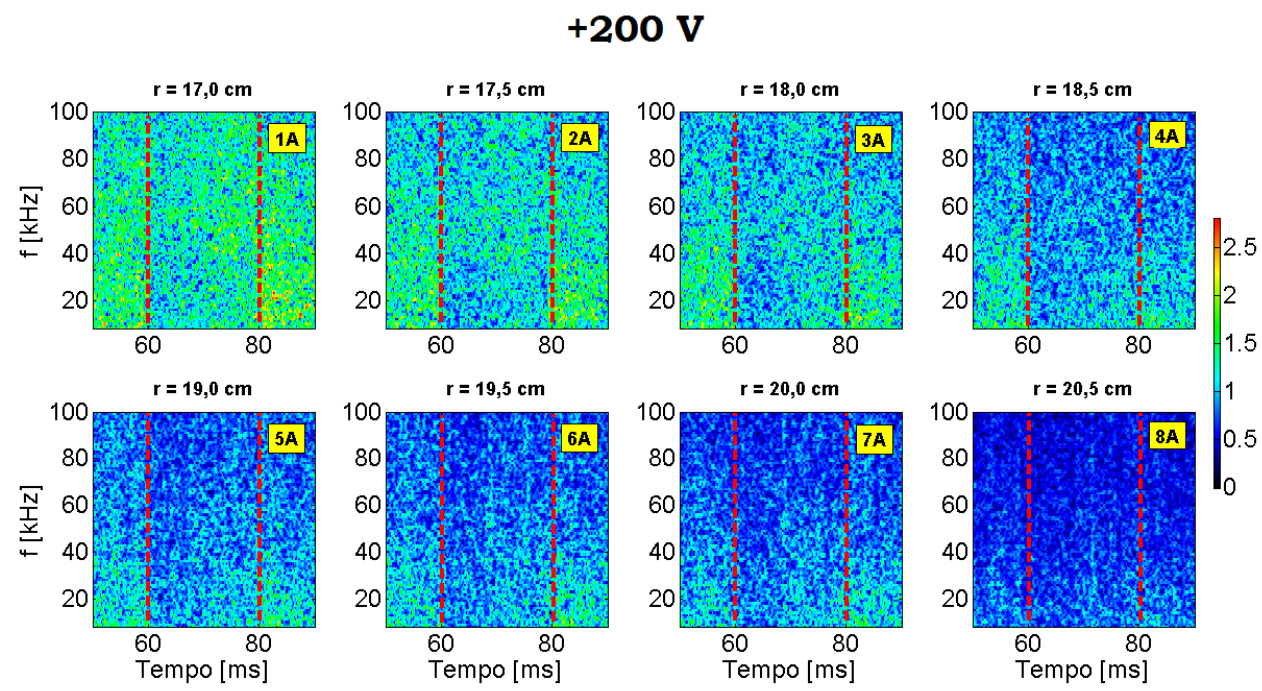

Figura 6.18: Espectrograma dos sinais de corrente de saturação de íons $\left(I_{\text {sat }}\right)$ dos oito pinos da fileira $A$ da sonda rake, entre 17,0-20,5 cm, com espaçamento de $5 \mathrm{~mm}$, em um disparo com polarização no eletrodo de $+200 \mathrm{~V}$ (disparo \#34107), entre 60-80 ms (linhas verticais tracejadas em vermelho).

Para tensão de $+200 \mathrm{~V}$ no eletrodo (figura 6.18) a redução do nível de flutuações em $I_{\text {sat }}$ é ainda menor, sendo novamente pouco perceptível no pino mais avançado. Já para tensão no eletrodo de $+150 V$ (6.19), praticamente não há redução alguma no grau de oscilações, o gráfico é semelhante ao apresentado na seção 5.11 do capitulo 5, para um disparo sem polarização no eletrodo. Contudo, como foi visto na seção anterior, há um pequeno aumento do gradiente no campo elétrico radial para tensão de $+150 \mathrm{~V}$ no eletrodo (figura 6.13), no entanto, tal valor possivelmente não é suficiente para destruir as correlações turbulentas 
$+150 \mathrm{~V}$
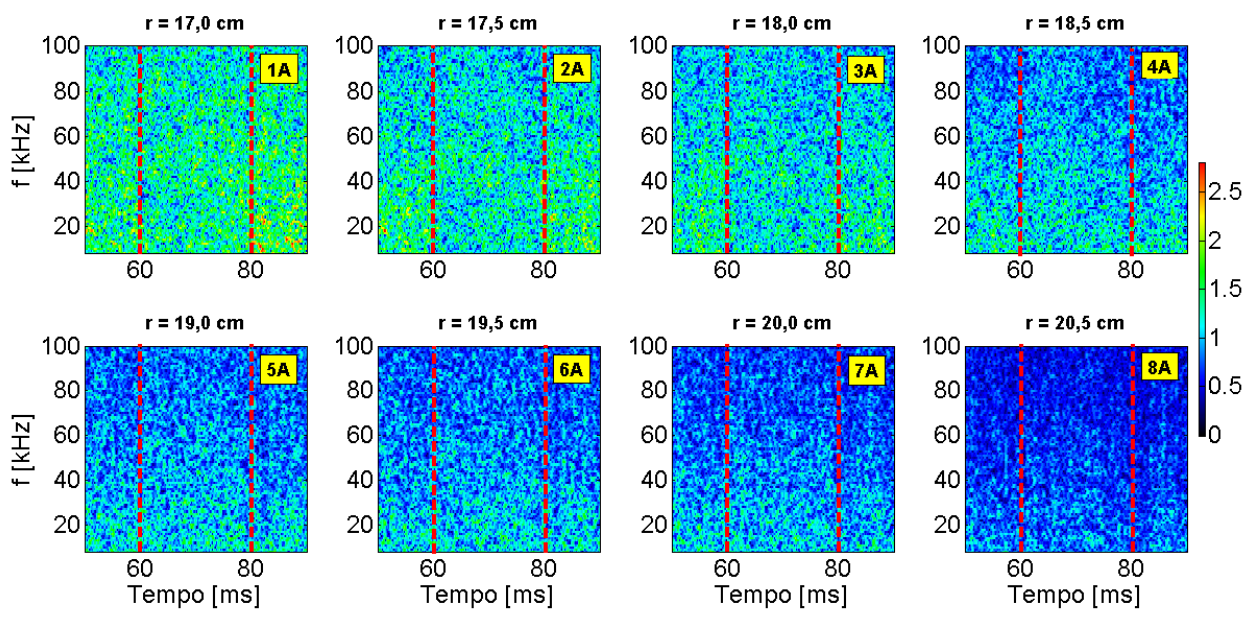

Figura 6.19: Espectrograma dos sinais de corrente de saturação de ions $\left(I_{\text {sat }}\right)$ dos oito pinos da fileira $A$ da sonda rake, entre 17,0 - 20,5 cm, com espaçamento de $5 \mathrm{~mm}$, em um disparo com polarização no eletrodo de $+150 \mathrm{~V}$ (disparo \#34105), entre 60-80 ms (linhas verticais tracejadas em vermelho).

induzindo, pois, uma redução nas flutuações, portanto não há condições para a formação de uma barreira de transporte, como de fato foi visto na seção 6.2.1.

\section{Sonda rake: potencial flutuante $\left(V_{f}\right)$}

O cisalhamento do fluxo de plasma também gera uma redução das flutuações eletrostáticas, que estão relacionadas com microinstabilidades na borda do plasma. O efeito, no entanto, se restringe a região de maior cisalhamento (maior gradiente do campo elétrico radial), entre aproximadamente $17,5-18,5 \mathrm{~cm}$. Em raios maiores o efeito é pouco intenso.

É apresentada a seguir a potência espectral dos sinais de potencial flutuante em forma de espectrograma dos oito pinos mais avançados na fileira A da rake: de 17,0-20,5 cm, com espaçamento entre eles de 5,0 mm, para disparos com o eletrodo nas polarizações: $+300 \mathrm{~V}$, $+250 \mathrm{~V},+200 \mathrm{~V}$ e $+150 \mathrm{~V}$.

Nota-se que para as tensões mais altas $(+300 \mathrm{~V}$ e $+250 \mathrm{~V})$ (figuras 6.20 e 6.21, respectivamente), a redução do nível de flutuações é bastante visível, principalmente para os pinos nas posições: $17,5 \mathrm{~cm}, 18,0 \mathrm{~cm}$ e 18,5 cm, que estão em uma região de alto cisalhamento, compatível com resultados apresentados anteriormente. Em $+300 \mathrm{~V}$ houve o surgimento de instabilidades MHD (faixa no espectrograma entre aproximadamente 65 - $75 \mathrm{~ms}$, na frequência $\sim 13 \mathrm{kHz}$ ), que dominou as oscilaçoes no intervalo em que apareceu, sendo suprimida só perto do final da polarização do eletrodo. O efeito é menos intenso nos pinos na região da camada-de-raspagem (scrape-off-layer) (maior do que $\sim 18,5 \mathrm{~cm}$ ). 


\section{$+300 \mathrm{~V}$}
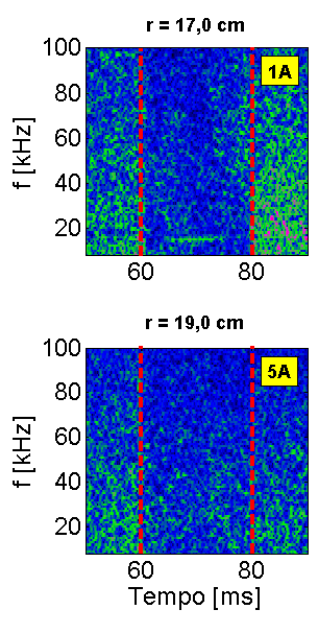
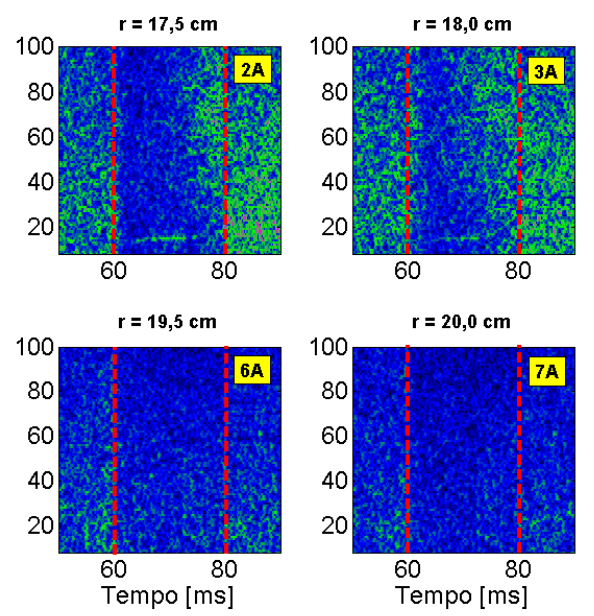

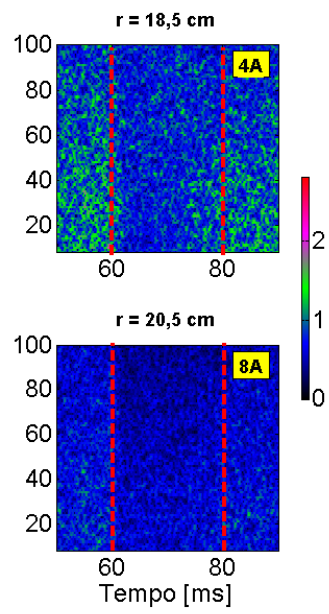

Figura 6.20: Espectrograma dos sinais de potencial flutuante $\left(V_{f}\right)$ dos oito pinos da fileira $A$ da sonda rake, entre 17,0 - 20,5 cm, com espaçamento de $5 \mathrm{~mm}$, em um disparo com polarização no eletrodo de $+300 \mathrm{~V}$ (disparo \#34113), entre 60-80 ms (linhas verticais tracejadas em vermelho).
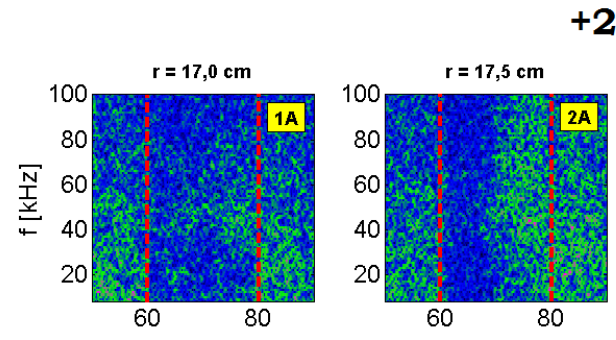

$+250 \mathrm{~V}$
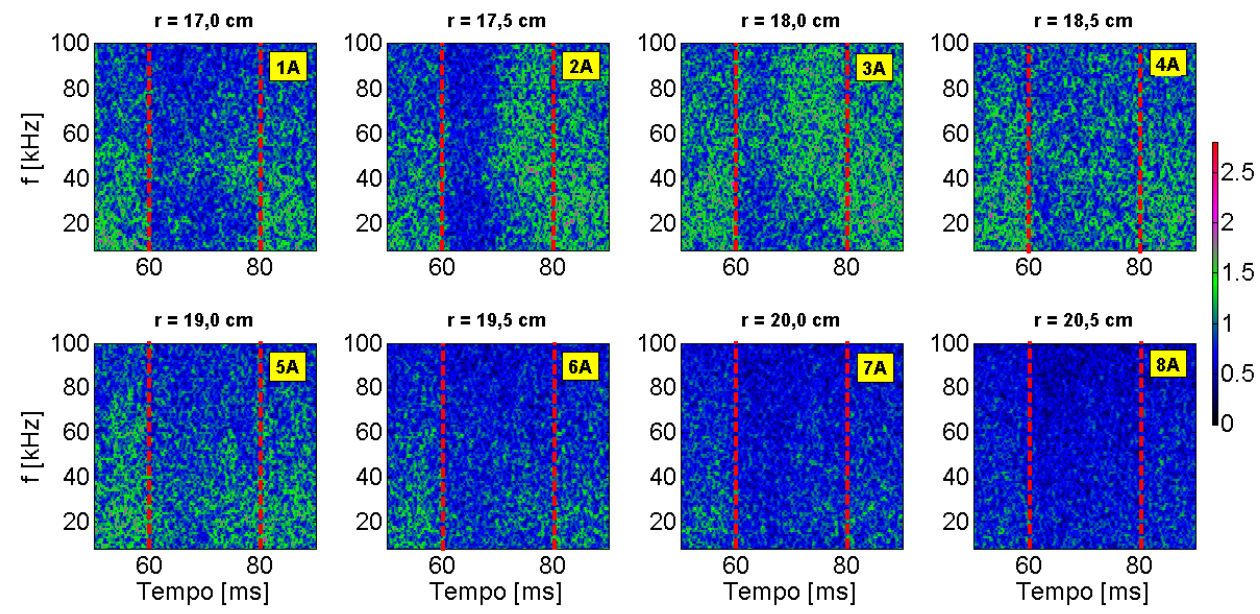

Figura 6.21: Espectrograma dos sinais de potencial flutuante $\left(V_{f}\right)$ dos oito pinos da fileira $A$ da sonda rake, entre 17,0 - 20,5 cm, com espaçamento de $5 \mathrm{~mm}$, em um disparo com polarização no eletrodo de $+250 \mathrm{~V}$ (disparo \#34111), entre 60-80 ms (linhas verticais tracejadas em vermelho)

Para as tensões mais baixas $(+200 \mathrm{~V}$ e $+150 \mathrm{~V})$, figuras 6.22 e 6.23 , respectivamente, a redução é bastante sutil, sendo um pouco visível para $+200 \mathrm{~V}$, principalmente para o segundo pino mais avançado, e praticamente inexistente para $+150 \mathrm{~V}$. Mostrando que esta tensão não é suficiente para destruir as correlações turbulentas. 

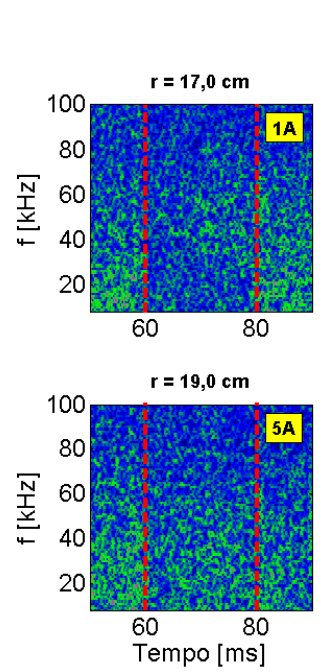
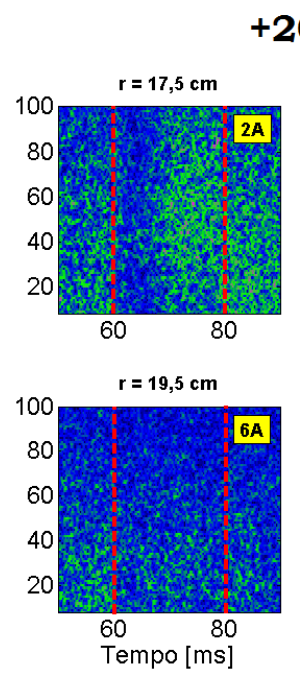

$200 \mathrm{~V}$
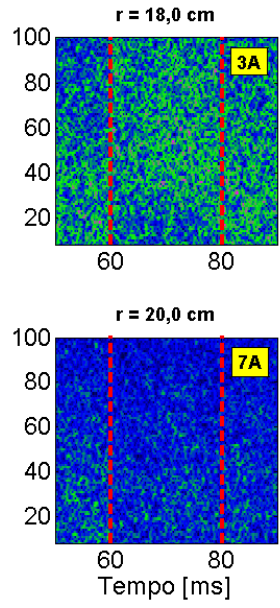

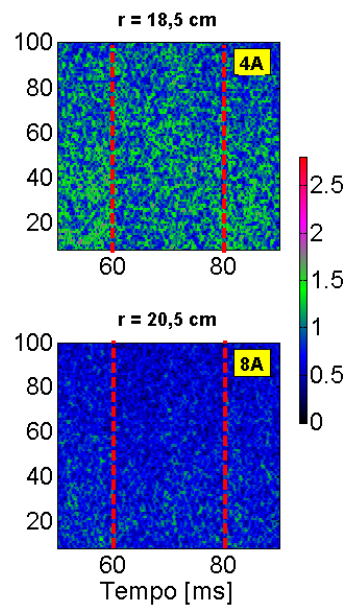

Figura 6.22: Espectrograma dos sinais de potencial flutuante $\left(V_{f}\right)$ dos oito pinos da fileira $A$ da sonda rake, entre 17,0 - 20,5 cm, com espaçamento de $5 \mathrm{~mm}$, em um disparo com polarização no eletrodo de $+200 \mathrm{~V}$ (disparo \#34112), entre 60-80 ms (linhas verticais tracejadas em vermelho)
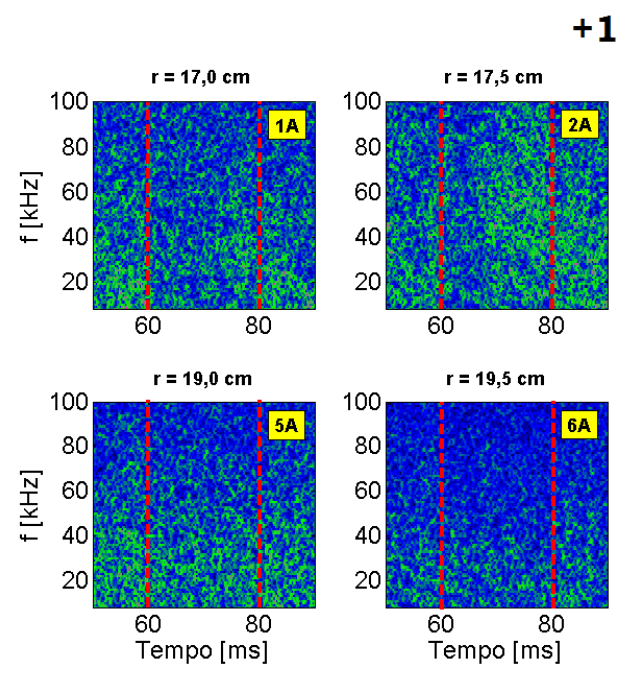

$+150 \mathrm{~V}$
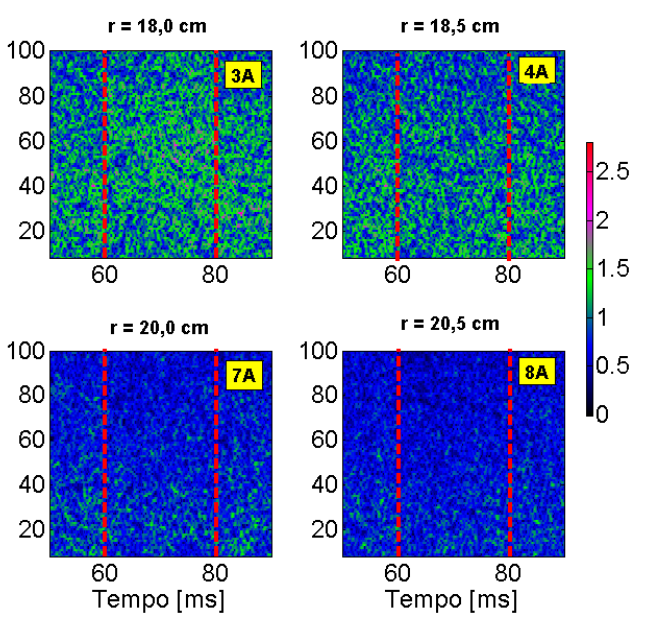

Figura 6.23: Espectrograma dos sinais de potencial flutuante $\left(V_{f}\right)$ dos oito pinos da fileira $A$ da sonda rake, entre 17,0 - 20,5 cm, com espaçamento de $5 \mathrm{~mm}$, em um disparo com polarização no eletrodo de $+150 \mathrm{~V}$ (disparo \#34110), entre 60-80 ms (linhas verticais tracejadas em vermelho)

Sonda de 5-pinos: potencial flutuante $\left(V_{f}\right)$, corrente de saturação de íons $\left(I_{s a t}\right)$ e campo elétrico poloidal $\left(E_{\theta}\right)$

As medidas com a sonda de 5-pinos foram realizadas na configuração de transporte de partículas (como discutido na seção 5.5). Nesse arranjo, três pinos medem $V_{f}$ e dois $I_{\text {sat }}$. Os pinos que medem $V_{f}$ estão espaçados poloidalmente, permitindo o cálculo aproximado do campo elétrico poloidal local. Já os pinos que medem $I_{\text {sat }}$ permitem a obtenção da série temporal de $n_{e}$, com as correções de $V_{f}$ (expansão da pré bainha) e de $T_{e}$, que é tomado como sendo um valor médio constante, já que todos os pinos da sonda nesse caso estão na mesma posição radial, na mesma superfície magnética, e $T_{e}$ não apresenta grandes alterações 
sob influência do eletrodo.

Nota-se pela figura 6.24, onde é apresentado, à direita, os espectrogramas dos sinais à esquerda, que de forma semelhante ao pino da sonda rake na posição $17,5 \mathrm{~cm}$ e o eletrodo na posição $17,0 \mathrm{~cm}$, com tensão de polarização de $300 \mathrm{~V}$ que há também uma redução nos níveis de flutuações de $V_{f}$ e $I_{\text {sat }}$ quando o eletrodo é polarizado. Bem como do campo elétrico poloidal, obtido da razão entre a diferença dos potenciais de plasma pela distância entre as sondas. Como visto na expressão (3.35), a redução da potência espectral de $n_{e}$ (obtida de $\left.I_{s a t}\right)$ e de $E_{\theta}$ está relacionada com a redução do transporte turbulento de partículas, levando em conta fatores que estão relacionados com a diferença de fase e a função de coerência entre os sinais.
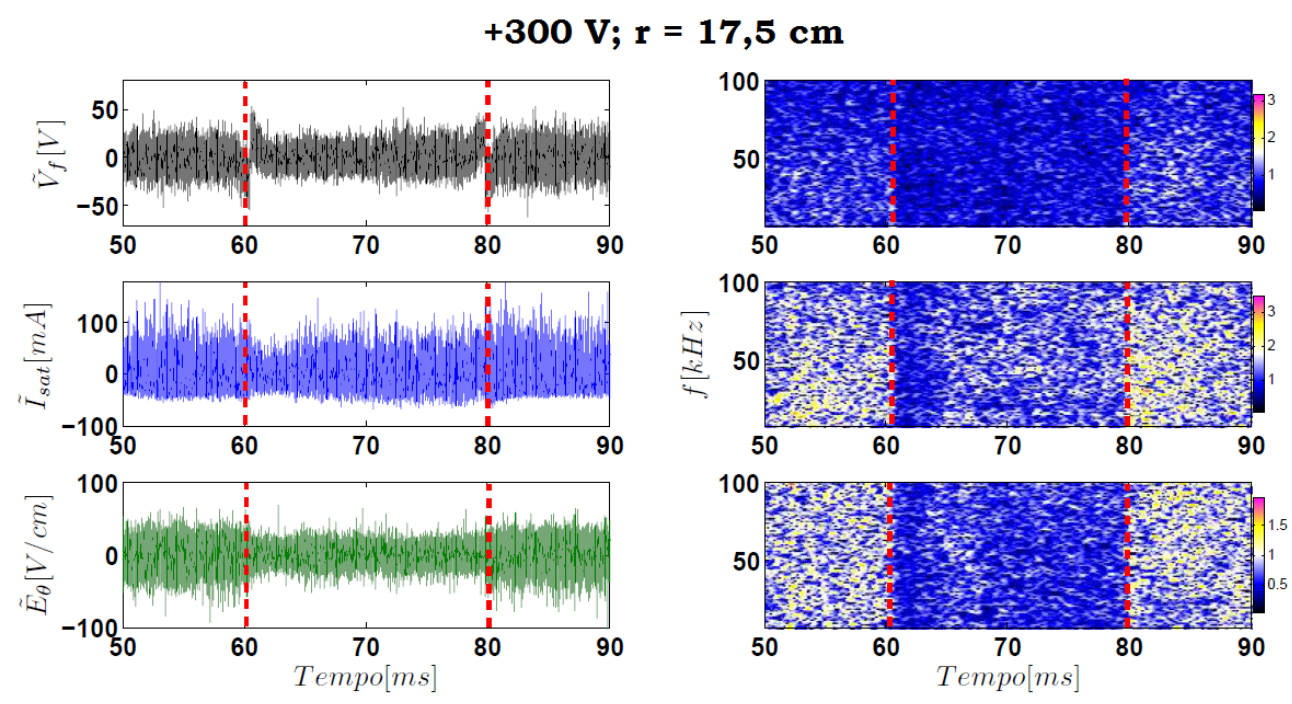

Figura 6.24: Espectrograma dos sinais de potencial flutuante $\left(V_{f}\right)$, corrente de saturação de ions $\left(I_{\text {sat }}\right)$ e campo elétrico poloidal $\left(E_{\theta}\right)$ medidos utilizando a sonda de 5-pinos, na pisição $17,5 \mathrm{~cm}$, em um disparo com polarização no eletrodo de $+300 \mathrm{~V}$ (disparo \#32928), entre 60-80 ms (linhas verticais tracejadas em vermelho)

A figura 6.25 mostra um exemplo de como a aplicação do eletrodo muda a fase entre os sinais de $n_{e}$ e $E_{\theta}$ e altera a função de coerência (no caso o quadrado dela), para o mesmo disparo discutido anteriormente: eletrodo em $17,0 \mathrm{~cm}$ com polarização de $+300 \mathrm{~V}$ e sonda em $17,5 \mathrm{~cm}$.

Nota-se que antes da polarização no eletrodo a diferença de fase está em torno de $\pi$ e a coerência ao quadrado próxima de 1.Porém, durante a polarização, a diferença de fase passa a ficar entre $-\pi$ e $\pi$ e a coerência ao quadrado fica menor do que antes. Essa variação, juntamente com a redução da potência espectral de $n_{e}$ e $E_{\theta}$, indicam uma diminuição do nível de transporte turbulento de partículas (segundo a expressão 3.35), como será visto na próxima seção. 

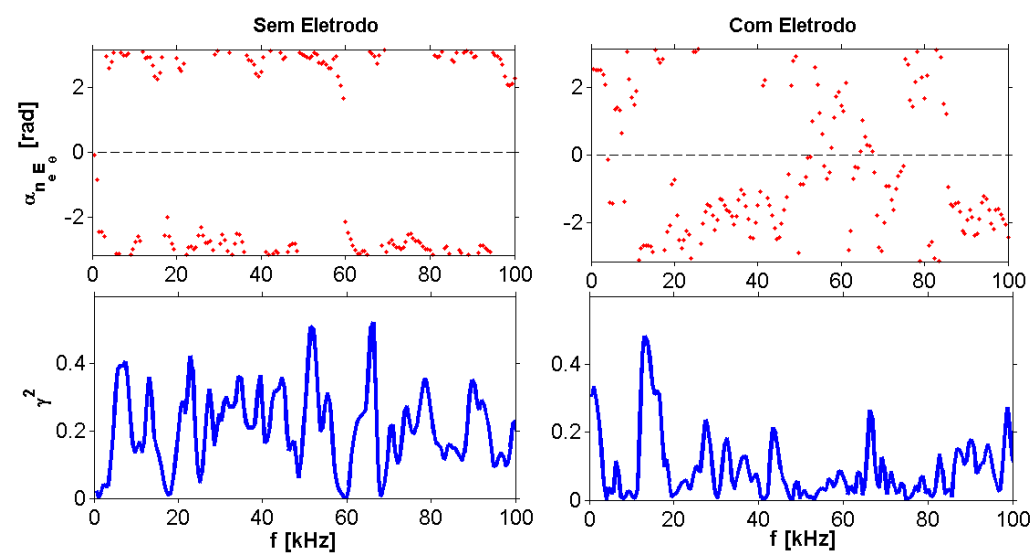

Figura 6.25: Diferença de fase e espectro de coerência ao quadrado entre $n_{e}$ e $E_{\theta}$ com (à direira) e sem (à esquerda) a polarização de $+300 \mathrm{~V}$ no eletrodo (disparo \#32928), medidos utilizando a sonda de 5-pinos em $17,5 \mathrm{~cm}$.

\subsubsection{Efeito do eletrodo no transporte de partículas}

Foi visto nas últimas seções que quando o eletrodo é polarizado em $+300 \mathrm{~V}$ na posição $17,0 \mathrm{~cm}$ há um aumento do gradiente do campo elétrico radial na borda, provocando um cisalhamento no fluxo de plasma, que gera uma redução no nível de flutuações na borda e cria uma barreira de transporte. Logo, é esperado que em consequência desses efeitos haja também uma redução do transporte turbulento de partículas na borda. Na seção anterior já foi possível ter uma pista de que isso realmente acontece, com a diminuição da potência espectral de $n_{e}$ e $E_{\theta}$, além da coerência e da fase relativa, que passa a ficar em valores intermediários ente 0 e $\pi$.

É apresentado a seguir na figura 6.26 o espectrograma da densidade espectral de transporte (parte de cima), função $T(f)$, e o transporte turbulento total de partículas (parte de baixo), obtido integrando a densidade espectral de transporte em todas as frequência para cada janela de tempo, em um disparo com tensão no eletrodo de $+300 \mathrm{~V}$. Nota-se que quando o eletrodo é polarizado (entre 60 - $80 \mathrm{~ms}$ ) há uma grande redução do transporte turbulento de partículas na direção radial, que é praticamente zerado. Tal resultado corrobora com os resultados anteriores, sendo uma indicação forte de que de fato está havendo uma melhora no confinamento do plasma.

Para tensão de $+250 \mathrm{~V}$ no eletrodo (figura 6.27), o transporte cai de maneira abrupta quando ele é polarizado, no entanto perto de $65 \mathrm{~ms}$ ele passa a aumentar novamente, mas abaixo ainda dos níveis iniciais, retornando apenas em $80 \mathrm{~ms}$. Tal efeito será discutido com mais detalhe no próximo capítulo, há uma forte degradação do confinamento em alguns disparos, mesmo antes da aplicação da polarização no eletrodo, sem que haja uma instabilidade significativa no plasma. 


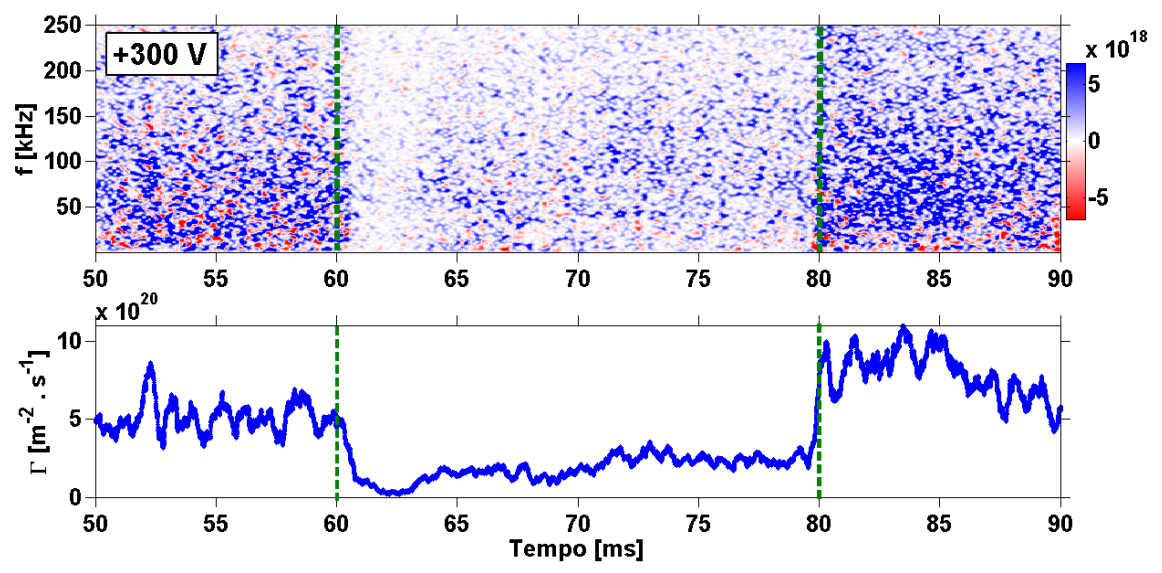

Figura 6.26: Gráfico do transporte radial turbulento de partículas obtido de medidas com a sonda de 5-pinos localizada em $17,5 \mathrm{~cm}$, em um disparo com eletrodo polarizado em $+300 \mathrm{~V}$ (disparo \#32928), entre 60-80 ms. Na parte de cima é apresentado o espectrograma da densidadde espectral de transporte em um gráfico de cores, em que azul indica transporte para fora e vermelho transporte para dentro, enquanto que o branco é a ausência de transporte. Na parte de baixo é mostrada a evolução temporal do transporte turbulento total na direção radial, obtido integrando $T(f)$ em todas as frequências.
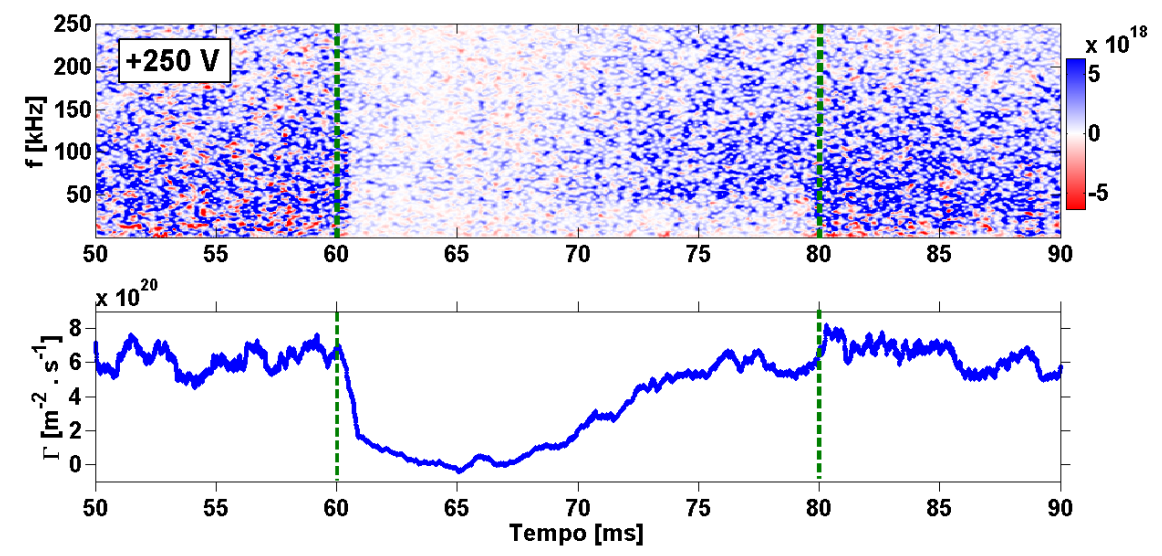

Figura 6.27: Gráfico do transporte radial turbulento de partículas obtido de medidas com a sonda de 5-pinos localizada em $17,5 \mathrm{~cm}$, em um disparo com eletrodo polarizado em $+250 \mathrm{~V}$ (disparo \#34027), entre 60-80 ms. Na parte de cima é apresentado o espectrograma da densidadde espectral de transporte em um gráfico de cores, em que azul indica transporte para fora e vermelho transporte para dentro, enquanto que o branco é a ausência de transporte. Na parte de baixo é mostrada a evolução temporal do transporte turbulento total na direção radial, obtido integrando $T(f)$ em todas as frequências.

Para tensão de +200 V (figura 6.28) no eletrodo a redução no transporte é menor, porém ainda ocorre; compatível com os resultados anteriores: redução da turbulência e criação da barreira de transporte.

E por fim, de forma compatível aos resultados anteriores, quando a tensão no eletrodo é de $+150 V$ (figura 6.29), a redução do transporte é pouco intensa, devido a pequena redução do nível de flutuações provocada por ele, e por, consequencia, não há indícios da criação de uma barreira de transporte para essa tensão. 


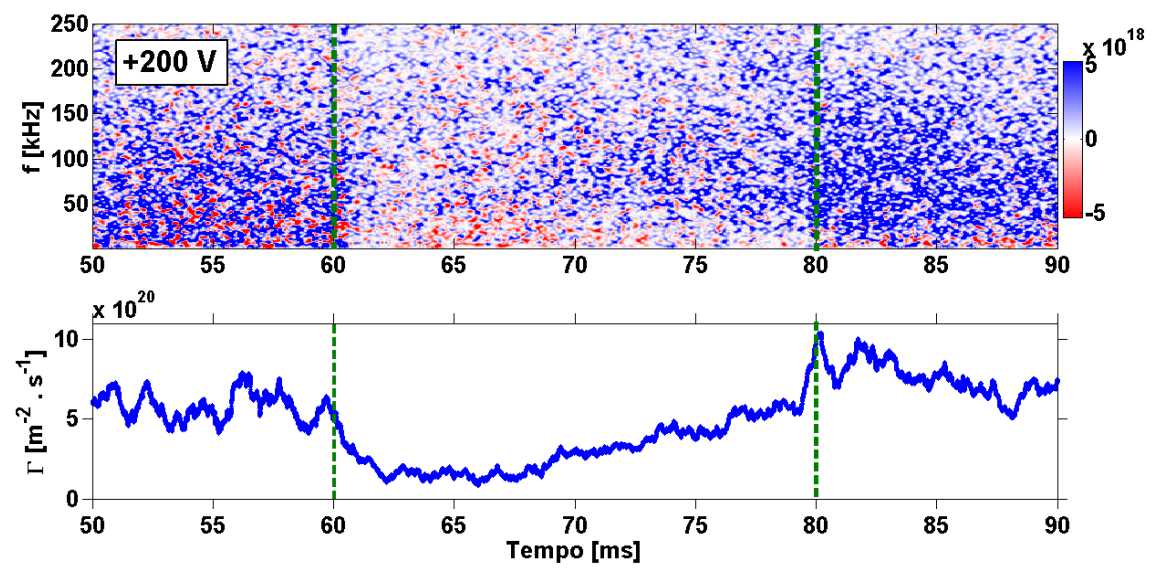

Figura 6.28: Gráfico do transporte radial turbulento de partículas obtido de medidas com a sonda de 5-pinos localizada em $17,5 \mathrm{~cm}$, em um disparo com eletrodo polarizado em $+200 \mathrm{~V}$ (disparo \#34025), entre 60-80 ms. Na parte de cima é apresentado o espectrograma da densidadde espectral de transporte em um gráfico de cores, em que azul indica transporte para fora e vermelho transporte para dentro, enquanto que o branco é a ausência de transporte. Na parte de baixo é mostrada a evolução temporal do transporte turbulento total na direção radial, obtido integrando $T(f)$ em todas as frequências.
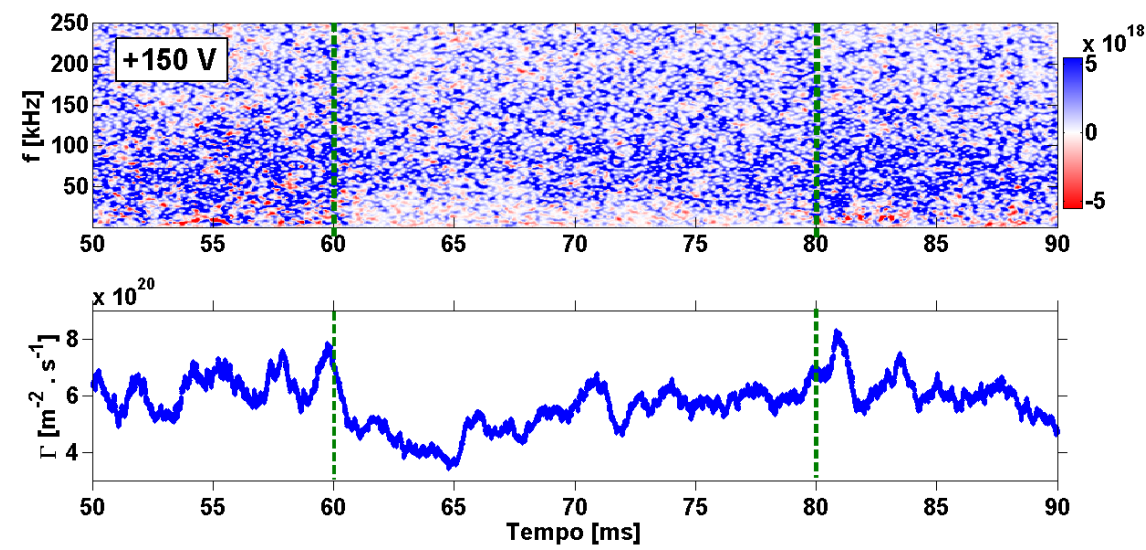

Figura 6.29: Gráfico do transporte radial turbulento de partículas obtido de medidas com a sonda de 5-pinos localizada em 17,5 cm, em um disparo com eletrodo polarizando em $+150 \mathrm{~V}$ (disparo \#34015), entre 60-80 ms. Na parte de cima é apresentado o espectrograma da densidadde espectral de transporte em um gráfico de cores, em que azul indica transporte para fora e vermelho transporte para dentro, enquanto que o branco é a ausência de transporte. Na parte de baixo é mostrada a evolução temporal do transporte turbulento total na direção radial, obtido integrando $T(f)$ em todas as frequências.

Na figura 6.30 é mostrado um resumo do transporte turbulento de partículas para as quatro tensões no eletrodo consideradas, com o espectrograma da densidade espectral de transporte; todos os gráficos estão na mesma escala de cores. No gráfico fica mais claro que a redução do transporte é tanto maior quanto maior é a tensão no eletrodo.

O transporte turbulento de partículas, no entanto, pode vir a aumentar, mesmo antes do final da polarização no eletrodo. Na figura 6.27 é mostrado um disparo no qual o transporte aumenta antes do final da polarização do eletrodo, porém o motivo de tal aumento não é tão claro, pode ser devido a pequenas mudanças em parâmetros globais do plasma, 

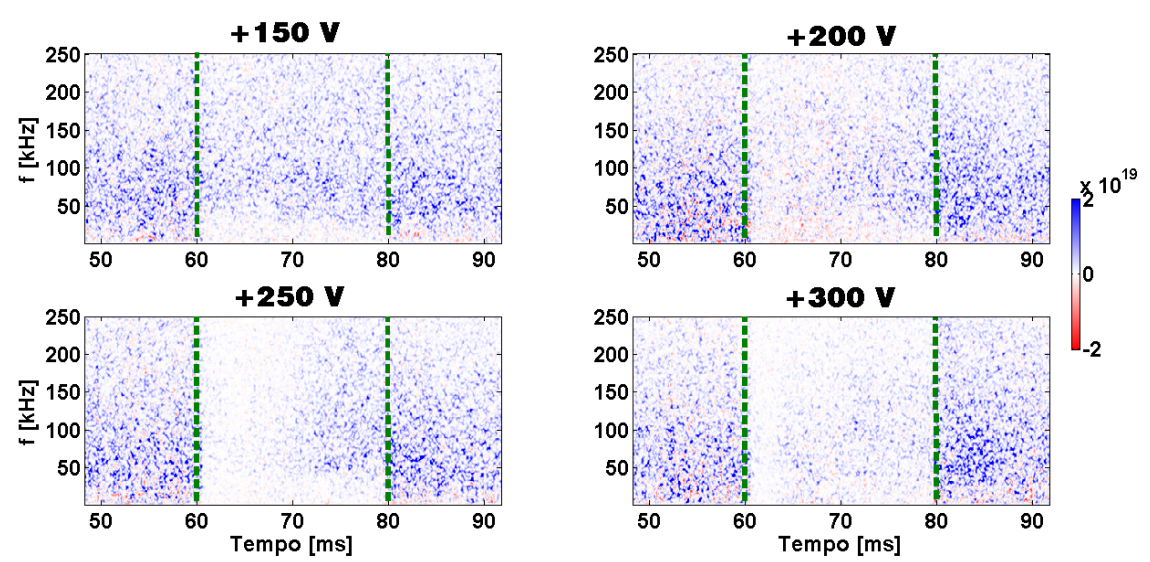

Figura 6.30: Espectrograma da densidade espectral de transporte para as tensões de polarização no eletrodo consideradas: $+150 \mathrm{~V},+200 \mathrm{~V},+250 \mathrm{~V} e+300 \mathrm{~V}$. Medidas realizadas com a sonda de 5-pinos em $r=17,5 \mathrm{~cm}$. No gráfico as cores indicam, azul transporte para fora e vermelho transporte para dentro, enquanto que o branco é a ausência de transporte.

como a sua corrente total, alterações na sua densidade ou aumento de impurezas. Contudo, instabilidades no plasma também podem degradar o confinamento, gerando um aumento do transporte turbulento. Uma dessas instabilidades são os ELMs (Edge-localized mode), que aparecem em muitas máquinas (inclusive em stellarators) [23] quando é induzido o modo H. No entanto, até o momento não há indícios de ELMs no TCABR. Outra instabilidade comum em tokamaks, que é bastante normal no TCABR, é a chamada instabilidade MHD. Geralmente com frequência bem definida $(\sim 13 \mathrm{kHz})$, essas instabilidades estão relacionadas com ilhas magnéticas na borda e impurezas. Para tensões altas no eletrodo (acima de $+300 \mathrm{~V}$ ) é comum o seu aparecimento no TCABR. O resultado é uma forte degradação do confinamento, como pode ser visto na figura 6.31 .

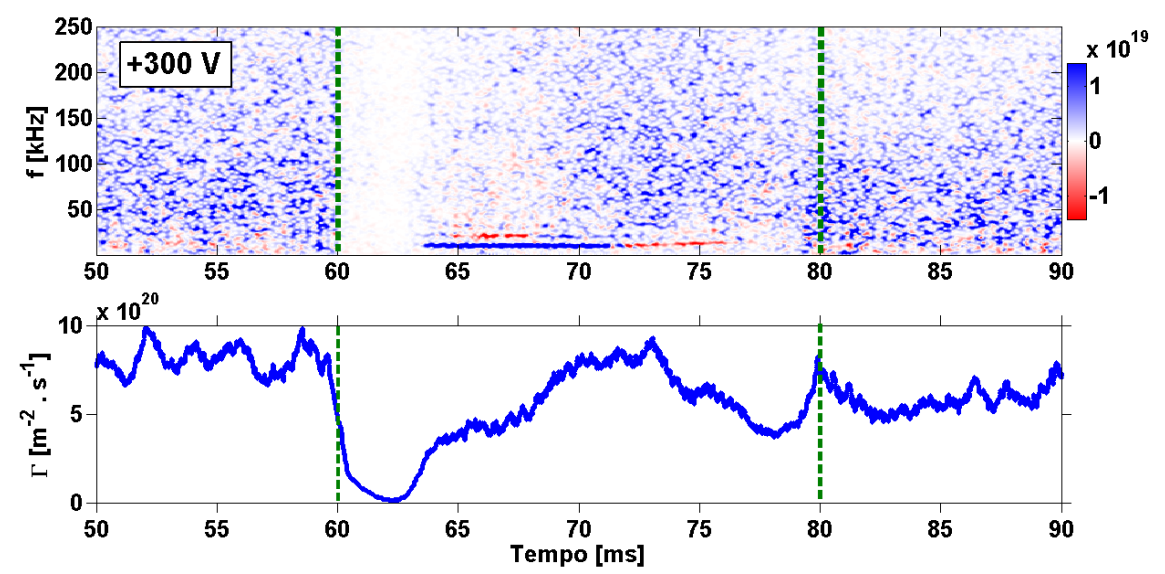

Figura 6.31: Gráfico do transporte radial turbulento de partículas obtido de medidas com a sonda de 5-pinos localizada em 17,5 cm, em um disparo com eletrodo polarizando em $+300 \mathrm{~V}$ (\#34016), entre 60-80 ms, no qual ocorre intensa atividade MHD durante a polarização. Na parte de cima é apresentado o espectrograma da densidadde espectral de transporte em um gráfico de cores, em que azul indica transporte para fora e vermelho transporte para dentro, enquanto que o branco é a ausência de transporte. Na parte de baixo é o transporte turbulento total na direção radial, obtido integrando $T(f)$ em todas as frequências. 
É possível notar (figura 6.31) que quando o eletrodo é aplicado há uma grande redução do transporte turbulento de partículas, que se mantém até por volta de $63 \mathrm{~ms}$, quando surge uma forte instabilidade MHD que degrada o confinamento, com uma alta contribuição do transporte para fora na frequência de $\sim 13 \mathrm{kHz}$. Antes do final da polarização no eletrodo, quando a instabilidade MHD desaparece, há novamente uma pequena redução do transporte, que volta a subir ao término da polarização.

\subsection{Função $\mathrm{S}(\mathrm{k}, \mathrm{f})$ e velocidade poloidal}

A função $\mathrm{S}(\mathrm{k}, \mathrm{f})$ permite o estudo das flutuações no espaço e no tempo em um determinado meio. Por conta da característica turbulenta da borda do plasma, existem diferentes modos de oscilação para diferentes números de ondas, que se relacionam de maneira não linear. Quando o eletrodo é aplicado, no entanto, ele gera um cisalhamento no fluxo de plasma, destruindo as correlações turbulentas na borda. Como efeito, é esperado que haja uma redução dos possíveis modos de oscilação, com a possibilidade da criação de fluxos característicos como fluxos zonais ("zonal flows") (que é reportado no TCABR [39]), em que as flutuações eletromagnéticas possuem números de onda poloidal e toroidal bem definidos, em torno de zero.

A seguir é discutido o efeito do eletrodo na função $\mathrm{S}(\mathrm{k}, \mathrm{f})$ para diferentes polarizações. Os sinais são de $V_{f}$ obtidos da sonda de 5-pinos na posição 18, $0 \mathrm{~cm}$ (borda do plasma).

Na figura 6.32 é mostrado $\mathrm{S}(\mathrm{k}, \mathrm{f})$ de um sinal de $V_{f}$ na borda, antes e durante a polarização de $+300 V$ no eletrodo; na parte de cima é mostrado o sinal de $V_{f}$, destacando as duas regiões em que $S(k, f)$ foi calculada. Nota-se que antes do eletrodo a função $S(k, f)$ é mais espalhada em números de onda, porém, quando o eletrodo é aplicado ela passa a ser mais estreita em torno de $k_{\theta} \approx 0$ e com intensidade menor, indicando que os modos de propagação são reduzidos e, assim, uma diminuição da turbulência. Além disso, nota-se que o gráfico como um todo é levemente deslocado para a esquerda quando o eletrodo é aplicado, indicando uma mudança na velocidade de fase poloidal local. O valor estimado para tal mudança é: $\Delta v_{\theta}=v_{\theta}^{d}-v_{\theta}^{a}=[15,7(1)-6,5(1)]=9,2 \pm 0,1 \mathrm{~km} / \mathrm{s}$ (o cálculo de $\bar{v}_{\theta}$ é discutido na sessão 5.6), e também é apresentado no gráfico 6.33; onde foi levado em conta a expressão (3.47) descrita no capitulo 3. Portanto, podemos concluir que o gradiente do campo elétrico radial provoca um aumento da velocidade de fase poloidal local e um cisalhamento no fluxo de plasma.

Para tensão de $+250 \mathrm{~V}$ no eletrodo (figura 6.34) o efeito também é claro: há uma diminuição e um estreitamento de $\mathrm{S}(\mathrm{k}, \mathrm{f})$. A variação da velocidade de fase poloidal nesse caso é: $\Delta v_{\theta} \approx[13,2(1)-6,5(1)] \mathrm{km} / \mathrm{s}=6,7 \pm 0,1 \mathrm{~km} / \mathrm{s}$. 

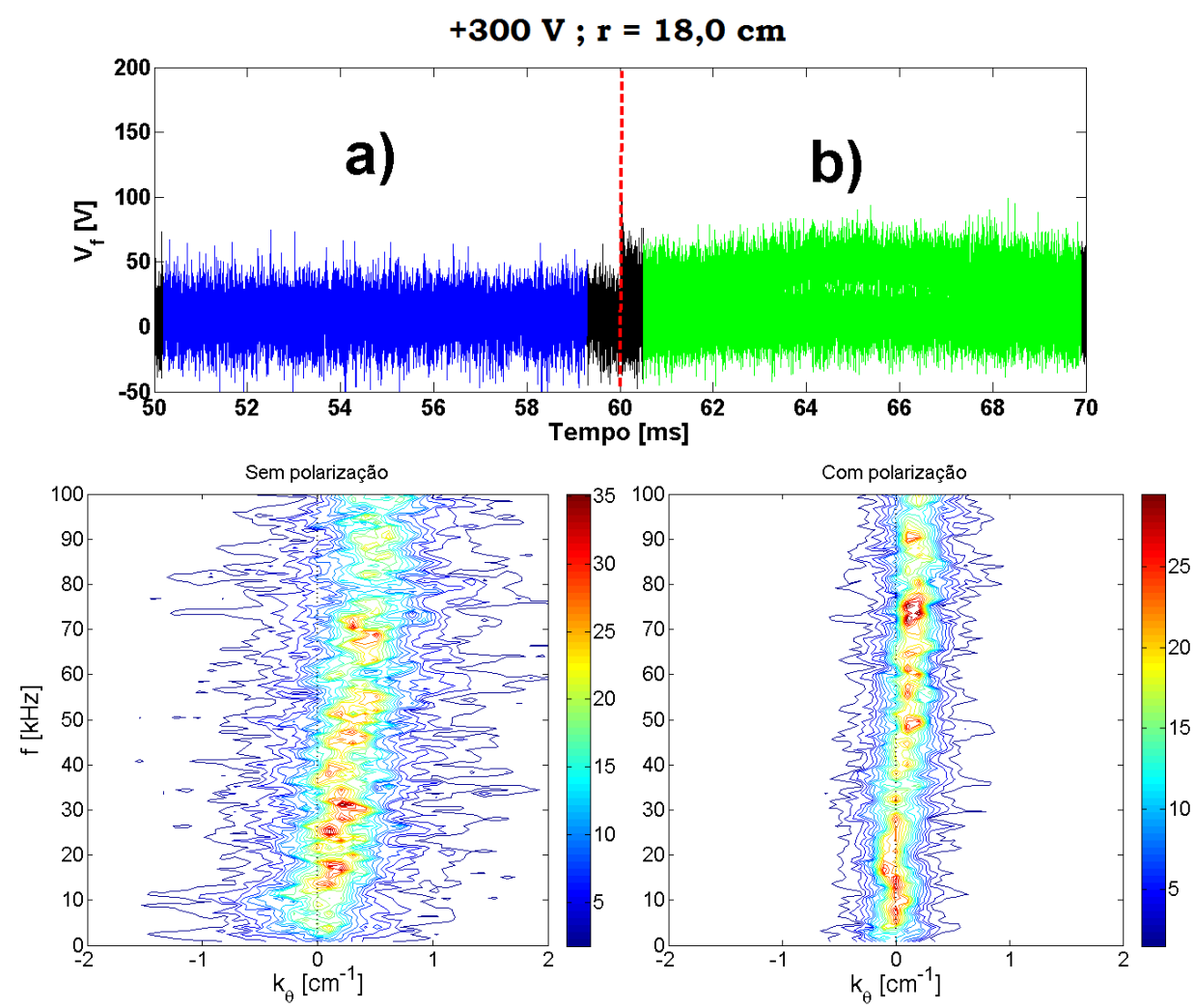

Figura 6.32: Função $S(k, f)$ de dois sinais de potêncial flutuante medidos na "borda"do plasma $(18,0 \mathrm{~cm})$ com a sonda de 5-pinos durante um disparo com polarização de $+300 \mathrm{~V}$ no eletrodo (disparo \#32927). Na parte de cima é mostrado um sinal de $V_{f}$, onde foram destacadas duas regiões em que foram feitos os cálculos de $S(k, f)$ : a) intervalo antes do eletrodo e b) intervalo durante o eletrodo. Na parte de baixo são apresentados os resultados para $S(k, f)$, em gráficos de cores.
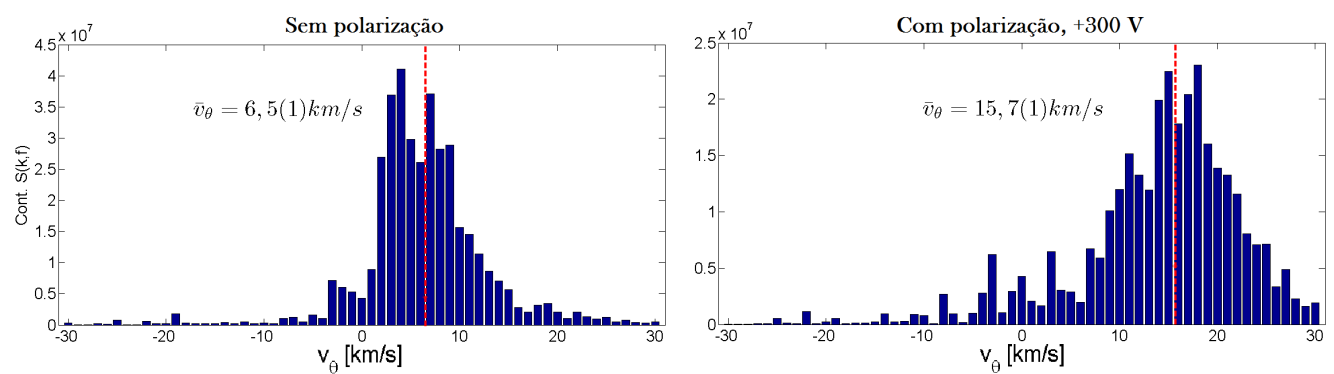

Figura 6.33: Velocidade de fase poloidal obtida a partir da função $S(k, f)$, antes (esquerda) e durante (direita) a polarização de $+300 \mathrm{~V}$ (disparo \#32927) no eletrodo. As barras verticais tracejadas indicam as velocidades médias.

Em $+200 V$ (figura 6.35) o efeito do eletrodo é menos intenso, o valor de $\mathrm{S}(\mathrm{k}, \mathrm{f})$ se altera pouco, ficando levemente estreito e inclinado. A variação da velocidade de fase poloidal é: $\Delta v_{\theta} \approx[11,5(1)-6,9(1)] \mathrm{km} / \mathrm{s}=4,6 \pm 0,1 \mathrm{~km} / \mathrm{s}$.

O efeito do eletrodo polarizado em $+150 \mathrm{~V}$ em $\mathrm{S}(\mathrm{k}, \mathrm{f})$ é bastante sutil (como pode ser visto na figura 6.36). A variação de velocidade de fase poloidal é de: $\Delta v_{\theta} \approx[10,6(1)-$ $6,9(1)] \mathrm{km} / \mathrm{s}=3,7 \pm 0,1 \mathrm{~km} / \mathrm{s}$. Como discutido nas sessões anteriores, para tensão de +150 $\mathrm{V}$ praticamente não há mudanças significativas que levam uma melhora no confina- 


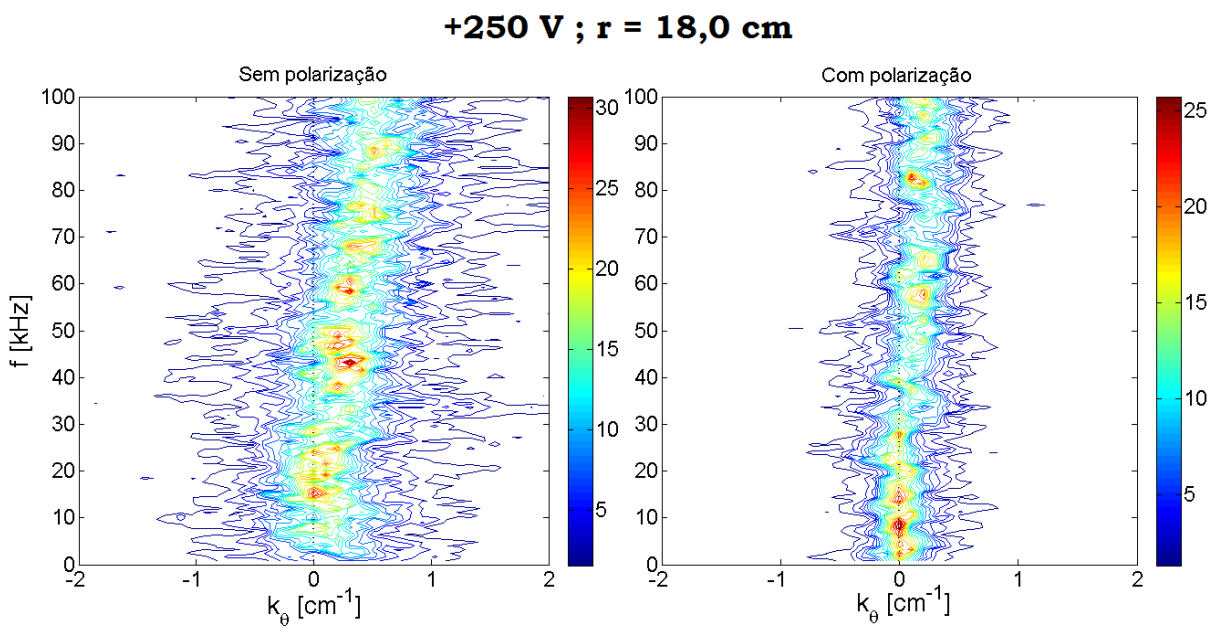

Figura 6.34: Função $S(k, f)$ de dois sinais de potêncial flutuante medidos na "borda" do plasma $(18,0 \mathrm{~cm})$ com a sonda de 5-pinos durante um disparo com polarização de $+250 \mathrm{~V}$ (disparo \#32922) no eletrodo. A esquerda antes da polarização (50-60 ms) e a direira durante a polarização (60-70 $m s)$.

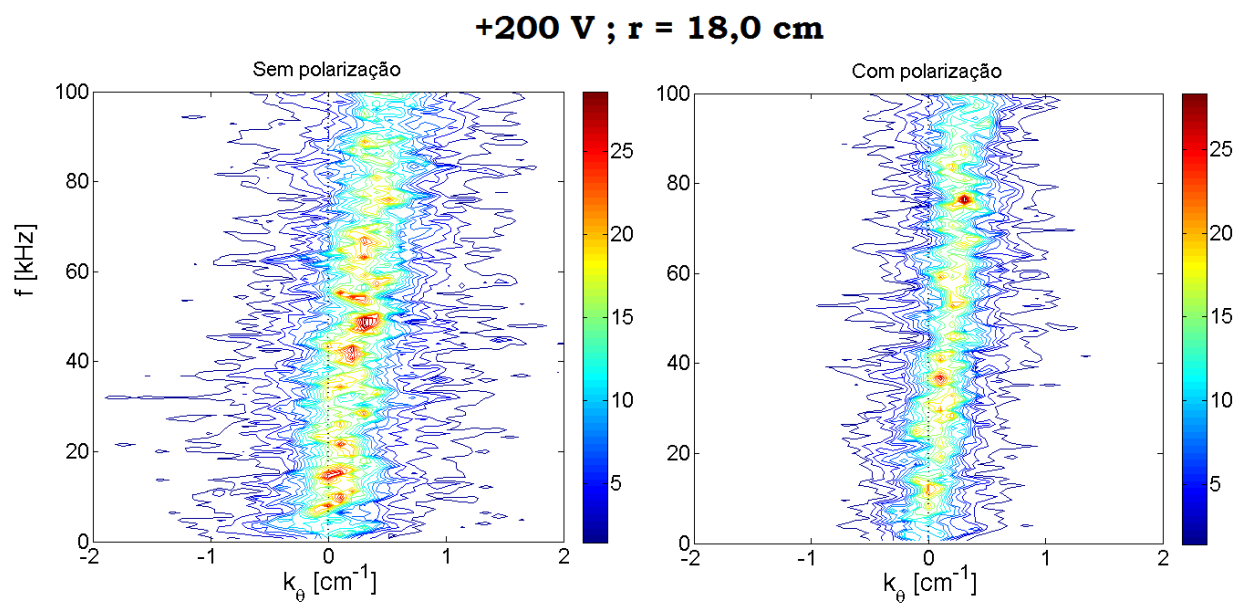

Figura 6.35: Função $S(k, f)$ de dois sinais de potêncial flutuante medidos na "borda" do plasma $(18,0 \mathrm{~cm})$ com a sonda de 5-pinos durante um disparo com polarização de $+200 \mathrm{~V}$ (disparo \#32920) no eletrodo. A esquerda antes da polarização $(50-60 \mathrm{~ms})$ e a direira durante a polarização (60-70 ms).

mento do plasma, não é notado barreira de transporte e não há uma queda relevante da turbulência e do transporte turbulento de partícula. De fato, o cisalhamento é pouco intenso (como pode ser visto por $\Delta v_{\theta}$ ). 


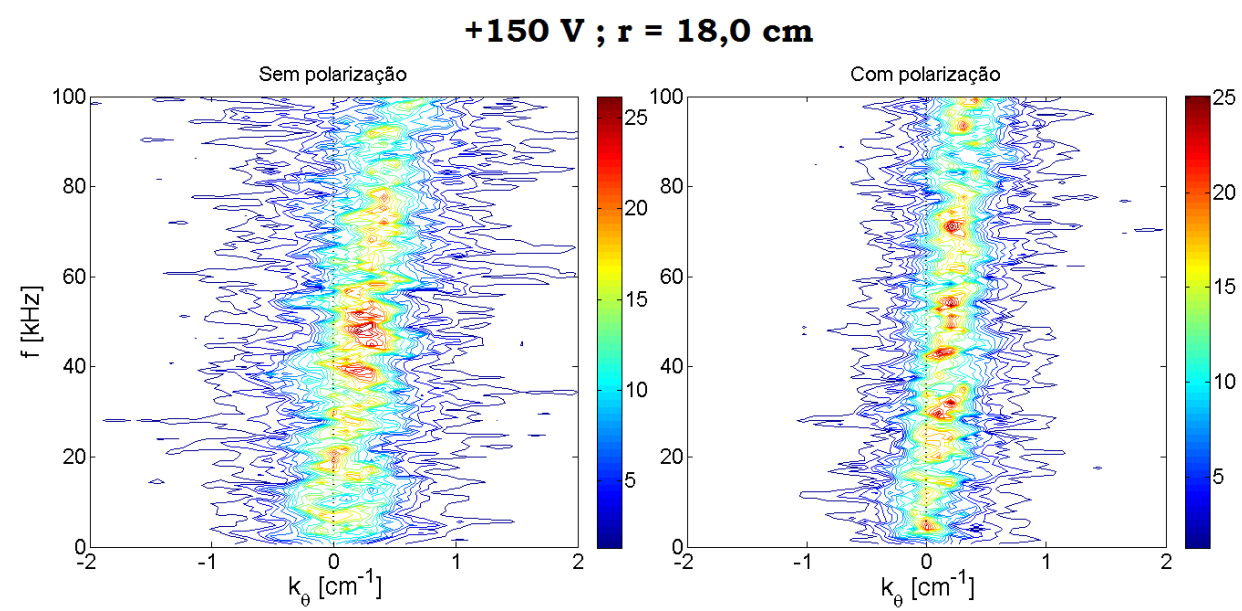

Figura 6.36: Função $S(k, f)$ de dois sinais de potêncial flutuante medidos na "borda"do plasma $(18,0 \mathrm{~cm})$ com a sonda de 5-pinos durante um disparo com polarização de $+150 \mathrm{~V}$ (disparo \#32919) no eletrodo. A esquerda antes da polarização (50-60 ms) e a direira durante a polarização (60-70 $m s)$. 


\section{Capítulo 7}

\section{Evolução temporal da transição para confinamento melhorado}

A aplicação de um eletrodo polarizado na borda do plasma no TCABR induz uma melhora de confinamento (como visto na capitulo 6). A tensão aplicada no eletrodo cria uma corrente elétrica entre ele e o limitador, gerando um alto gradiente no campo elétrico radial local, que provoca um cisalhamento no fluxo de plasma. Por consequência disso, há uma grande diminuição do nível de flutuações dos sinais de potencial flutuante $\left(V_{f}\right)$ e corrente de saturação de íons $\left(I_{\text {sat }}\right)$, indicando uma diminuição do grau de turbulência, além de uma redução clara no transporte turbulento radial de partículas. A linhal central de densidade medida pelo interferômetro tem um significativo aumento (de até um fator 2 em outros trabalhos), enquanto que a linha espectral de $H_{\alpha}$ cai de maneira expressiva, indicando diminuição da taxa de reciclagem ou quantidade de partículas escapando do confinamento. Somado a tudo isso, o perfil de densidade eletrônica muda de maneira significativa na borda, tornando-se mais íngreme nessa região, compatível com a criação de uma barreira de transporte.

No entanto, a maneira como ocorre esses efeitos ainda não é completamente entendida. Particularmente, em que condições ocorre a transição? Qual é a ordem de ocorrência dos efeitos? É sabido que a polarização do eletrodo é o "gatilho"para o efeito, mas o aumento do campo elétrico precede ou sucede a diminuição da turbulência? Além disso, em que condições é formada uma barreira de transporte neste caso, ela se mantém durante todo o tempo em que o eletrodo é polarizado? E o gradiente do campo elétrico? Com objetivo de tentar dar uma resposta a essas perguntas, neste capítulo será estudada a evolução temporal de parâmetros do plasma obtidos, como $V_{p}, E_{r}, n_{e}$ e transporte turbulento de partículas.

\subsection{Evolução temporal de $V_{p}$ e $E_{r}$}

O perfil de potencial de plasma $\left(V_{p}\right)$ é obtido dos perfis de potencial flutuante $\left(V_{f}\right)$ e de temperatura eletrônica $\left(T_{e}\right)$. No entanto, como visto, a temperatura pouco se altera 
sob influência do eletrodo. Dessa forma, considerou-se o perfil médio de $T_{e}$. Logo, qualquer mudança em $V_{p}$, deve-se a mudanças em $V_{f}$. Com a finalidade de também estudar a evolução temporal de $E_{r}$, foi calculado seu valor a partir de $V_{p}$, usando a aproximação: $E_{r} \approx-\Delta V_{p} / d$, onde $d$ é a distância radial de separação entre sinais de $V_{f}$.

Como visto na seção 6.2.3, no intervalo em que o eletrodo é polarizado o perfil médio de $V_{p}$ muda, tornando-se mais íngreme na região mais interna do plasma e, praticamente, não se altera na região mais externa. No entanto essa condição não se mantém em todo o tempo em que o eletrodo é polarizado, há um aumento abrupto logo que ele é acionado, chegando a um valor máximo em torno de 65 ms. Porém, a situação vai se deteriorando antes do final da polarização, como pode ser visto na figura 7.1, onde foram feitas médias de $V_{p}$ em janelas de $5 \mathrm{~ms}$, antes, durante e depois da polarização do eletrodo.

\section{$+250 \mathrm{~V}$}
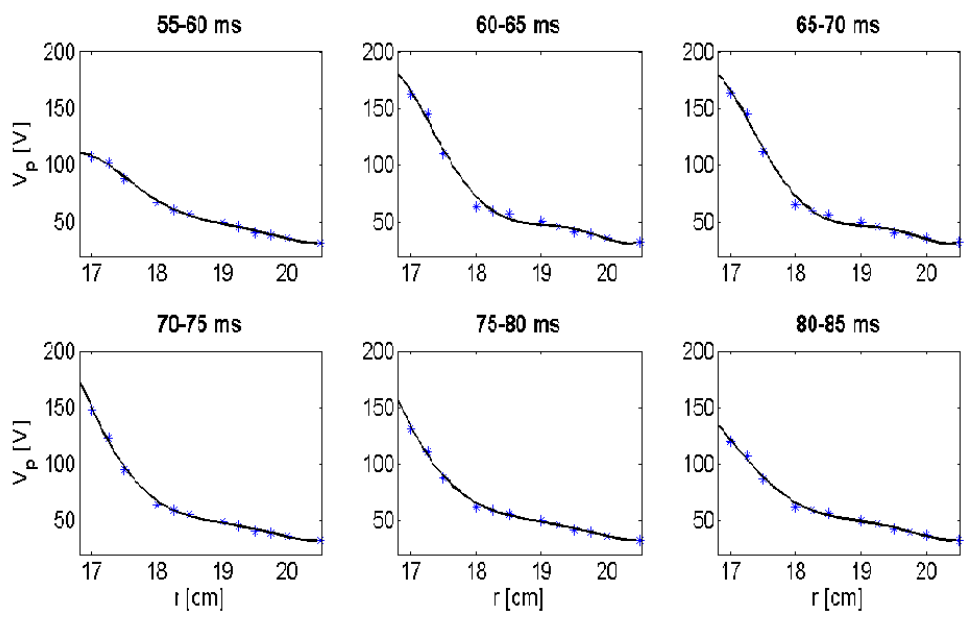

Figura 7.1: Evolução temporal do perfil de potencial de plasma $V_{p}$ em um disparo com $+250 \mathrm{~V}$ no eletrodo (\#34142). Polarização aplicada entre 60-80 ms.

A situação pode ser vista com maior clareza tomando a média em janelas temporais ainda menores. Nesse caso o mais conveniente é representar a evolução temporal de $V_{p}$ em um gráfico de cores (figura 7.2). Nota-se que quando o eletrodo é polarizado, em torno de $60 \mathrm{~ms}$, há um aumento súbito acentuado nos três sinais mais internos. O efeito se mantém intenso até por volta de $70 \mathrm{~ms}$, quando começa haver uma redução gradativa até $80 \mathrm{~ms}$ (final da polarização), retornando a condição inicial antes da polarização.

O efeito é semelhante para $E_{r}$. Por conta do aumento de $V_{p}$ na região mais interna e como consequência, surge um elevado gradiente no campo elétrico radial nessa região; tal efeito é responsável pelo cisalhamento do fluxo de plasma. Acompanhando a evolução de $V_{p}, E_{r}$ também não se mantém íngreme e intenso em todo o intervalo em que o eletrodo é polarizado (figura 7.3). Há um aumento abrupto logo que o eletrodo é acionado, em torno de $60 \mathrm{~ms}$, que se mantém até $70 \mathrm{~ms}$, perdendo depois sua intensidade aos poucos até retornar a situação inicial perto de $80 \mathrm{~ms}$. 


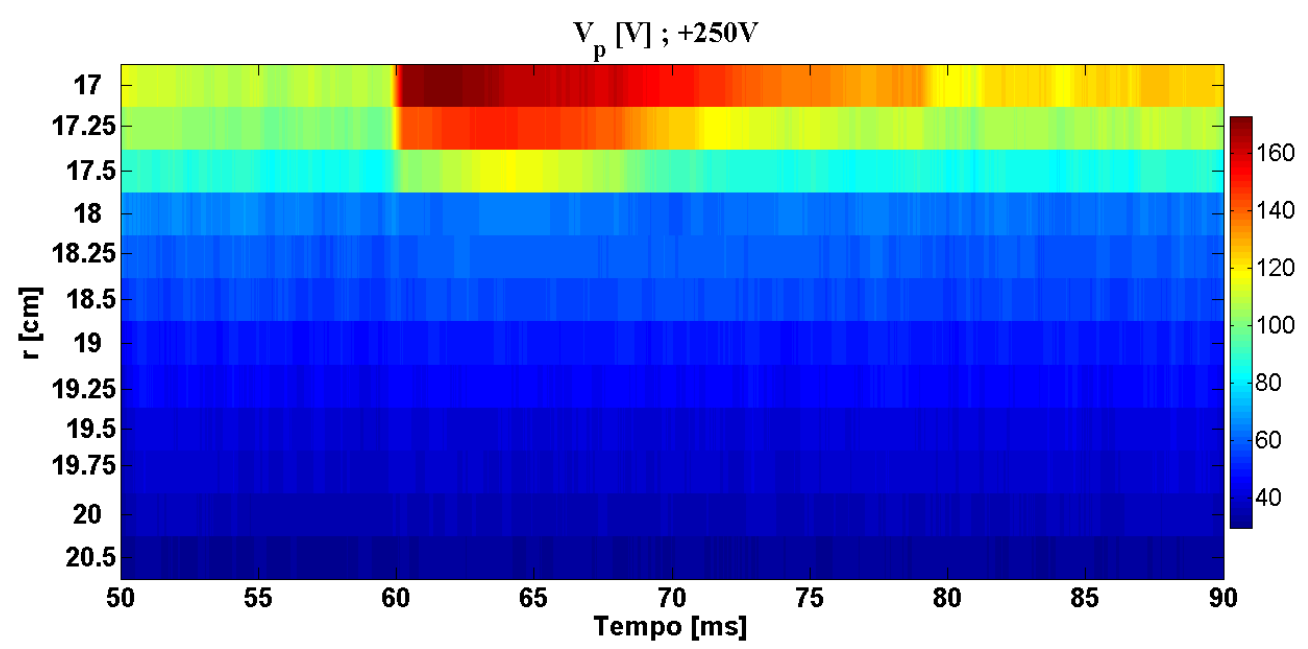

Figura 7.2: Evolução temporal do perfil de potencial de plasma $V_{p}$ em um gráfico de cores para um disparo com +250 V no eletrodo (\#34142. Polarização aplicada entre 60-80 ms. O eixo x identifica o tempo e o y a posição dos pinos; as cores são a intensidade de $V_{p}$.

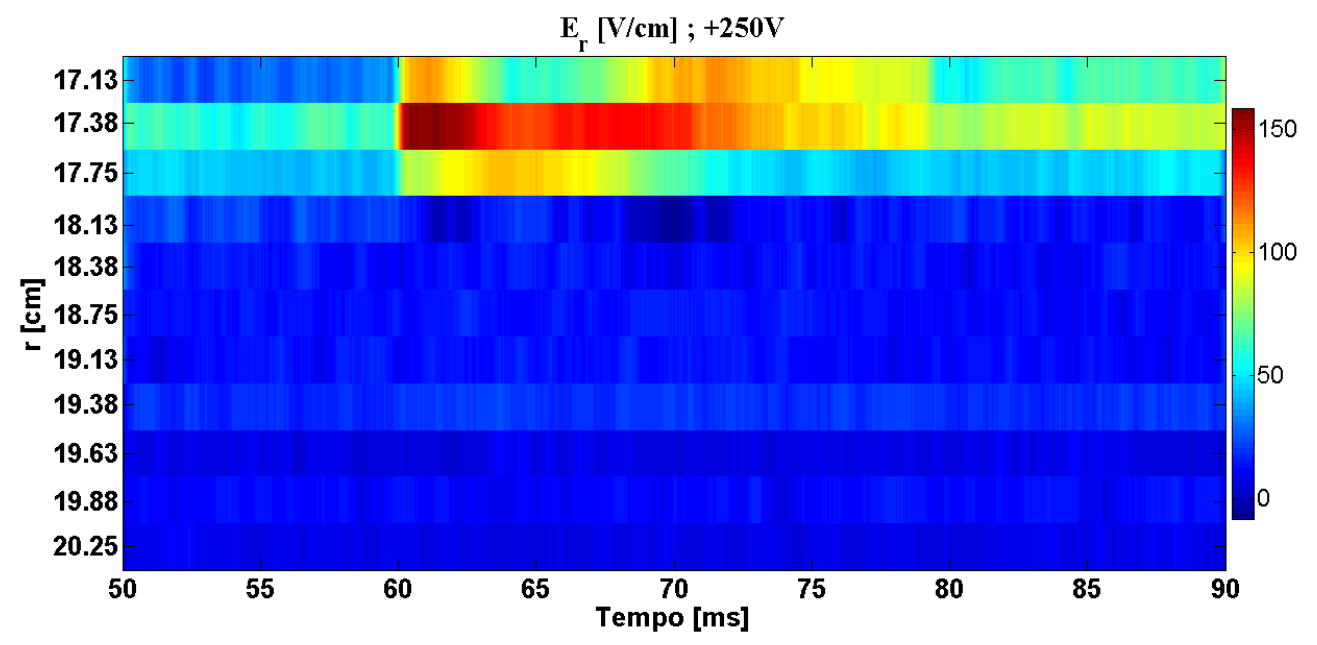

Figura 7.3: Evolução temporal do perfil do campo elétrico radial obtido do potencial de plasma $V_{p}$ (através da diferença entre os sinais) em um gráfico de cores em um disparo com +250 V no eletrodo (\#34142). A polarização foi aplicada entre 60-80 ms. O eixo x identifica o tempo e o y a posição dos pinos; as cores são a intensidade de $E_{r}$.

Evidente que tal efeito é prejudicial para a melhora no confinamento, já que o cisalhamento será reduzido, possivelmente fazendo com que retorne as atividades turbulentas na região de borda, o que provoca a volta do crescimento do transporte turbulento de partículas e a degradação da barreira de transporte (próxima seção). 
De fato há um aumento do nível de flutuações antes do término da polarização no eletrodo (figura 7.4), em torno de $70 \mathrm{~ms}$ o aumento se torna bastante significativo, compatível com o intervalo temporal em que começa ocorrer uma redução clara no gradiente do campo elétrico (figura 7.3).

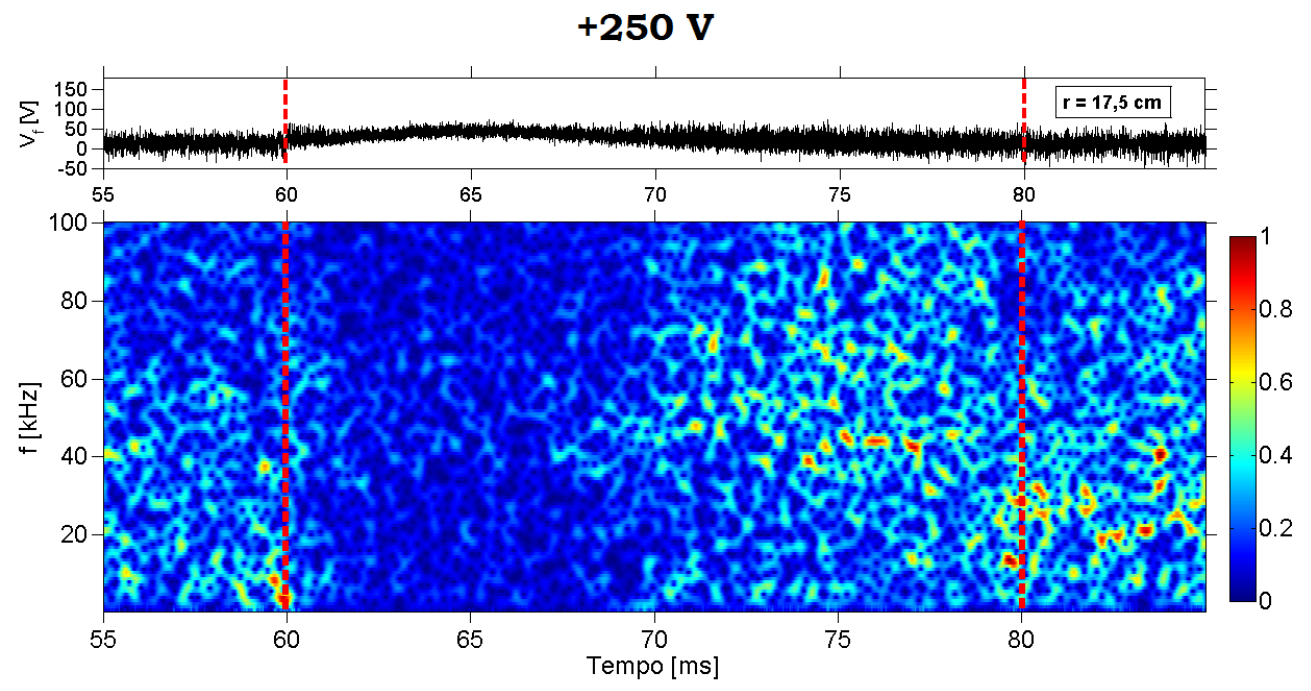

Figura 7.4: Potencial flutuante e correspondente espectrograma da potência espectral para o mesmo disparo dos gráficos 7.2 e 7.3 (\#34142).

Infelizmente não se estava medindo transporte de partículas com a sonda de 5-pinos durante o disparo em que são mostrados os resultados anteriores, no entanto o efeito da degradação do confinamento foi bastante reprodutível, como por exemplo pode ser visto na figura 7.4, ou na figura a seguir (7.5) para um disparo também em $+250 \mathrm{~V}$.
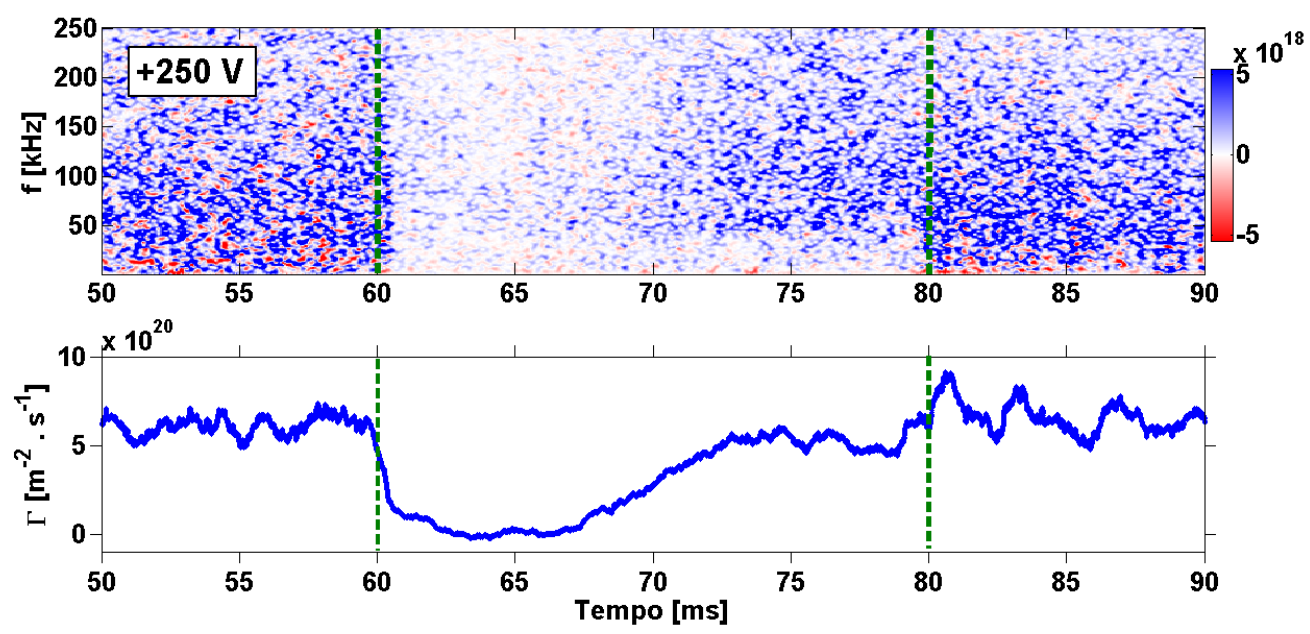

Figura 7.5: Transporte turbulento de partículas para +250V (\#34023). 
Nota-se que o transporte caí de maneira abrupta quando o eletrodo é polarizado ( $60 \mathrm{~ms}$ ), porém, ele volta a subir de maneira gradativa em torno de $70 \mathrm{~ms}$, evidenciando uma degradação no confinamento.

\subsection{Evolução temporal de $n_{e}$}

A polarização do eletrodo pode induzir a criação de uma barreira de transporte, que é evidenciada no perfil de densidade eletrônica na borda, com um aumento do seu gradiente na região mais interna e uma diminuição do seu valor absoluto em regiões mais externas, como discutido em [31] e como visto na seção 6.21. Contudo a evolução temporal da barreira depende de vários fatores, desde parâmetros responsáveis pela sua criação até de instabilidades que podem causar sua deterioração.

A seguir á apresentado o perfil médio de $n_{e}$ na borda antes e durante o eletrodo (figura 7.6). Cada curva corresponde a média realizada em uma janela de 5 ms. Inicialmente o perfil de densidade apresenta pouca inclinação (curva em azul), porém após a sua aplicação nos primeiros $5 \mathrm{~ms}$ (curva em preto) há um aumento significativo nas posições mais internas e uma diminuição nas posições mais externas. Entre 65-70 ms o gradiente é máximo, a curva passa a ter uma maior inclinação. Em intervalos de tempo posteriores, ainda sob influência do eletrodo, o perfil passa a ter sua inclinação diminuída, reduzindo gradativamente a um formato parecido com o inicial. Há uma degradação do confinamento também em torno de $70 \mathrm{~ms}$, a barreira de transporte é aos poucos desfeita e a turbulência e o transporte de partículas voltam a subir.

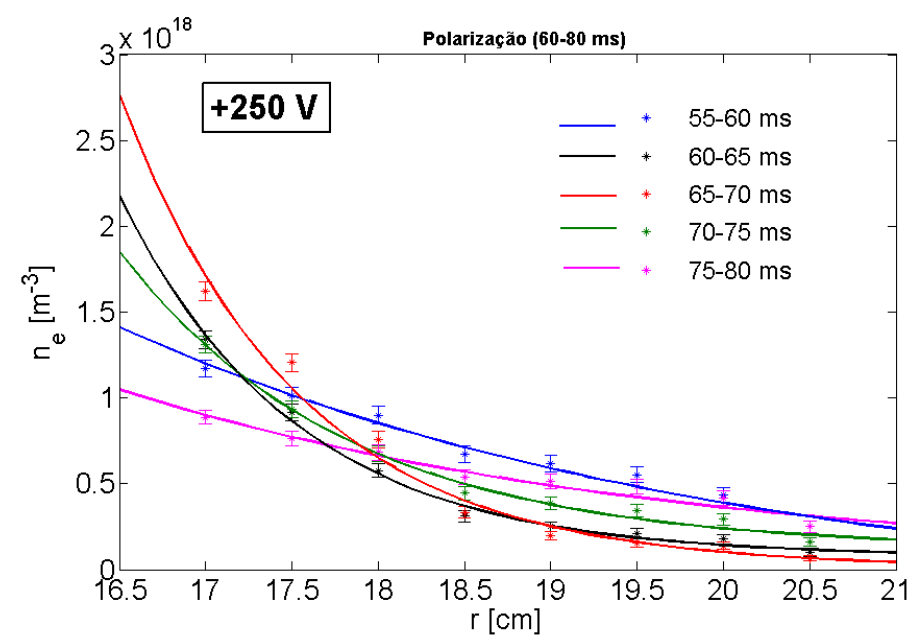

Figura 7.6: Evolução temporal do perfil de densidade eletrônica $n_{e}$ para um disparo com $+250 \mathrm{~V}$ no eletrodo (\#34108). Polarização aplicada entre 60-80 ms. 
Considerando janelas ainda menores em um gráfico de cores (figura 7.7) é possível ver claramente quando a barreira se forma de maneira plena, quando sua inclinação torna-se máxima $(\sim 65 \mathrm{~ms})$, e a sua subsequente degradação a partir de aproximadamente $70 \mathrm{~ms}$.

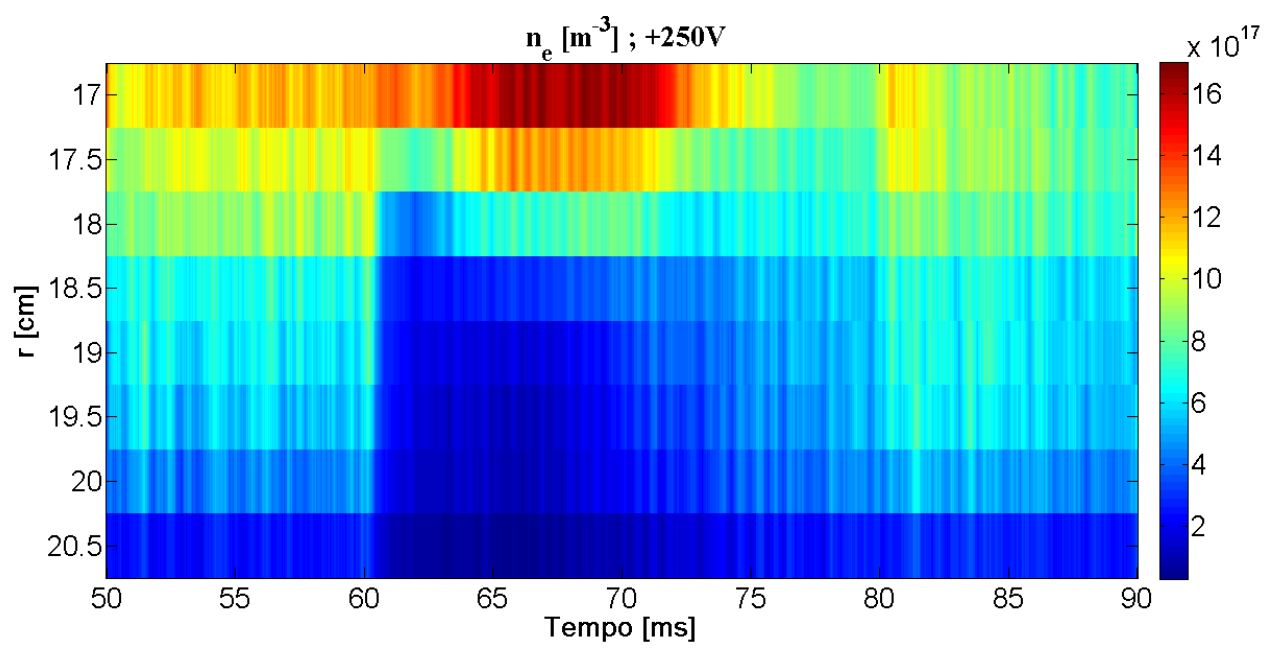

Figura 7.7: Evolução temporal do perfil de densidade eletrônica $n_{e}$ para um disparo com $250 \mathrm{~V}$ no eletrodo (\#34108). Polarização aplicada entre 60-80 ms. O eixo x identifica o tempo e o y a posição dos pinos; as cores são as amplitudes de $n_{e}$.

A degradação da barreira em torno de $70 \mathrm{~ms}$ foi recorrente em todas as tensões no eletrodo, como pode ser visto na figura 7.8.

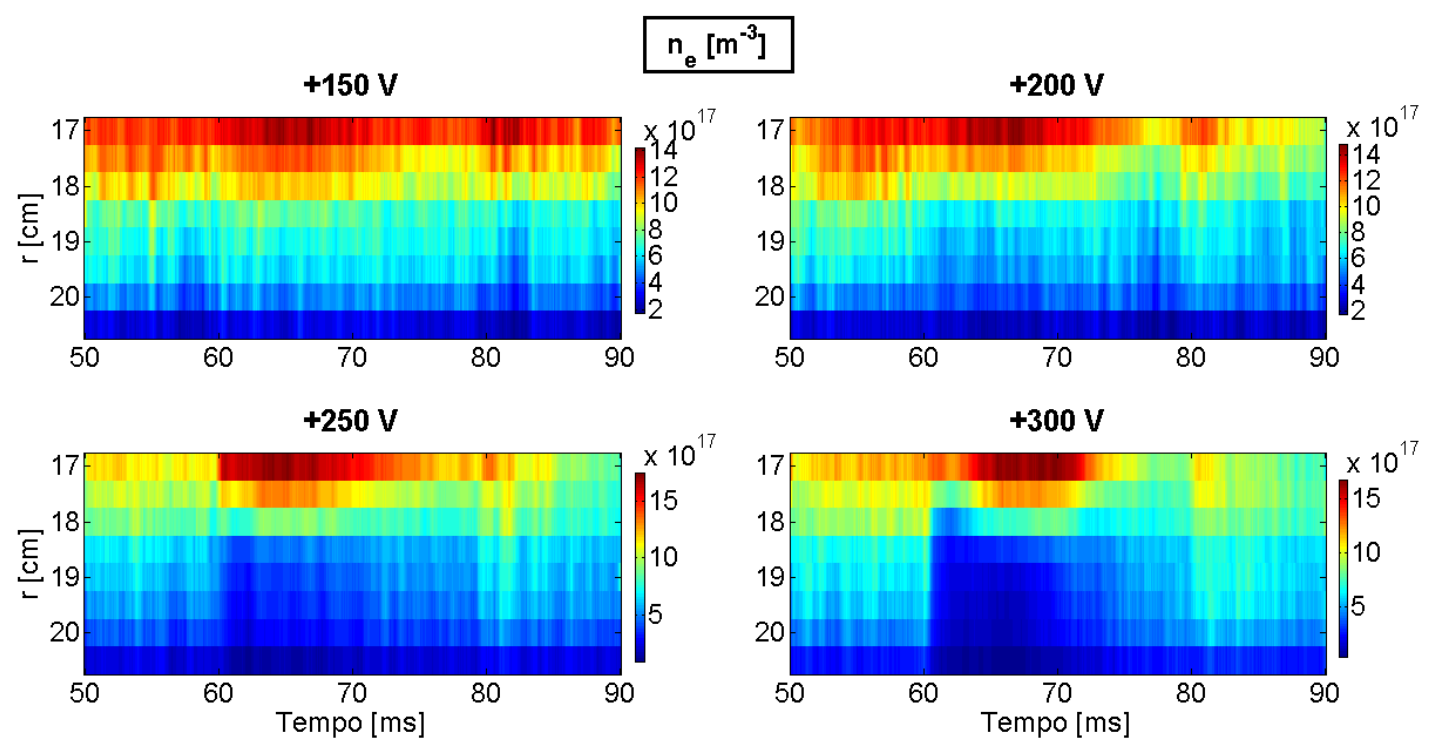

Figura 7.8: Evolução temporal do perfil de densidade eletrônica $n_{e}$ para diferentes polarizações no eletrodo: +150 V(\#34105), +200 V(\#34107), +250V (\#34106) e +300 V (\#34108). 


\subsection{Escalas de tempo da transição para confinamento melhorado}

A mudança dos parâmetros devido a aplicação do eletrodo se dá de maneira muito rápida, a tensão no eletrodo varia de $0 \mathrm{~V}$ até $+300 \mathrm{~V}$ em um intervalo de $\approx 20 \mu$ s estabelecendo um "trigger"para a transição. O plasma "sente"a perturbação externa, que é evidente através da mudança nos seus parâmetros. O aumento do gradiente do campo elétrico radial, a diminuição da turbulência e transporte, a queda de $H_{\alpha}$ e a criação da barreira de transporte são resultados de tal pertubação. No entanto, a forma como se dá a mudança nesses parâmetros não é obvia, o tempo de resposta dos parâmetros à polarização e sobretudo a ordem na qual os eventos ocorrem.

Com o intuito de tentar encontrar uma relação causal entre os fenômenos e discutir as escalas de tempo da transição, será feito nessa seção uma comparação entre a evolução temporal de vários parâmetros. Infelizmente não foram feitas medidas na configuração de tensão constante, para medir $I_{\text {sat }}$ na sonda rake, quando se estava medindo transporte de partículas com a sonda 5-pinos, isso porque no último mês de medidas a sonda 5-pinos teve problemas no seu sistema de movimentação. Dessa forma, as comparações foram feitas usando dois disparos com tensão de polarização de $+300 \mathrm{~V}$. As medidas de tensão de polarização no eletrodo estavam com alguns problemas, o sinal estava com alto ruído e apresentava um alto erro na escala de tempo. Por esse motivo, o tempo tomado como sendo o tempo em que o eletrodo era polarizado foi escolhido como sendo o instante em que o sinal de $V_{f}$ do pino mais avançado da sonda rake sofria um rápido aumento de amplitude (figura 7.9).

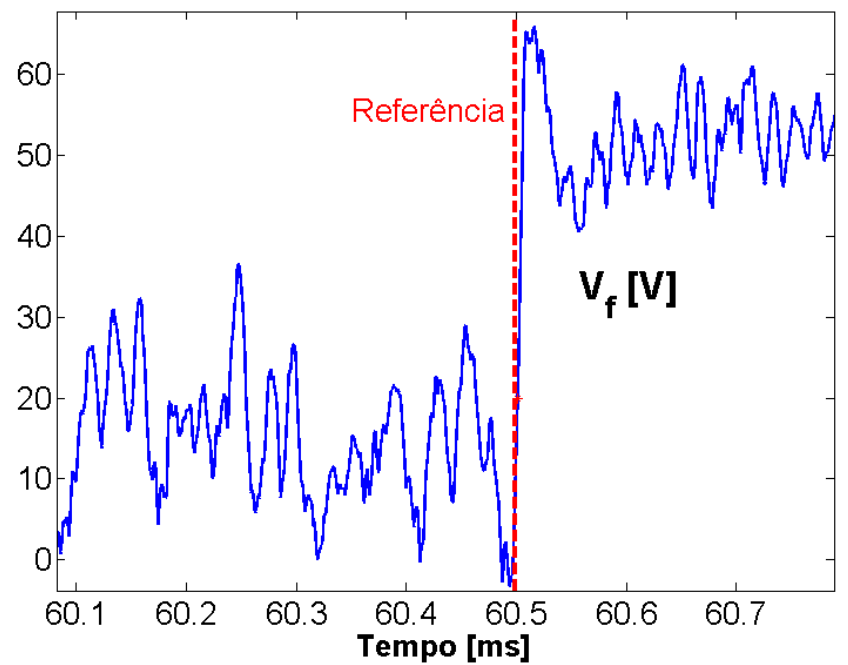

Figura 7.9: Referência na escala de tempo da polarização do eletrodo, sinal de potencial flutuante em $17,0 \mathrm{~cm}$. 
Na figura 7.10 é mostrado um sinal de $I_{\text {sat }}$ (em unidades arbitrárias) na região de borda $(18,0 \mathrm{~cm})$ em um disparo com $+300 \mathrm{~V}$ no eletrodo. Nota-se na parte de cima do gráfico (a), em uma janela de $\approx 2,5 \mathrm{~ms}$, que quando o potencial flutuante (ou campo elétrico, considerando dois sinais) sofre um aumento abrupto devido a polarização do eletrodo (linha vertical tracejada em vermelho), há uma diminuição significativa da amplitude do sinal (como também foi visto em figura 6.15 na potência espectral para o mesmo disparo e posição de sonda). Na parte de baixo (b), é possível ver com mais detalhe como ocorre essa diminuição, pois é feito um "zoom"no gráfico de cima (a), em uma janela de $\approx 0,35 \mathrm{~ms}(\approx 350 \mu \mathrm{s})$. É possível perceber um atraso entre o instante de aumento do potencial flutuante (ou campo elétrico) e o tempo em que começa haver uma redução da amplitude das oscilações. Esse atraso é de aproximadamente $50 \mu s$.
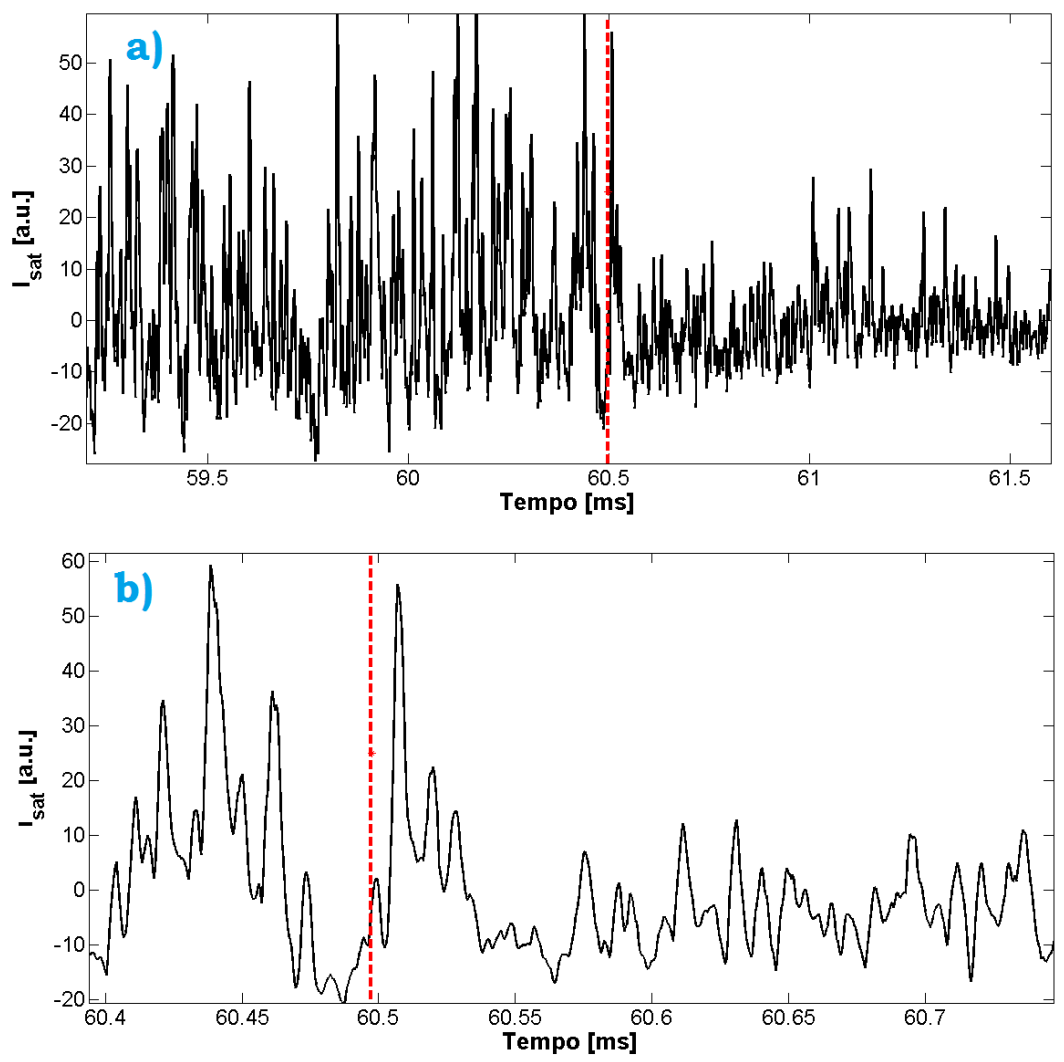

Figura 7.10: Sinal de corrente de saturação de íons (em unidades arbitrárias) em um pino na posição 18, $0 \mathrm{~cm}$ para um disparo com eletrodo polarizado em $+300 \mathrm{~V}$ (\#34144. Em a) é mostrado $I_{\text {sat }}$ em uma janela temporal no entorno do início da polarização no eletrodo (referência tomada como sendo o tempo em que $V_{f}$ sofre um aumento abrupto devido a polarização do eletrodo) no qual é possivel notar uma redução da amplitude das oscilações; em b) é um "zoom"na janela temporal de a), possibilitando perceber um atraso entre o início da polarização e a redução das flutuações. A linha vertical tracejada em vermelho identifica o instante em que o eletrodo foi polarizado. 
É esperado que devido a redução das flutuações e do nível de turbulência haja também uma redução do grau de transporte turbulento de partículas na direção radial, pois ele está associado as flutuações de $I_{\text {sat }}$. De fato é o que acontece, como pode ser visto na figura 7.11, em um disparo com eletrodo polarizado em $+300 \mathrm{~V}$. Assim que se inicia a polarização, o campo elétrico sobe e o transporte caí.

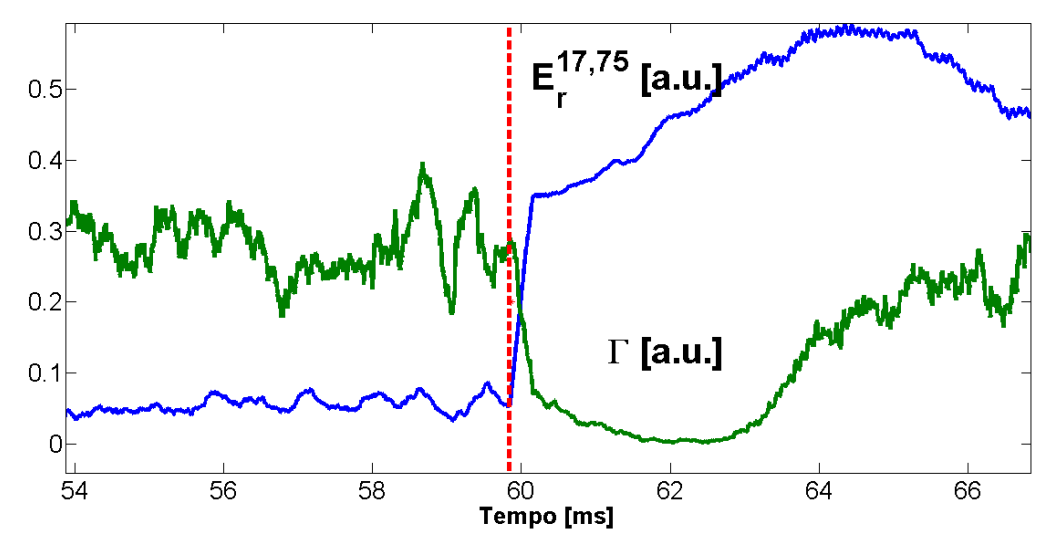

Figura 7.11: Comparação entre escalas de tempo do eletrodo, campo elétrico radial na região de borda $(\approx 18 \mathrm{~cm})$ e transporte turbulento de partículas em um disparo com $+300 \mathrm{~V}$ (\#34016). A referência de tempo é identificada por uma linha vertical tracejada em vermelho. O campo elétrico é a curva em azul e o transporte a curva em verde.

Há também um atraso entre o instante em que o tempo em que $V_{f}$ sofre um aumento abrupto devido a polarização do eletrodo e o instante em que começa a cair o transporte (figura 7.12). O intervalo é de aproximadamente $\approx 60 \mu s$, compatível com o atraso entre a polarização e a redução das flutuações.

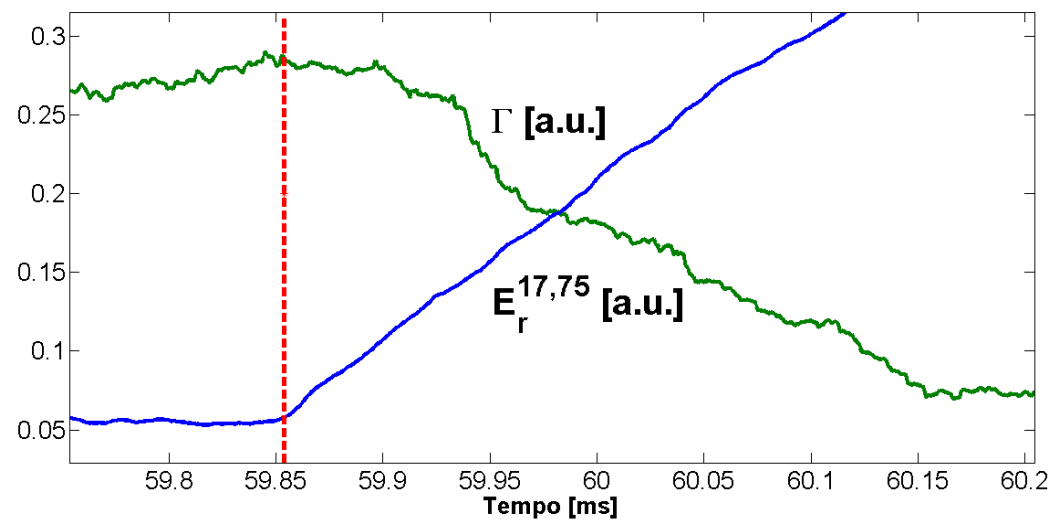

Figura 7.12: Ampliação na escala temporal do gráfico da figura anterior mostrando apenas a referência de tempo e a curva de transporte. Polarização $+300 \mathrm{~V}$ (\#34016).

Comparando também a escala temporal da densidade eletrônica (com dois sinais: um pino em $17 \mathrm{~cm}$ e outro em $20 \mathrm{~cm}$ ) com o tempo de referência e o tempo do campo elétrico na região de borda (figura 7.13). Nota-se que a densidade na camada de raspagem (scrapeoff-layer) caí quase no mesmo instante em que se dá a polarização e o aumento do campo elétrico radial. No entanto, a densidade no pino em $17 \mathrm{~cm}$ demora mais para mudar, depois 
de $\approx 1,5 \mathrm{~ms}$ ela sobe e satura. Isso ocorre, aproximadamente, no mesmo instante em que a densidade em $20 \mathrm{~cm}$ é mínima. Ou seja, nesse tempo a barreira se formou na sua forma plena, com um atraso, portanto, em relação ao inicio da polarização de aproximadamente 6 ms.

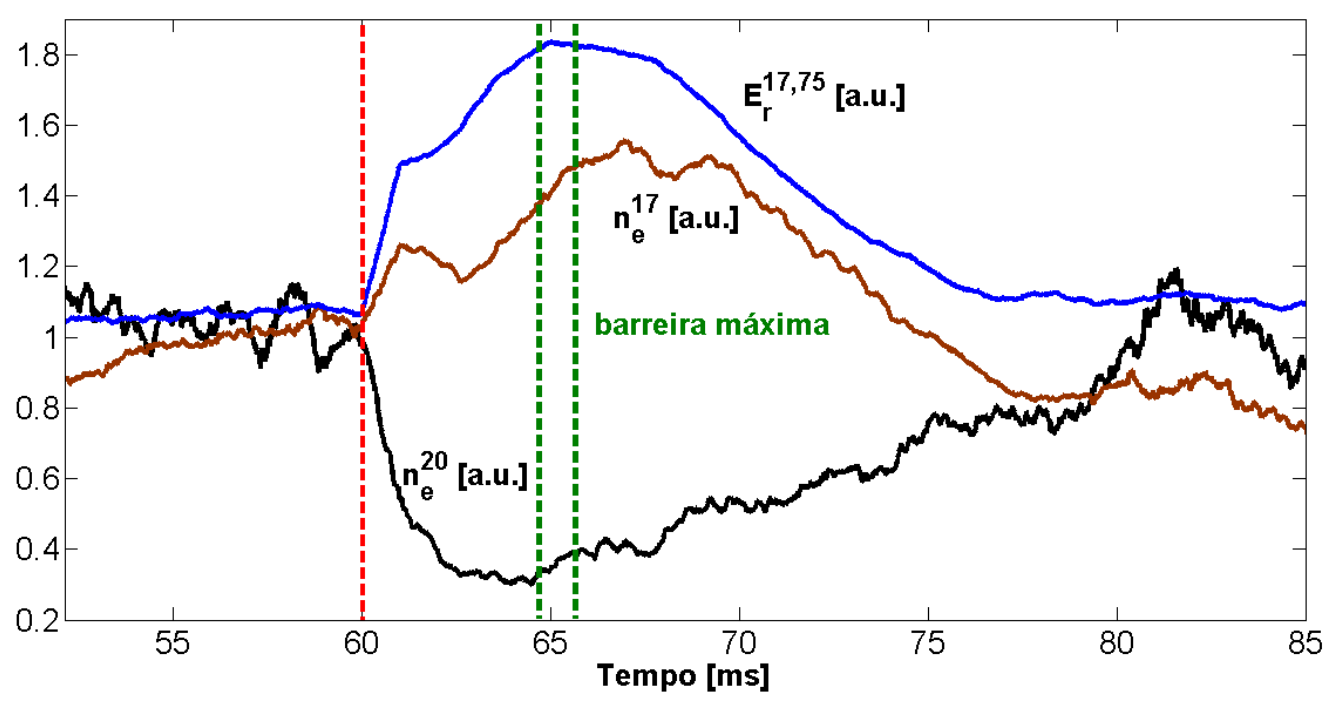

Figura 7.13: Comparação entre escalas de tempo de referência (inicio do aumento de $V_{f}$ em 17 $\mathrm{cm})$, campo elétrico radial na região de borda $(\approx 18 \mathrm{~cm})$ e densidade eletrônica (nas posições 17,0 e 20,0 cm) em um disparo com $+300 \mathrm{~V}$ (\#34144). O instante em que o eletrodo é aplicado é identificado por uma linha vertical tracejada em vermelho. O campo elétrico é a curva em azul e as densidades são as curvas em preto $(20 \mathrm{~cm})$ e marrom $(17 \mathrm{~cm})$. 
Pelo o que foi visto, portanto, é possível estabelecer uma relação causal entre os eventos (com ressalvas em fazer esse tipo de comparação em sinais de plasma em tokamaks, cuja característica turbulenta é inerente). Quando o eletrodo é polarizado há um aumento do campo elétrico radial na mesma escala de tempo da subida do eletrodo, que provoca um cisalhamento no fluxo de plasma, destruindo as correlações turbulentas, diminuindo posteriormente as flutuações e o transporte turbulento de partículas. Simultaneamente a isso, a densidade cai nas posições mais recuadas (camada de raspagem) e sobe posteriormente nas mais avançadas. Depois de aproximadamente $6 \mathrm{~ms}$, quando o transporte e as flutuações são mínimas, a barreira de transporte é formada na sua forma plena, sendo depois mitigada (como discutido na sessão anterior). 
114 EVOLUÇÃO TEMPORAL DA TRANSIÇÃO PARA CONFINAMENTO MELHORADO 


\section{Capítulo 8}

\section{Discussões finais e conclusão}

No capítulo 6 foi visto que a aplicação de um eletrodo polarizado na borda do TCABR pode induzir uma melhora do confinamento do plasma e que essa melhora depende da tensão de polarização no eletrodo. Para as tensões de $+200 \mathrm{~V},+250 \mathrm{~V}$ e $+300 \mathrm{~V}$ e com o eletrodo posicionado em 17,0 cm há claramente uma melhora no confinamento do plasma, é notada uma forte redução da linha de $H_{\alpha}$ do hidrogênio, indicando diminuição da taxa de reciclagem dos átomos de hidrogênio, ou seja do fluxo de partículas que escapam do confinamento em direção à parede ou limitador. Nota-se, também, pelas medidas com as duas sondas usadas no trabalho: sonda rake e sonda 5-pinos, uma forte diminuição dos níveis de flutuações dos sinais de corrente de saturação de íons $\left(I_{\text {sat }}\right)$ e de potencial flutuante $\left(V_{f}\right)$ em diferentes posições radiais na região da borda do plasma e da camada de raspagem ("scrape-off-layer"), indicando uma diminuição do nível de turbulência. Acompanhado, há uma forte diminuição do transporte turbulento de partículas na direção radial na posição $17,5 \mathrm{~cm}$. Analisando os perfis radias da densidade e da temperatura eletrônica na borda, notou-se que o perfil de temperatura pouco se altera por conta da aplicação do eletrodo, porém, o perfil de densidade é drasticamente alterado, a densidade em pontos da "camada-deraspagem"diminui, em relação aos seus valores antes da polarização do eletrodo, e em pontos internos ela aumenta, estabelecendo um alto gradiente na região intermediária; enquanto que a densidade média na linha central do interferômetro torna-se mais intensa. Esses são indícios claros da formação de uma barreira de transporte na região da borda do plasma, que como foi visto, localiza-se em torno de $17,5 \mathrm{~cm}$, próximo ao centro do máximo gradiente de $n_{e}$.

Tendo em vista o paradigma de que o cisalhamento do fluxo de plasma por $E \times B$ é responsável pela redução das flutuações do plasma, destruindo as correlações turbulentas na borda, o campo elétrico radial é o gatilho ("trigger") da transição para confinamento melhorado. Assim, ele foi monitorado na borda do plasma (com a sonda rake) em disparos com o eletrodo. Notou-se que há um aumento do seu gradiente na região da borda do plasma quando o eletrodo é aplicado e que tal aumento é tão maior quanto maior é a tensão de polarização do eletrodo. O gradiente mais intenso, ou o maior cisalhamento, ocorre no entorno de 17,7 cm. De forma compatível, é a região que há a maior redução do nível de 
flutuação de $V_{f}$ e $I_{\text {sat }}$; o pino mais avançado $(17,0 \mathrm{~cm})$, por exemplo, localiza-se em uma região na qual o gradiente do campo elétrico já não é tão intenso e, de forma coerente, a redução da flutuação nessa posição é pouco intensa. Também, de forma compatível, o intervalo em que o gradiente da densidade eletrônica é máximo é concordante com o intervalo em que o gradiente do campo elétrico também é máximo. Ou seja, há uma conexão direta entre o cisalhamento do fluxo de plasma e a criação da barreira de transporte. Nesse sentido é possível estimar um comprimento para a barreira de transporte a partir do intervalo em que o cisalhamento (ou gradiente) do campo elétrico é máximo. Porém, são necessárias algumas ressalvas, pois como visto, a tensão de $+150 \mathrm{~V}$ não é suficiente para induzir uma barreira de transporte, embora haja um aumento do gradiente do campo elétrico radial. Para as tensões acima de $+150 \mathrm{~V}$ a barreira de transporte é induzida, para $+200 \mathrm{~V}$ sua formação pode ser notada de maneira mais sutil, enquanto que para tensão de $+300 \mathrm{~V}$ ela é mais evidente. O campo elétrico radial $\left(E_{r}\right)$ e o seu gradiente aumentam com a tensão no eletrodo, o intervalo radial em que esse gradiente é máximo é estimado da seguinte forma (figura 8.1): ajusta-se uma reta na região entre os dois extremos do campo elétrico e mais duas retas levando em conta só as duas extremidades. O ponto de intersecção entre as duas retas e a reta principal delimita o intervalo radial do cisalhamento máximo. $\mathrm{O}$ valor aproximado é $\approx 1,2 \mathrm{~cm}$.
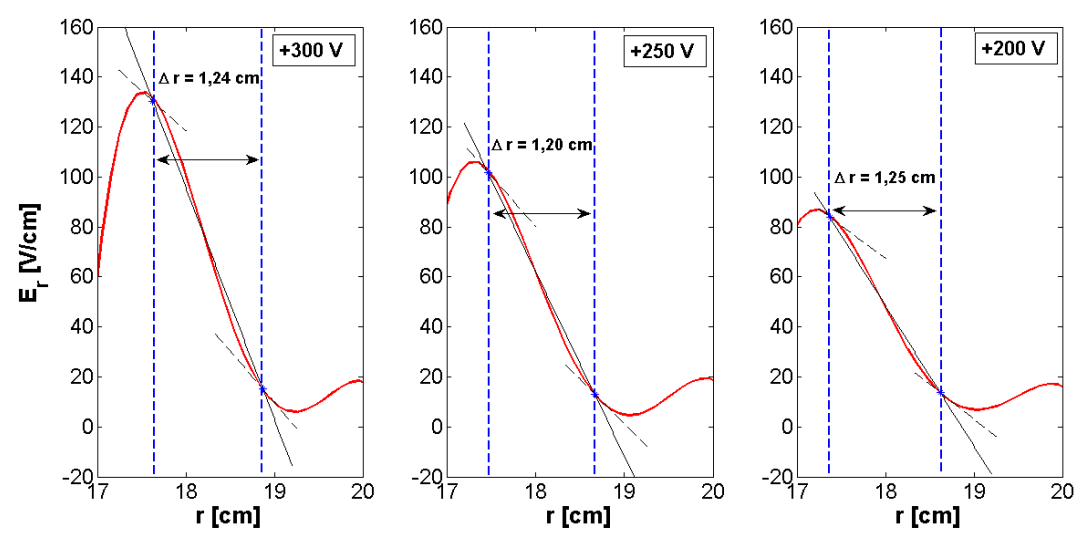

Figura 8.1: Comprimento estimado do cisalhamento máximo para $+300 \mathrm{~V}$ (\#34113), $+250 \mathrm{~V}$ (\#34111) e +200V (\#34112), levando em conta a região com maior campo elétrico radial.

Como discutido, existe um limiar de potência para a transição para o modo H espontâneo, por aquecimento auxiliar. A expressão obtida teoricamente, por primeiros princípios, é ainda objeto de pesquisa, porém existem expressões semi-empíricas que levam em conta dados de muitos tokamaks, de diferentes tamanhos e características. Uma primeira expressão foi obtida pelo grupo do ASDEX [8] e é dada por:

$$
P_{L}^{A S D E X}=0,04\left(\bar{n}_{e} / 10^{20}\right) B S(M W)
$$

onde $\bar{n}_{e}$ é a densidade média de linha central, $B$ é o campo magnético total e $S$ a área do plasma. Outra expressão mais recente foi obtida pelo grupo do ITER [20], 


$$
P_{L}^{I T E R}=(0,45 \pm 0,10)\left(\bar{n}_{e} / 10^{20}\right)^{0,75} B R^{2}\left[0,6\left(\bar{n}_{e} / 10^{20}\right) R^{2}\right]^{\alpha}(M W)
$$

onde $R$ é o raio maior e $|\alpha| \leq 0,25$. Aplicando essas fórmulas para o TCABR e levando em conta as potências aplicadas no plasma para as diferentes polarizações no eletrodo, o resultado é resumido na tabela 8.1.

Tabela 8.1: Comparação entre os limiares de potência das fórmulas do ASDEX e ITER com as potências aplicadas ao plasma com o eletrodo para diferentes polarizações

\begin{tabular}{c|c|c|c|c|c|c|c}
\hline $\mathbf{P}_{\mathbf{L}}^{\text {ASDEX }}$ & $\begin{array}{c}\mathbf{P}_{\mathbf{L}}^{\mathrm{ITER}} \\
\alpha=-\mathbf{0 , 2 5}\end{array}$ & $\begin{array}{c}\mathbf{P}_{\mathbf{L}}^{\mathrm{ITER}} \\
\alpha=\mathbf{0}\end{array}$ & $\begin{array}{c}\mathbf{P}_{\mathbf{L}}^{\mathrm{ITER}} \\
\alpha=\mathbf{0 , 2 5}\end{array}$ & $\mathbf{P}^{+\mathbf{3 0 0 V}}$ & $\mathbf{P}^{+\mathbf{2 5 0 V}}$ & $\mathbf{P}^{+\mathbf{2 0 0 V}}$ & $\mathbf{P}^{+\mathbf{1 5 0 V}}$ \\
\hline $22 \mathrm{~kW}$ & $91 \mathrm{~kW}$ & $37 \mathrm{~kW}$ & $15 \mathrm{~kW}$ & $51 \mathrm{~kW}$ & $29 \mathrm{~kW}$ & $16 \mathrm{~kW}$ & $8 \mathrm{~kW}$ \\
\hline
\end{tabular}

Comparando inicialmente com a fórmula do ASDEX, cujo limiar de potência estimado para o TCABR, tomando $\bar{n}_{e}=1,2 \times 10^{19} \mathrm{~m}^{-3}, B=1,07 \mathrm{~T}$ e $S \approx 4,4 \mathrm{~m}^{2}$, é: $22 \mathrm{~kW}$; nota-se nesse caso que somente para as tensões de $+250 \mathrm{~V}$ e $+300 \mathrm{~V}$ o TCABR estaria em "modo H", considerando que o eletrodo polarizado na borda do plasma funciona como uma fonte de aquecimento auxiliar. A fórmula do ITER é mais abrangente, pois ela depende de um parâmetro $\alpha$ que pode variar no intervalo $|\alpha| \leq 2,5$. Para critérios de comparação com a potência real aplicada ao plasma, foram tomados três valores de $\alpha$, os dois limites: -0,25 e 0,25; e o médio: 0 . Para $\alpha=-0,25$ a potência é $91 \mathrm{~kW}$, nesse caso todas as potências consideradas no experimento estariam abaixo do limiar de potência, o TCABR não estaria em modo H. Tal resultado talvez seja coerente com a situação real de experimentos com eletrodo no TCABR, já que não se observam bifurcação nem ELMs. Para $\alpha=0$, a situação é semelhante à potência de limiar usando a expressão do ASDEX, apenas para $+300 \mathrm{~V}$ no eletrodo o TCABR estaria em modo $\mathrm{H}$; de fato nessa tensão os efeitos da melhora do confinamento são bastante claros. O caso talvez mais curioso é para $\alpha=0,25$, nas tensões aplicadas ao eletrodo neste trabalho apenas quando seu valor é +150 V o TCABR não estaria em modo H. O interessante é que de fato essa é a única tensão que não induziu efeitos claros de melhora no confinamento do plasma, não houve evidências da formação de uma barreira de transporte, a queda das flutuações foi pouco perceptível (embora houvesse um aumento no gradiente do campo elétrico radial na borda) e por consequência a redução do transporte turbulento de partículas também foi pequena.

Contudo, apesar da aparente compatibilidade é necessário cautela, pois não é possível ter certeza que o valor de alfa é 0,25 para o TCABR, além das formulas de limiar serem para aquecimento auxiliar. Mas, também, não é possível afirmar que o TCABR não estava em modo $\mathrm{H}$ nas tensões consideradas neste trabalho. Porém, ficou claro que houve uma melhora no confinamento do plasma, mesmo utilizando um sistema muito mais simples do que, por exemplo, através da injeção de partículas neutras. Como discutido, uma característica 
marcante da transição é a bifurcação do campo elétrico radial, que poderia ser percebida monitorando a corrente coletada pelo eletrodo (como em [31]), ela se manifestaria como uma queda súbita no seu valor. Porém, a qualidade da medida da corrente (e tensão) no eletrodo no TCABR não foi adequada, pois o sinal era bastante ruidoso, o que dificultava a visualização de qualquer mudança sútil no sinal. Além disso, outra dificuldade é o tempo rápido de subida da tensão de polarização no eletrodo $(\approx 20 \mu \mathrm{s})$; o tempo do efeito também poderia ser dessa ordem, sendo mais difícil de detectar. Outra característica marcante do modo H os ELMs, também não foram detectados no TCABR. Porém, novamente, é necessário cautela. Não se sabe exatamente qual seria a amplitude que tais oscilações apareceriam em uma máquina como o TCABR, o ELM tipo III, por exemplo, tem um nível de amplitude bastante baixo, comparado aos outros dois tipos [29]. Geralmente, também, ele é precedido por uma oscilação magnética coerente entre $50-70 \mathrm{kHz}$. Uma frequência desse tipo comumente aparece em disparos com eletrodo no TCABR (figura 8.2), ela normalmente é interpretada como GAM (global acoustic modes) que juntamente com fluxos zonais ("zonal flow"), estariam de acordo com a idéia de confinamento melhorado intermediário entre modo L e H [34],

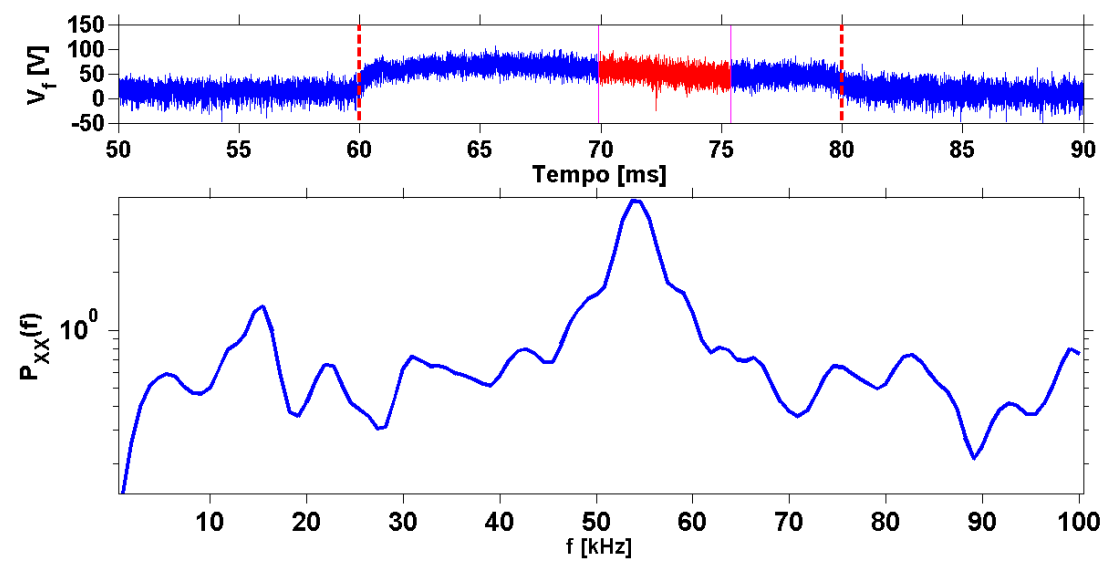

Figura 8.2: Sinal de potencial flutuante (em cima) e potência espectral correspondente (em baixo) para janela de tempo indicada em vermelho. A tensão no eletrodo era $+250 \mathrm{~V}$ (\#32268) entre 60-80 ms e sua posição 16,5 cm. É possivel perceber uma frequência dominante em torno de $55 \mathrm{kHz}$.

A frequência de GAM estimada para o TCABR é $\approx 20 k H z$, ou seja, abaixo da frequência mostrada no gráfico 8.2, porém há divergências em relação as frequências de GAM para algumas maquinas, alguns efeitos geométricos precisam ser levados em conta [50]. Tal oscilação está sob investigação atualmente no TCABR.

Estudando a evolução temporal do confinamento melhorado induzido por um eletrodo externo polarizado no TCABR (capitulo 7), foi possível notar em muitos disparos uma degradação do confinamento do plasma, mesmo antes do fim da polarização no eletrodo (entre 60-80 ms) e na ausência de fortes instabilidades (como oscilações MHD). Próximo de $70 \mathrm{~ms}$ o nível de flutuação voltava a subir ao nível anterior ao eletrodo, bem como o de transporte turbulento de partículas. Nesse mesmo instante o gradiente do campo elétrico radial caia, possivelmente causando a retomada da alta turbulência e do transporte, pois o cisalhamento era drasticamente reduzido. Mais ou menos no mesmo instante, começava ocorrer um gra- 
dual relaxamento da barreira de transporte formada, o gradiente da densidade eletrônica aos poucos era reduzido e o perfil de densidade retomava a forma anterior ao eletrodo, mesmo antes do final da polarização. Esse efeito ocorreu com bastante frequência nos disparos com eletrodo realizados, porém em alguns, como \#32928 (com +300 V de polarização), ele não aparecia. Analisando alguns parâmetros globais do plasma é possível ter uma pista das possíveis causas. Ele poderia ser um efeito real da dinâmica do confinamento melhorado induzido no TCABR, possivelmente resultado de alguma instabilidade no plasma associada à melhora no confinamento. Ou poderia ser por limitações técnicas no TCABR, que nesse caso poderia envolver quantidades elevadas de impurezas, problemas na injeção de gás, problemas na fonte do eletrodo, dificuldades no controle da corrente de plasma etc. Na corrente de plasma e na voltagem de enlace do TCABR aparecem variações rápidas que podem provocar interferências indesejáveis. Isto ocorre devido a corrente no solenoide central do sistema ôhmico ser máxima no instante de breakdown, devendo variar ao longo do tempo para criar a corrente de plasma o que é feito através da colocação ou retirada de resistores no circuito. Estas variações de corrente são obtidas ligando ou desligando "ignitrons"e chaves a vácuo, o que permite aumentar a duração e a parte plana da corrente de plasma. Entretanto, durante a transição liga-desliga o próprio plasma se modifica, o que é indesejável para os trabalhos de pesquisa, procura-se adequar o instante dessas variações às necessidades das experiências. Empiricamente notou-se em disparos com eletrodo que quando um dos chaveamentos ocorria durante a polarização, o transporte, que havia caído devido a aplicação do eletrodo, apresentava um súbito aumento, que poderia se manter até o final da polarização. Em alguns disparos ele aumentava durante o chaveamento, porém caia novamente, retomando a melhora de confinamento. O que ocorria era que durante o chaveamento das "vacuum switch"a corrente de plasma variava de maneira abrupta: de uma tendência de queda ela rapidamente sofria um aumento. Possivelmente, essa mudança provocava instabilidades no plasma, alterando a dinâmica das ilhas magnéticas, o que resultava em uma degradação no confinamento melhorado. Esse problema foi contornado alterando o tempo dos chaveamentos, de maneira que eles ocorressem fora (ou ao menos no início ou no fim) do intervalo da polarização no eletrodo. Na figura 8.3 é mostrado um exemplo da possível influência do chaveamento da corrente de plasma no transporte turbulento de partículas.

A causa da degradação do confinamento não ficou claro, provavelmente as impurezas desempenham um papel importante no seu efeito. O eletrodo ao ser polarizado certamente libera impurezas no plasma (mesmo sendo submetido a limpeza antes de uma sessão de disparos). Contudo, o monitoramento de impurezas no TCABR não é feito rotineiramente. A linha espectral do carbono III (triplamente ionizado) é uma forma de monitorar, pois esse átomo que provem do eletrodo ou limitador (ambos de grafite) localiza-se na região de borda quando está na sua forma triplamente ionizada (maior probabilidade de ser encontrado). Assim, seu monitoramente é uma boa ferramenta de monitoramento de impurezas na borda e já foi feita em outras experiências. Além disso, medidas de raio X "mole"(raio X de baixa energia) e "duro"(raio X de alta energia) podem ser monitorados. Com raio X "mole"é 

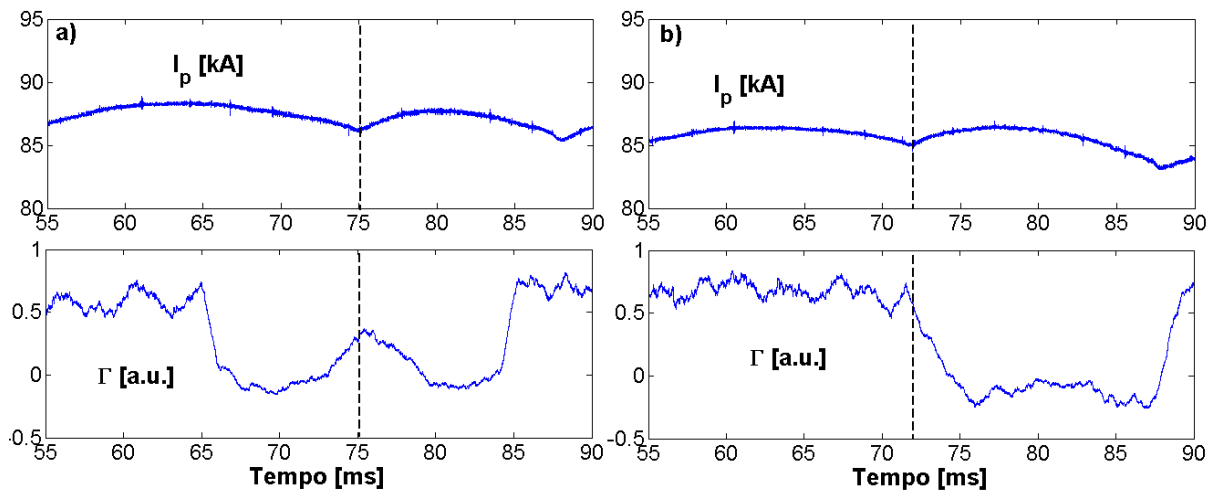

Figura 8.3: Possivel influência do chaveamento da corrente de plasma no transporte turbulento de partículas. a) disparo com eletrodo em $+200 \mathrm{~V}$ polarizado entre 65-85 ms (\#33819), não houve alta instabilidade MHD. b) disparo com eletrodo em $+250 \mathrm{~V}$ polarizado entre 72-92 $\mathrm{ms}$, de maneira a evitar o chaveamento.

possível estudar o que acontece em regiões mais internas na coluna de plasma, a influência de instabilidades como "dente de serra". Infelizmente isto não foi explorado neste trabalho.

Ainda no capítulo 7 foi possível determinar uma relação de causualidade entre os efeitos durante a transição. Contudo, devido a erros no instante de disparo da tensão no eletrodo não foi possível usá-lo nas comparações. Dessa forma, o tempo inicial da polarização foi tomado como o instante em que o potencial flutuante em regiões mais internas (ou o campo elétrico, considerando dois potenciais flutuantes) "sentia"a influência do eletrodo, através de um súbito aumento no seu valor. Possivelmente, há um atraso entre o instante em que o eletrodo foi aplicado e o instante em que $V_{f}$ sente sua influência, porém, não foi possível verificar. Notou-se (figura 7.10) que há um atraso entre o tempo do aumento do potencial flutuante e o instante de queda das flutuações e também do tempo de queda do transporte. Sugerindo que quando o campo elétrico radial aumenta há também um aumento no cisalhamento do fluxo de plasma, provocando uma redução das flutuações e consequente redução do transporte turbulento de partículas. Notou-se, também, que, embora a formação da barreira pareça ocorrer poucos instantes após a polarização do eletrodo, ela só se formará na sua forma plena (máximo gradiente) depois de um longo tempo nessa escala (da ordem de ms), figura 7.13. Apenas quando as flutuações e o transporte atingem seus valores mínimos é que ela alcança sua forma máxima.

Para uma continuação do trabalho seria interessante realizar medidas com o eletrodo polarizado com tempo de subida de tensão mais lento, o que não foi possível realizar nesse experimento apesar de o sistema ter a possibilidade de variar o tempo de subida da tensão na região de ms, tendo como objetivo verificar indícios da bifurcação do campo elétrico radial, sendo, também, necessário melhorar a estabilidade da corrente de plasma e o controle de impurezas. Por outro lado, para uma melhor determinação da ordem de ocorrência dos sinais de caracterização da melhoria do confinamento é necessário que a escala de tempo se inicie no instante de disparo do eletrodo, detectado com precisão, sem variações para 
diferentes descargas, isto é, deve haver sincronia com os diferentes disparos dos diagnósticos. Futuramente serão também feitas medidas em configuração de sonda tripla no TCABR, o que permitirá estudar o transporte de energia (termo condutivo turbulento), já que nessa configuração obtém-se a série temporal local da temperatura eletrônica. Além disso, medidas de rotação do plasma (toroidal e poloidal) por desvio Doppler do carbono III também estarão disponíveis para disparos com eletrodo. Com todas essas informações será possível estudar com mais detalhe o confinamento melhorado no TCABR. 
122 DISCUSSÕES FINAIS E CONCLUSÃO 


\section{Referências Bibliográficas}

[1] Energy, electricity and nuclear power estimates for the period up to 2050. IAEA-RDS1/35 ISBN 978-92-0-105915-4 ISSN 1011-2642, 2015.

[2] COWLEY S. C. The quest for fusion power. Nature Physics, 12(5):384-386, 2016.

[3] ONGENA J. et al. Magnetic-confinement fusion. Nature Physics, 12(5):398-410, 2016.

[4] BUCKINGHAM R. ; LOVING A. Remote-handling challenges in fusion research and beyond. Nature Physics, 12(5):391-393, 2016.

[5] FREIDBERG J. P. Plasma physics and fusion energy. Cambridge University Press, 2008.

[6] SÁKHAROV A. Memórias. Editora Saraiva, São Paulo, Primeira Edição, 1992.

[7] WAGNER F. et al. Regime of improved confinement and high beta in neutralbeam-heated divertor discharges of the ASDEX tokamak. Physical Review Letters, 49(19):1408, 1982.

[8] WESSON J.; CAMPBELL D. J. Tokamaks. Oxford University Press, Third Edition, 2011.

[9] BITTEnCOURT J. A. Fundamentals of plasma physics. Springer Science \& Business Media, Third Edition, 2013.

[10] STANGEBY P. C. The plasma boundary of magnetic fusion devices. Institute of Physics Publishing Bristol, 2000.

[11] NASCIMENTO I. C. et al. VII Latin American Workshop on Plasma Phys., 1998, 15, Tandil, Argentina.

[12] GALVÃO R.M.O. et al. Report on recent results obtained in TCABR. In Journal of Physics: Conference Series, volume 591. IOP Publishing, 2015.

[13] ELIZONDO J. I. et al. TCABR interferometer. Brazilian Journal of Physics, 32(1):123130, 2002. 
[14] MOTT-SMITH H. M. ; LANGMUIR I. The theory of collectors in gaseous discharges. Physical Review, 28(4):727, 1926.

[15] HUTCHINSON I. H. Principles of plasma diagnostics. Principles of plasma diagnostics., by Hutchinson, IH. Cambridge University Press, Cambridge (UK), 1990, 379 p., ISBN 0-521-32622-2, Price£ 55.00 (cloth). ISBN 0-521-38583-0, Price£ 14.95 (paper)., 1, 1990.

[16] WAGNER F. et al. Development of an edge transport barrier at the H-mode transition of ASDEX. Physical Review Letters, 53(15):1453, 1984.

[17] TAYLOR R.J. et al. H-mode behavior induced by cross-field currents in a tokamak. Physical Review Letters, 63(21):2365, 1989.

[18] WEYNANTS R.R. et al. Confinement and profile changes induced by the presence of positive or negative radial electric fields in the edge of the TEXTOR tokamak. Nuclear Fusion, 32(5):837, 1992.

[19] ASKINAZI L.G. et al. Radial current in a tokamak caused by a biased electrode. Nuclear Fusion, 32(2):271, 1992.

[20] CONNOR J.W ; WILSON H.R. A review of theories of the LH transition. Plasma Physics and Controlled Fusion, 42(1):R1, 2000.

[21] BUSH C.E. et al. Peaked density profiles in circular-limiter H modes on the TFTR tokamak. Physical Review Letters, 65(4):424, 1990.

[22] ERCKMANN V. H mode of the W 7-AS stellarator. Physical Review Letters, 70(14):2086, 1993.

[23] WAGNER F. A quarter-century of H-mode studies. Plasma Physics and Controlled Fusion, 49(12B):B1, 2007.

[24] BIGLARI H. et al. Influence of sheared poloidal rotation on edge turbulence. Physics of Fluids B: Plasma Physics (1989-1993), 2(1):1-4, 1990.

[25] ITOH S. I. ; ITOH K. Model of 1 to H-mode transition in tokamak. Physical review letters, 60(22):2276, 1988.

[26] KIM Y.B et al. Neoclassical poloidal and toroidal rotation in tokamaks. Physics of Fluids B: Plasma Physics (1989-1993), 3(8):2050-2060, 1991.

[27] SHAING K.C ; CRUME JR E.C. Bifurcation theory of poloidal rotation in tokamaks: A model for L-H transition. Physical Review Letters, 63(21):2369, 1989.

[28] CONNOR J.W. et al. Edge localised modes (ELMs): experiments and theory. In AIP Conference Proceedings, volume 1013, page 174, 2008. 
[29] ZOHM H. Edge localized modes (ELMs). Plasma Physics and Controlled Fusion, 38(2):105, 1996.

[30] RYTER F. et al. Survey of the H-mode power threshold and transition physics studies in ASDEX Upgrade. Nuclear Fusion, 53(11):113003, 2013.

[31] BOEDO. J. et al. Enhanced particle confinement and turbulence reduction due to $\mathrm{E} \times \mathrm{B}$ shear in the TEXTOR tokamak. Nuclear Fusion, 40(7):1397, 2000.

[32] MOYER R.A. et al. Beyond paradigm: Turbulence, transport, and the origin of the radial electric field in low to high confinement mode transitions in the DIII-D tokamak. Physics of Plasmas, 2(6):2397-2407, 1995.

[33] SUN Y. et al. The influence of electrode biasing on plasma confinement in the J-TEXT tokamak. Plasma Physics and Controlled Fusion, 56(1):015001, 2013.

[34] XU Y. et al. Observation of geodesic acoustic modes (GAMs) and their radial propagation at the edge of the textor tokamak. Plasma Physics and Controlled Fusion, 53(9):095015, 2011.

[35] COLCHIN R.J. et al. Slow L-H transitions in DIII-D plasmas. Physical Review Letters, $88(25): 255002,2002$.

[36] SHEN H.G. et al. Observations of zonal flows in electrode biasing experiments on the Joint Texas Experimental tokamak. Physics of Plasmas, 23(4):042305, 2016.

[37] NASCIMENTO I.C. et al. Plasma confinement using biased electrode in the TCABR tokamak. Nuclear Fusion, 45(8):796, 2005.

[38] NASCIMENTO I.C. et al. Suppression and excitation of MHD activity with an electrically polarized electrode at the TCABR tokamak plasma edge. Nuclear Fusion, 47(11):1570, 2007.

[39] KUZNETSOV Y.K. et al. Long-distance correlations in TCABR biasing experiments. Nuclear Fusion, 52(6):063004, 2012.

[40] BENDAT J. S. ; PIERSOL A. G. Random data: analysis and measurement procedures. John Wiley \& Sons, 2011.

[41] BICKERTON R.J. Particle diffusion due to fluctuations in toroidal systems. Nuclear Fusion, 13(2):290, 1973.

[42] POWERS E.J. Spectral techniques for experimental investigation of plasma diffusion due to polychromatic fluctuations. Nuclear Fusion, 14(5):749, 1974.

[43] WOOTTON A.J. et al. Fluctuations and anomalous transport in tokamaks. Physics of Fluids B: Plasma Physics (1989-1993), 2(12):2879-2903, 1990. 
[44] BEALL J.M et al. Estimation of wavenumber and frequency spectra using fixed probe pairs. Journal of Applied Physics, 53(6):3933-3940, 1982.

[45] HELENE O. Metodo dos Mínimos Quadrados. Editora Livraria da Física, 2006.

[46] NOLD B. et al. Electronic issues of Langmuir probe measurements on the midplane manipulator of ASDEX Upgrade. 2012.

[47] OTT H.W. Noise reduction techniques in electronic systems. Wiley New York, Scond Edition, 1988.

[48] CHEN F. F. Langmuir probe diagnostics. In IEEE-ICOPS Meeting, Jeju, Korea, 2003.

[49] MATTHEWS G.F. Tokamak plasma diagnosis by electrical probes. Plasma physics and controlled fusion, 36(10):1595, 1994.

[50] MELNIKOV A.V et al. The features of the global GAM in OH and ECRH plasmas in the T-10 tokamak. Nuclear Fusion, 55(6):063001, 2015. 
Appendices 



\section{Apêndice A}

\section{Circuito eletrônico das fontes de tensão senoidal}

É apresentado a seguir o circuito eletrônico das fontes de tensão senoidal usadas neste trabalho. Elas foram projetadas pelo Engenheiro Ablicio Pires Reis. 


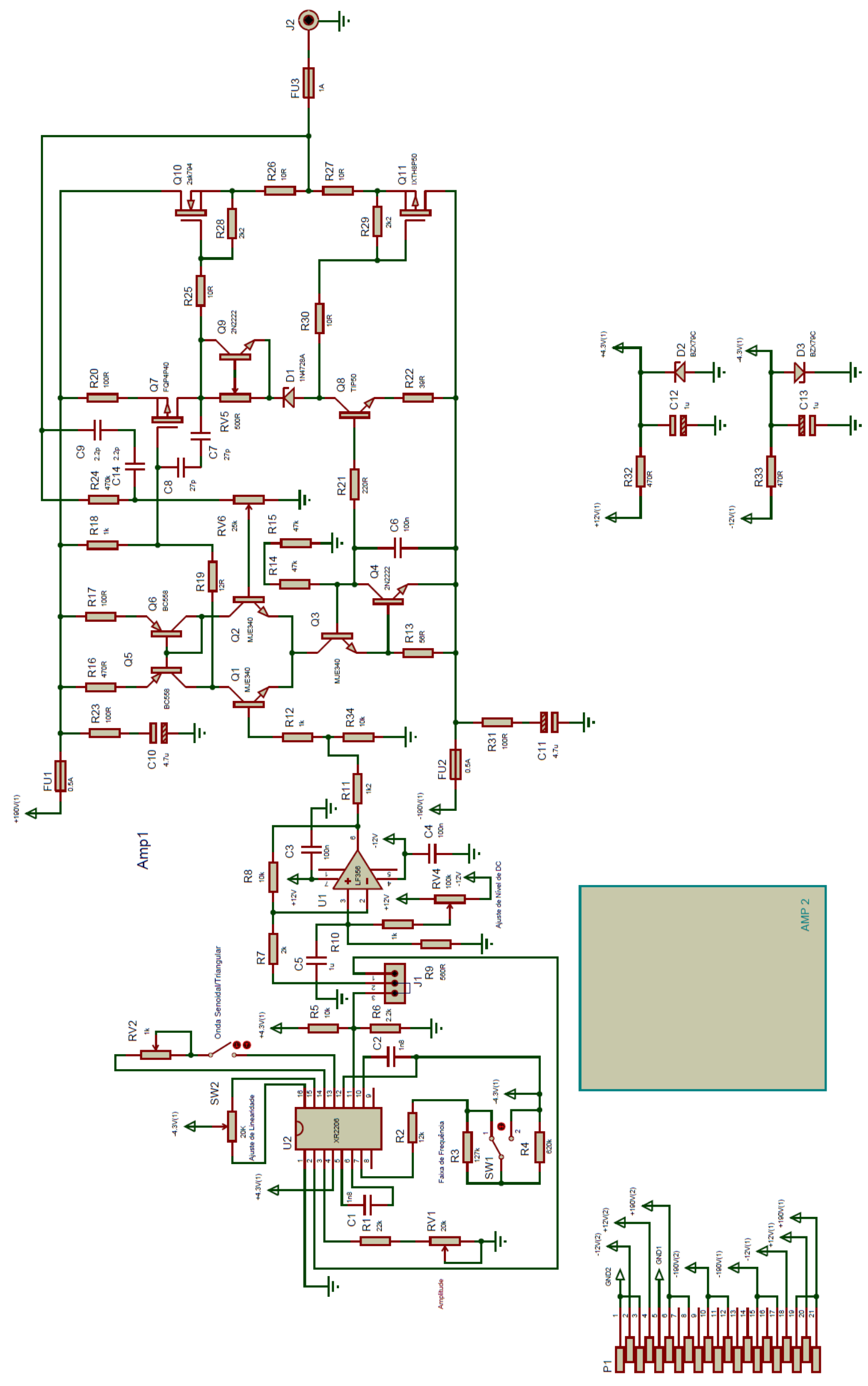

Figura A.1: Circuito da fonte de tensão senoidal. 


\section{Apêndice B}

\section{Circuito eletrônico esquemático do eletrodo}

Circuito do eletrodo de forma esquemática:

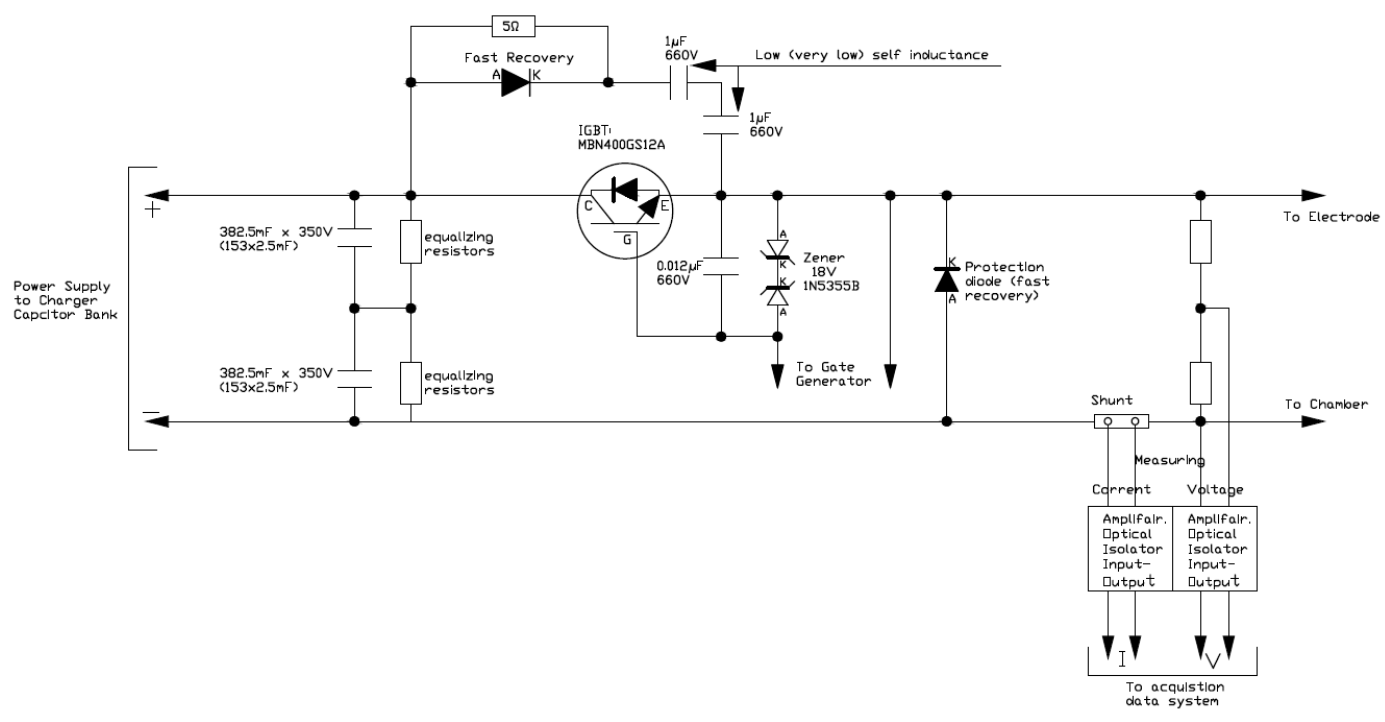

Figura B.1: Esquema do circuito de alimentação do eletrodo. 
132 CIRCUITO ELETRÔNICO ESQUEMÁtICO DO ELETRODO 


\section{Apêndice C}

\section{Formula de Spitzer clássica: estimativa para temperatura eletrônica média do plasma}

Medindo a tensão de enlace média e a corrente de plasma é possível estimar a temperatura média do plasma pela conhecida Formula de Spitzer (clássica) ${ }^{1}$.

A resistividade paralela as linhas de campo magnético é:

$$
\eta_{\|}(r)=\frac{E_{\|}}{j_{\|}(r)} \approx \frac{V_{\text {loop }}}{2 \pi R_{0}} \frac{1}{j_{z}(r)}
$$

onde a densidade de corrente é na direção toroidal. $\mathrm{O}$ valor da resistividade no raio para o qual a temperatura é média, $T\left(r_{T}\right)=\bar{T}_{n}$, é:

$$
\eta_{\|}\left(r_{T}\right)=\frac{V_{\text {loop }}}{2 \pi R_{0}} \frac{1}{j_{z}\left(r_{T}\right)}
$$

mas como,

$$
j\left(r_{T}\right) \approx j_{0}\left(1-\frac{r_{T}^{2}}{a^{2}}\right)^{3 / 2} \approx 0,46 j_{0}
$$

pois $r_{T} \approx 0,63 a$, onde $a$ é o raio menor do plasma (onde foi considerado um perfil aproximado para a densidade de corrente na direção toroidal); já que, aproximadamente,

$$
\begin{gathered}
T(r) \approx T_{0}\left(1-\frac{r^{2}}{a^{2}}\right) \\
\bar{T}_{n}=\frac{2}{a^{2}} \int_{0}^{a} T(r) r d r=\frac{3}{5} T_{0}
\end{gathered}
$$

${ }^{1}$ NRL/PU/6790 - 04-477, NRL Plasma Formulary, Revised 2004, Naval Research Laboratory, WASHINGTON, de 20375-5320 
134 FORMULA DE SPITZER CLÁSSICA: ESTIMATIVA PARA TEMPERATURA ELETRÔNICA MÉDIA DO PLASMA

e

$$
\frac{\bar{T}_{n}}{T_{0}}=\left(1-\frac{r_{T}}{a^{2}}\right)=\frac{3}{5} \rightarrow r_{T}=0,63 a
$$

Além disso,

$$
I_{p}=2 \pi \int_{0}^{a} j(r) r d r=\frac{2}{5} j_{0} \pi a^{2}
$$

segue portanto que,

$$
\eta_{\|}\left(r_{T}\right) \approx \frac{0,43 a^{2}}{R_{0}} \frac{V_{\text {loop }}}{I_{p}}
$$

A Formula de Spitzer (clássica) considera que:

$$
\eta_{\|}\left(T_{e}\right)=1,32 \times 10^{-4} Z_{e f f} \alpha\left(Z_{e f f}\right) \frac{\ln \Lambda_{e i}}{T_{e}^{3 / 2}}
$$

mas como $\ln \Lambda_{e i} \approx 16$ (logaritmo de Coulomb) e $\alpha\left(Z_{e f f}\right)=\frac{2,67+Z_{e f f}}{3,4\left(1,13+Z_{e f f}\right)} \approx 0,4$; obtém-se que:

$$
\begin{gathered}
Z_{e f f} \approx 1180 \cdot \eta_{\|}\left(\bar{T}_{n}\right) \cdot \bar{T}_{n}^{3 / 2} \\
Z_{e f f}=1180 \frac{0,43 a^{2}}{R_{0}} \frac{V_{l o o p} \bar{T}_{n}^{3 / 2}}{I_{p}}
\end{gathered}
$$

